\title{
Vergleichende Genomanalyse bei Mensch und Schwein am Beispiel ausgewählter syntenischer Regionen des humanen Chromosoms 6
}

\author{
Dissertation \\ zur Erlangung des Doktorgrades \\ der Mathematisch-Naturwissenschaftlichen Fakultäten \\ der Georg-August-Universität zu Göttingen
}

vorgelegt von

Sonja Duscher

aus Vöcklabruck/Oberösterreich

Göttingen 2001 
D 7

Referent: Prof. Dr. H.-J. Fritz

Korreferent: Prof. Dr. med. W. Engel

Tag der mündlichen Prüfung: 
Alles Wissen und alles Vermehren unseres Wissens endet nicht mit einem Schlußpunkt, sondern mit einem Fragezeichen.

Hermann Hesse

meiner Oma 


\section{Danksagung}

Die vorliegende Arbeit wurde in der Zeit von September 1998 bis März 2001 unter der Anleitung von Prof. Dr. Dr. Bertram Brenig am Tierärztlichen Institut der Georg-AugustUniversität Göttingen angefertigt. Die Arbeit wurde von Prof. Dr. H.-J. Fritz im Sinne der Promotionsordnung der Mathematisch-Naturwissenschaftlichen Fakultäten betreut und vor der Fakultät vertreten.

Herrn Prof. Dr. Dr. Bertram Brenig danke ich für die Überlassung des Themas und für die ausgezeichneten Arbeitsbedingungen in seinem Labor. Vor allem aber danke ich ihm für seine ständige Diskussionsbereitschaft, für sein Verständnis während meiner „PromotionsUnlust-Phase“" und dafür, daß er auch nicht immer alles so tierisch ernst nimmt.

Bei Herrn Prof. Dr. H.-J. Fritz bedanke ich mich für die Übernahme des Referats, ebenso bei Herrn Prof. Dr. med. W. Engel für die Übernahme des Korreferats im Fachbereich Biologie. Bei Herrn Dr. Günther Rettenberger und bei Frau Sonja Kollers bedanke ich mich für die Durchführung der in situ-Hybridisierungen.

Meinen herzlichen Dank möchte ich auch allen Mitarbeitern des Tierärztlichen Instituts aussprechen. Besonders bedanken möchte ich mich bei Alex Deppe, mit der ich so manchen „deal“ ausgehandelt habe. Christoph Knorr danke ich sehr herzlich für die „Motivase“, für viele wertvolle Tips und für die konstruktive Kritik an dieser Arbeit. Brigitte Dierkes danke ich für ihre aufmunternden Worte: „Du siehst immer noch gut aus..." Außerdem bedanke ich mich bei Uli Peters, Reza Nezamzadeh, Leonard Bull, Stefan Jansen, Melanie Scharfenstein, Anne-Cathrin Uibeleisen, Ina Pfeiffer und Frau Friedrichs.

Darüber hinaus danke ich den Mitgliedern der „brasilianischen Delegation“, Paula Schneider, Artur Silva und Marcelo Vallinoto dafür, daß sie ein bißchen südländisches Flair hier in den hohen Norden gebracht haben. Marcelos Kaffee hat mich über so manches Wochenende gerettet und seine Unterbrechungen waren durchaus willkommen (,Can I bother you again ...?"-Marcelo, du immer!).

Von den inzwischen ehemaligen Mitstreitern am Tierärztlichen Institut danke ich besonders Herrn Tosso Leeb und Frau Andrea Krempler für die stets kompetenten Hilfestellungen im Laboralltag. Nicht zu vergessen, der Bär, Bernhard Baumgartner, der für mich nicht nur in fachlichen Anglegenheiten immer noch ein wichtiger Ansprechpartner ist, sondern vor allem auch ein sehr guter Freund.

„Meinem“ Gerold danke ich besonders für seine Liebe, sein Verständnis und seine Geduld. Vor allem dann, wenn die Arbeit mal wieder nicht im Labor geblieben war, sondern mit uns zu Abend gegessen hat. Darüber hinaus hat Gerold mich so manches Mal fachlich weitergebracht und mir einen anderen Blickwinkel aufgezeigt. Auch in Computerangelegenheiten und bei der Durchführung der PRE-Analyse war Gerold mein Mann.

Außerdem danke ich dem Erfinder der Kaffeemaschine, Hans Riegel, Bonn (HARIBO) und dem „La Romantica“ Pizza-Lieferdienst. 
Teile dieser Arbeit wurden veröffentlicht in:

S Duscher, U Peters, B Brenig (2000) A polymorphic microsatellite located within the second intron of the Methylmalonyl-CoA Mutase (MUT) gene on SSC 1.

Animal Genetics 31: 33 - 346.

S Duscher, I Pfeiffer, B Brenig (1999) Identification of a highly polymorphic microsatellite within the porcine skeletal muscle triadin (SMTRD) gene.

Animal Genetics 30: 466 - 7.

Al-Bayati HK, Duscher S, Kollers S, Rettenberger G, Fries R, Brenig B (1999) Construction and characterization of a porcine P1-derived artificial chromosome (PAC) library covering 3.2 genome equivalents and cytogenetical assignment of six type I and type II loci.

Mamm Genome 10: 569 - 72. 
2 LITERATURÜBERSICHT 3

$\begin{array}{lll}2.1 & \text { Strategien zur Genomanalyse } & 3\end{array}$

2.1.1 Kopplungsanalysen ermöglichen eine grobe Kartierung des Genoms 3

2.1.2 Genomsequenzierungsprojekte 4

2.1.3 Vergleichende Genomanalyse $\quad 5$

2.2 Triadin, ein Membranprotein im sarkoplasmatischen Retikulum $\quad 8$

2.2.1 Strukturelle Eigenschaften des Triadins $\quad 8$

2.2.2 Triadin-Isoformen unterschiedlicher Funktion $\quad 9$

$\begin{array}{ll}2.2 .3 & 10\end{array}$

$2.3 \quad$ Das Enzym MethylmalonylCoA-Mutase (MCM) 12

2.3.1 Funktionelle Bedeutung im Aminosäureabbau

2.3.2 Das funktionelle Enzym 12

2.3.3 Das Coenzym B 12 $_{2} 13$

2.3.4 Das Methylmalonyl-CoA-Mutase-Gen (mut) 14

2.3.5 Mutationen im mut-Gen und die Auswirkungen 16

3 MATERIAL 19

3.1 Bakterien, Plasmide und Genbanken $\quad 19$

$\begin{array}{llr}3.1 .1 & \text { Bakterien } & 19\end{array}$

$\begin{array}{llr}3.1 .2 & \text { Plasmide } & 19\end{array}$

$\begin{array}{ll}3.1 .3 \quad \text { Genbanken } & 19\end{array}$

3.2 Enzyme, DNA-, Nukleotide, Chemikalien und Kits $r$

$\begin{array}{ll}\text { 3.2.1 Enzyme und DNA-Marker } & 19\end{array}$

$\begin{array}{ll}3.2 .2 \quad \text { Nukleotide } & 20\end{array}$

$\begin{array}{ll}3.2 .3 \quad \text { Chemikalien } & 20\end{array}$

$\begin{array}{ll}3.2 .4 & 20\end{array}$

3.3 Verbrauchsartikel, Glaswaren und Laborgeräte $\quad 21$

$\begin{array}{llr}\text { 3.3.1 Verbrauchsartikel } & 21\end{array}$

$\begin{array}{ll}\text { 3.3.2 Glaswaren } & 21\end{array}$

$\begin{array}{ll}\text { 3.3.3 Laborgeräte } & 21\end{array}$

4 METHODEN 22

4.1 Vermehrung und Isolierung von Plasmid-DNA $\quad 22$

4.1.1 Bakterienkultur (Ausubel et al., 1990) 22

4.1.2 Herstellung transformationskompetenter E. coli XL1-Blue 23

4.1.3 Transformation von Plasmiden in E. coli 23

4.2

DNA-Isolierung

Isolierung von genomischer DNA aus Vollblut $\quad 24$

4.2 .2

4.2 .3

Isolierung von Plasmiden mit Qiagen Plasmid Kits $\quad 25$

Isolierung von PAC-DNA mit Qiagen Plasmid Kits $\quad 26$

$\begin{array}{llr}\text { 4.2.4 Schnellaufschluß durch alkalische Lyse } & 26\end{array}$

$\begin{array}{llr}4.3 & \text { Manipulation und Analyse von DNA } & 27\end{array}$

$\begin{array}{ll}\text { 4.3.1 Spaltung von DNA mit Restriktionsendonukleasen } & 27\end{array}$

$\begin{array}{ll}\text { 4.3.2 Dephosphorylierung von linearisierten Plasmiden } & 27\end{array}$ 
4.3 .3

Ligation von DNA-Fragmenten und Vektoren $\quad 27$

$\begin{array}{ll}\text { Polymerase-Kettenreaktion } & 28\end{array}$

Agarose-Gelelektrophorese $\quad 29$

$\begin{array}{ll}\text { Pulsfeldgelelektrophorese } & 29\end{array}$

Elution von DNA aus Agarosegelen $\quad 30$

Transfer und Detektion von DNA auf Membranen $\quad 30$

Nicht-radioaktive Hybridisierung mit dem ECL direct labelling system 31

Nicht-radioaktive Sequenzierung doppelsträngiger DNA 31

$\begin{array}{ll}\text { Automatisches Sequenzieren } & 32\end{array}$

$\begin{array}{ll}\text { Mikrosatelliten-Analyse } & 32\end{array}$

RNA-Analyse $\quad 33$

Isolierung von Gesamt-RNA aus Geweben $\quad 33$

$\begin{array}{ll}\text { RT-PCR } & 33\end{array}$

5'- und 3'- RACE (Rapid Amplification of cDNA Ends) mit dem Marathon cDNA Amplification Kit und dem Advantage ${ }^{\circledR} 2$ PCR Enzyme System 33 Nicht-radioaktive Primer Extension Analyse $\quad 34$

Transfer und Detektion von RNA auf Membranen $\quad 35$

\section{ERGEBNISSE}

5.1

Herstellung der humanen und porcinen Triadin-cDNA aus Skelettmuskel $\begin{array}{ll}\text { Identifizierung unterschiedlicher cDNA-Klone } & 38\end{array}$

$\begin{array}{lll}5.2 & \text { Genomische Organisation des Triadin Gens } & 39\end{array}$

$\begin{array}{lll}\text { 5.2.1 Identifizierung alternativ gespleißter Exons } & 44\end{array}$

5.2.2 Chromosomale Lokalisation des porcinen Triadin-Gens 54

$\begin{array}{llr}5.3 & \text { Herstellung porciner mut-cDNA aus Lebergewebe } & 57\end{array}$

5.4 Molekulargenetische Analyse des porcinen mut-Locus $\quad 57$

$\begin{array}{lll}5.4 .1 & \text { Subklonierung des PAC-Klones A3F11 } & 58\end{array}$

$\begin{array}{lll}\text { 5.4.2 Ermittlung der Sequenzcharakteristik } & 61\end{array}$

5.4.3 Chromosomale Lokalisation des porcinen Mehtylmalony-CoA-Mutase-Gens 71

$\begin{array}{lll}\text { 5.4.4 Identifizierung weiterer PAC-Klone } & 73\end{array}$

$\begin{array}{lll}\text { 5.4.5 Shot gun Klonierung des PAC A13B5 } & 77\end{array}$

5.4.6 Chromosomale Lokalisation des PAC A13B5 83

$\begin{array}{lll}\text { 5.4.7 Analyse der PRE } & 85\end{array}$

$\begin{array}{lll}6 & \text { DISKUSSION } & 91\end{array}$

6.1 Molekulargenetische Untersuchung des humanen und porcinen Triadin-Gens 91

6.1.1 Das Triadin-Gen erstreckt sich mit mehr als 38 Exons über einen genomischen Bereich von mindestens $451 \mathrm{~kb} \quad 91$

6.1.2 Identifizierung bisher unbekannter Triadin-cDNA-Varianten im Skelettmuskel 92

6.1.3 Die chromosomale Lokalisation des Triadin-Gens entspricht nicht den bekannten
Syntenieverhältnissen

$\begin{array}{llr}\text { 6.2 Charakterisierung des porcinen } \text { mut-Locus } & 95\end{array}$

$\begin{array}{lll}\text { 6.2.1 Das mut-Gen ist stark konserviert } & 95\end{array}$

6.2.2 Polymorphismen im porcinen mut-Locus 96

6.2.3 Die shot gun Klonierung eines weiteren PAC-Klones führt zur Identifizierung bisher nicht bekannter codierender Bereiche 96

6.2.4 Die chromosomale Lokalisation des porcinen mut-Gens und des PAC A13B5 deuten auf eine Bruchlinie im Synteniebereich hin 
$\begin{array}{lll}7 & \text { ZUSAMMENFASSUNG } & 100\end{array}$

8 LITERATURVERZEICHNIS 102

9 ANHANG 105 


\section{$1 \quad$ Einleitung}

Begriffe wie Humanes Genomprojekt, Genanalyse, genetisch veränderte Organismen und Gentherapie sind in den letzten Jahren wesentlicher Bestandteil der täglichen Medienberichterstattung. Nicht immer wird der rapide Fortschritt in der Genforschung als positiv empfunden. Die komplexen, für den Laien wenig durchschaubaren Techniken und die theoretischen Einsatzmöglichkeiten sind faszinierend, hoffnungsvoll, verunsichernd und beunruhigend zugleich. Die öffentliche Erwartungshaltung weicht in vielen Punkten von den tatsächlichen Forschungszielen ab. Dennoch wird letztendlich die Nachfrage das Marktangebot bestimmen. Die öffentliche und kritische Diskussion ist dabei ein wichtiger Schritt zur Festlegung ethischer Grenzen der Forschung.

Die Sequenzierung des menschlichen Genoms ist trotz des umstrittenen Kosten-/NutzenFaktors ein Meilenstein in der Geschichte der Genomforschung. Obwohl die Auswertung der Daten noch Jahre dauern wird, sind bereits einige überraschende Ergebnisse bekannt geworden. So liegt die Anzahl der, nach ersten Analysen ermittelten, tatsächlich vorhandenen Gene nur etwa bei der Hälfte der erwarteten Zahl. Dies bedeutet gleichzeitig, daß die Komplexität der regulatorischen Mechanismen wesentlich höher ist, als erwartet. Die Fülle der bereits jetzt vorhandenen Daten steht Wissenschaftlern sämtlicher biologischer und medizinischer Disziplinen in aller Welt zur Verfügung. Durch Vergleich der genomischen Daten verschiedener Spezies können hochkonservierte Regionen, die meist mit Schlüsselfunktionen physiologischer und entwicklungsspezifischer Regulation zu tun haben, schnell ausfindig gemacht werden. Letztendlich wird sich auch zeigen, welche Faktoren die einzelnen Spezies ausmachen, bzw. welche Unterschiede zur Ausbildung unterschiedlicher Organismen führen.

Obwohl auch im Bereich der Nutztierforschung in den letzten Jahren große Anstrengungen unternommen wurden, gibt es hier noch erheblichen Forschungsbedarf. Das Klonen von Tieren, das 1998 mit dem Schaf „Dolly“ iniziiert wurde, ist zwar immer noch ein medienwirksames und spektakuläres Experiment, der praktische Nutzen ist allerdings vor allem aus ökonomischer Sicht gering. Die Hauptaugenmerke richten sich auch bei den Nutztieren auf die Erforschung der genetischen Disposition für Erbkrankheiten, Krankheitsresistenzen und wirtschaftlich verwertbaren Merkmalen. Die Genomforschung beim Schwein konzentriert sich dabei vor allem auf die Kartierung von QTLs (quantitative trait loci) und ETLs (economic trait loci) und auf möglichst effiziente und sichere Methoden der Abstammungskontrolle. Die vergleichende Genomforschung kann hier ein wertvolles Mittel sein den sich kontinuierlich ändernden Anforderungen gerecht zu werden.

Natürlich sind die Spezies Mensch und Schwein phänotypisch sehr verschieden, doch die genetisch festgelegten, physiologischen Parameter sind im Wesentlichen gleich. Deshalb bietet sich die Methode der vergleichenden Genomanalyse an, um die verhältnismäßig weit fortgeschrittenen Erkenntnisse humaner Genomforschung für die porcine Genomanalyse zu nutzen. Selbstverständlich sind solche Schlußfolgerungen auch in 
umgekehrter Richtung möglich. Die hier präsentierte Arbeit ermittelt sowohl Daten einzelner codierender Bereiche, wie auch definierter chromosomaler Abschnitte.

Als Ausgangspunkt für die vorliegende Untersuchung wurden zwei, beim Menschen bereits kartierte Gene ausgewählt. Zum einen das Triadin-Gen (skmtrd), das beim Menschen auf Chromosom 6q22 - 23 lokalisiert wurde. Bezüglich der chromosomalen Lokalisation kann man aufgrund der publizierter Daten erwarten, da $\beta$ das porcine Triadin Gen auf dem kurzen Arm des SSC 1 lokalisiert ist. Hingegen lassen eigene Voruntersuchungen auf eine Lokalisation auf dem langen Arm des SSC 1 schließen. Als ein Protein der sogenannten Triade, vermutet man, daß Triadin wesentlich an den Mechanismen der Muskelkontraktion beteiligt ist. Zumindest eine Fehlfunktion der Muskelkontraktion wurde mit einem, für ein weiteres Trias-Protein codierenden Gen in Zusammenhang gebracht. Von einer Punktmutation im RyR1-Gen (Ryanodin-Rezeptor 1) konnte gezeigt werden, daß sie die Ursache für maligne Hyperthermie bei Schweinen, aber auch in einigen Fällen beim Menschen zu sein. Die Ursache dieser genetischen Disposition beim Menschen ist jedoch noch nicht restlos geklärt. Die Charakterisierung weiterer TriasProteine bzw. der dafür codierenden Gene ist der konsequente Schritt zur Klärung dieser Befunde.

Als zweites Gen wurde das Methylmalonyl-CoA-Mutase-Gen ( $m u t)$, das beim Menschen auf Chromosom 6p12 - 21.1 lokalisiert wurde, ausgewählt. Von diesem Bereich hat man bereits zahlreiche Hinweise auf Syntenie zum porcinen Chromosom 7 (SSC 7). Beim Methylmalonyl-CoA-Mutase-Gen ( $m u t$ ) handelt es sich darüber hinaus um ein Gen, dessen Defektvarianten beim Menschen zu einer Stoffwechselerkrankung, der Methylmalonazidurie führt. Es ist nicht auszuschließen, daß einige bisher ungeklärte Krankheitsfälle bei Schweinen, die unter anderem mit Tremor, Parese und hoher Ferkelsterblichkeit einhergehen, möglicherweise auf einen Defekt im porcinen mut-Locus zurückzuführen sind. Die molekulargenetische Charakterisierung des porcinen mut-Locus ist Basis für nachfolgende Mutationsanalysen.

Die für die vorliegende Arbeit gewählten Genloci sind beide auf dem humanen Chromosom 6 lokalisiert. Hier sind zwar zwei syntenische Bereiche zu porcinen Chromosomen bekannt, der Verlauf der Grenzen ist jedoch sowohl auf humaner, wie auch auf porcinen Seite unklar.

Ziel der vorliegenden Untersuchung war es, einerseits die beiden oben genannten Genloci zu charakterisieren und darüber hinaus die Kenntnisse über die Syntenieverhältnisse des humanen Chromosom 6 und Bereichen porciner Chromosomen zu verbessern. 


\section{Literaturübersicht}

\subsection{Strategien zur Genomanalyse}

\subsubsection{Kopplungsanalysen ermöglichen eine grobe Kartierung des Genoms}

Speziesspezifische Kopplungskarten dienen als Basis zur Identifizierung chromosomaler Regionen, die mit interessanten Phänotypen in Zusammenhang stehen. Die Kartierung von Krankheitsgenen, aber auch die Kartierung von Loci, die mit besonderen biologischen und wirtschaftlichen Merkmalen assoziiert sind, ist die Grundlage markergestützer Züchtungsprogramme.

Die Rate der genetischen Rekombination spielt eine große Rolle in der Evolution diploider Spezies und zeigt sowohl intra- wie auch inter-speziesspezifische Variationen [1]. Von allen Säugetieren existieren bisher bei Mensch und Maus die umfangreichsten Kopplungsstudien. Der Vergleich der erhaltenen Daten zeigte zwar annähernd die gleiche physikalische Genomgröße (etwa 3 x $10^{9} \mathrm{bp}$ ), die Rekombinationsraten unterscheiden sich jedoch deutlich. So konnte beim Menschen eine durchschnittliche Rekombinationsdistanz von 3.800 - 4.000 Centimorgan (cM) ermittelt werden [2], bei der Maus liegt dieser Wert bei etwa 1.600 [3].

Das porcine Genom besteht aus 19 Chromosomenpaaren (inklusive Geschlechtschromosomen) und entspricht in seiner physikalischen Größe etwa dem des Menschen, die Rekombinationsdistanz ist jedoch signifikant niedriger [4-6]. Die porcine Genkarte enthält derzeit etwa 1.550 anonyme, sogenannte Typ II Marker (meist Mikrosatelliten) und etwa 250 Gene, als sogenannte Typ I Marker. Bei der Kopplungsuntersuchung mit Hilfe von 15 polymorphen Markern auf dem porcinen Chromosom 1 (sus scrofa chromosome 1, SSC 1) konnte festgestellt werden, daß die Rekombinationsrate nicht nur geschlechtsspezifisch variiert, sondern auch abhängig ist von der Region innerhalb des Chromosoms. So zeigte sich zum Beispiel, daß bei weiblichen Tieren die Rekombinationsrate in den terminalen Bereichen des Chromosoms, im Vergleich zu den männlichen Tieren um den Faktor fünf erhöht war. Über große Bereiche des q-Armes hingegen zeigten männliche Tiere erhöhte Rekombination. Das durchschnittliche Verhältnis der genetischen Rekombination zum physikalischen DNAGehalt beträgt bei SSC 1 etwa $1 \mathrm{cM}$ pro $2-4$ Megabasen $(\mathrm{Mb})$. Dieser Wert gilt für den größten Teil des Chromosoms. In den telomeren Bereichen des langen Armes ist die Rekombinationsrate deutlich erhöht, so daß sich ein Verhältnis von $1 \mathrm{cM}$ zu etwa $0.4 \mathrm{Mb}$ ergibt [5]. Mit Hilfe von Kopplungsanalysen gelang es der Arbeitsgruppe um Andersson den proximalen Bereich des Chromosoms 4 als jene Region einzuschränken, die unter anderem, für Wachstum und Ausmaß des Fettgewebes beim Schwein verantwortlich ist 
[7]. In den letzten Jahren wurde die Kartierung solcher quantitativer Merkmaler (QTL) besonders forciert. Die Anzahl der DNA-Marker ist jedoch, insbesondere auf den Chromosomen 5 und 18 noch relativ gering, die genetischen Distanzen demnach zu groß und die Möglichkeiten zur Kartierung von QTLs dadurch limitiert.

\subsubsection{Genomsequenzierungsprojekte}

Ehrgeizige Projekte, die die Sequenzierung ganzer eukaryontischer Genome zum Ziel haben, wurden bereits mehrfach erfolgreich zu Ende geführt. In den 90er Jahren wurde das Genom der Bäckerhefe Saccharomyces cerevisiae als erstes Großprojekt fertiggestellt [8,9], gefolgt von einer Reihe andere Organismen wie etwa Caenorhabditis elegans [10], Drosophila melanogaster [11,12] und Arabidopsis thaliana [13], um nur einige zu nennen. Die fast vollständige Entzifferung des menschlichen Genoms, als das bisher größte und aufwendigste Projekt der Genomforschung wurde im Juni 2000 bekanntgegeben. Mittlerweile sind nach den ersten Analysen der erhaltenen Sequenzdaten einige überraschende Details bekannt geworden. Lange Zeit war man von 80.000 bis 100.000 Genen im menschlichen Genom ausgegangen. Inzwischen zeigt sich jedoch, daß das Genom nur etwa 30.000 bis 40.000 Gene enthält. Die Vielfalt zellulärer Funktionen entsteht demnach nicht nur durch die Vielfalt vorhandener Gene, sondern vor allem auch durch die Anzahl unterschiedlicher Proteine, die aus einem Gen zum Beispiel durch alternatives Spleißen der codierenden Bereiche entstehen. Derzeit geht man davon aus, daß auf diese Weise von jedem dritten Gen mehr als ein Genprodukt entsteht. Dabei ist noch immer unklar, welche Rolle einzelnen Strukturelementen der Introns bei diesen Spleißprozessen zukommt und welche Mechanismen die Spleißvorgänge steuern.

\subsubsection{Strukturen des Genoms}

Die bisherigen Analysen des humanen Genomprojektes zeigen, daß nur etwa $5 \%$ des menschlichen Genoms von proteincodierenden Genen eingenommen werden. Die restlichen $95 \%$ bestehen aus nicht-codierenden Bereichen, hauptsächlich sind dies repetitive Elemente. Man unterscheidet hier die sogenannten long interspersed nuclear elements (LINE) von den short interspersed nuclear elements (SINE), sowie SatellitenDNA. Man geht davon aus, daß LINE-Sequenzen von Transposons abstammen, bei SINESequenzen sprechen viele Befunde dafür, daß diese als Retroposons von tRNAs stammen $[14,15]$. Lange Zeit wurden diese Sequenzabschnitte für genetischen „Schrott“ gehalten, der sich im Laufe der Evolution angereichert hat. In jüngster Zeit allerdings werden immer mehr Eigenschaften dieser DNA-Bereiche bekannt, die auf spezifische regulatorische Funktionen schließen lassen. So zeigen mehrere Beobachtungen, daß SINE-Elemente unter Streß transkribiert werden [16,17]. Die entstandene RNA kann die Synthese bestimmter Proteine durch Inhibierung einer PKR (RNA-dependent protein kinase) stimulieren. Da diese Kinase die Phosphorylierung unterschiedlicher Proteine, zum Beispiel die von elf2 (eukaryotic initiation factor 2) katalysiert, liegt die Vermutung nahe, 
daß SINE-Elemente noch eine Reihe weiterer zellulärer Funktionen beeinflussen können [18].

\subsubsection{Methoden der Genomanalyse}

Die Analyse der Nukleotidsequenzen eines gesamten Genomes wird in mehreren Schritten durchgeführt. Zunächst wird die hochmolekulare chromosomale DNA in kleinere Fragmente zerteilt. Dies geschieht mit Hilfe von Restriktionsendonukleasen. Die entstandenen Fragmente werden daraufhin in Vektoren einkloniert und in Bakterien vermehrt. Die auf diese Weise angereicherten DNA-Fragmente werden wiederum isoliert und aufgereinigt und in einem sogenannten Schrotschußverfahren sequenziert. Die Sequenzen der einzelnen Fragmente werden anschließend wieder in der richtigen Reihenfolge zusammengesetzt. Auf diese Weise erhält man die Sequenzen der einzelnen Chromosomen. Danach werden mittels Computerprogrammen wie BLAST [19], RepeatMasker [20] und Genscan [21] möglichst viele Charakteristika der einzelnen Sequenzabschnitte ermittelt. Dabei spürt BLAST jene Sequenzabschnitte auf, die mehr oder weniger große Ähnlichkeit mit bereits in den Datenbanken enthaltenen Sequenzen haben. RepeatMasker ermöglicht die Kartierung von repetitiven DNA-Abschnitten und Genscan versucht potentiell codierende Bereiche aufzuspüren. Das Programm Genscan wurde entwickelt um vor allem in Vertebratengenomen proteincodierende Abschnitte zu kartieren. Es wurde an 570 Vertebraten auf die Genauigkeit dieser Vorhersagen getestet. Mit Genscan werden durchschnittlich 70 - $80 \%$ der tatsächlich vorhandenen Exons gefunden. Dabei ist die Kartierung des ersten und des letzten Exons eines Gens meist präziser, als die Kartierung interner Exons. Insbesondere sehr kleine Exons werden von dem Programm häufig nicht erkannt. Die Präzision kann aber durch Vergleiche mit sogenannten EST-Sequenzen verbessert werden. EST (expressed sequence tags) entstehen durch Klonierung und Sequenzierung von cDNA-Abschnitten und stellen somit Kopien der messengerRNA, also tatsächlich exprimierter Gene dar. Genscan sucht vor allem nach charakteristischen Sequenzmotiven wie Spleiß-Stellen, Start- und Stop-Codons und Polyadenylierungssignalen. Darüberhinaus verwendet das Programm auch Daten über Proteinsequenz-Homologien und ist damit die erfolgreichste Software in der Identifizierung von Genen in Vertebratengenomen [21].

\subsubsection{Vergleichende Genomanalyse}

Bei der Lokalisierung und Charakterisierung von Genen, die die Ausbildung wichtiger Phänotypen steuern, konzentrieren sich die Untersuchungen beim Menschen hauptsächlich darauf Gene zu lokalisieren, die mit verschiedenen Erbkrankheiten in Verbindung gebracht werden. Das Hauptinteresse in der Nutztierforschung hingegen, besteht in der Identifizierung von ökonomisch wertvollen Merkmalen (economic trait loci, ETL). Die genetischen Karten der meisten Nutztiere sind jedoch aufgrund der geringen Anzahl von Markern noch recht ungenau, verglichen mit jenen für Mensch und Maus. Die Verfügbarkeit genetischer Karten und Sequenzinformationen verschiedener Spezies bietet 
jedoch die Möglichkeit des Informationsaustausches und der Identifizierung homologer Regionen. Auf diese Weise kann die Position eines Genes bei einer Spezies abgeschätzt werden, wenn das homologe Gen bei einer anderen Spezies bereits kartiert wurde.

Eine als ZOO-FISH bezeichnete Hybridisierungstechnik wurde ursprünglich eingesetzt um konservierte Chromosomenregionen in der Primatenevolution zu analysieren. Die Methode funktioniert aber auch bei anderen Säugetierspezies. 1995 zeigten Rettenberger et al. die Ergebnisse einer ZOO-FISH Analyse zwischen Mensch und Schwein [22]. Die dazu verwendeten Hybridisierungssonden stammten aus chromosomen-spezifischen Genbanken. Die Sonden wurden durch spezielle PCR-Verfahren wie zum Beispiel DOPPCR (degenerated oligonucleotide-primed PCR) oder PARM-PCR (priming authorizing random mismatches PCR) hergestellt. Die aus dem humanen Genom stammenden Sonden wurden mit den Chromosomen der Test-Spezies hybridisiert. Aus diesem zunächst in eine Richtung durchgeführten Experiment entwickelte sich das sogenannte „bidirectional chromosome painting“, bei dem Hybridisierungssonden beider Spezies mit den Metaphasechromosomen der jeweils anderen Spezies hybridisiert werden. Auf diese Weise konnte insbesondere die Genauigkeit der Grenzen der einzelnen Synteniebereiche verbessert werden [23]. Abbildung 2-1 zeigt einen Überblick über die derzeit bekannten syntenischen Bereiche des porcinen Chromosoms 1 (SSC 1 oder Sscr 1) mit Bereichen der humanen Chromosomen (Hsap) 6, 9, 14, 15 und 18. Insgesamt kennt man derzeit 37 syntenische Regionen zwischen Mensch und Schwein. 


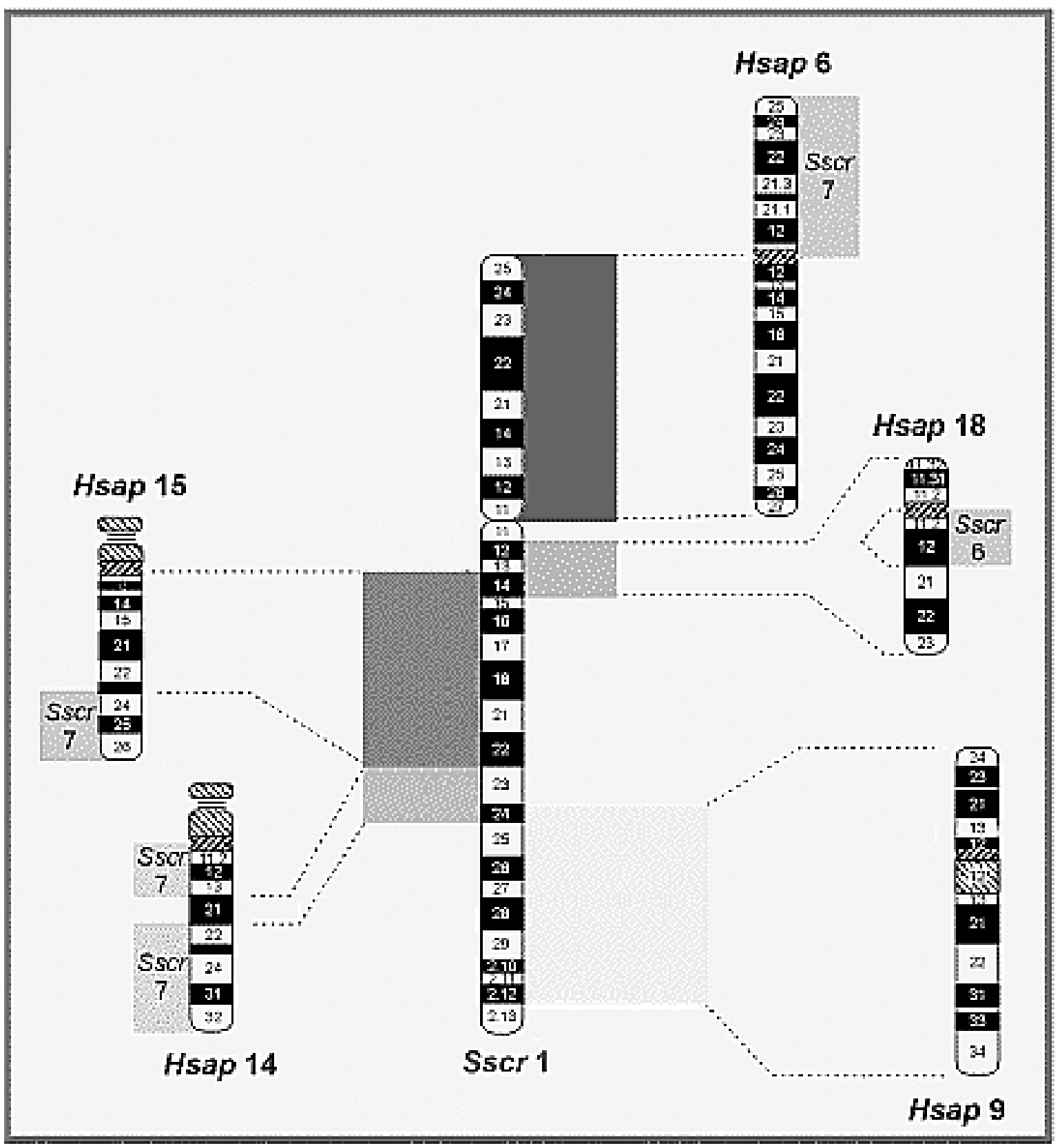

Abb. 2-1 Schematische Darstellung bekannter syntenischer Bereiche des porcinen Chromosoms 1 (Sscr 1) und der humanen Chromosomen (Hsap) 6, 9, 14, 15 und 18

Die Abbildung stammt aus http://www.toulouse.inra.fr/lgc/pig/compare/SSCHTML/SSC1S.HTM und wurde leicht modifiziert.

Neuere Arbeiten wenden sich einem nach wie vor bestehenden Problem der porcinen Genomforschung zu, nämlich der geringen Anzahl von kartierten Genen. Ausgehend von humanen expressed sequence tags (EST), die über verschiedene Datenbanken verfügbar sind, können PCR-Primer synthetisiert werden, die später zur Analyse eines Cell Hybrid Panels herangezogen werden können. Dabei handelt es sich um spezielle Zellinien, in denen das porcine Genom in Form von mehr oder weniger großen Chromosomenfragmenten in Maus-und/oder Hamster-Zellen eingeschleust wurden. Die einzelnen Zellinien werden dann auf den Gehalt porciner Chromosomen getestet. Dies 
geschieht mittels PCR bereits bekannter und kartierter Marker. Die Genauigkeit einer Cell Panel-Analyse hängt im Wesentlichen von der Anzahl bzw. der Dichte der bekannten Marker und von der Größe und Anzahl der chromosomalen Fragmente ab. Unlängst konnten mit Hilfe dieser Methode 65 solcher ESTs im porcinen Genom lokalisiert werden [24]. Von diesen 65 potentiellen Genen wurden 7 in chromosomalen Regionen kartiert, die man aufgrund bisheriger Homologievergleiche nicht erwarten würde. Auch die Arbeit von Larsen und Kollegen verfeinert die Genkarte beim Schwein. Die Arbeitsgruppe konnte mittels PCR-Analyse eines somatischen Cell Hybrid Panels weitere elf Gene kartieren, fünf davon ebenfalls in unerwarteten Regionen. Darüberhinaus konnten Neuanordnungen von Genen innerhalb bekannter syntenischer Regionen entdeckt werden [25].

\subsection{Triadin, ein Membranprotein im sarkoplasmatischen Retikulum}

Das Transmembranprotein Triadin erhielt seinen Namen aufgrund der Lokalisation in der sogenannten Trias-Region des Muskels. Die Triade wird gebildet aus den terminalen Zisternen der sarkoplasmatischen Reticuli (SR) zweier aneinandergrenzender Sarkomere und einem T-Tubulus, der zwischen den beiden eingebettet liegt. In Skelettmuskelzellen führt eine Depolarisation der Plasmamembran (T-Tubulus-Membran) zur Freisetzung von $\mathrm{Ca}^{2+}$ aus dem sarkoplasmatischen Retikulum und daraufhin zu einer Kontraktion. Dieser Prozess wird als EC-Kopplung (excitation-contraction) bezeichnet. Er wird vor allem durch die speziellen Eigenschaften des Dihydropyridin-Rezeptors (DHPR) und des Ryanodin-Rezeptors (RyR1 im Sekelettmuskel, RyR2 im Herzmuskel) ermöglicht [26,27]. Der Dihydropyridin-Rezeptor, dessen $\alpha_{1}$-Untereinheit sowohl als Spannungs-Sensor, wie auch als spannungsabhängiger Calciumkanal fungiert, befindet sich in der T-TubulusMembran. Der RyR, ein weiterer Calciumkanal, befindet sich, dem DHPR gegenüber, in der Membran des SR. Einige Untersuchungen deuten darauf hin, daß die beiden Rezeptoren mechanisch interagieren und es ist sehr wahrscheinlich, daß diese Interaktion von anderen Proteinen unterstützt bzw. stabilisiert wird [28-30]. Aufgrund seiner CoLokalisation mit dem Ryanodin-Rezeptor und seiner regelmäßigen Anordnung in der SRMembran, ist das Triadin eines der wichtigsten Proteine, die in diesem Zusammenhang untersucht werden.

\subsubsection{Strukturelle Eigenschaften des Triadins}

Triadin wurde zunächst als ein $95 \mathrm{kDa}$ großes Protein aus dem Skelettmuskel des Kaninchens isoliert [31]. Die Primärstruktur aus 706 Aminosäuren wurde aus der cDNA abgeleitet. Computergestützte Analysen der Aminosäuresequenz ließen drei Domänen erkennen. Den N-Terminus, der mit nur 47 Aminosäuren den cytoplasmatischen Teil des Proteins bildet, eine einzige hydrophobe Ausdehnung zwischen den Aminosäuren 48 und 68 als Transmembrandomäne und den stark geladenen, basichen und größten Anteil des Proteins, der sich im Lumen des SR befindet [32,33]. Der C-terminale Bereich des Proteins weist besonders viele Lysin- und Glutaminsäure-Reste auf, die durch multiple 
Wiederholungen zu sogenannten KEKE-Motiven organisiert sind. Diese Motive gelten als mögliche Bereiche für Protein-Protein-Interaktionen [34]. Triadin liegt im nativen Zustand als Homopolymer vor, wobei die genaue Anzahl der Untereinheiten umstritten ist. Da sich innerhalb des Proteins nur zwei Cystein-Reste befinden, die für Disulfidbrücken in Frage kommen, ist das Vorhandensein intramolekularer Disulfidbrücken unwahrscheinlich. Triadin besitzt mehrere N-Glycosylierungsstellen und mehrere potentielle Phosphorylierungsstellen [33,35-38] .

Die Primärstruktur und topologischen Eigenschaften des Triadins, insbesondere die Tatsache, daß sich der größte Teil des Proteins mit seinen KEKE-Motiven im Lumen des SR befindet, legt die Vermutung nahe, daß Triadin als Verbindungsmolekül zwischen dem RyR1 und dem $\mathrm{Ca}^{2+}$-bindenden Calsequestrin fungieren könnte [39]. Um die funktionelle Rolle des Triadins aufzuklären, konzentrierten sich Forscher in den letzten Jahren vor allem auf die Analyse seiner Bindungseigenschaften.

\subsubsection{Triadin-Isoformen unterschiedlicher Funktion}

Der Isolierung des Skelettmuskel-Triadins beim Kaninchen folgte bald die Identifizierung unterschiedlicher Isoformen, sowohl im Skelettmuskel, wie auch im Herzmuskel verschiedener Spezies [40-43]. Die tatsächliche Anzahl funktioneller Isoformen ist allerdings noch unklar, zumal verschiedene Arbeitsgruppen diesbezüglich zu unterschiedlichen Ergebnissen gelangen. Konsens besteht derzeit in dem Befund, daß im Herzmuskel die kleinste Isoform, CT 1 (cardiac Triadin 1), im Sekelettmuskel aber die größte Isofom, Trisk 95 (Triadin, Skelettmusklel, $95 \mathrm{kDa}$ ) die am stärksten exprimierte Form in adulten Tieren ist [44]. Die bisherigen Untersuchungen zeigen, daß sich alle gefundenen Isoformen jeweils in ihren C-Termini unterscheiden. Abbildung 2-2 zeigt einen Aminosäurevergleich verschiedener Triadin-Isoformen aus Herz- und Skelettmuskel. CT 1 stimmt demnach mit Trisk 95 bis zur Aminosäure 257 überein. Die Homologie endet hier abrupt und es folgen 21, für CT 1 charakteristische Aminosäuren. Für beide ProteinVarianten konnte gezeigt werden, daß sie mit ihrer luminalen Domäne sowohl an RyR, wie auch an Calseqestrin binden können [45-47]. Insbesondere konnten die Gruppe um Kobayashi. die Calsequestrin-Bindungs-Domäne des caninen Triadin 1 (CT 1) auf einen Bereich von nur 25 Aminosäuren (Postion 210 - 224) einschränken [48]. In diesem Bereich führt der Austausch der Aminosäuren Lys ${ }^{210}$, Lys $^{212}$, Glu ${ }^{214}$ und Lys ${ }^{216}$ sowie der Aminosäuren $\mathrm{Gly}^{218}, \mathrm{Gln}^{220}$, Lys $^{222}$ und Lys $^{224} \mathrm{zu}$ einem Verlust der Bindungsfähigkeit. Dieser Befund unterstützt damit die Hypothese, daß die Interaktion von Triadin mit anderen Proteinen der Trias-Region sehr spezifisch ist [39].

$\mathrm{Da}$ sich die Funktion des Triadins nicht ausschließlich auf die Verankerung des Calsequestrins an der SR-Membran in unmittelbarer Nähe des RyR beschränkt, zeigen auch die Befunde von Ohkura et al. [49]. Die Arbeitsgruppe konnte zeigen, daß Triadin die Aktivität des gereinigten und in eine Lipidmembran eingebetteten Calciumkanals RyR hemmt. Wertvolle Hinweise auf die Rolle der verschiedenen Trias-Proteine im ECKopplungs-Prozeß geben Studien mit transgenen Tieren, die eines der beteiligten Proteine überexprimieren. Bei einer Überexpression von Triadin 1 (CT1) im Myocard kann, wie 
auch bei der Überexpression von Calsequestrin, eine selektive Herabsetzung der Expression anderer Trias-Proteine, zum Beispiel Junctin und Ryanodin-Rezeptor (RyR2) beobachtet werden. Auffallend ist hierbei, daß die Expression von Junctin am stärksten heruntergesetzt ist. Da Junctin dem Triadin in vielen Eigenschaften ähnelt, könnte dies ein Hinweis auf eine ähnliche Funktion der beiden Proteine sein. Auch die Expression des RyR2 ist um $55 \%$ herabgesetzt. Interessanterweise erniedrigt sich die Bindungskapazität zu Ryanodin nur um 30 \%. Da der Rezeptor nur im geöffneten Zustand Ryanodin bindet, ist es denkbar, daß die quantitativen Einbußen durch eine leichtere Aktivierbarkeit des Rezeptors kompensiert werden. Proteine in anderen Bereichen des SR bleiben in ihren Expressionsraten unbeeinflußt. Darüberhinaus verändern sich bei Triadin-transgenen Tieren die Kontraktionseigenschaften des Herzmuskels. Der Phänotyp ist gekennzeichnet von Hypertrophie, unvollständiger Relaxation und Veränderungen der Myocyten [50].

Trotz all dieser interessanten Befunde ist die funktionelle Bedeutung des Triadins noch nicht klar. Ebensowenig weiß man bisher über die Aufgaben der unterschiedlichen Isoformen dieses Proteins, obwohl einige Untersuchungen darauf hindeuten, daß die Isoformen entwicklungsspezifisch exprimiert werden [43].

\subsubsection{Das Triadin-Gen}

Bisher beschränken sich die Untersuchungen zum Triadin hauptsächlich auf seine biochemischen Eigenschaften. Immerhin weist die Klonierung und Sequenzierung der cDNAs unterschiedlicher Isoformen und deren Homologie im 5'-Bereich darauf hin, daß die einzelnen Isoformen durch alternatives Spleißen aus einem Gen entstehen. Das humane Triadin-Gen konnte auf Chromosom 6q22 - q23 lokalisiert werden [51]. Die chromosomale Lokalisation des Gens bei anderen Spezies ist noch nicht erfolgt. Auch die genomische Organisation ist noch unbekannt, allerdings konnte beim Schwein der 3'Bereich des Gens kartiert werden und mittels somatischem Cell Hybrid Panel eine vorläufige chromosomale Lokalisation auf Chromosom 1 vorgenommen werden [52,53]. 
CT3 MTEITAEGNASTTTTVIDSKNGSVPKSPGKVLKRTVTEDLVTTFSSPAAWLLVIALIITW MTEITAEGNASTTTTVIDSKNGSVPKSPGKVLKRTVTEDLVTTFSSPAAWLLVIAIIITW MTEITAFGNASTTTTVIDSKNGSVPKSPGKVL KRTVTEDIVTTFSSPAAWITVIAIIITW Trisk 95 MTEITAEGNASITTTVIDNKNGSVPKSPGKVLKRTVTEDIVTTFSSPAAWLIVIALIITW Trisk 51 MTEITAEGNASITE*

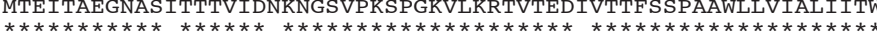
CT3 SAVAVVMFDLVDYKNFSASSIAKMGSDPLKLVHDAVEETTDWIYGFFSLLSDIISSDGDE
CT2 SAVAVVMFDLVDYKNFSASSIAKMGSDPLKLVHDAVEETTDWIYGFFLLSDIISSDGDE CT1 SAVAVVMFDIVDYKNFSASSIAKMGSDPIKLVHDAVEETTDWIYGFFSLLSDIISSDGDE Trisk 95 SAVAIVMFDLVDYKNFSASSIAKIGSDPLKLVNDAVEETTDWIYGFFSLLSDIISSDGDE Trisk 51 SAVAIVMFDLVDYKNFSASSIAKIGSDPLKLVNDVVEETTDWIYGFFSLLSDIISSDGDE

CT3 EDDEGDEDTAKGEIEEPPLKRKDIHKEKIEKOEKPERKIPTKVVHKEKEKEKEKVKEKEK CT2 EDDEGDEDTAKGEIEEPPLKRKDIHKEKIEKQEKPERKIPTKVVHKEKEKEKEKVKEKEK CT1 1 EDDEGDEDTAKGEIEEPPLKRKDIHKEKIEKQEKPERKIPTKVVHKEKEKEKEKVKEKEK Trisk 51 DDEDADEDIDKGEIEEPPLKRKEIQKEKAEKQEKPEKKIQTKVSHREKEKGKEKLKG-EK $\underset{*}{\mathrm{DDEDADEDIDKGEIEEPPLKRKDIQKEKAEKQEKPEKKIQTKVSHREKEKGKEKLKG-EK}}$

CT3
СT2

СT2 1 Trisk 95 Trisk 51

PEKKATHKEKLEKKEKPETKTVTKEEKKARTKEKIEEKTKKEVKGVKOEKVKOTVAKAKE PEKKATHKEKLEKKEKPETKTVTKEEKKARTKEKIEEKTKKEVKGVKOEKVKOTVAKAKE PEKKATHKEKLEKKEKPETKTVTKEEKKARTKEKIEEKTKKEVKGVKOEKVKOTVAKAK

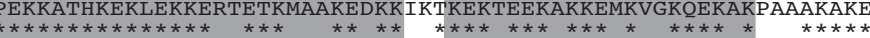

CT3 VQKT-PKPKEKESKETAAVSKQEQKDQYAFCRYMIDIFVHGDLKPGQSPAIPPPSPTEQA CT2 VQKT-PKPKEKESKETAAVSKQEQKECIFLSAATPQGI PNRQQLNDI HHCFLKTKKGGNG

CT1 Trisk 95 VQKT-PKPKEKESKETAAVSKQEQKG KQSEEAAGCFKRTLGKKQMQ---1--1TPKTTPKAREKDDKETPAVPKHEQKDQYAFCRYMIDMFVHGDLKPGQSPAVPPPSLTASR
$* * * * * * * * * * * * *$

CT3 SRPTPALPTPEEKEGEKKKAEKKVTTETKKKEKEDAKKKSEKETDIDMKKKEPGKSPDTK

CT2

CT1 1 95

QHAFCLKGC------

PALSTPSLEEKEKE-EKKKVEKKVTSDTKKKEKGEAKKKSEKETVIDGKGKEPGKPPETK PALSTPSLEEKEKE-EKKKVEKKVTSDTKKKEKGEAKKKSEKETVIDGKGKEPGKPPETK

CT3

QAKAKIERKEEVSAASTKKAVPAKKEEKTTKTVEQETRKEKPGKISSVLKDKELTKEKEV

CT2 2 - - -

Trisk 95 HRKAKAEQAKEEIAPASTKKALHGKKEEKAKTVEQGKDVKPKLPQPQLKKEEKSEPQPKK $\begin{array}{lll}\text { Trisk } & 95 & \text { HRKAKAEQAKEEIAPASTKKALHGKKEEKAKTVEQGKDVKPKLPQPQLKKEEKSEPQPKK } \\ \text { Trisk } 51 & \text { HRKAKAEQAKEEIAPASTKKALHGKKEEKAKTVEQGKKKSEAG------------- }\end{array}$

CT3 KVP-ASLKEKGSETKKDEKTSKPEPQIKKEEKPGKEVKPKPPQPQIKKEEKPEQDIMKPE

CT2

Trisk 95

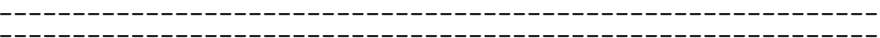
EVKLETOLKKEEKSEPOVKKEAKLASSEKGOTRKONITRPEOVIPHGKPEOKVPKOIKAI EVKLETQLKKEEKSEPQVKKEAKLASSEKGQTR

KTALHGKPEEKVLKQVKAVTTEKHVKPKPAKKAEHQEKEPPSIKTDKPKSTSKGMPEVTE

Ст3
СT2
CT1 TAEKTEKAERQEKYHPSIKTEGKPEVTDSGKKKIEKPEKESKVPPKOENLQVRNVTRAEK

Trisk 95 TAEKTEKAERQEKYHPSIKTEGKPEVTDSGKKKIEKPEKESKVPPKQENLQVRNVTRAEK

СT3

SGKKKIEKSEKEIKVPARRESHQLQNVTKAEKPARGSKEGFEDVPALATVGIWGMNQWME

СT2 SGKKKIEKSEKEIKVPARRESHQLQNVTKAEKPARGSKEGFEDVPALATVGIWGMNOWME

Abb. 2-2 Vergleich der Aminosäuresequenzen verschiedener Triadin-Isoformen

Die Sequenzen CT 1, CT 2 und CT 3 wurden als Herzmuskel-Isoformen des Triadins beim Kaninchen identifiziert. Trisk 95 und 51 sind murine Skelettmuskel-Isofomen. Sterne $\left(^{*}\right)$ markieren Bereiche, die in allen Isoformen identisch sind, die sog. KEKE-Motive sind grau untelegt. 


\subsection{Das Enzym MethylmalonylCoA-Mutase (MCM)}

\subsubsection{Funktionelle Bedeutung im Aminosäureabbau}

Aminosäuren, die nicht unmittelbar zur Synthese von Proteinen oder anderen Biomolekülen gebraucht werden, können im Gegensatz zu Fettsäuren und Glucose vom Körper nicht gespeichert werden. Daher ist es Ziel des Aminosäureabbaus Stoffwechselzwischenprodukte $\mathrm{zu}$ bilden, die in Glucose umgewandelt oder im Citratzyklus oxidiert werden können. Die Aminogruppen werden dabei in Harnstoff umgewandelt und das Kohlenstoffgerüst in Acetyl-CoA, Acetoacetyl-CoA, Pyruvat oder in ein Zwischenprodukt des Citratzyklus überführt. Der Aminosäureabbau findet bei Säugetieren hauptsächlich in der Leber statt. Hier wird bei den meisten Aminosäuren zunächst die $\alpha$-Aminogruppe auf $\alpha$-Ketoglutarat übertragen, wobei Glutamat entsteht. Dieses wird dann oxidativ desaminiert und liefert so $\mathrm{NH}_{4}^{+}$. Bei landlebenden Wirbeltieren wird das Ammoniumion im Harnstoffzyklus in Harnstoff umgewandelt und in dieser Form ausgeschieden [54,55].

Die Kohlenstoffgerüste der Aminosäuren werden über zwei verschiedene Wege verwertet. Die Gruppe der ketogenen Aminosäuren wird zu Acetyl-CoA abgebaut, während die glycogenen Aminosäuren zu Pyruvat, $\alpha$-Ketoglutarat, Succinyl-CoA, Fumarat oder Oxalacetat abgebaut werden. Die Aminosäuren Isoleucin, Methionin und Valin werden über Succinyl-CoA in den Citratzyklus eingeschleust. Als Zwischenprodukt ihres Abbaus tritt Methylmalonyl-CoA auf. Succinyl-CoA entsteht aus dem L-Methylmalonyl-CoA durch eine intramolekulare Umlagerung. Die -CO-S-CoA-Gruppe wandert im Austausch gegen ein Wasserstoffatom vom C2 zum C3. Diese ungewöhnliche Isomerisierung wird von der Methylmalonyl-CoA-Mutase (MCM) katalysiert. Dabei handelt es sich um ein Enzym dessen Coenzym ein Derivat des Vitamins $\mathrm{B}_{12}$ ist.

Die oben beschriebene Isomerisierung ist auch Bestandteil der Oxidation von Fettsäuren mit ungerader Anzahl von Kohlenstoffatomen. Die letzte thiolytische Spaltung eines ungeradzahligen Acyl-CoA liefert Acetyl-CoA und Propionyl-CoA. Dieses wird wie bei den oben genannten Aminosäuren zum D-Isomer des Methylmalonyl-CoA carboxyliert. Nach der Racemisierung zum L-Isomer erfolgt die Isomerisierung zu Succinyl-CoA [56].

\subsubsection{Das funktionelle Enzym}

Methylmalonyl-CoA-Mutase gehört zu einer Gruppe von Enzymen, die ungewöhnliche molekulare Umgruppierungen katalysieren und dafür Adenosincobalamin (AdoCbl) als Coenzym benötigen [57,58]. Als einziges Enzym dieser Gruppe ist Methylmalonyl-CoA sowohl in Eukaryonten wie auch in Prokaryonten zu finden. In Bakterien, wie zum Beispiel in Propionibacterium shermanii besteht das Enzym aus einer $\alpha$ - und einer $\beta$ Untereinheit, dabei bindet die $\alpha$-Untereinheit sowohl das Substrat wie auch AdoCbl. Die Funktion der $\beta$-Untereinheit ist noch nicht geklärt. Die $\alpha$-Untereinheit ist ein $80 \mathrm{kDa}$ großes Protein, das aus 728 Aminosäuren besteht, die $\beta$-Untereinheit besteht aus 638 
Aminosäuren und ist $70 \mathrm{kDa}$ groß. Bei Eukaryonten besteht das funktionelle Enzym aus zwei $\alpha$-Untereinheiten, mit einem Molekulargewicht von je etwa $78 \mathrm{kDa}$. Die Untereinheiten werden zunächst als Propeptide synthetisiert und aufgrund des Signalpeptides in die Mitochondrien transportiert. Nach Abspaltung des Signalpeptides erfolgt die Dimerisierung. Die $\alpha$-Untereinheiten binden je ein Molekül AdoCbl. Die Klonierung und Sequenzierung des humanen, sowie des MCMs von P. shermanii zeigen eine Homologie der Aminosäurensequenz von $65 \%$ zwischen den $\alpha$-Untereinheiten. Die Homologie zwischen humanen und murinen MCM ist erwartungsgemäß höher und liegt bei $94 \%$. Abbildung 2-3 veranschaulicht diese Befunde [59].

Nach dem derzeitigen Stand der Forschung besteht jede $\alpha$-Untereinheit aus zwei wesentlichen Domänen. Der N-terminale Bereich setzt sich aus einem etwa 100 Aminosäuren langen Abschnitt und der daran anschließenden sogenannte $\beta / \alpha$-barrelDomäne, ein Bereich von acht sich abwechselden $\beta$-Faltblatt-/ $\alpha$-Helix-Strukturen, zusammen. In diesem Bereich befindet sich der Substratkanal. Eine ausgedehnte Verbindungsregion (Linker) verbindet den N-Terminus mit dem C-terminalen Bereich des Proteins. Der C Terminus enthält fünf $\beta$-Faltblatt-/ $\alpha$-Helix-Strukturen und bildet mit der Cobalamin-Bindungsdomäne das aktive Zentrum des Enzyms [60].

Wie auch bei anderen bekannten Cobalamin-abhängigen Enzymen, läuft auch die von MCM katalysierte Isomerisierung über die Bildung eines Radikals. Die Bindung des Substrates induziert die homolytische Spaltung der Co-C-Bindung des Coenzyms, wobei ein Adenosin-Radikal entsteht. Dieses Radikal entfernt ein H-Atom vom Substrat, wodurch ein Substratradikal entsteht. Aus dem Substratradikal entsteht durch eine noch unzulänglich verstandene Reaktion ein Produktradikal. Durch Reabsorption des H-Atoms durch den Cofaktor wird das Produkt gebildet und gleichzeitig wird das katalytische Potential regeneriert $[60,61]$.

\subsubsection{Das Coenzym $B_{12}$}

Das von MCM benötigte Coenzym ist ein Derivat des Vitamins B ${ }_{12}$, des Cobalamins. 1957 gelang Dorothy Hodkin die Aufklärung der komplexen, dreidimensionalen Struktur des Cobalamins. Danach besteht sein Innenbereich aus einem Corrinringsystem, mit einem zentral angeordneten Kobaltatom. Das Kobaltatom wird von den vier Stickstoffatomen der Pyrrolringe des Corrinringsystems kovalent gebunden. Als fünfter Ligand tritt ein Derivat des Dimethylbenzimidazols auf. Der sechste Ligand des Kobaltatoms kann eine Methyloder Hydroxyl-Gruppe, oder eine 5'-Desoxyadenosineinheit sein. Cobalamin kann in den Oxidationsstufen $+1\left(\mathrm{Co}^{+}, \mathrm{B} 12 \mathrm{~s}\right),+2\left(\mathrm{Co}^{2+}, \mathrm{B} 12 \mathrm{r}\right)$ und $+3\left(\mathrm{Co}^{3+}, \mathrm{B} 12 \mathrm{a}\right)$ auftreten. Die B12s-Form ist das Substrat einer enzymatischen Reaktion, die zum aktiven Coenzym führt. $\mathrm{Co}^{+}$greift das 5'-Kohlenstoffatom von ATP an und verdrängt die Triphosphatgruppe, sodaß 5'-Desoxyadenosincobalamin, das Coenzym $\mathrm{B}_{12}$ entsteht. Diese Verbindung ist insofern bemerkenswert, als sie eine Kohlenstoff-Metallbindung enthält, die Einzige, die man bisher in einem Biomolekül kennt.

Auch andere Enzyme, wie zum Beispiel Methionin-Synthase und RibonukleotidReduktase, benützen Coenzym $\mathrm{B}_{12}$ zur Radikalerzeugung. So unterschiedlich die von 
Cobalamin-abhängigen Enzymen katalysierten Reaktionen auch sind, allen ist eine Eigenschaft gemeinsam: Die Umwandlung des Substrates in das Produkt ist thermodynamisch zwar möglich, aber kinetisch äußerst schwierig, weil eine extrem hohe Aktivierungsenergie notwendig wäre. Die Kopplung dieser Reaktionen an die Erzeugung eines hochreaktiven Radikals erniedrigt die Aktivierungsenergie deutlich und ermöglicht auf diese Weise die Reaktion unter physiologischen Bedingungen [62,63].

\subsubsection{Das Methylmalonyl-CoA-Mutase-Gen (mut)}

Der mut-Locus, codierend für die Methylmalonyl-CoA-Mutase wurde bei Mensch [64] und Maus $[65,66]$ bereits charakterisiert. Das humane Gen konnte auf Chromosom 6p12 21.1 kartiert werden, das murine Gen befindet sich auf Chromosom 17C - D. Der mutLocus umfaßt jeweils 13 Exons und 12 Introns und erstreckt sich bei der Maus über einen Bereich von etwa 30 Kilobasenpaaren $(\mathrm{kb})$ und codiert für 742 Aminosäuren. Beim Menschen umfaßt das Gen mehr als $35 \mathrm{~kb}$ und codiert für 750 Aminosäuren. Das erste Exon sowie ein Teil des zweiten Exons sind untranslatiert. Exon 2 codiert außerdem für das 32 Aminsäuren lange Signalpeptid, das für den korrekten Transport des Proteins in die Mitochondrien sorgt. Sowohl das humane, wie auch das murine Gen zeigen die Charakteristika eines TATA-Box-losen "housekeeping"-Gens mit CG-reichen Bereichen in der 5'-untranslatierten Region (UTR). Innerhalb dieses CG-reichen Abschnittes befinden sich mehrere Consensus-Motive für die Bindung von CRE (cyclic AMPresponsive elements), Ap-2 (cyclic AMP and phorbol ester responsive elements), Sp 1 und anderer eukaryontischer Transkriptionsfaktoren. Das murine Exon 13 (950 bp) ist bedeutend größer, als das Humane (440 bp), was vor allem auf ein im 3'-UTR enthaltenes B1 repetitives Element zurückzuführen ist. Die Homologie der cDNAs beträgt 87,4 \%. 


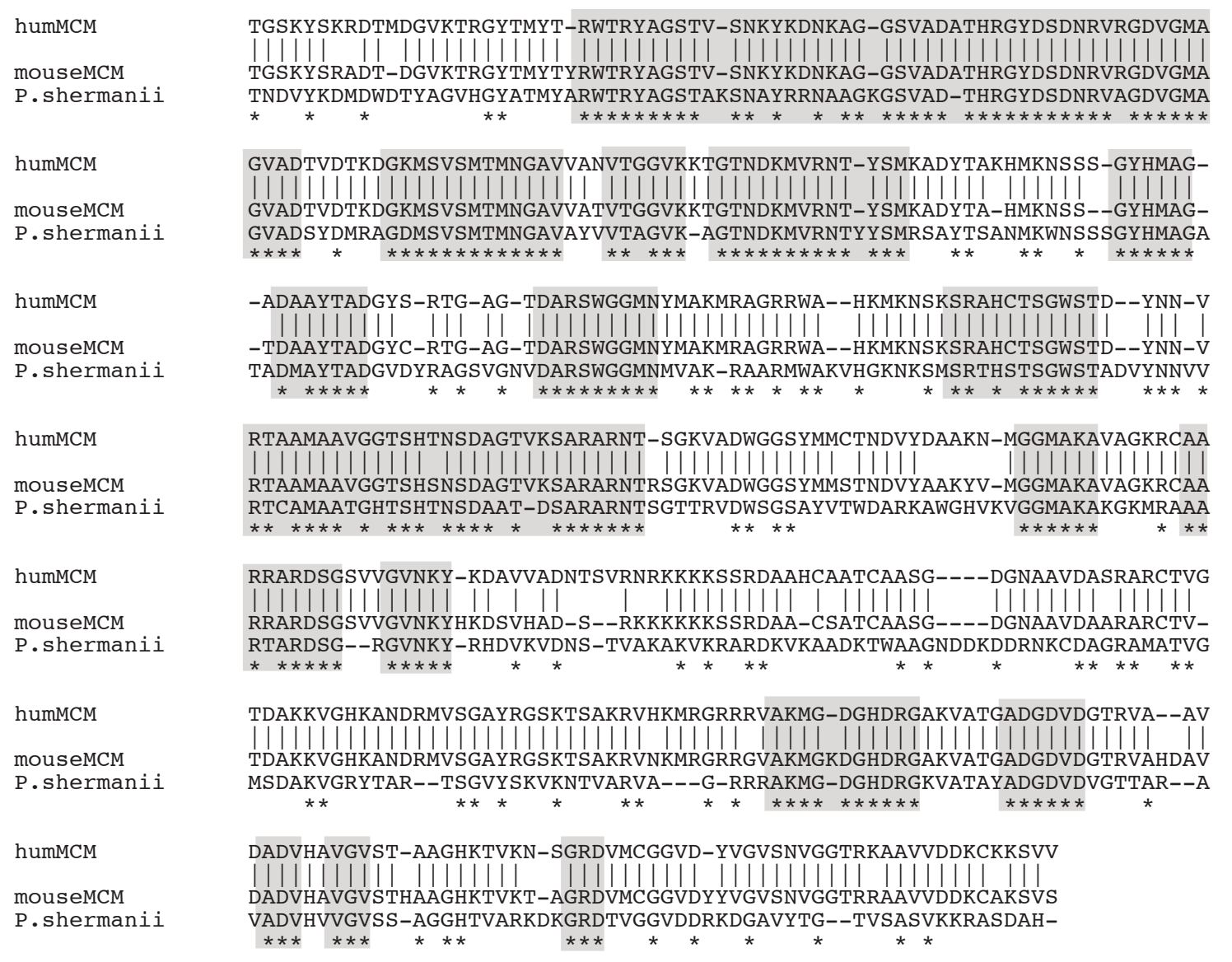

Abb. 2-3 Aminosäurenvergleich der $\alpha$-Untereinheiten der Methylmalonyl-CoA-Mutase von Mensch, Maus und $P$. shermanii.

Sterne (*) markieren jene Aminosäuren, die in allen drei Spezies identisch sind, gerade Striche $(\mid)$ markieren jene Positionen, die bei Mensch und Maus identisch sind. Größere homologe Bereiche sind zusätzlich grau unterlegt. 


\subsubsection{Mutationen im mut-Gen und die Auswirkungen}

Bereits 1968 berichteten Rosenberg et al. von einem in seiner Entwicklung merklich zurückgebliebenen, 8 Monate alten Jungen mit hochgradiger Azidose, Ketonurie und Hyperglycinämie [67]. Die Aufnahme von eiweißreicher Nahrung verstärkte diese Symptome, wohingegen sich die Gabe von Vitamin $B_{12}$ positiv auf den Zustand des Kindes auswirkte. Rosenberg vermutete einen Defekt in der Methylmalonyl-CoA-MutaseAktivität, die zur sogenannten Methylmalonazidurie führt. Eine Reihe von ähnlich gelagerten Fällen wurde in den darauffolgenden Jahren [68,69] beschrieben. 1983 definierte man sechs biochemisch und genetisch unterschiedliche Formen von Methylmalonazidurie. $M u t^{0}$ und $m^{-} t^{-}$repräsentieren Defekte im Methylmalonyl-CoAMutase-Apoenzym und sind auf eine Mutation in einem oder in beiden mut-Allelen zurückzuführen. Außerdem kennt man Defekte in unterschiedlichen Stadien im Biosyntheseweg des Mutase-Cofaktors Adenosylcobalamin bzw. Methylcobalamin. Die verschiedenen Cobalamin-Defekte (cbl) werden demnach $c b l \mathrm{~A}$ und $c b l \mathrm{~B}$ sowie $c b l \mathrm{C}$ und cbl D bezeichnet [70]. Mittels Gentransfer eines Methylmalonyl-CoA-Mutase-cDNAKlons konnten 1991 eindeutig die cbl-Formen der Krankheit von den mut-Formen unterschieden werden [71]. Damit war klar, daß nur die mut-Formen der Krankheit auf einen Defekt im mut-Locus zurückzuführen sind.

Das klinische Spektrum der Methylmalonazidurie ist weitläufig und reicht von leichten Symptomen, wie zum Beispiel periodisch auftretender Azidose, bis zu fatalen frühkindlichen Fehlentwicklungen, wie geistiger Retardiertheit. Die Krankheit konnte in manchen Fällen auch für den sogenannten plötzlichen Kindstod verantwortlich gemacht werden [72]. Shevell et al. verglichen in ihrer Studie von 1993 die klinischen Eigenschaften von $11 m u t^{0}$-Patienten mit denen von $9 m u t^{-}$-Patienten. Bei allen $11 m u t^{0}$ Patienten konnten die Symptome bereits im frühen Säuglingsalter festgestellt werden, 6 von ihnen starben noch in der Kindheit. Drei der fünf Überlebenden waren geistig zurückgeblieben, litten an spastischer Parese und Dystonie. Von den beiden Weiteren war ein 27 Monate altes Kind in seinen verbalen und motorischen Leistungen nur leicht zurückgeblieben und ein bereits erwachsener Patient erwies sich ebenfalls als nur leicht retardiert. Sieben der neun $m u t$-Patienten wurden im Laufe ihrer Kindheit symptomatisch, bei zwei Betroffenen wurde die Krankheit bei einer Routineuntersuchung festgestellt. Vier Patienten zeigten periodische Azidose und waren neurologisch kaum betroffen, drei weitere zeigten ebenfalls periodische Azidose, waren aber neurologisch ohne Befund. Einer der Patienten war geistig etwas zurückgeblieben während ein Weiterer deutliche Retardiertheit und autistische Symptome zeigte [73].

Bis dato konnten 34 verschiedene Mutationen im mut-Locus des Menschen festgestellt werden [74-77]. Die Auswirkungen auf die Funktion des Enzymes sind unterschiedlich. Grundsätzlich unterscheidet man $m u t^{0}$-Mutanten, bei denen keine Enzymaktivität festgestellt werden kann und $m u t^{-}$-Mutanten, bei denen eine mehr oder weniger große Restaktivität des Enzyms vorhanden ist, die durch diätetische Maßnahmen, insbesondere durch Gabe von Vitamin $B_{12}$, positiv beeinflußt werden kann. Die genotypische und 
phänotypische Variabilität der Methylmalonazidurie wird nicht nur von den oben beschriebenen Varianten bestimmt, sondern ist auch das Ergebnis interallelischer Komplementation [78]. Biochemische Studien homologer Bereiche innerhalb des Proteins, sowie die molekulargenetische Beschreibung von Mutationen lassen auch Schlüsse auf funktionell wichtige Domänen zu. So wirken sich zum Beispiel Mutationen, die die Cobalaminbindung direkt beeinträchtigen fatal auf die Enzymfunktion aus, ebenso wie Mutationen, die die Dimerisierung verhindern. Tabelle 2-1 zeigt zusammenfassend die bisher kartierten Mutationen im humanen Methylamlonyl-CoA-Mutase-Gen mit ihren phänotypischen Auswirkungen und den möglichen Einfluß auf die Molekülstruktur [59]. 
Tab. 2-1. Zusammenfassung bisher bekannter Mutationen im humanen mut-Locus

\begin{tabular}{lll}
\hline Mutation & Phänotyp & Beeinflussung \\
\hline K54X & $m u t^{0}$ & N-terminaler Bereich, Dimer-Interface \\
R93H & $m u t^{0}$ & N-terminale Ausdehnung \\
W105R & $m u t^{0}$ & Substratkanal \\
A137V & $m u t^{0}$ & $\beta / \alpha$-barrel-Domäne \\
F174S & $m u t^{0}$ & $\beta / \alpha$-barrel-Domäne \\
A191E & $m u t^{0}$ & $\beta / \alpha$-barrel-Domäne \\
G203R & $m u t^{0}$ & $\beta / \alpha$-barrel-Domäne \\
Q218H & $m u t^{0}$ & $\beta / \alpha$-barrel-Domäne \\
R228Q & $m u t^{0}$ & $\beta / \alpha$-barrel-Domäne \\
G312V & $m u t^{0}$ & $\beta / \alpha$-barrel-Domäne \\
346delL & $m u t^{0}$ & $\beta / \alpha$-barrel-Domäne \\
R369H & $m u t^{0}$ & Dimer-Interface \\
A377E & $m u t^{0}$ & Dimer-Interface \\
A535P & $m u t^{0}$ & Linker-Domäne \\
620insA & $m u t^{0}$ & direkter Einfluß auf AdoCbl-Bindung \\
G623R & $m u t^{0}$ & direkter Einfluß auf AdoCbl-Bindung \\
G626C & $m u t^{0}$ & direkter Einfluß auf AdoCbl-Bindung \\
H627R & $m u t^{0}$ & His 627 Interaktion mit Co-Atom des AdoCbl \\
G630E & $m u t^{0}$ & direkter Einfluß auf AdoCbl-Bindung \\
V633G & $m u t$ & AdoCbl-Bindungsdomäne \\
G648D & $m u t$ & AdoCbl-Bindungsdomäne \\
V669E & nicht definiert & AdoCbl-Bindungsdomäne \\
V671R & polymorph & AdoCbl-Bindungsdomäne \\
684insL & $m u t$ & AdoCbl-Bindungsdomäne \\
L685R & $m u t$ & AdoCbl-Bindungsdomäne \\
R694W & $m u t$ & AdoCbl-Bindungsdomäne \\
G703R & $m u t^{0}$ & direkter Einfluß auf AdoCbl-Bindung \\
G717V & $m u t$ & AdoCbl-Bindungsdomäne \\
\hline
\end{tabular}

Bis heute gibt es keine Studien darüber, ob eine der in Tab. 2-1 beschriebenen Mutationen auch bei Tieren zu finden ist. Defekte in der Methylmalonyl-CoA-Mutase sind in Japan eine der häufigsten Ursachen organischer Azidosen beim Menschen [79]. Aufgrund der verhältnismäßig hohen Inzidenz insbesondere innerhalb einzelner ethnischer Gruppen, ist die Wahrscheinlichkeit dafür, daß ähnliche Mutationen auch bei Tieren auftreten, hoch. 


\section{$3 \quad$ Material}

\subsection{Bakterien, Plasmide und Genbanken}

Alle verwendeten Bakterien, Plasmide und Genbanken stammen aus den Beständen der molekularbiologischen Abteilung des Tierärztlichen Instituts der Universität Göttingen.

\subsubsection{Bakterien}

E. coli XL1-Blue

(mcrA)183 (mcrCB-hsd SMR-mrr)173, endA1, sup E44, thi-1 gyrA96, tellA1, lac F'proAB, lacIqZ M15, Tn10 (tetR) von Stratagene, Heidelberg

E. coli TOP10

F- mcrA (mrr-hsdRMS-mcrBC) 80lacZM15 lacX74 recA1 deo $\mathrm{R}$ araD139 (ara-leu)7697 galK rpsL (StrR) end $\mathrm{A} 1$ nup $\mathrm{G}$ von Invitrogen, Groningen

\subsubsection{Plasmide}

pGEM®4-Z von Promega GmbH, Mannheim

pCR ${ }^{\circledR}$ 2.1-TOPO $®$ von Invitrogen, Groningen

\subsubsection{Genbanken}

Porcine PAC Genbank (IVM PAC 714) (Al-Bayati et al., 1999)

\subsection{Enzyme, DNA-, Nukleotide, Chemikalien und Kits}

\subsubsection{Enzyme und DNA-Marker}

Es wurden Enzyme folgender Firmen verwendet:

Boehringer-Mannheim GmbH, Mannheim 
New England Biolabs, Schwalbach

Amersham Pharmacia Biotech Europe GmbH, Freiburg

Life Technologies, Karlsruhe

Qiagen GmbH, Hilden

Roche Diagnostics GmbH, Mannheim

Roth GmbH, Karlsruhe

GibcoBRLLife Technologies GmbH, Karlsruhe

\subsubsection{Nukleotide}

Sämtliche fluoreszenzmarkierten (IRD 800) Oligonukleotide wurden von der Firma MWG-Biotech GmbH (Ebersberg) synthetisiert. Unmarkierte Oligonukleotide wurden darüberhinaus bei den Firmen Interactiva Biotechnologie GmbH (Ulm) oder Metabion (Martinsried) in Auftrag gegeben, dNTPs stammten von der Firma Roth GmbH (Karlsruhe).

\subsubsection{Chemikalien}

Es wurden Chemikalien folgender Firmen verwendet:

Bio-Rad Laboratories, USA

Fulka Feinchemikalien, Neu-Ulm

Merk AG, Darmstadt

Amersham Pharmacia Biotech Europe GmbH, Freiburg

Roth GmbH, Karlsruhe

Qiagen GmbH, Düsseldorf

FMC BioProducts, Dänemark

Sigma Chemie, München

National Diagnostics,

\subsubsection{Kits}

Amersham Pharmacia Biotech Europe GmbH, Freiburg: ECL DNA labelling system, Thermo Sequenase Fluorescent Labelled Cycle Sequencing Kit

Qiagen GmbH, Hilden: Plasmid-Kit, QiaexII Kit

Stratagene GmbH, Heidelberg: cDNA Synthesis Kit

Clontech Laboratories $\mathrm{GmbH}$, Heidelberg: Marathon ${ }^{\mathrm{TM}}$ cDNA Amplification Kit, Advantage ${ }^{\circledR} 2$ PCR Enzyme System

Invitrogen, Groningen: TOPO TA Cloning ${ }^{\circledR}$ Kit 


\subsection{Verbrauchsartikel, Glaswaren und Laborgeräte}

\subsubsection{Verbrauchsartikel}

Verbrauchsartikel wurden von folgenden Firmen bezogen:

Greiner Labortechnik GmbH, Solingen

Integra Biosciences $\mathrm{GmbH}$, Fernwald

Kranich GmbH \& Co KG, Göttingen

Nerbe plus GmbH, Winsen/Luhe

Sarstedt, Nürmbrecht

Schütt Labortechnik, Göttingen

Schleicher und Schuell, Dassel

\subsubsection{Glaswaren}

Sämtliche Glaswaren stammten von den Firmen Schütt Labortechnik (Göttingen) und Kranich GmbH \& Co KG (Göttingen).

\subsubsection{Laborgeräte}

Agfa-Gevaert AG, Leverkusen: Entwicklermaschine

Bender \& Hobein, Zürich: Vortex Genie 2

Bethesda Research Laboratories, USA: Gelelektrophoresekammern für Agarosegele, Pulsfeldgelelektrophorese-System

Eppendorf Gerätebau, Hamburg: Tischzentrifugen, Kühlzentrifugen, Heizblock

Haake: Wasserbad

Heraeus Christ, Osterode: Biofuge 28RS, Megafuge 1.0R, Inkubator

Infors, Schweiz: Schüttelinkubator

Janke \& Kunkel GmbH \& Co KG, Staufen: Magnetrührer

Stratagene, Heidelberg: Eagle EyeII, Robo Cycler Gradient 2000

Bachofer Laborgeräte GmbH: UV-Schirm $366 \mathrm{~nm}$

Du Pont und Sorvall Instruments: Sorvall RC 5B Refrigerated Superspeed Centrifuge

Pharmacia, Freiburg: Elektorphoresis Power Supply ES 3500

MWG Biotech GmbH, Ebersberg: Hybaid Omni Gene Thermocycler, Elektrophoresekammern für Agarosegele, LI-COR DNA Sequencer Model 4000L

Janke \& Kunkel GmbH \& Co. KG Ika-Labortechnik, Staufen: Ultra-Turrax ${ }^{\circledR}$ T25 


\section{Methoden}

\subsection{Vermehrung und Isolierung von Plasmid-DNA}

\subsubsection{Bakterienkultur (Ausubel et al., 1990)}

\subsubsection{Flüssigkultur}

Autoklaviertes L-Broth Medium (LB-Medium) wurde, nach Zugabe adäquater Antibiotika, mit Bakterien einer Plattenkultur oder einer flüssigen Vorkultur angeimpft. Die Flüssigkulturen wurden bei $37^{\circ} \mathrm{C}$ im Schüttelinkubator inkubiert.

LB-Medium:

$$
\begin{aligned}
& 10 \mathrm{~g} \text { Trypton } \\
& 5 \mathrm{~g} \mathrm{Hefeextrakt} \\
& 5 \mathrm{~g} \mathrm{NaCl} \\
& \text { ad } 1000 \mathrm{ml} \mathrm{H}_{2} \mathrm{O} \text { bidest. }
\end{aligned}
$$

Die Antibiotika wurden in folgenden Endkonzentrationen zugesetzt:

Ampicillin: $\quad 50 \mu \mathrm{g} / \mathrm{ml}$ aus einer Stammlösung von $50 \mathrm{mg} / \mathrm{ml}$ in $\mathrm{H}_{2} \mathrm{O}$ bidest.

Tetracyclin: $\quad 12,5 \mu \mathrm{g} / \mathrm{ml}$ aus einer Stammlösung von $12,5 \mathrm{mg} / \mathrm{ml}$ in $70 \%$ Ethanol

Kanamycin: 25 bzw. $50 \mu \mathrm{g} / \mathrm{ml}$ aus einer Stammlösung von $50 \mathrm{mg} / \mathrm{ml}$ in $\mathrm{H}_{2} \mathrm{O}$ bidest.

Flüssigkulturen wurden bei $4{ }^{\circ} \mathrm{C}$ kurzfristig, maximal 1 - 2 Wochen aufbewahrt.

\subsubsection{Plattenkultur}

LB-Agar wurde autoklaviert, auf etwa $55^{\circ} \mathrm{C}$ abgekühlt und je nach Selektionsanforderung

\begin{tabular}{|c|c|}
\hline LB-Agar: & $\begin{array}{l}10 \mathrm{~g} \text { Trypton } \\
5 \mathrm{~g} \mathrm{Hefeextrakt} \\
5 \mathrm{~g} \mathrm{NaCl} \\
15 \mathrm{~g} \mathrm{Agar}-\text { Agar } \\
\text { ad } 1000 \mathrm{ml} \mathrm{H}_{2} 0\end{array}$ \\
\hline
\end{tabular}
mit Ampicillin, Tetracyclin, X-Gal und Kanamycin versetzt und ca. $5 \mathrm{~mm}$ hoch in sterile Petrischalen gegossen.

Plattenkulturen wurden bei Bedarf bei $4{ }^{\circ} \mathrm{C}$ mehrere Wochen aufbewahrt. 


\title{
4.1.2 Herstellung transformationskompetenter $E$. coli XL1-Blue
}

$20 \mathrm{ml}$ TYM-Medium mit 12,5 $\mu \mathrm{g} / \mathrm{ml}$ Tetracyclin (TYM/tet-Medium) wurde in einem $250 \mathrm{ml}$ fassenden Kolben mit $50 \mu \mathrm{E}$. coli XL1-Blue aus einer flüssigen Vorkultur angeimpft und unter Schütteln bei $37^{\circ} \mathrm{C}$ inkubiert, bis die Bakterien eine $\mathrm{OD}_{600}$ von 0,5 0,8 erreicht hatten. Die Kultur wurde dann mit TYM/tet-Medium auf $100 \mathrm{ml}$ verdünnt und erneut bis zu einer $\mathrm{OD}_{600}$ von 0,5 - 0,8 vermehrt. Daraufhin wurde die Kultur in einen 2000 $\mathrm{ml}$ fassenden Kolben überführt und mit dem gleichen Medium auf $500 \mathrm{ml}$ verdünnt. Sobald die Kultur eine $\mathrm{OD}_{600}$ von 0,6 erreicht hatte, wurde sie unter vorsichtigem Schütteln in einem $\mathrm{NaCl} /$ Eiswasserbad rasch auf $0{ }^{\circ} \mathrm{C}$ abgekühlt und bei $2.500 \mathrm{x} \mathrm{g}$ und 2 ${ }^{\circ} \mathrm{C}$ für 10 Minuten abzentrifugiert. Das Pellet wurde in $20 \mathrm{ml} 0{ }^{\circ} \mathrm{C}$ kaltem TfBI resuspendiert und erneut wie oben abzentrifugiert. Dieses Pellet wurde in $20 \mathrm{ml} 0{ }^{\circ} \mathrm{C}$ kaltem TfBII resuspendiert. Die fertigen kompetenten Bakterien wurden nun als $200 \mu \mathrm{l}$ Aliquots in vorgekühlte $1,5 \mathrm{ml}$ Eppendorf-Reaktionsgefäße pipettiert und sofort in flüssigem Stickstoff schockgefroren. Die Bakterien wurden bei $-80{ }^{\circ} \mathrm{C}$ aufbewahrt.

TYM-Medium:

$$
\begin{aligned}
& 20 \text { g Trypton } \\
& 5 \mathrm{~g} \mathrm{Hefeextrakt} \\
& 5 \mathrm{~g} \mathrm{NaCl} \\
& 2 \mathrm{~g} \mathrm{Mg} \mathrm{SO}_{4} \times 7 \mathrm{H}_{2} \mathrm{O}
\end{aligned}
$$

TfBI:

$$
\begin{aligned}
& 30 \mathrm{mM} \mathrm{KOAc} \\
& 50 \mathrm{mM} \mathrm{MnCl}_{2} \\
& 100 \mathrm{mM} \mathrm{KCl} \\
& 10 \mathrm{mM} \mathrm{CaCl}_{2} \\
& 15 \% \text { (v/v) Glycerin }
\end{aligned}
$$

TfBII:

\author{
$10 \mathrm{mM}$ Na-MOPS (pH 7,0) \\ $75 \mathrm{mM} \mathrm{CaCl}_{2}$ \\ $10 \mathrm{mM} \mathrm{KCl}$ \\ $15 \%$ (v/v) Glycerin
}

\subsubsection{Transformation von Plasmiden in E. coli}

Transformationskompetente Bakterien wurden auf Eis aufgetaut und $100 \mu \mathrm{lu}$ der zu transformierenden DNA-Lösung (Ligationsansatz siehe 4.3.5) pipettiert. Der Ansatz wurde 15 Minuten auf Eis inkubiert und nach einer zweiminütigen Wärmehandlung bei $42{ }^{\circ} \mathrm{C}$ wieder im Eis abgekühlt. Darufhin wurden $250 \mu 1$ NZCYM-Medium (nicht-selektives Nährmedium) zugegeben und der Ansatz 1 Stunde bei $37^{\circ} \mathrm{C}$ im Schüttelinkubator inkubiert. Von dem Transformationsansatz wurden je nach Ausgangskonzentration des 
Plasmids 50 - $200 \mu$ l auf selektiven LB-Agarplatten ausplattiert und 12 - 16 Stunden bei 37 ${ }^{\circ} \mathrm{C}$ inkubiert.

NZCYM-Medium: $10 \mathrm{~g} \mathrm{NZ-Amine}$

$5 \mathrm{~g} \mathrm{Hefeextrakt}$

1 g Casaminoacids

$5 \mathrm{~g} \mathrm{NaCl}$

$2 \mathrm{~g} \mathrm{MgSO}_{4} \times 7 \mathrm{H}_{2} \mathrm{O}$

ad $1000 \mathrm{ml} \mathrm{H}_{2} \mathrm{O}$ bidest.

\subsection{DNA-Isolierung}

\subsubsection{Isolierung von genomischer DNA aus Vollblut}

3 - $5 \mathrm{ml}$ Blut wurden mit $10 \mathrm{ml} 1 \mathrm{x}$ SSC versetzt und gut gemischt. Die Probe wurde daraufhin bei $10.000 \mathrm{x} g$ für 10 Minuten bei Raumtemperatur zentrifugiert und der Überstand verworfen. Das Leukozytenpellet wurde wiederum in $10 \mathrm{ml} 1 \mathrm{x}$ SSC resuspendiert und abzentrifugiert. Dieser Schritt wurde so oft wiederholt, bis das Pellet weiß war. Die Leukozyten wurden anschließend in $5 \mathrm{ml} \mathrm{0,2} \mathrm{M} \mathrm{NaO}$-Acetat, $\mathrm{pH}$ 7,0 resuspendiert und es wurden $0,5 \mathrm{ml} 10 \%(\mathrm{v} / \mathrm{v})$ SDS zugegeben. Nach vorsichtigem Schwenken wurden $5 \mathrm{ml}$ Phenol/CIA zupipettiert und der Ansatz gut gemischt. Die Phasen wurden durch Zentrifugation bei 10.000 x g 10 Minuten bei Raumtemperatur getrennt. Die wässrige Phase wurde in ein neues Röhrchen überführt und mit $5 \mathrm{ml} \mathrm{CIA} \mathrm{gut} \mathrm{gemischt} \mathrm{und}$ erneut wie oben zentrifugiert. Der Überstand wurde wieder in ein neues Röhrchen überführt. Zum Fällen der DNA wurden $5 \mathrm{ml}$ Isopropanol zugegeben. Die ausgefallene DNA konnte mit einer Pasteurpipette gefischt werden. Sie wurde mit 70 \%igem Ethanol gewaschen und an der Luft getrocknet. Die DNA wurde anschließend über mehrere Stunden in einem adäquaten Volumen TE gelöst.
1x SSC:
$150 \mathrm{mM} \mathrm{NaCl}$
$15 \mathrm{mM} \mathrm{Na}_{3}$-Citrat

Phenol/CIA: $\quad$ Phenol, Chloroform und Isoamylalkohol wurden im Verhältnis 25:24:1 gemischt

CIA: Chloroform und Isoamylalkohol wurden im Verhältnis 24:1 gemischt 


\subsubsection{Isolierung von Plasmiden mit Qiagen Plasmid Kits}

Um größere Mengen hochreiner Plasmide zu isolieren, wurden Qiagen Plasmid Kits verwendet. Die Bakterien wurden dabei durch eine NaOH/SDS-Behandlung lysiert. Proteine und assoziierte genomische DNA wurden durch KOAcetat gefällt. Die weitere Reinigung der Plasmid-DNA erfolgte durch eine Ionenaustauschchromatographie. 20 - 200 $\mathrm{ml}$ flüssige Bakterienkultur wurden für 10 Minuten bei $6.000 \mathrm{x} \mathrm{g}$ und $4{ }^{\circ} \mathrm{C}$ abzentrifugiert. Das Bakterienpellet wurde in einem der Ausgangskultur angepaßten Volumen Puffer P1 resuspendiert. Zur Lyse der Bakterien wurde das gleiche Volumen Puffer P2 zugegeben, vorsichtig gemischt und für 5 Minuten bei Raumtemperatur inkubiert. Danach wurde das entsprechende Volumen Puffer P3 zugegeben und das Lysat geschüttelt. Nach einer Inkubation von 15 Minuten auf Eis wurde für 30 Minuten bei ca. $10.000 \mathrm{x} \mathrm{g}$ und $4{ }^{\circ} \mathrm{C}$ abzentrifugiert. Der Überstand wurde auf eine mit Puffer QBT equilibrierte Qiagen-Säule aufgetragen. Nachdem mit Puffer QC gewaschen worden war, wurde die Plasmid-DNA mit Puffer QF eluiert. Durch Zugabe von 0,7 Volumen Isopropanol und Zentrifugation für 90 Minuten bei ca. 15.000 x g und $4{ }^{\circ} \mathrm{C}$ wurde die DNA präzipitiert. Das Pellet wurde in TE (10/1) gelöst und die Konzentration der DNA durch Messung der optischen Dichte bei $260 \mathrm{~nm}$ im Spektrophotometer bestimmt.

Puffer P1:

$50 \mathrm{mM}$ Tris/HCl $\mathrm{pH} 8.0$

$10 \mathrm{mM}$ EDTA

$100 \mathrm{~g} / \mathrm{ml}$ DNAse freie RNAse A

RNAse- $\quad 210 \mathrm{mg} / \mathrm{ml}$ in $\mathrm{H}_{2} \mathrm{O}$ bidest.

Stammlösung:

zur Inaktivierung von DNAsen

für 15 Minuten auf $100{ }^{\circ} \mathrm{C}$ erwärmen,

Lagerung bei $-20{ }^{\circ} \mathrm{C}$

Puffer P2: $\quad 200 \mathrm{mM} \mathrm{NaOH}$

$1 \%$ SDS

Puffer P3:

$3 \mathrm{M} \mathrm{KOAc,} \mathrm{pH}$ 5,5

Puffer QBT: $\quad \quad 750 \mathrm{mM} \mathrm{NaCl}$

$50 \mathrm{mM}$ Na-MOPS, pH 7,0

$15 \%(\mathrm{v} / \mathrm{v})$ Ethanol

$0,15 \%(v / v)$ Triton X-100

Puffer QC: $\quad 1 \mathrm{M} \mathrm{NaCl}$

$50 \mathrm{mM}$ Na-MOPS, pH 7,0

$15 \%(\mathrm{v} / \mathrm{v})$ Ethanol 


$\begin{array}{ll}\text { Puffer QF: } & 1,25 \mathrm{M} \mathrm{NaCl} \\ & 50 \mathrm{mM} \text { Na-MOPS } \\ & 15 \%(\mathrm{v} / \mathrm{v}) \text { Ethanol } \\ & \\ \text { TE }(10 / 1): & 10 \mathrm{mM} \text { Tris/HCl, } \mathrm{pH} 8,0 \\ & 1 \mathrm{mM} \text { EDTA }\end{array}$

\subsubsection{Isolierung von PAC-DNA mit Qiagen Plasmid Kits}

Eine $500 \mathrm{ml}$ Übernacht-Kultur wurde zunächst bei $6.000 \mathrm{x} \mathrm{g}$ in einer Sorvall RC5B 10 Minuten bei Raumtemperatur zentrifugiert. Das Pellet wurde daraufhin in $50 \mathrm{ml}$ Puffer P1 resuspendiert. Die Bakterienlyse erfolgte durch Zugabe von $50 \mathrm{ml}$ Puffer P2 und anschließendem vorsichtigem Schütteln. Nach einer Inkubation von 5 Minuten bei Raumtemperatur wurden $50 \mathrm{ml}$ Puffer P3 zugegeben und der Ansatz vorsichtig gemischt. Nach weiteren 20 Minuten Inkubation auf Eis wurde der Ansatz bei $10.000 \mathrm{x}$ g und $4{ }^{\circ} \mathrm{C}$ in der Sorvall RC5B zentrifugiert. Der Überstand wurde in ein neues Gefäß überführt und gegebenenfalls nochmals bei gleicher Umdrehungszahl zentrifugiert um einen Debrisfreien DNA-Überstand zu erhalten. Eine Qiagen Säule wurde mit $10 \mathrm{ml}$ Puffer QBT equilibriert und der DNA-Überstand wurde auf die Säule aufgetragen. Danach wurde die Säule zwei Mal mit Puffer QC gewaschen. Die PAC-DNA wurde mit 5 Aliquots zu je $3 \mathrm{ml}$ $65^{\circ} \mathrm{C}$ warmen Puffer QF eluiert und in einem $50 \mathrm{ml}$ Reaktionsgefäß aufgefangen. Durch Zugabe von 10,5 ml Isopropanol wurde die DNA gefällt und durch Zentrifugation bei $15.000 \mathrm{x} \mathrm{g}$ und $4{ }^{\circ} \mathrm{C}$ in einer Heraeus Megafuge präzipitiert. Das Pellet wurde mit $5 \mathrm{ml}$ 70 \%igem Ethanol gewaschen und der verbliebene Flüssigkeitsfilm wurde sorgfältig mit eine Pasteurpipette und einer Wasserstrahlpumpe entfernt. Das Pellet wurde über mehrere Stunden in $300 \mu 1 \mathrm{TE}$ gelöst.

\subsubsection{Schnellaufschluß durch alkalische Lyse}

$5 \mathrm{ml}$ LB-Selektivmedium wurden mit einer einzelnen Plattenkolonie angeimpft und bei $37^{\circ} \mathrm{C} 10$ - 18 Stunden im Schüttelinkubator inkubiert. Die Kultur wurde bei $6.000 \mathrm{x} g$ und $4{ }^{\circ} \mathrm{C} 10$ Minuten abzentrifugiert. Das Pellet wurde in $150 \mu$ Puffer P1 resuspendiert und in ein 1,5 ml Eppendorf-Reaktionsgefäß überführt. Es wurden $150 \mu 1$ Puffer P2 zugegeben und für ca. 5 Minuten bis zur vollständigen Lyse der Bakterien bei Raumtemperatur inkubiert. Nach Zugabe von Puffer P3 wurde der Ansatz gemischt und nach 15minütiger Inkubation auf Eis bei 10.000 x g 20 Minuten abzentrifugiert. Der Überstand wurde in ein neues 1,5 ml Eppendorf-Reaktionsgefäß überführt und mit $1 \mathrm{ml} 100 \%$ igem Ethanol versetzt. Nach kurzem Mischen und weiteren 15 Minuten bei Raumtemperatur wurde der Ansatz bei $15.000 \mathrm{x}$ g und $4{ }^{\circ} \mathrm{C} 30$ Minuten abzentrifugiert. Das Pellet wurde mit $1 \mathrm{ml} \mathrm{-20}$ ${ }^{\circ} \mathrm{C}$ kaltem, 70 \%igem Ethanol gewaschen und im Vakuum für 10 Minuten getrocknet. Das Pellet wurde in 40 - $50 \mu \mathrm{TE}$ aufgenommen. 


\subsection{Manipulation und Analyse von DNA}

\subsubsection{Spaltung von DNA mit Restriktionsendonukleasen}

Gereinigte DNA wurde mit kommerziell erhältlichen Restriktionsendonukleasen gespalten. Die Reaktionsbedingungen wurden entsprechend den Herstellerangaben gewählt. Die DNA wurde je nach Reinheitsgrad mit 1 bis 5 Units Enzym pro $\mu \mathrm{g}$ DNA für mindestens 1 Stunde bei der Aktivitätstemperatur des verwendeten Enzyms inkubiert.

\subsubsection{Dephosphorylierung von linearisierten Plasmiden}

Nach Spaltung mit Restriktionsendonukleasen trägt das 5'-Ende der gespaltenen DNA eine Phosphatgruppe. Um eine Religation von linearisierten Plasmiden zu verhindern, wurde dieser Phosphatrest mit alkalischer Phosphatase abgespalten. $10 \mu \mathrm{g}$ linearisierte DNA wurden mit 5 Units alkalischer Phosphatase in 1x Reaktionspuffer des Herstellers für 30 Minuten bei $37{ }^{\circ} \mathrm{C}$ inkubiert. Zur Inaktivierung des Enzyms wurde die Reaktion 20 Minuten auf $68^{\circ} \mathrm{C}$ erhitzt.

\subsubsection{Herstellung glatter Enden mit T4-DNA-Polymerase}

$1 \mu \mathrm{g}$ DNA wurde mit 1 Unit T4-DNA-Polymerase und $100 \mathrm{mM}$ Desoxynukleotidtriphosphaten (dNTPs) im Reaktionspuffer des Herstellers für 20 Minuten bei Raumtemperatur inkubiert. Die Polymerase wurde anschließend durch 20minütiges Erhitzen auf $68^{\circ} \mathrm{C}$ inaktiviert.

\subsubsection{5'-Kinasierung von DNA}

Um DNA-Moleküle ligieren zu können, müssen diese an ihrem 5'-Ende eine Phosphatgruppe tragen. Daher müssen PCR-Produkte, die an ihren Enden synthetische Nukleotide ohne 5'-Phosphatgruppe tragen, vor einer Ligation mit einer dephosphorylierten Plasmid-DNA kinasiert werden. Ein Reaktionsansatz aus $1 \mu \mathrm{g}$ DNA, 10 Units T4-Polynukleotidkinase, sowie $0,5 \mu 110 \mathrm{mM}$ ATP in 1x Reaktionspuffer wurde für 30 Mintuen bei $37^{\circ} \mathrm{C}$ inkubiert und die Polynukleotidkinase anschließend 20 Minuten bei $68^{\circ} \mathrm{C}$ inaktiviert.

\subsubsection{Ligation von DNA-Fragmenten und Vektoren}

DNA-Fragment und dephosphorylierter Vektor wurden etwa in einem molaren Verhältnis von 1:1 in eine Reaktion eingesetzt. Das Reaktionsvolumen lag zwischen 30 und $70 \mu 1$. Der Ansatz enthielt neben dem Reaktionspuffer des Herstellers etwa 400 - 800 Units T4- 
DNA Ligase. Die Ligation erfolgte über Nacht bei $16{ }^{\circ} \mathrm{C}$ oder alternativ 2 - 3 Stunden bei Raumtemperatur.

\subsubsection{Polymerase-Kettenreaktion}

Geeignete Primer-Paare wurden mit Hilfe verschiedener Software ermittelt. Ein Standardansatz enthielt in $50 \mu \mathrm{l}$ Gesamtvolumen ca. $100 \mathrm{ng}$ Matrizen-DNA, $5 \mu 1$ 10x TaqPolymerase-Puffer des Herstellers, je 50 - 100 pmol Primer, 0,2 mM dNTPs und 1 - 2 Units Taq-DNA-Polymerase. Die Komponenten des Ansatzes wurden auf Eis pipettiert, gemischt und die Reaktion in einem Thermocycler ausgeführt. Dabei folgten nach 1 5minütiger Denaturierung bei $94{ }^{\circ} \mathrm{C} 25$ - 30 Zyklen mit je einem Denaturierungsschritt, einem Primer-Anlagerungs-Schritt (Annealing) und einem Polymerisationsschritt (Extension). Dauer und Temperatur der Annealing- und Extension-Schritte wurde den jeweiligen Primer-Schmelztemperaturen sowie der zu erwartenden Amplifikatlänge angepaßt.

\subsubsection{Durchmusterung einer PAC-Genbank mittels PCR}

Die im Tierärztlichen Institut hergestellte porcine genomische PAC-Genbank (IVM PAC 714 besteht aus 95.000 Klonen, die in 13 Supersuperpools (ssp), 66 Superpools (sp) und 645 Plattenpools organisiert sind. Als Verktor wurde pCYPAC2 verwendet [80]. 12 Supersuperpools (ssp) beinhalten jeweils 5 Superpools (sp), Supersuperpool 11 beinhaltet 6 Superpools. Die Superpools wiederum beinhalten jeweils 10 Plattenpools (pp). Die in den Supersuperpools 1 bis 11 zusammengefaßten PAC-Klone sind auf insgesamt 560 96well Mikrotiterplatten aufgeteilt. Die Klone der Supersuperpools 12 und 13 sind auf insgesamt 95 384-well Mikrotiterplatten verteilt. Tabelle 3-1 gibt einen Überblick über die Nomenklatur und Organisation der IVM 174 PAC-Genbank.

Tab. 4-1 Nomenklatur und Organisation der porcinen genomischen PAC-Genbank IVM 174

\begin{tabular}{|c|c|c|c|c|c|}
\hline \multicolumn{6}{|c|}{ 96-well-Platten } \\
\hline ssp & $\mathrm{sp}$ & $\mathrm{pp}$ & $\operatorname{ssp}$ & $\mathrm{sp}$ & $\mathrm{pp}$ \\
\hline 1 & $1-5$ & A $1-$ A 50 & 2 & $6-10$ & A $51-A 100$ \\
\hline 3 & $11-15$ & A $101-A 150$ & 4 & $16-20$ & A $151-A 200$ \\
\hline 5 & $21-25$ & $\mathrm{~A} 201-\mathrm{A} 250$ & 6 & $26-30$ & $\mathrm{~A} 251-\mathrm{A} 300$ \\
\hline 7 & $31-35$ & A301 - A350 & 8 & $36-40$ & A $351-A 400$ \\
\hline 9 & $41-45$ & A401 - A450 & 10 & $46-50$ & A451 - A500 \\
\hline 11 & $51-56$ & A501 - A560 & & & \\
\hline \multicolumn{6}{|c|}{ 384-well-Platten } \\
\hline $\operatorname{ssp}$ & $\mathrm{sp}$ & $\mathrm{pp}$ & $\operatorname{ssp}$ & $\mathrm{sp}$ & $\mathrm{pp}$ \\
\hline 12 & $57-61$ & $001-0050$ & 13 & $62-66$ & $0091-0095$ \\
\hline
\end{tabular}




\subsubsection{Agarose-Gelelektrophorese}

Zur Analyse bzw. Gewinnung von definierten DNA-Fragmenten nach enzymatischen Reaktionen wurden horizontale Agarosegele verwendet. Je nach Größe der zu untersuchenden DNA-Fragmente wurden Agarose-Konzentrationen von 0,5 - $2 \%$ (w/v) gewählt. Die jeweilige Menge an Agarose wurde in einem Erlenmeyer-Kolben eingewogen und im entsprechendem Volumen 1x TBE-Laufpuffer suspendiert. Die Agarosesuspension wurde in einem Mikrowellenherd aufgekocht bis sich die Agarose vollständig darin gelöst hatte. Nach dem Abkühlen auf ca. $50-60{ }^{\circ} \mathrm{C}$ wurde Dimidiumbromid-Lösung auf eine Endkonzentraion von $0,4 \mathrm{~g} / \mathrm{ml}$ zugegeben und die Lösung luftblasenfrei in eine vorbereitete Gelform mit geeignetem Kamm gegossen. Nach dem Verfestigen wurde der Kamm vorsichtig gezogen und das Gel in einer Elektrophoresekammer mit 1x TBELaufpuffer bedeckt. Die DNA-Lösung wurde mit 0,1 Volumen 10x Auftragspuffer versetzt und in eine Tasche des Gels pipettiert. Die Elektrophorese erfolgte bei Feldstärken von 1 $20 \mathrm{~V} / \mathrm{cm}$. Die DNA-Fragmente wurden durch Fluoreszenz des in die DNA interkalierten Dimidiumbromids bei 366 oder $312 \mathrm{~nm}$ sichtbar gemacht. Die Dokumentation erfolgte mit Hilfe eines Eagle-Eye II.

$10 \times$ TBE-Laufpuffer:

$121 \mathrm{~g}$ Tris

51,4 g Borsäure

3,72 g EDTA

ad $1000 \mathrm{ml} \mathrm{H}_{2} \mathrm{O}$ bidest.

10 x Auftragspuffer:

$50 \%(\mathrm{v} / \mathrm{v})$ Glycerin

0,1 M EDTA, pH 8,0

$0,25 \%(\mathrm{w} / \mathrm{v})$ Bromphenolblau

$0,25 \%(w / v)$ Xylencyanol

Dimidiumbromid-Lösung: $\quad 12 \mathrm{mg} / \mathrm{ml}$ in $\mathrm{H}_{2} \mathrm{O}$ bidest.

\subsubsection{Pulsfeldgelelektrophorese}

Zur Auftrennung und Größenanlyse der PAC-Klone wurde die Pulsfeldgelektrophorese angewendet. Dazu wurden zunächst 3 Liter 0,5 x TBE hergestellt und ein 1\%iges AgaroseGel (ebenfalls mit 0,5 x TBE) mit einer Dimidiumbromid-Konzentration von $1 \mathrm{~g} / \mathrm{ml}$ gegossen. Der Rest des TBEs wurden in die Elektrophoresekammer gefüllt und auf $14{ }^{\circ} \mathrm{C}$ temperiert. Um PAC-Klone zu linearisieren wurde ein Restriktionsspaltung mit dem Enzym NotI angesetzt. Dabei wurde jeweils $2 \mu \mathrm{g}$ DNA mit 10 Units Enzym in einem Gesamtvolumen von $50 \mu 11$ Stunde bei $37^{\circ} \mathrm{C}$ gespalten. Der gesamte Ansatz wurde danach auf das Agarosegel im vorgekühlten TBE aufgetragen und der Gellauf gestartet. 


$\begin{array}{lll}\text { Laufbedingungen: } & \text { Laufzeit: } & 20 \text { Stunden } \\ & \text { Pulswinkel: } & 120^{\circ} \\ & \text { Puls/Rampe: } & 1 \mathrm{sec} \text {. bis } 30 \mathrm{sec} . \\ & \text { Spannung: } & 6 \text { Volt }\end{array}$

\subsubsection{Elution von DNA aus Agarosegelen}

\subsubsection{Elution durch Zentrifugation}

Die zu isolierende DNA wurde nach elektrophoretischer Auftrennung auf einem UVSchirm (366 nm) ausgeschnitten und in ein 1,5 ml Eppendorf-Reaktionsgefäß überführt. In vielen Fällen von Restriktionsspaltungen, in denen keine weitere Manipulation der DNAFragmente mehr notwendig war, konnte eine für die Ligation ausreichende Menge an DNA durch Abzentrifugieren der Agarose-Stücke gewonnen werden. Die Gelstücke wurden bei Raumtemperatur und maximaler Geschwindigkeit in der Tischzentrifuge 10 Minuten abzentrifugiert. Dabei kollabiert die Agarose und gibt die DNA in den flüssigen Überstand frei. Die im Überstand enthaltene DNA wurde direkt in den Ligationsansatz eingesetzt.

\subsubsection{Elution mit Qiaex II}

Die zu isolierende DNA wurde in diesem Fall nach elektrophoretischer Auftrennung auf einem UV-Schirm (366 nm) ausgeschnitten, abgewogen und in ein 1,5 ml EppendorfReaktionsgefäß überführt. Daraufhin wurden 3 Volumina Puffer QX 1 und 10 - $12 \mu 1$ QIAEX II zugegeben. Dieser Ansatz wurde anschließend für 10 Minuten bei $50{ }^{\circ} \mathrm{C}$ inkubiert und dabei alle 2 Minuten gemischt. Danach wurde die Probe 30 Sekunden lang abzentrifugiert und der Überstand sorgfältig entfernt. Das Pellet wurde mit $500 \mu \mathrm{l}$ QX 1 gewaschen, wiederum wie oben abzentrifugiert und der Überstand entfernt. Das Pellet wurde nun noch zwei Mal auf gleiche Weise mit je $500 \mu$ l Puffer PE gewaschen und anschließend 15 Minuten luftgetrocknet. Das Pellet wurde dann mit $20 \mu 1$ TE 5 Minuten bei Raumtemperatur inkubiert um die DNA zu eluieren. Nach dem Abzentrifugieren wurde der Überstand sorgfältig abgehoben und in ein neues 1,5 ml Eppendorf-Reaktionsgefäß überführt. Der Elutionsschritt wurde gegebenfalls wiederholt und die beiden Eluate in einem Reaktionsgefäß gesammelt.

Der gleiche QIAGEN-Kit wurde auch für die Reinigung von DNA in Lösung verwendet.

\subsubsection{Transfer und Detektion von DNA auf Membranen}

Die Agarosegele mit der zu transferierenden DNA wurden für 20 Minuten zur Depurinierung in 0,25 M HCl, danach zur Denaturierung $2 \times 15$ Minuten in $0,4 \mathrm{M} \mathrm{NaOH}$ geschwenkt. Anschließend wurde das Gel mit der Unterseite nach oben auf eine 
Haushaltsfolie gelegt und eine passend zurechtgeschnittene Nylonmembran (Hybond $\mathrm{N}^{+}$) luftblasenfrei auf das Gel aufgebracht. Zwei Lagen Whatmanpapier wurden mit $\mathrm{NaOH}$ angefeuchtet und ebenfalls luftblasenfrei aufgelegt. Zuletzt wurde ein ca. $5 \mathrm{~cm}$ hoher Stapel Papiertücher daraufgelegt, eine Glasplatte sowie ein Gewicht von etwa $1 \mathrm{~kg}$ vervollständigten den Blot. Nach 24 Stunden wurde die Nylonmembran kurz in 2 x SSC geschwenkt und zwischen zwei Blättern Whatmanpapier luftgetrocknet.

2 x SSC:

$30 \mathrm{mM} \mathrm{Na}_{3}$-Citrat

$300 \mathrm{mM} \mathrm{NaCl}$

ad $1000 \mathrm{ml} \mathrm{H}_{2} \mathrm{O}$

\subsubsection{Nicht-radioaktive Hybridisierung mit dem ECL direct labelling system}

Die getrocknete Nylonmembran wurde in der vorbereiteten Hybridisierungslösung 1 Stunde bei $42{ }^{\circ} \mathrm{C}$ vorhybridisiert. Zur Markierung der spezifischen Sonde wurden $10 \mathrm{ng}$ DNA/ml Hybridisierungslösung in einer Konzentration von $10 \mathrm{ng} / \mu \mathrm{l}$ einem verschraubbaren 1,5 ml Reaktionsgefäß für 5 Minuten im kochenden Wasserbad denaturiert und sofort auf Eis gekühlt. Anschließend wurden 1 Volumen Glutaraldehyd und 1 Volumen labelling reagent zugegeben und gut gemischt. Der Raktionsansatz wurde für 10 Minuten bei $37{ }^{\circ} \mathrm{C}$ inkubiert. Die Sonde wurde unmittelbar danach zur Hybridisierlösung pipettiert. Die Hybridisierung erfolgte bei $42{ }^{\circ} \mathrm{C}$ über Nacht oder alternativ für 3 bis 4 Stunden. Zur Detektion wurde die Membran 2 x 5 Minuten bei $55^{\circ} \mathrm{C}$ mit Waschlösung I und anschließend 2 x 5 Minuten bei Raumtemperatur mit 2 x SSC gewaschen. Die Membran wurde anschließend kurz an der Luft getrocknet und 1 Minute lang bei Raumtemperatur in einer der Größe entsprechenden Menge Detektionsflüssigkeit inkubiert. Die Membran wurde daraufhin auf ein Blatt Whatmanpapier gelegt, mit Haushaltsfolie bedeckt und ein für Chemilumineszenz geeigneter Röntgenfilm aufgelegt. Die Expositionszeit variierte zwischen 2 und 60 Minuten.

Waschlösung I: $\quad 0,5 \times \mathrm{SSC}$

$0,4 \%$ SDS

\subsubsection{Nicht-radioaktive Sequenzierung doppelsträngiger DNA}

Sequenzreaktionen wurden mit dem Thermo Sequenase Fluorescent Labelled Cycle Sequencing Kit durchgeführt. 200 ng Plasmid-DNA pro kb Insert wurden mit 2 pmol IRD 800 markiertem Primer und $1 \mu$ l Dimethylsulfoxid (DMSO) versetzt und mit $\mathrm{H}_{2} \mathrm{O}$ bidest. auf $25 \mu \mathrm{l}$ aufgefüllt. Je $6 \mu 1$ dieses Ansatzes wurden zu je $2 \mu 1$ der unterschiedlichen Terminationsmixe pipettiert, mit Mineralöl überschichtet und der PCR zugeführt. Die PCR wurde auf einem RoboCycler ${ }^{\circledR}$ Gradient 2000 mit 25 Zyklen mit jeweils 45 Sekunden Denaturierung bei $94{ }^{\circ} \mathrm{C}, 45$ Sekunden Annealing bei $58{ }^{\circ} \mathrm{C}$ und 45 Sekunden Extension bei $68{ }^{\circ} \mathrm{C}$ durchgeführt. Um unspezifische Kettenabbrüche an 7-deaza-dGTPs zu vermeiden wurden $5 \mu$ l Auftragspuffer erst nach der PCR zugegeben. 
Auftragspuffer: $\quad 97,5 \%$ deionisiertes Formamid

$10 \mathrm{mM}$ EDTA $\mathrm{pH} 8,0$

$0,1 \%$ Bromphenolblau

\subsubsection{Automatisches Sequenzieren}

Für die Auftrennung von nicht-radioaktiven Sequenzreaktionen wurde das LI-COR Modell 4000L und die Steuersoftware BaseImageIR v 2.30 verwendet. Als Gelmatrix für die Auftrennung bis zu ca. 850 bp (Einzelbasenpaarauftrennung bis ca. $650 \mathrm{bp}$ ) wurde Sequagel XR unter Zusatz von $1 \%$ DMSO und Verwendung von $41 \mathrm{~cm}$ langen Glasplatten verwendet. Die Auftrennung erfolgte bei $1500 \mathrm{~V}, 35 \mathrm{~mA}$ und 31 Watt für ca. 12 - 14 Stunden. Als Laufpuffer wurde 1 x TBE Standard verwendet. Größere Leseweiten wurden mit Long Ranger ${ }^{\mathrm{TM}}$ Fertiggellösung erreicht. Die entgaste 4 \%ige Gellösung wurde in $66 \mathrm{~cm}$ Glasplatten gegossen. Die Auftrennung erfolgte bei $2000 \mathrm{~V}, 25 \mathrm{~mA}$ und $45 \mathrm{Watt}$ für ca. 20 Stunden. Als Laufpuffer wurde an der Kathode 0,8 x TBE und an der Anode 1,4 x TBE verwendet. Im Idealfall konnte bis zu 1000 bp in einem Lauf gelesen werden. Nach dem Gellauf wurden die Sequenzen mit V2.30 Image Analysis automatisch gelesen, korrigiert und in das SCF-Dateiformat (sequence chromatogram file) umgewandelt. Die Sequenzen wurden mit dem Sequencher 3.0 weiter bearbeitet bzw. ausgewertet.

\subsubsection{Mikrosatelliten-Analyse}

Für die Analyse potentiell polymorpher Nukleotidwiederholungen wurde einer der beiden PCR-Primer mit IRD 800 markiert. Die PCR wurde mit dem "Ready to Go"-System (Pharmacia) durchgeführt. Ein Standard-Mastermix beinhaltete:

$400 \mathrm{mM}$ eines geeigneten forward-Primers

$400 \mathrm{mM}$ eines geeigneten revers-Primers

1/10 Volumen 10 x PCR-Puffer

ad $\mathrm{H}_{2} \mathrm{O}$ auf das entsprechende Gesamtvolumen

Jeweils ein PCR-"Bead" (10 mM Tris/HCl pH 9, $50 \mathrm{mM} \mathrm{KCl,} \mathrm{1,5} \mathrm{mM} \mathrm{MgCl} 2,200 \mathrm{mM}$ jedes dNTPs und 1,5 U Taq-Polymerase) wurde in $12 \mu$ l dieses Mastermixes aufgelöst, gemischt und nach Zugabe von je $1 \mu$ lder zu testenden DNA-Probe der PCR zugeführt.

$\begin{array}{llll}\text { Temperaturprofil der PCR: } & \text { Denaturierung } & 5 \text { Minuten } & \\ & & & \\ 25 \text { Zyklen } & \text { Denaturierung } & 1 \text { Minute } & 94{ }^{\circ} \mathrm{C} \\ & \text { Annealing } & 30 \text { Sekunden } & * \\ \text { Extension } & 45 \text { Sekunden } & 72{ }^{\circ} \mathrm{C} \\ \text { *der Schmelztemperatur (Tm) des Primers angepaßt } & \end{array}$




\subsection{RNA-Analyse}

\subsubsection{Isolierung von Gesamt-RNA aus Geweben}

Für RNA-Analyse vorgesehene Gewebe wurden sofort nach der Euthanasierung des Tieres unter sterilen Bedingungen entnommen und in einem beschrifteten $50 \mathrm{ml}$ Röhrchen in flüssigem Stickstoff schockgefroren.

Zur Isolierung von Gesamt-RNA wurde etwa $1 \mathrm{~g}$ Gewebe in $10 \mathrm{ml}$ TRIZOL® Reagent mit einem Ultraturrax und dem entsprechenden Vorsatz bei mittlerer Umdrehungszahl homogenisiert und anschließend 5 Minuten bei Raumtemperatur inkubiert. Nach Zugabe von $2 \mathrm{ml}$ Chloroform wurde der Ansatz gut gemischt und weitere 3 Minuten bei Raumtemperatur inkubiert. Es folgte eine 15 minütige Zentrifugation bei $6.200 \mathrm{x} \mathrm{g}$ und 4 ${ }^{\circ} \mathrm{C}$. Nach der Zentrifugation konnte deutlich eine Phasentrennung beobachtet werden. Die wässrige Phase wurde abgehoben und in ein neues Röhrchen überführt. Zur Ausfällung der RNA wurden $5 \mathrm{ml}$ Isopropanol dazugegeben. Für die weitere Analyse wurden Aliquots zu je $1 \mathrm{ml}$ hergestellt und bei $-20{ }^{\circ} \mathrm{C}$ aufbewahrt.

\subsubsection{RT-PCR}

Um aus isolierter RNA doppelsträngige DNA-Kopien zu erhalten wurde eine PCR mittels Reverser Transkriptase durchgeführt. Für die Erststrangsynthese wurden zunächst $1 \mu \mathrm{g}$ Gesamt-RNA und 500 ng Poly-dT(24) in $12 \mu$ sterilem Wasser 10 Minuten bei $70{ }^{\circ} \mathrm{C}$ erhitzt, um Sekundärstrukturen der RNA aufzulösen. Der Ansatz wurde auf Eis abgekühlt und kurz zentrifugiert. Nach Zugabe von $4 \mu 1$ xx Erststrang-Puffer, $2 \mu 1$ 0,1 M DTT und 1 l $10 \mathrm{mM}$ dNTP-Mix wurde der Ansatz gemischt, abzentrifugiert und bei $42{ }^{\circ} \mathrm{C} 2$ Minuten vorinkubiert und nach Zugabe von 200 U Superscript $^{\mathrm{TM}}$ II Reverse Transcriptase weitere 50 Minuten bei $42{ }^{\circ} \mathrm{C}$ inkubiert. Darauf erfolgte die Inaktivierung der Trankriptase durch Erhitzen auf $70{ }^{\circ} \mathrm{C}$ für 15 Minuten. Aus diesem Ansatz wurden $2 \mu l$ in eine Standard-PCRRaktion mit genspezifischen Primern eingesetzt.

\subsubsection{5'- und 3'- RACE (Rapid Amplification of cDNA Ends) mit dem Marathon cDNA Amplification Kit und dem Advantage ${ }^{\circledR} 2$ PCR Enzyme System}

Etwa $1 \mu \mathrm{g}$ mRNA (eingesetzt wurde jeweils Gesamt-RNA, der Anteil an mRNA wurde anhand der in der Literatur angegebenen Werte für verschiedene Gewebe abgeschätzt) wurde mit $1 \mu \mathrm{l}$ cDNA Synthesis Primer $(10 \mathrm{mM})$ in einem Gesamtvolumen von $5 \mu 12$ Minuten bei $70{ }^{\circ} \mathrm{C}$ inkubiert. Anschließend wurde der Ansatz 5 Minuten in Eis abgekühlt und kurz zentrifugiert. Danach wurden $2 \mu 15$ x Erststrangpuffer, $1 \mu 110$ mM dNTP-Mix, 1 $\mu l$ DEPC-behandeltes Wasser und $1 \mu 1$ MMLV Reverse Trankriptase (100 U/1) 
dazupipettiert. Dieser Reaktionsansatz wurde für 1 Stunde bei $42{ }^{\circ} \mathrm{C}$ im Wärmeschrank inkubiert. Nach Erststrangsynthese wurden $16 \mu \mathrm{l} 5$ x Zweitstrangpuffer, 1,6 $\mu 110 \mathrm{mM}$ dNTP-Mix, 48,4 $\mu 1$ DEPC-behandeltes Wasser und $4 \mu 120 \times$ Zweitstrang Enzym-Mix zugegeben und die Reaktion für weitere 1,5 Stunden bei $16{ }^{\circ} \mathrm{C}$ inkubiert. Darauf folgte eine Inkubation von 45 Minuten bei $16{ }^{\circ} \mathrm{C}$ mit $10 \mathrm{U}$ T4 DNA-Polymerase. Um die Reaktion zu stoppen, wurden $4 \mu \mathrm{l}$ EDTA/Glycogen zugegeben. Die cDNA wurde daraufhin mit $100 \mu 1$ Phenol/CIA extrahiert, die wäßrige Phase in ein neues Reaktionsgefäß überführt und nochmals mit CIA behandelt. Nach der Zentrifugation wurde der Überstand wiederum in ein neues Reaktionsgefäß überführt und die cDNA mit 0,5 Vol. 4 M Ammoniumacetat und 2,5 Vol. 95 \%igem Ethanol gefällt. Nach 20minütiger Zentrifugation bei maximaler Umdrehungszahl in der Tischzentrifuge wurde das Pellet mit $-20{ }^{\circ} \mathrm{C}$ kaltem 70 \%igem Ethanol gewaschen und nochmals 5 Minuten bei Raumtemperatur zentrifugiert. Nach sorgfältigem Entfernen des Überstandes wurde das Pellet etwa 5 Minuten an der Luft getrocknet und in $10 \mu \mathrm{l}$ Wasser gelöst.

Zur Ligation des Adaptors wurden $5 \mu \mathrm{l}$ der cDNA mit $2 \mu \mathrm{l}$ cDNA-Adaptor $(10 \mathrm{mM}), 2 \mu \mathrm{l}$ 5x DNA Ligationspuffer und $1 \mu \mathrm{T} 4 \mathrm{DNA}$-Ligase $(1 \mathrm{U} / \mu \mathrm{l})$ bei $16{ }^{\circ} \mathrm{C}$ über Nacht inkubiert. Das Enzym wurde am nächsten Tag durch Erhitzen auf $70{ }^{\circ} \mathrm{C}$ für 10 Minuten deaktiviert und anschließend wurden die cDNA im Verhältnis 1:50 und 1:250 in EDTA/Tricine Puffer verdünnt. Die verdünnte cDNA wurde nach einem zweiminütigen Denaturierungsschritt bei $94{ }^{\circ} \mathrm{C}$ in die PCR eingesetzt.

Für die PCR wurden $5 \mu 1$ doppelsträngige cDNA, $5 \mu 1$ 10x Advantage 2 PCR Puffer, $1 \mu 1$ $10 \mathrm{mM}$ dNTP-Mix, $1 \mu \mathrm{l}$ 50x Polymerase-Mix und je $1 \mu \mathrm{l}$ Primer AP 1 und genspezifischer Primer (jeweils 10 pmol/l) gemischt und in einem Robo Cycler Gradient 2000 amplifiziert. Die genspezifischen Primer wurden jeweils so gewählt, daß eine sogenannte two step touch down PCR durchgeführt werden konnte, das heißt der Primerbindungs- (Annealing) und Kettenverlängerungsschritt (Extension) fanden jeweils bei gleicher Temperatur statt. Nach einem Denaturierungsschritt von 5 Minuten bei $94{ }^{\circ} \mathrm{C}$ folgten zunächst 5 Zyklen mit 45 Sekunden Denaturierung bei $94{ }^{\circ} \mathrm{C}$ und 2 - 5 Minuten (je nach erwarteter Produktlänge) Annealing/Extension bei $72{ }^{\circ} \mathrm{C}$, danach 10 Zyklen mit gleicher Denaturierung und einer Annealing/Extension-Temperatur von $70{ }^{\circ} \mathrm{C}$ und zuletzt 15 Zyklen, gleicher Denaturierung mit einer Annealing/Extension-Temperatur von $68^{\circ} \mathrm{C}$.

\subsubsection{Nicht-radioaktive Primer Extension Analyse}

Für die nicht-radioaktive Primer Extension Analyse [81] auf einem automatischen Sequenziergerät wurden 1 - $9 \mu \mathrm{g}$ Gesamt-RNA aus entsprechenden Geweben mit 7 pmol IRD 800 markierten Oligonukleotiden in einem Gesamtvolumen von $10 \mu$ für 2 Minuten bei $95{ }^{\circ} \mathrm{C}$ denaturiert. Die Probe wurde für 30 Minuten auf Raumtemperatur abgekühlt und anschließend pro Reaktion 7,5 $\mu 1$ 5x Erststrangpuffer, 3,5 $\mu 1$ 0,1 M DTT, $1 \mu 110 \mathrm{mM}$ dNTP-Mix, 24,5 $\mu$ l Wasser und $1 \mu$ l Superscript ${ }^{\mathrm{TM}}$ II Reverse Transkriptase (200U/ $\left.\mu 1\right)$ zugegeben. Die Probe wurde 90 Minuten bei $42{ }^{\circ} \mathrm{C}$ lichtgeschützt inkubiert. Danach wurden 3,3 $\mu 1$ 0,2 M EDTA/RNAse A (3 ng/ $\mu 1$ ) zupipettiert und 30 Minuten bei $37{ }^{\circ} \mathrm{C}$ lichtgeschützt inkubiert. Zum Fällen der DNA wurden $4 \mu 1100 \mathrm{mM}$ Spermine zu der 
Probe gegeben und 10 Minuten bei Raumtemperatur inkubiert. Durch Zentrifugation bei maximaler Umdrehungszahl und $4{ }^{\circ} \mathrm{C}$ in einer Eppendorf Kühlzentrifuge für 30 Minuten wurden die Extensions-Produkte pelletiert. Der Überstand wurde abpipettiert und das Pellet in $2 \mu \mathrm{l}$ LICOR-Auftragspuffer gelöst. Kurz vor dem Auftrag auf ein $6 \%$ iges Sequagel wurden die Proben 2 Minuten bei $70{ }^{\circ} \mathrm{C}$ denaturiert und anschließend $1 \mu \mathrm{der}$ Reaktion in die Geltaschen pipettiert. Die Laufbedingungen des Gel entsprachen jenen eines Standard-Sequenzgeles.

\subsubsection{Transfer und Detektion von RNA auf Membranen}

\subsubsection{Probenaufbereitung}

Zur Analyse von RNA mittels Northern Blot Verfahren wurde Gesamt-RNA nach der oben beschriebenen Methode isoliert. Die RNA-Pellets wurden in einem adäquaten Volumen DEPC-behandeltem $\mathrm{H}_{2} \mathrm{O}$ gelöst, sodaß die Konzentration etwa $1-3 \mu \mathrm{g} / \mu \mathrm{l}$ betrug. Ein Volumen von $10 \mu \mathrm{l}$ der RNA-Lösung wurden mit $25 \mu$ Proben Puffer gemischt und zur Denaturierung 15 Minuten auf $75^{\circ} \mathrm{C}$ erhitzt. Den einzelnen Proben wurde daraufhin $1 \mu 1$ Dimidiumbromid-Lösung zugefügt und nach gutem Mischen wurden die Proben sofort auf das vorbereitete Formamid-Gel aufgetragen.

\subsubsection{Vorbereitung des Gels, Elektrophorese und Transfer der RNA}

Je 1,0 - 1,5 g Agarose wurden in $10 \mathrm{ml} 10 \mathrm{x}$ MOPS/EDTA-Puffer und $87 \mathrm{ml}$ DEPCbehandeltem Wasser durch Aufkochen gelöst und auf etwa $50{ }^{\circ} \mathrm{C}$ abgekühlt. Daraufhin wurden je 5,1 ml 37 \%iges Formaldehyd zugegeben, gut gemischt und die AgaroseLösung in eine vorbereitete RNAse-freie Gelform mit einem passenden Kamm gegossen. Das Gel sollte eine Stunde vor dem Probenauftrag gegossen werden. Das Gel wurde nach dem Erstarren in eine Gelkammer überführt, mit 1 x MOPS/EDTA-Puffer bedeckt und die Taschen mehrmals mit diesem gespült. Die wie oben vorbereiteten Proben wurden auf das Gel aufgetragen. Die Elektrophorese erfolgte 15 Stunden lang bei 40 Volt. Anschließend wurde das Gel mit aufgetrennter RNA fotographiert und zum Transfer auf eine Nylonmembran vorbereitet. Dazu wurde das Gel zwei Mal 20 Minuten in 10 x SSC geschwenkt. In der Zwischenzeit wurde die Membran zunächst in DEPC-behandeltem Wasser und anschließend in 10 x SSC getränkt. Ein in seiner Größe dem Gel angepaßter Schwamm mit kleinen Poren wurde in $10 \mathrm{x}$ SSC getränkt und 3 Lagen ebenfalls in $10 \mathrm{x}$ SSC getränktes Filterpapier wurde daraufgelegt. Anschließend wurde das Gel mit der Unterseite nach oben auf eine Haushaltsfolie gelegt. Anschließend wurden die vorbereitete Membran, sowie drei Lagen Whatmanpapier aufgelegt. Zwischen den einzelnen Lagen wurde durch Ausrollen einer sterilen Glaspipette die Luftblasen entfernt. Dem Stapel 
wurden eine etwa $10 \mathrm{~cm}$ Schicht von Papiertüchern hinzugefügt. Der Transfer dauerte etwa 20 Stunden.

Hybridisierung und Detektion erfolgten nach der bereits beschriebenen nicht-radioaktiven Methode mittels ECL direct labelling system.

Probenpuffer:

\author{
$750 \mu 1$ Formamid \\ $150 \mu 1$ 10x MOPS/EDTA-Puffer \\ $240 \mu 1$ Formaldehyd \\ $100 \mu \mathrm{H} \mathrm{H}_{2} \mathrm{O}$ (RNAse frei) \\ $100 \mu 1$ Glycerol \\ $80 \mu 1$ 10\%iges (w/v) \\ Bromphenolblau
}

$10 \times$ MOPS/EDTA-

Puffer:

0,2 M MOPS
$50 \mathrm{mM} \mathrm{NaO}-$ Acetat
$10 \mathrm{mM}$ EDTA
pH 7,0
$0,3 \mathrm{M} \mathrm{Na}_{3}$-Citrat
$3 \mathrm{M} \mathrm{NaCl}$
ad $1000 \mathrm{ml} \mathrm{H}_{2} \mathrm{O}$

20 x SSC:

ad $1000 \mathrm{ml} \mathrm{H}_{2} \mathrm{O}$ 


\section{Ergebnisse}

\subsection{Herstellung der humanen und porcinen Triadin-cDNA aus}

\section{Skelettmuskel}

Wie sich in einer eigenen Voruntersuchung (Diplomarbeit) zeigte, sind die vergleichsweise kleinen Exons im porcinen Triadin-Gen durch große intronische Bereiche getrennt. Die Herstellung der Triadin-cDNA sollte primär einen direkten Vergleich der codierenden Bereiche zwischen Mensch und Schwein ermöglichen. Eine 5'-RACE- und 3'-RACE-PCR auf Basis der porcinen RNA konnte kein Amplifikat hervorbringen, da die Homologie zwischen den Spezies in den für die Primer-Bindung in Frage kommenden Bereichen offensichtlich nicht hoch genug war. Da im Rahmen der Diplomarbeit der 3'-Bereich des porcinen Triadin-Gens bereits kartiert worden war, wurde auf die Erstellung einer Vollängen-cDNA verzichtet. Die durch RT-PCR erhaltene cDNA des Skelettmuskels diente als Matrize für eine PCR mit genspezifischen Primern aus dem 5'- und 3'-Bereich des Gens. Dabei wurde zur Auswahl der Primer die Sequenzinformation aus dem letzten Exon des porcinen Triadin-Gens und aus dem durch Sequenzvergleich mit anderen Spezies ermittelten hochkonservierten 5'-Bereich des humanen Triadin-Gens herangezogen. Folgende Primer wurden in der oben beschriebenen PCR eingesetzt:

$\begin{array}{llll}\text { forward Primer: } & \text { Tri-60R } & \text { reverse Primer: } & \text { Tri-76R } \\ & \text { Tri-75R } & & \text { Tri-77R }\end{array}$

Die Sequenzen der Primer sind im Anhang in Tabelle 8-1 zu finden. Die Primerpositionen wurden so gewählt, daß im Bedarfsfall eine sogenannte nested-PCR durchgeführt werden konnte. Mit beiden möglichen Primerkombinationen konnten spezifische Amplifikate erzeugt werden. Wie in Abb. 5-1 gezeigt, ergaben sich aufgrund der Positionen der Primer innerhalb der cDNA zwei unterschiedlich lange Fragment. Alle Fragment wurden in den Vektor pGEM-4Z einkloniert und vollständig doppelsträngig sequenziert. 

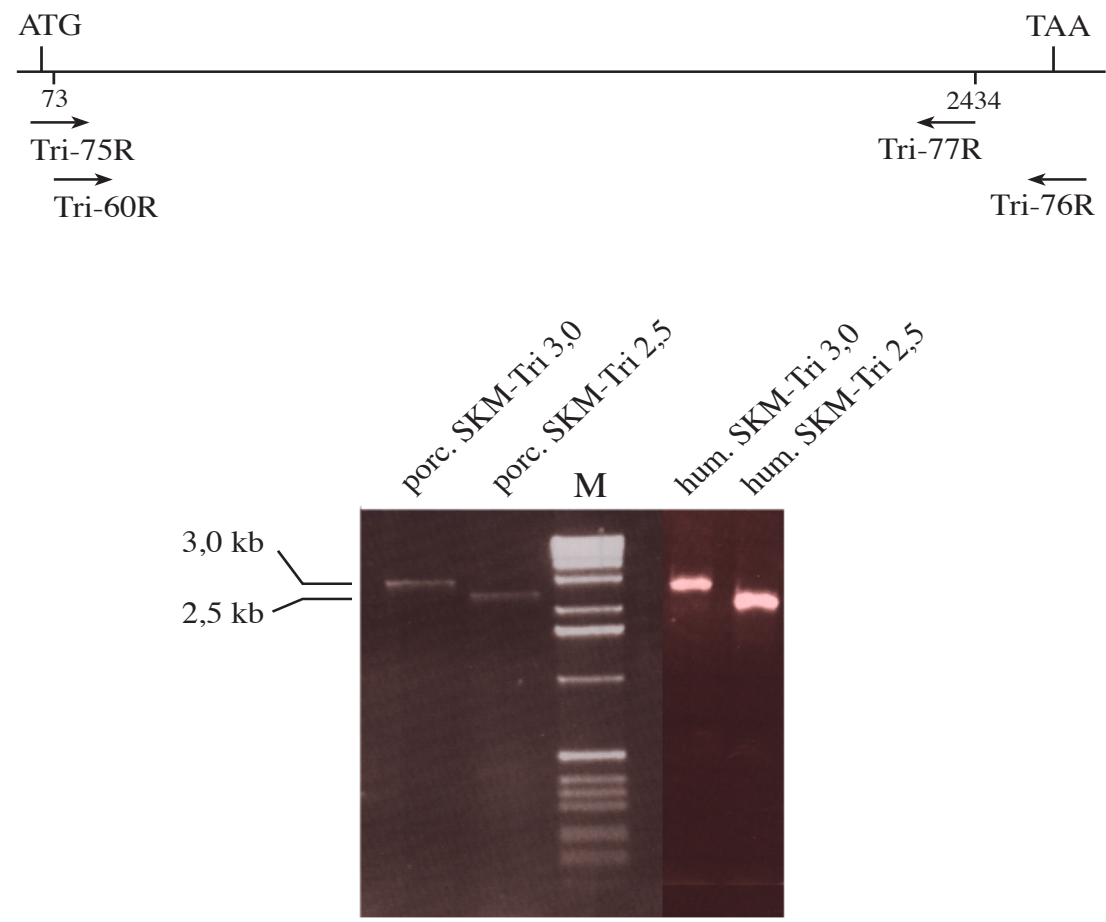

Abb. 5-1 Darstellung der PCR-Produkte porciner und humaner Skelettmuskel-Triadin-cDNA

Die PCR auf Skelettmuskel-cDNA ergab für die beiden Primerkombinationen unterschiedlich lange Fragmente. Die Primerpositionen sind im oberen Teil der Abbildung schematisch dargestellt. Das START-Codon (ATG) sowie das STOP-Codon (TAA) sind eingezeichnet. Aus der Kombination Tri-60R und Tri-76R entstand ein Fragment, das im 1\%igen Agarosegel als Bande bei etwa 3 kb erschien. Die Kombination Tri-75R und Tri-77R erzeugte ein Fragment, das im Agarosegel bei etwa 2,5 kb erkennbar war. Die Fragmente wurden entsprechend als porcine bzw. humane SKM (Skelettmuskel) 3,0 und 2,5 bezeichnet. In der Mitte diente eine 1kb-Leiter als Maker (M), aufgetragen wurden jeweils 5 $\mu l$ des PCR-Ansatzes.

\subsubsection{Identifizierung unterschiedlicher cDNA-Klone}

Abgesehen von den durch die versetzte Positionierung der Primer entstandenen Längenunterschiede der PCR-Produkte, wurde die Sequenz der humanen SkelettmuskelTriadin-cDNA in einem BLAST-Vergleich bestätigt. Die Sequenzierung der porcinen cDNA-Klone ergab zwei unterschiedliche Sequenzen. Beide Sequenzen wiesen über weite Bereiche Homologien von etwa 90 \% zur humanen cDNA auf. Es konnten jedoch, beim Vergleich mit der humanen cDNA jeweils zwischen den Positionen 573 und 633, zwischen den Positionen 1.158 und 1.209 sowie zwischen den Positionen 1.852 und 1972 deutlich erkennbare Lücken festgestellt werden. Die Sequenzierung von insgesamt 10 unabhängigen porcinen cDNA-Klonen zeigte daß, abgesehen von den durch die Primerpositionierung entstandenen Längenvarianten, zwei unterschiedliche cDNAs vorhanden waren. Die längere gefundene und klonierte cDNA, als pSKM1 bezeichnet, war 2.785 bp lang. Die kürzere wurde als pSKM2 bezeichnet und war 2.200 bp lang. pSKM 1 enthält einen offenen Leserahmen (ORF) von 1.458 bp, pSKM2 enthält einen ORF von 
1.358 bp. Die klar abgrenzbaren Sequenzlücken im Vergleich zur humanen cDNA wiesen auf das Vorhandensein alternativ gespleißter Exons hin.

\subsection{Genomische Organisation des Triadin Gens}

Die Durchmusterung einer genomischen, porcinen Phagen-Genbank hatte die Untersuchung im Rahmen der Diplomarbeit bereits zur Identifizierung der letzten drei Exons des porcinen Triadin-Gens geführt. Da die genomische Organisation und die Anzahl der Exons unbekannt waren, wurden diese Exons als Exon X, Y und Z bezeichnet. Das Exon $\mathrm{X}$ umfaßt 42 bp, Exon $\mathrm{Y} 39$ bp und Exon $\mathrm{Z}>1258$ bp (bis zum ersten Polyadenylierungssignal). Keines der weiter stromaufwärts gelegenen Exons konnte mittels PCR amplifiziert werden. Daher war eine Durchmusterung der porcinen, genomischen PAC-Genbank nach dem 5'-Bereich des Triadin-Gens nicht möglich. Um dennoch die genomische Organisation ermitteln zu können, wurde mittels BLAST nach humanen, genomischen Abschnitten gesucht, die Übereinstimmungen mit der humanen Triadin-cDNA-Sequenz aufwiesen. Zunächst konnten auf diese Weise drei überlappende humane PAC-Klone gefunden werden. Auf den Klonen AL133257 (130.748 bp), AL445259 (106.601 bp) und AL357352 (134.687 bp) wurden übereinstimmende Bereiche in colinearer Abfolge zur cDNA gefunden. Darüberhinaus war der PAC-Klon AL133257 bereits auf dem humanen Chromosom 6q22.1 - q22.3 kartiert worden. Dies stimmt mit der chromosomalen Lokalisation des humanen Triadin-Gens überein. Die weiteren Klone AL445259 sowie AL357352 überlappten jeweils nacheinander über einen Bereich von etwa 100 bp. Beide Klone waren laut Genbank-Report zwar dem humanen Chromosom 6 zugeordnet, eine genauere Lokalisation war aber noch nicht erfolgt.

Die Kartierung der Exons erfolgte durch Vergleich der cDNA mit den genomischen Abschnitten mit Hilfe des Programms Compare. Insgesamt wurden auf den 3 Klonen 24 Exons gefunden. Wie in Tabelle 5-1 dargestellt, entsprechen fast alle Exon-IntronÜbergänge den Konsensussequenzen der Spleiß-Akzeptor- und Spleiß-Donor-Stellen eukaryontischer Gene. Nur das Intron 11 beginnt mit einem GC-Dinukleotid an Stelle eines GT. In den 5'-Bereichen unmittelbar vor den einzelnen Exons konnte in allen Fällen das gehäufte Auftreten von Pyrimidinbasen festgestellt werden. Eine Analyse der Sequenzen mit Hilfe des Programmes Genscan konnte hingegen nur 8 der 24 Exons, namentlich die Exons 3, 6, 8, 11, 13, 14, 18 und 21 an den ermittelten Positionen festlegen. Die Abbildungen 5-2 bis 5-4 zeigen eine schematische Darstellung der tatsächlich auf den einzelnen PAC-Klonen kartierten Exons und die Analyse mit dem Programm Genscan. 

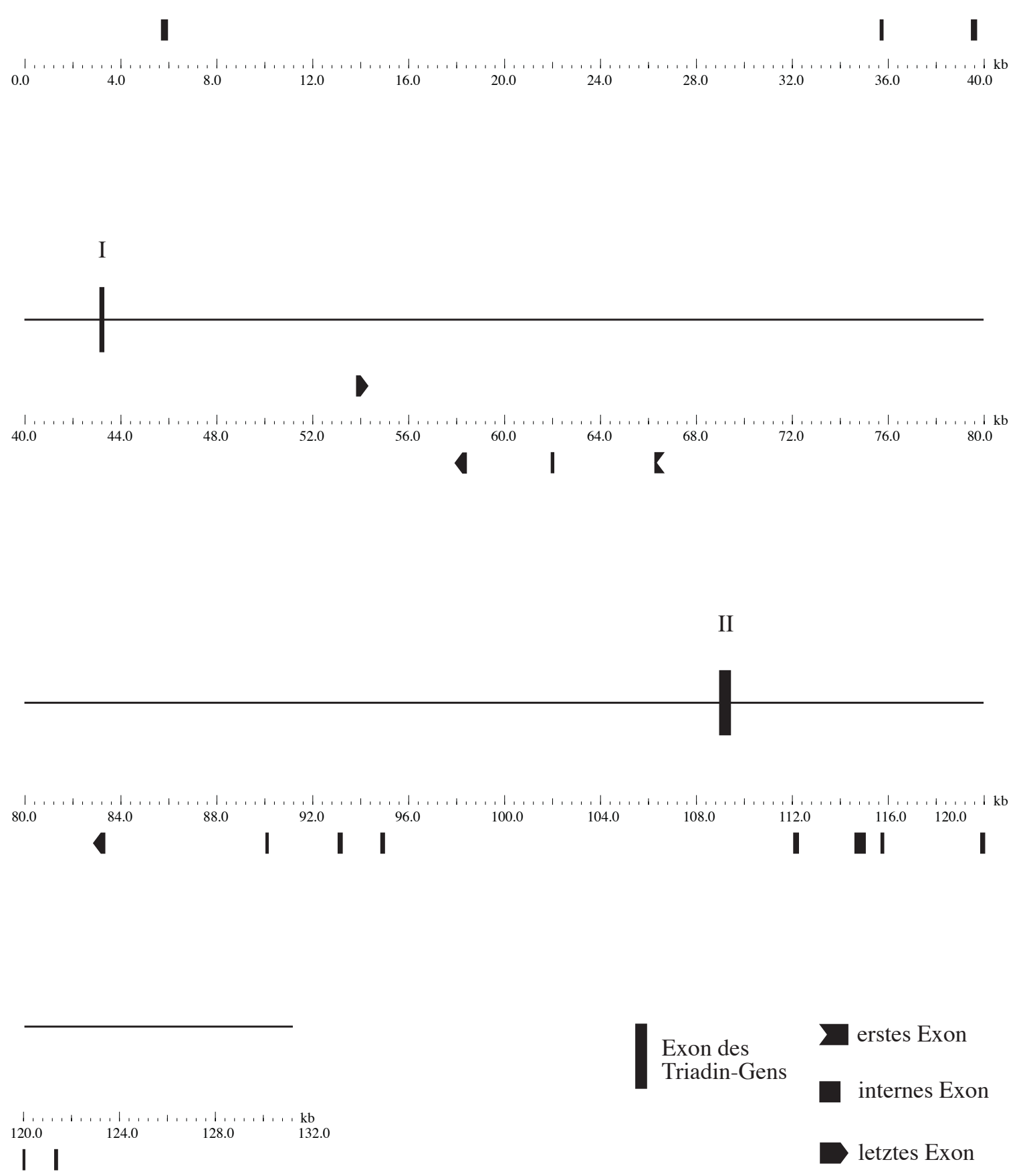

Abb. 5-2 Vergleich der Genescan-Analyse des humanen PAC Klones AL133257 mit den kartierten codierenden Bereichen des humanen Triadin-Gens

Die kleinen oberhalb und unterhalb des kb-Lineals dargestellten Symbole, zeigen die mittels Genscan ermittelten codierenden Regionen. Das Programm unterscheidet dabei, wie in der Legende dargestellt, erstes, internes, sowie letztes Exon. Symbole oberhalb des Lineals markieren Exons die in +/+ Orientierung liegen, Symbole unterhalb des Lineals markieren Exons in +/- Richtung zur dargestellten PAC-Sequenz. Auf dem PAC-Klon AL133257 konnten das erste und das zweite Exon des humanen Triadin-Gens kartiert werden. Vergleichend zur Genscan-Analyse sind entlang der Linie oberhalb des kb-Lineals die tatsächlich kartierten Exons als schwarze Rechtecke eingezeichnet. 

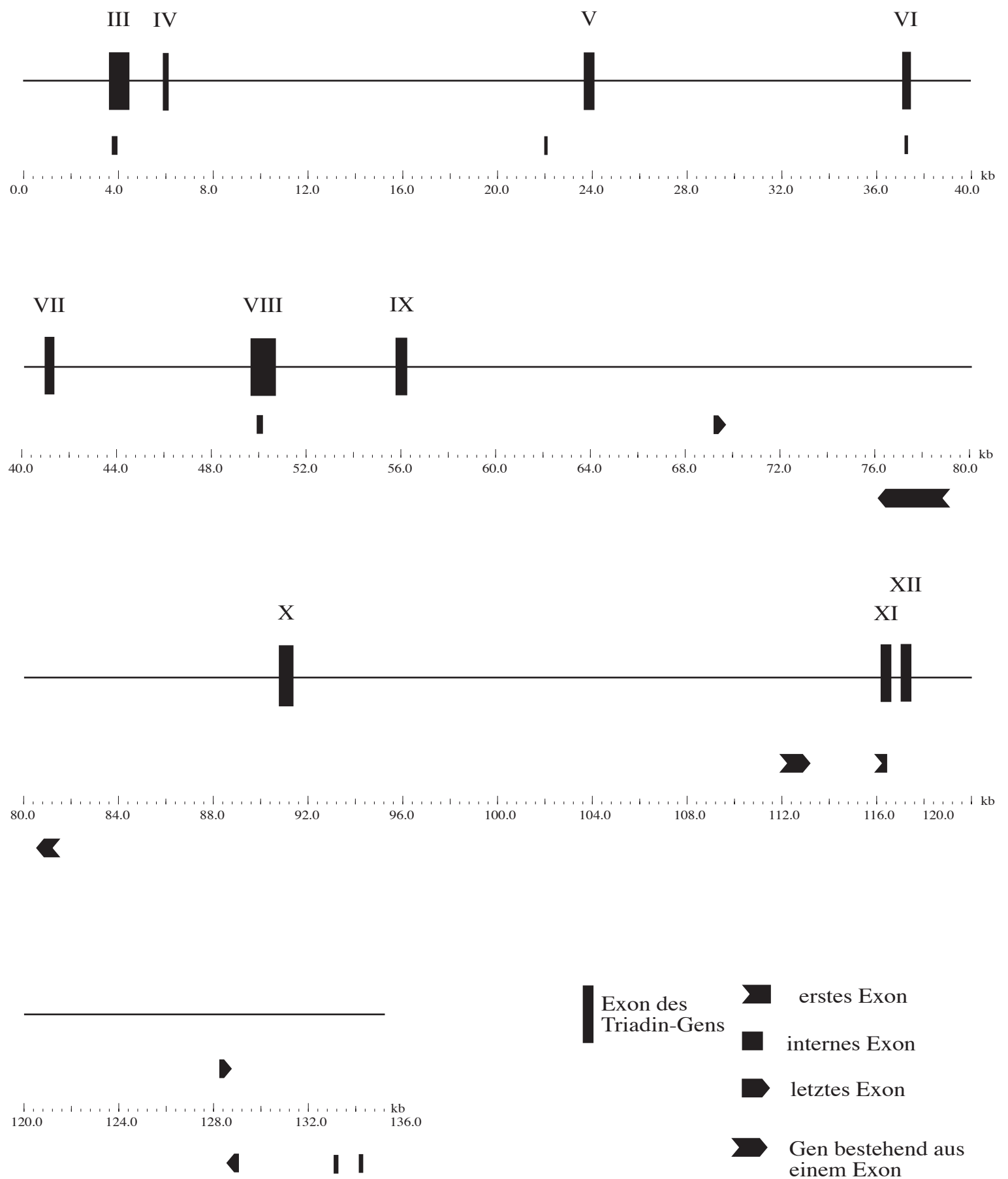

Exon des

2 erstes Exon

Triadin-Gens

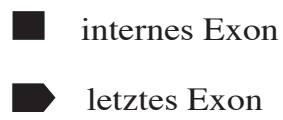

$D$ Gen bestehend aus einem Exon

Abb. 5-3 Vergleich der Genescan-Analyse des humanen PAC-Klones AL445259 mit den kartierten, codierenden Bereichen des humanen Triadin-Gens

Die kleinen oberhalb und unterhalb des kb-Lineals dargestellten Symbole zeigen die mittels Genscan ermittelten codierenden Regionen. Das Programm unterscheidet dabei, wie in der Legende dargestellt, erstes, internes oder letztes Exon, sowie Gene, die aus einem einzelnen Exon bestehen. Symbole oberhalb des Lineals markieren Exons die in $+/+$ Orientierung liegen, Symbole unterhalb des Lineals markieren Exons in +/- Richtung zur dargestellten PAC-Sequenz. Auf dem PAC-Klon AL445259 konnten die Exons 3 bis 12 in +/- Orientierung kartiert werden. Diese sind zum Vergleich als schwarze Rechtecke entlang der oberen Linie eingezeichnet. Vier dieser Exons wurden auch vom Programm Genscan an gleicher Position und in gleicher Orientierung kartiert. 

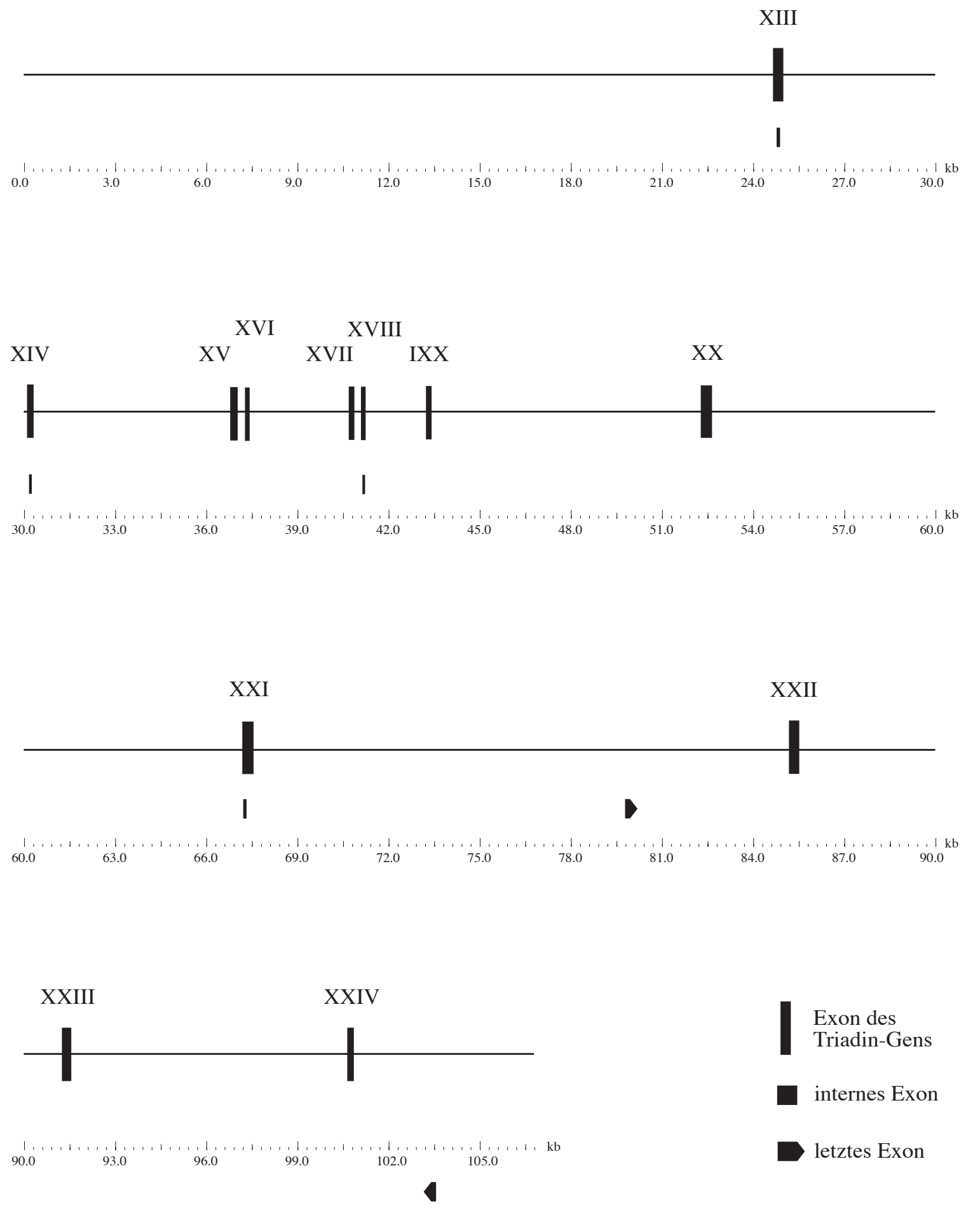

Abb. 5-4 Vergleich der Genescan-Analyse des humanen PAC-Klones AL357352 mit den kartierten, codierenden Bereichen des humanen Triadin-Gens

Die kleinen oberhalb und unterhalb des kb-Lineals dargestellten Symbole zeigen die mittels Genscan ermittelten codierenden Regionen. Das Programm unterscheidet dabei, wie in der Legende dargestellt, internes oder letztes Exon. Symbole oberhalb des Lineals markieren Exons die in $+/+$ Orientierung liegen, Symbole unterhalb des Lineals markieren Exons in +/- Richtung zur dargestellten PAC-Sequenz. Auf dem PAC-Klon AL357352 konnten die Exons 13 bis 24 des humanen Triadin-Gens kartiert werden. Vergleichend sind die tatsächlich kartierten Exons (in +/- Orientierung bezogen auf die DNA-Sequenz des Klones) entlang der oberen Linie als schwarze Rechtecke eingezeichneten. Das Programm Genscan kartierte vier dieser Exons an übereinstimmender Position und Orientierung. 
Anhand der kartierten Exons des humanen Triadin-Gens, sowie der letzten drei Exons des porcinen Triadin-Gens konnte festgestellt werden, daß zwar der Großteil der cDNA als Exons kartiert werden konnte, allerdings nach wie vor ein Bereich von etwa 500 bp nicht auf den untersuchten genomischen Klonen gefunden werden konnte. Eine erneute Suche mittels BLAST nach humanen, genomischen Klonen, die diesen Bereich abdecken führte zu keinem Ergebnis. Durch die direkte Suche über die „Human Genome BLAST Page“, in der auch noch unvollständig sequenzierte Klone enthalten sind, konnte jedoch ein, über weite Bereiche mit AL357352 überlappender Klon identifiziert werden. Dieser PAC-Klon war bereits auf Chromosom 6 im Bereich q21 - q23 lokalisiert worden und hatte die Bezeichnung NT023407. Da die Sequenz dieses Klones in einigen Bereichen noch unvollständig war, wurde keine Genscan-Analyse durchgeführt. Auf dem Klon wurden weitere 9 Exons des humanen Triadin-Gens kartiert. Die Sequenzen in diesen Bereichen wiesen keine Unsicherheiten auf. Wie in Abbildung 5-5 dargestellt, wurden anhand dieser vier humanen, genomischen PAC-Klone und eines im Rahmen der Diplomarbeit untersuchten porcinen, genomischen Phagen-Klones insgesamt 36 Exons kartiert. Dennoch repräsentieren diese 36 Exons noch nicht die gesamte cDNA. In Abbildung 5-6 sind die noch fehlenden 168 bp der humanen cDNA sowie die beiden angrenzenden Exons dargestellt. Der Anteil der noch nicht als Exons kartierten cDNA wird im folgenden als „not mapped“ (n/m) bezeichnet.

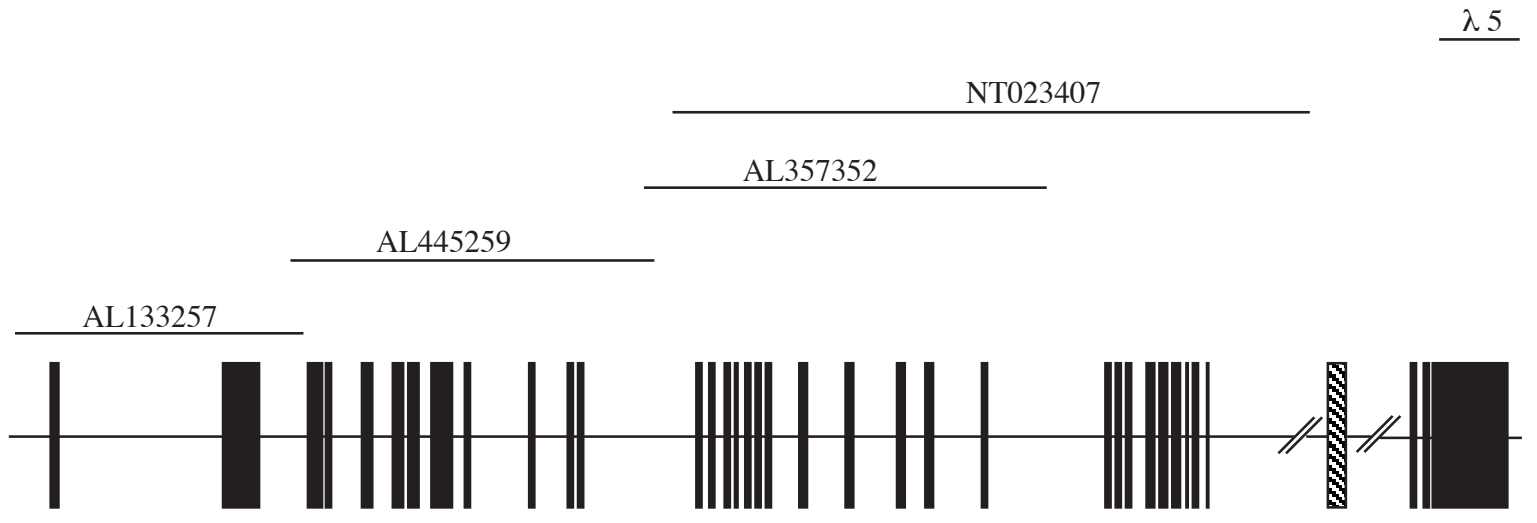

Abb. 5-5 Schematische Darstellung der genomischen Organisation des Triadin-Gens

Dargestellt ist die Anordnung der analysierten humanen PAC-Klone mit der Bezeichnung AL133257, AL445259, AL357352 sowie des noch unvollständigen Klones NT023407 und die darauf kartierten 33 Exons. $\lambda 5$ bezeichnet den porcinen genomischen Phagen-Klon, durch den die letzten 3 Exons kartiert werden konnten, das schraffierte Rechteck stellt den noch nicht kartierten Bereich dar. Die dargestellten Klone umfassen einen genomischen Bereich von mehr als $451 \mathrm{~kb}$, dabei konnte die Größe der Exons nicht proportional dargestellt werden. 


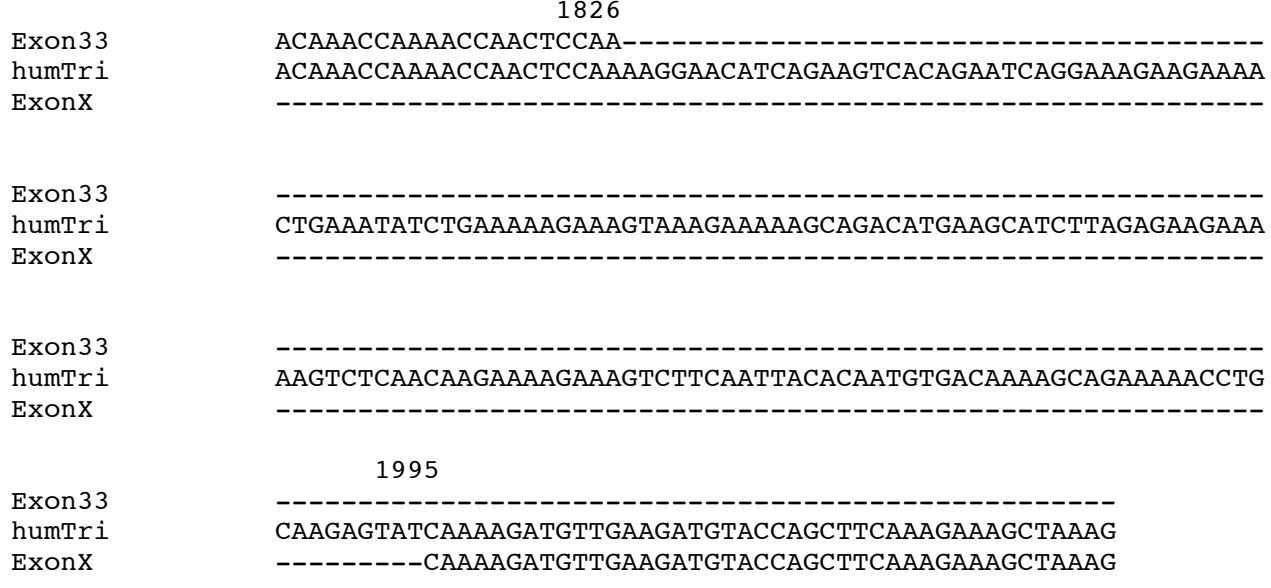

Abb. 5-6 Darstellung des n/m-Bereichs der humanen Triadin-cDNA

Dargestellt ist der noch nicht als Exons kartierte Bereich $(\mathrm{n} / \mathrm{m})$ des humanen Triadin-Gens mit den angrenzenden Exons 33 und X. Die Nummerierung gibt die Anfangs- bzw. Endposition dieses Abschnittes innerhalb der humanen cDNA an.

\subsubsection{Identifizierung alternativ gespleißter Exons}

Der Vergleich der beiden porcinen Triadin-cDNAs mit der humanen cDNA ließ aufgrund deutlich erkennbarer Sequenzlücken bereits auf das Vorhandensein alternativ gespleißter Exons schließen. Ein Vergleich mit den einzelnen beim Menschen kartierten Exons zeigte, daß die meisten von ihnen auch in gleicher Größe und mit einer Homologie zwischen 60 und $100 \%$ beim Schwein identifiziert werden konnten. Variationen waren bei Exon 3, Exon $\mathrm{Y}$ und Exon $\mathrm{W}$ zu finden, die im humanen Gen um 6, 3 und 3 bp kürzer sind als im porcinen. Umgekehrt sind die Exons 6, 16 und 22 im porcinen Gen um 12, 3 und 3 bp kürzer als im humanen Gen. Die Abbildungen 5-7 bis 5-40 zeigen die Sequenzvergleiche der gefundenen Exons zwischen Mensch und Schwein. Exon 7 konnte nicht in diesen Vergleich einbezogen werden, da dieses Exon in beiden gefundenen porcinen cDNAVarianten fehlte. In jeder Abbildung ist die obere Sequenz jeweils die porcine, die untere jeweils die humane Sequenz im entsprechenden Bereich. Die Homologiewerte sind in Klammern angegeben. 
porcin tATAGAATA CGAATTCGA CTCGGTACCC GACAGCAAAA ATGGATCTGT GCCCAAATCC || | | | | || | || |||||||||| |||||||||| ||||||||||

porcin CCTGGAAAg tGCTGAAGAg GACAgtCACA GAAGACATAG TGACAACATT CAgCTCCCCA ||||||||||||||||||||||||||||||||||||||||||||||||||||||||||

human CCCGGAAAAG TGCTGAAGA GACAGTCACA GAAGACATAG TGACGACGTT CAGCTCCCCT

porcin GCAGCCTGGC TTCTGGTCAT CGCTCTGATC ATCACGTGGT CAGCTGTGGC CGTTGTTATG |||||||||| |||||||||| || ||||| |||||||||| ||||||| || | | |||||| human GCAGCCTGGC TTCTGGTCAT TGCCCTGATA ATCACGTGGT CAGCTGTTGC CATCGTTATG

porcin TTTGACTTAG TGGATTACAA AAACTTTTCA G |||||||||||||||||||||||||||||| $\mid$

human TTTGATTTAG TGGATTACAA AAACTTTTCA G

Abb. 5-7 Homologievergleich des humanen und porcinen Exons 2 (93,37 \%)

porcin CAAGCTCTAT TTCCAAGATT GGCTCAGATC CTCTAAAACT TGTACATGAT GCTGTGGAGG

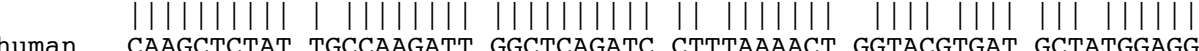

porcin AAACCACGGA CTGGGTCTAT GGCTTCTTTT CTTTGTTGTC TGACATCATC TCATCTGAGG |||||||||| |||| ||||| |||||||||| ||||||| || |||||||||| |||||||| human AAACCACGGA CTGGATCTAT GGCTTCTTTT CTTTGTTATC TGACATCATC TCATCTGA--

porcin GTGATGAAGA AGATGATGAA GGTGGAGTCG AgGACACTGA TAAAG ||||||| |||||||| | |||| || | || |||||| ||||| human -AGATGAAGA AGATGATGAT GGTGA---CG AAGATACTGA TAAAG

Abb. 5-8 Homologievergleich des humanen und porcinen Exons 3 (92,13\%)

porcin GAGAAATAGA GGAGCCTCCA --GTGAAAAA AAAAG

human $\quad||||||||||+|||||||\quad||||||||\quad|||$

Abb. 5-9 Homologievergleich des humanen und porcinen Exons 4 (80\%)

porcin AAATACATAA AGAAAAGACT GAAAAGCAGG AAAAACCTGA AAGGAAAACA CAAACTAAAG |||||| || ||| ||||| ||||| || | | ||||||| |||||||| | |||||||||

human AAATACACAA AGATAAGACT GAAAAACAAG AGAAACCTGA AAGGAAAATA CAAACTAAAG

Abb. 5-10 Homologievergleich des humanen und porcinen Exons 5 (98,10\%)

porcin TTACACACAG AGAAAAAGAC AAAGCAAAAG AAAAAGAA-AAACCTGAAA AGAAAG |||||||||| |||||||||| |||| |||||| ||||||| |

Abb. 5-11 Homologievergleich des humanen und porcinen Exons 6 (91,67 \%) 
porcin AAGAGAAGAA AACTAAGACT AAAGAAAAGG CTGAAGAAAA GAGTAAAAAG GAAGTGAAAG || ||||||| | |||||||| ||||||| |||||||||||||||||||||||||||||||

human AACAGAAGAA AGCTAAGACT GCAGAAAAGA GTGAAGAAAA GACTAAAAAG GAAGTGAAAG

porcin GTGGGAAACA GGAGAAAGTG AAGCAAACAG CTGCAAAAAT AAAAGACGCA CAGAAACCAT

human

porcin CCC-CTAAAC CCAAAGGGAA GGATGAGAAA GATGCT-GCA GCTCTGTCCA AGCATGAACAG || | |||| ||||||| || ||| || ||| || | ||| ||| |||| | ||||||||||| human CCATCAAAAC CCAAAGAAAA GGAGGACAAA GA-GAAAGCA GCTGTGTCAA AGCATGAACAG

porcin AAAG

human ||||

Abb. 5-12 Homologievergleich des humanen und porcinen Exons 8 (86,62 \%)

porcin ATCAGTATGC ATTCTGTCGA TATATGATTG ACATATTTGT CCATGGGGAT TTAAAACCAG |||||||||| |||||||||| |||||||||| |||||||||| |||||||||| |||||||||| human ATCAGTATGC ATTCTGTCGA TATATGATTG ACATATTTGT CCATGGGGAT TTAAAACCAG

Abb. 5-13 Homologievergleich des humanen und porcinen Exons 9 (100\%)

porcin GACAAAGCCC AGCCATACCA CCTCCATTAC CAACAGAACA AGCTTCCAGA CCCACTCCAG ||||||||| |||||| ||| ||||| |||| | |||||||| |||||||||| |||||||| |

human GACAAAGCCC AGCCATTCCA CCTCCCTTAC CGACAGAACA AGCTTCCAGA CCCACTCCGG

porcin CATCACCTAC TCTTGAAG

human $\quad||||||||||||||||$

Abb. 5-14 Homologievergleich des humanen und porcinen Exons 10 (94,83 \%)

porcin AAAAAGAAGG AGAAAAGAAG AAAGCTGAGA AGAAAGTGAC TCCTGAAGCA AAAAAGAAAG ||||||||| ||||||||| || ||||||| ||||||||| | ||||||| ||||||||||

human AAAAAGAAGG GGAAAAGAAG AAGGCTGAGA AGAAAGTTAC TTCTGAAACA AAAAAGAAAG

Abb. 5-15 Homologievergleich des humanen und porcinen Exons 11 (91,89\%)

porcin AAAAAGAAGA CGCCAAAAAG AAAACGGAGA AGGAAA-TAG CCACGGATGT GAAAAAAAAG |||||||||| ||||||| |||| |||| |||||| | | ||| ||||| | |||||||||

human AAAAAGAAGA TATCAAAAAG AAAAGTGAGA AGGAAACT-G CCATTGATGT GGAAAAAAAAG

Abb. 5-16 Homologievergleich des humanen und porcinen Exons 12 (87,42 \%)

porcin AGCCTGGCAA AGCCCCAGAA ACCAAACAAG GGACAATAAA AGTTGCAGCA CAAG

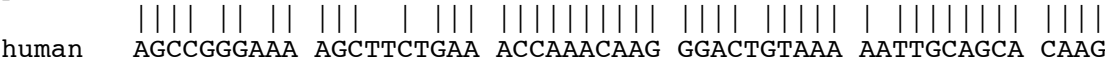

Abb. 5-17 Homologievergleich des humanen und porcinen Exons 13 (89,74 \%) 
porcin CAGCAACTAA AAAAGATGAA AAGAAAGAAG

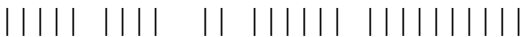

human CAGCAGCTAA GAAGGATGAA AAGAAGGAAG

Abb. 5-18 Homologievergleich des humanen und porcinen Exons 14 (90.0 \%)

porcin ATTTAAAGAA AACAAAAACA CCTACAGAAG

||| ||||| |||||||| | ||| ||||||

human ATTCCAAGAA AACAAAAAAA CCTGCAGAAG

Abb. 5-19 Homologievergleich des humanen und porcinen Exons 15 (86,67\%.)

porcin
human
TAGAACAACC CAAGGGAAAA A

Abb. 5-20 Homologievergleich des humanen und porcinen Exons 16 (80,95 \%)

porcin AACAGGAAAT GAAAGAAAAA CATGTGGAAC CAG

|||||||| |||||||||| |||||||||| |||

human AGCAGGAAAA GAAAGAAAAA CATGTGGAAC CAG

Abb. 5-21 Homologievergleich des humanen und porcinen Exons 17 (96,96 \%)

porcin CAAAATCACC AAAGAAGGAA CATTCAG

||||||||| |||||| ||| || ||||

Abb. 5-22 Homologievergleich des humanen und porcinen Exons 18 (88,89 \%)

porcin CTCCAAGTGA AAAACAAGTT AAAGCAA

| |||||||| ||||||||| |||||||

human TTCCAAGTGA CAAACAAGTA AAAGCAA

Abb. 5-23 Homologievergleich des humanen und porcinen Exons 19 (92,59 \%)

porcin AAACTGAACG AGCCAAAGAA GAGGTTGGTG CTGCCTCAAC TAAAAAAG human

Abb. 5-24 Homologievergleich des humanen und porcinen Exons 20 (87,50 \%)

porcin CTGTACCTGG TAAGAAGGAA GAGAAAACAA CCAAGACAGT GGAGCAAG ||||||||| ||||||||| ||||||||| |||||||||| |||||||

human CTGTACCTGG AAAGAAGGAA GAGAAAACAA CCAAGACAGT GGAGCAAG

Abb. 5-25 Homologievergleich des humanen und porcinen Exons 21 (98,83 \%)

porcin AAATTAGAAA AGAAAA-CCT GGGAAGACTT CTTCAGCTCC AAAGGACAAA GA |||||||||||||||| ||| |||||||||| ||||| |||| ||| || ||| |

human AAATTAGAAA AGAAAAATCT GGGAAGACTT CTTCAATTCT GAAAGATAAA G-

Abb. 5-26 Homologievergleich des humanen und porcinen Exons 22 (94,29 \%) 
porcin --ACCTGTTA AGGGAAAGAA GTGAAGGCTC CAGCTTCCCT AAAGGAAAA- G

human aAcCTATTAA AGGGAAAGA

Abb. 5-27 Homologievergleich des humanen und porcinen Exons 23 (90.48 \%)

porcin AACCTGAAAT TAAAAAAGAT GAAAAGATGT CCAAAGCAG

||||||||| |||||||||||| |||||||||||| ||||||||||

human AACCTGAAAC TAAAAAAGAT GAAAAGATGT CCAAAGCAG

Abb. 5-28 Homologievergleich des humanen und porcinen Exons 24 (97,43 \%)

porcin GCAAAGAAGT CAAGCCCAAG TCTCCAC

human GCAAAGAAGT CAAGCCTAAA CCTCCAC

Abb. 5-29 Homologievergleich des humanen und porcinen Exons 25 (88,89 \%)

porcin CTGGGTCTAT-GG CTTCTTTT-C TTTGTTGTC

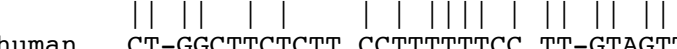

Abb. 5-30 Homologievergleich des humanen und porcinen Exons 26 (60,00 \%)

porcin AGCCACAAG- TAAAAA-GAA GAGAAGCCAG AG

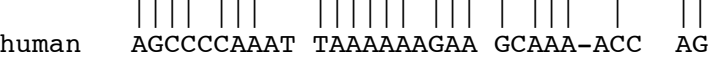

Abb. 5-31 Homologievergleich des humanen und porcinen Exons 27 (66,67 \%)

porcin TTTCATCTGA AAAAGCTCAA ATACACA

human CTATATCTGA AAAAGTGCAA ATACACA

Abb. 5-32 Homologievergleich des humanen und porcinen Exons 28 (81,48 \%)

porcin AACAAGACTT ACCCAAACCG GAAAAGACTG TTTCTCATGG TAAACCAG |||||||| | ||||| |||||||||| |||||||||| ||||||||

human AACAAGACAT AGTGAAACCA GAAAAGACTG TTTCTCATGG TAAACCAG

Abb. 5-33 Homologievergleich des humanen und porcinen Exons 29 (89,58 \%)

porcin ATGAAAAAGT TGCCAAGCAG GTAAAAGCTA AT-GCAACAG AAAAAATAG | |||||||| ||||||| |||||||| | ||| || ||||||| human AAGAAAAAGT TCTCAAGCAG GTAAAAGCTG -TCACAATAG AAAAAACAG

Abb. 5-34 Homologievergleich des humanen und porcinen Exons 30 (84,85\%) 
porcin TTAAACCCAA ACCAGCAA

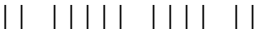

human CCAAGCCCAA ACCAACAA

Abb. 5-35 Homologievergleich des humanen und porcinen Exons 31 (77,78 \%)

porcin AAAAAGCTGA ACATCAAGAA AAAGAATCTC CATCTATAAA AACAG

||||||||| ||||| |||| | ||| ||| |||||||||| |||||

human AAAAAGCTGA ACATCGAGAA AGAGAACCTC CATCTATAAA AACAG

Abb. 5-36 Homologievergleich des humanen und porcinen Exons 32 (93,33 \%)

porcin ACAAACCAAA ACCAACTCCA A

human ACAAACCAAA ACCAACTCCA A

Abb. 5-37 Homologievergleich des humanen und porcinen Exons 33 (100 \%)

porcin GGGAAGATTC TGAGGATGTA CCAGCTTCAA AGAAAGCTAA AG

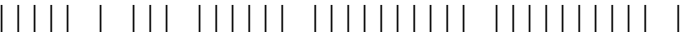

human CAAAAGATGT TGAAGATGTA CCAGCTTCAA AGAAAGCTAA AG

Abb. 5-38 Homologievergleich des humanen und porcinen Exons X (90,47 \%)

porcin ATGAAGCTGA AGATGTGTCT TCTACAAAGA AGCAAAAAA-

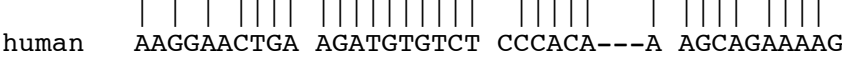

Abb. 5-39 Homologievergleich des humanen und porcinen Exons Y (80,0 \%) 
porcin CCCCATCAGC TTCTTCCAGT GTGTCTACTT GGATGGATAC AATGGCTATG GATTTCAGTT |||||||| ||||||||||||||||||| |||||| ||| |||||||||| |||||||||| human tCCCATCAGT TTCTTCCAGT GTGTCTACTT GGATGGGTAC AATGGCTATG GATTTCAGTT

porcin TCCTGTCACT CCTGCACACC GCCCTGGGGA GAGCTCTGGT CAACCAAGTT CTCCAGGACA |||||||| |||||||| |||||||| |||||||||||||||||| ||||||||||

human TCCTTTCACT CCTGCAGACC GCCCTGGAGA GAGCTCTGGT CAAGCAAATT CTCCAGGACA

porcin GAAGCAACAA GGGCAATAAG AGACACATGC AC-AGCCCCT ACAAGTGCTT TAAGACTTTG

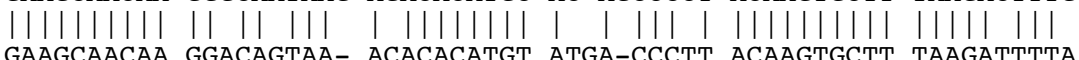

human GAAGCAACAA GGACAGTAA- ACACACATGT ATGA-CCCTT ACAAGTGCTT TAAGATTTTA

porcin AAAATAG-GA TCTTCCATTT GCCCACAGTG GCACAGGCAA TTGA-AATCA TATAGTCCAG ||||| | || | || || | ||||||| | ||||||| || | ||| | | | |||| human AAAAT-GTGA TGTT---TT- GTCCACAGTA GTTCAGGCAA TTAAGAAT-A TGCAACCCAG

porcin AGAATTTCTT TGAAAATATT TTACTTTTCT GTC-TGGTGT AGAAAGAAAG GGTGAGC-AA |||||||| |||||| ||| || ||||| | | | |||||| || ||||| |||| || ||

human AGAATTTCTG TGAAAACATT TTGCTCTT-T GGCCTGGTGT GGACGGAAAG GGTG-GCCAA

porcin AGGGATTGAA TAATAAGCAG ACAAACGGGA GGGTCTGGAG -CACAAGAAT TTGTCAT-T|||||||||||||||||| $\mid$ | |||||||||| | ||||||| ||| ||||

human ATGGATTGA TGATGAGCAG ACATGTTTAA GGGTCTA-Ag tCTCAAGAAT CTGTTATGTG

porcin TGTT-GCTG- GGTGTG-GG- --TGCTTATA TTT-T-TTAA ACTTCCATTC ACTGTAGGGT ||||||| |||| ||| ||||| || ||| | ||| ||||| || ||| || ||| human tGTTtGCTGC GGTGGGAGG GGTGCTTGTA TTTATCTTAT --TTCCAGTC ACTATAAGGT

porcin TGTTCACAAA TTAATTTAAA GTTTGCTTAA ATA-TGGTCT -TTTAAACAT AATTGACACA ||| ||||| ||||||||||||||||| || |||| | |||||||| |||||||||| human TGTACACAAA CTAATTTAAA GTTTACTTAA -TAATGGTAT CTTTAAA-AT AATTGACACA

porcin ATTACAAAAT GAAGTTCCTG GCTTCAGTTA GATATTTACT TTTAAGTGAA AATAAGACCA ||| ||||| ||| ||||| ||||||||| | ||||| | || | ||| || | |

human ATTGCAAAAT GAA-TTCCTG GCTTCAGTTA GCTATTATTT TTTTAATGAC AACATAGACT

porcin tgCTTTAAGT TGAAAgGGTA TACTAGCATA GGCTGTTTTT TTTCCATCAT GTAGTAGGTA human GTGCTCTAAg TTTAAAAGAT GGGGAGCTT ATATAAAAGT GACCCTTTTG CATCATATGG

porcin AACTCAACTT ACCCAGTAAG TTGATGTGTA ATAGTTTAAT TTTATTTCTA TCTGAACTTT human GTATCTAAAC TTAATTTACC CAATAAGTTG ATGCTTAATG ATTTTATTTT ATTTTTGTCT porcin tAgCTGTGAC TATGCTCTAA AAAAGGGGTA ACAGTTGCAC CAAAGAATGC TATAAGTTCT human ATTTTCTATT TTAGTTGTGG CTTTGCTCTA AGAATGGGTA ATAGTTGTAC porcin tTGTGATGTT CTCTTAGAgC TCAAAATATC TCTGAACTTT AGACATGGTA AGATGGAgtA human TATAAATTTC TTGTGATACT CTTTTAGAGC TCAAAATATC TCTGAGCTTT AGACATGGTA porcin GAAATGTCTG ATGAATCTTG TCTCTAAGAT TTGTCTTGAA GTACAATTAG GACATTCACT human AgGTGGAGAg TAAATGCTTG ATAAATCTTT AAGATATGTC TTGAATGATA ATTAGGACAT

Abb. 5-40 Homologievergleich des humanen und porcinen Exons Z (81,84 \%) 
Abbildung 5-41 zeigt ein Alignment des n/m-Bereichs der cDNA der porcinen Transkripte pSKM1 und pSKM2 und des humanen Transkriptes hSKM. Der $\mathrm{n} / \mathrm{m}$-Bereich des porcinen SKM1 ist mit 171 bp um 3 bp länger als der des humanen SKM (168 bp). Im Transkript 2 der porcinen cDNA ist der $\mathrm{n} / \mathrm{m}$-Bereich nur $51 \mathrm{bp}$. Durch Vergleich mit pSKM1 und hSKM lassen sich diese $51 \mathrm{bp}$ in zwei Abschnitte von 27 und 24 bp teilen. Damit wurden weitere 2 Exons bestimmt, die als Exon 34 und Exon W geführt werden.

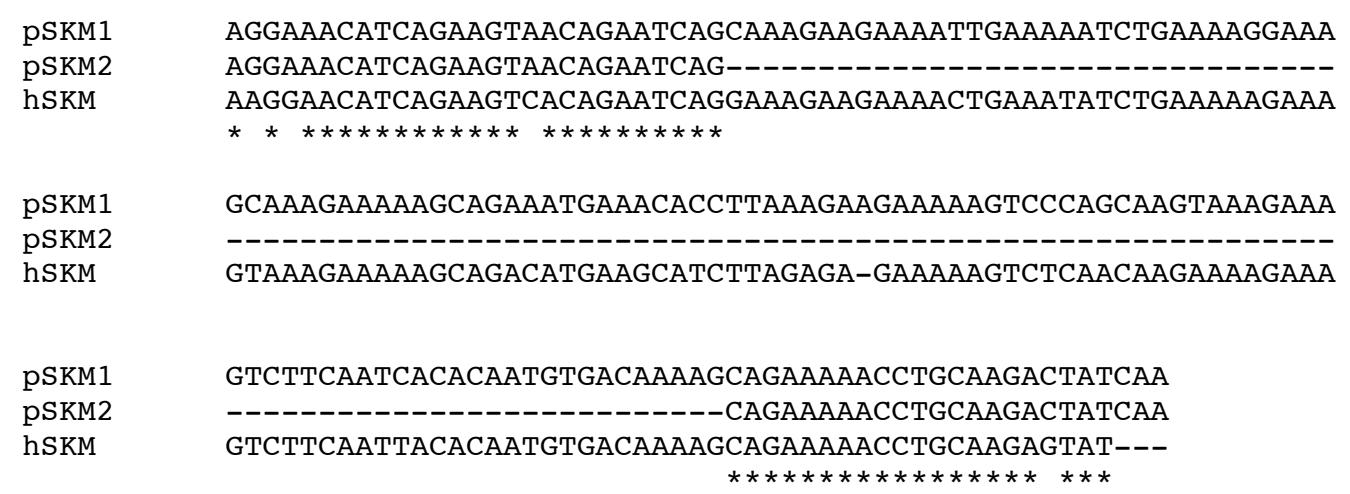

Abb. 5-41 Darstellung der n/m-Bereiche der gefundenen cDNA-Varianten

Die lange Variante der porcinen cDNA, als pSKM1 bezeichnet weist n/m-Bereich von $171 \mathrm{bp}$ auf, in der zweiten porcine cDNA-Variante pSKM2 ist dieser Bereich nur 51 bp groß. Diese 51 bp lassen sich aufgrund der Homologie zu SKM1 in zwei weitere Abschnitte aufteilen. Der n/m-Bereich der humanen cDNA (hSKM) ist 168 bp groß. Sterne (*) markieren die in allen drei Sequenzen identischen Nukleotide. 
Wie aus Tabelle 5-1 ersichtlich wurden insgesamt 38 Exons kartiert. Die HomologieWerte der einzelnen Exons sind zusammenfassend in Tabelle 5-2 dargestellt. Die Exons 7 und 1 sind nicht in diesen Vergleich miteinbezogen. Exon 1 ist in den aus RT-PCR entstanden porcinen cDNA-Klonen durch die Primerpositionierung unvollständig, Exon 7 ist in beiden cDNA-Varianten gespleißt.

Tab. 5-1 Übersicht über die kartierten Exons des humanen Triadin-Gens

\begin{tabular}{|c|c|c|c|c|c|}
\hline $\begin{array}{l}\text { Exon } \\
\text { Nr. }\end{array}$ & Größe (bp) & Intron & Exon & Intron & Introngröße $(\mathrm{kb})$ \\
\hline 1 & 44 & acgggaactttcaactg & acttt - 1 - tgaag & gtattgctaccattttcc & 65,6 \\
\hline 2 & 210 & ttctgaatgtttgattag & gaaat - 2- ttcag & gtaagttccataaaattt & 22,3 \\
\hline 3 & 159 & ttttttaattacttttag & caagc - 3 - taaag & gtacaaagaacatagag & 1,0 \\
\hline 4 & 33 & cttttaatcttggtctag & gagaa - 4 - aaaag & gttagttgttttcacctttg & 1,6 \\
\hline 5 & 60 & aaattctattttttcttag & aaata - 5 - taaag & gtaaacatttcattttatgt & 14,3 \\
\hline 6 & 66 & tttatctgtttcttttcag & ttaca - 6 - gaaag & gtatgaagttacttttattac & 3,7 \\
\hline 7 & 60 & taaaattttctgtttaag & caact - 7 - gaaag & gtaacttttcaatttattattt & 8,4 \\
\hline 8 & 183 & atcttttaactttatacag & aacag - 8 - gaaag & gtaaacattcagagcagg & 6,4 \\
\hline 9 & 60 & tttctttctactctgtcag & atcagt - 9 - accag & gtattccaagcaattcttgt & 32,2 \\
\hline 10 & 78 & tacttctacattgtgtag & gacaa - 10 - tgaag & gcaagtactttttttttctta & 25,9 \\
\hline 11 & 60 & ttttaaatgtattctctag & aaaaa - 11 - gaaag & gtaggaaatttaaaagccc & 0,8 \\
\hline 12 & 60 & tttcttattttaccagcag & aaaaa - 12 - aaaag & gtattgcactttctttgtttc & 44,3 \\
\hline 13 & 54 & atgtttttttcattccaag & agccg - 13 - acaag & gtaagcaataaaacacttt & 5,1 \\
\hline 14 & 30 & gctattttcattacttcag & cagca - 14 - ggaag & gtatgttttatgcaaaatcc & 6,2 \\
\hline 15 & 30 & tttatctttgtgttttcag & attcc - 15 - agaag & gtactggacatatttttttct & 0,7 \\
\hline 16 & 21 & ttgtttgtatttctttcag & tagaa - 16 - aaaaa & gtaaggaaatgcatgcagt & 3,4 \\
\hline 17 & 33 & aataataatatgtttcag & agcag - 17 - accag & gtaactgtttttaaattcctc & 0.1 \\
\hline 18 & 27 & tctttcctttttgatacag & caaag - 18 - ctcag & gtgagtaagaccactgttg & 2,0 \\
\hline 19 & 27 & tatttcttgtcattaacag & ttcca - 19 - agcaa & gtatgttgaacaaaattttta & 9,4 \\
\hline 20 & 48 & taatatctgaacttgcag & aaact - 20 - aaaag & gtaaatgcagcttaaagat & 13,5 \\
\hline 21 & 48 & ccttatctttgttttgcag & ctgta - 21 - gcaag & gtaaaaaaaaatgaagg & 20,6 \\
\hline 22 & 51 & ccatgatctctcttgcag & aaatt - 22 - taaag & gtaacagagttaatttaata & 5,6 \\
\hline 23 & 51 & tccgatgtttcttttcag & aacct - 23 - aaaag & gtaatattatacaatgaaat & 15,3 \\
\hline 24 & 39 & tgtacgttttgccccag & aacct - 24 - agcag & gtaaggatattttgtaagat & 37,9 \\
\hline 25 & 27 & attttttacttttttctag & gcaaa - 25 - tccac & gtatgttatatgcatgctca & 0,7 \\
\hline 26 & 30 & tgttcatctatattttag & aacta - 26 - gccag & gtatgtatattttatttataca & 3,6 \\
\hline 27 & 30 & gecttttctctcectcag & agccc- 27 - accag & gtaacatgagctttattttat & 1,2 \\
\hline 28 & 27 & atgttatttatttattttag & ctata - 28 - acaca & gtatgtattaattttatctttt & 0,3 \\
\hline 29 & 48 & tttctttttattattttcag & aacaa - 29 - accag & gtattttgcaggtggtattt & 1,8 \\
\hline 30 & 48 & acattttttcctatcacag & aagaa - 30 - aacag & gtaaataaggtattttatatt & 1,2 \\
\hline 31 & 18 & tgcctccattctccacag & ccaag - 31 - aacaa & gtaagagatgaatagaata & 2,0 \\
\hline 32 & 45 & ttttgatttctttctctag & aaaaa - 32 - aacag & gtattttaccatttttggttta & 1,8 \\
\hline 33 & 21 & ttttcttttttcetttttag & acaaa - 33 - tccaa & gtaagtgtaccattttagaa & $>35$ \\
\hline 34 & 27 & unbekannt & aggaa -34 - atcag & unbekannt & unbekannt \\
\hline $\mathrm{n} / \mathrm{m}-\mathrm{W}$ & 120 & unbekannt & gaaag -n/m - aaaag & unbekannt & unbekannt \\
\hline $\mathrm{W}$ & 21 & unbekannt & cagaa - W - agtat & unbekannt & unbekannt \\
\hline $\mathrm{X}$ & 42 & *tctttctttactctgag & caaaa-X - taaag & $*$ gtaagcttgttatcttcaa & $* 1,9$ \\
\hline $\mathrm{Y}$ & 39 & *tgttttctatccaatag & aagga $Y$ aaaag & $*_{\text {gtgagttttttttttttttt }}$ & $* 2,8$ \\
\hline $\mathrm{Z}$ & $>874$ & *catgctctgttccttag & tccca - & & \\
\hline
\end{tabular}

\footnotetext{
*Sequenzinformationen aus dem porcinen Triadin-Gen
} 
Tab. 5-2 Zusammenfassung der Homologie-Werte zwischen den humanen und porcinen Exons

\begin{tabular}{llllll}
\hline Exon & Homologie (\%) & Exon & Homologie (\%) & Exon & Homologie (\%) \\
\hline 2 & 93,70 & 15 & 86,67 & 28 & 81,48 \\
3 & 92,13 & 16 & 80,95 & 29 & 89,58 \\
4 & 80,00 & 17 & 96,96 & 30 & 84,85 \\
5 & 98,10 & 18 & 88,89 & 31 & 77,78 \\
6 & 91,67 & 19 & 92,59 & 32 & 93,33 \\
7 & & 20 & 87,50 & 33 & 100,00 \\
8 & 86,62 & 21 & 98,83 & 34 & 88,89 \\
9 & 100,00 & 22 & 94,29 & $\mathrm{n} / \mathrm{m}$ & 89,17 \\
10 & 94,83 & 23 & 90,48 & $\mathrm{~W}$ & 95,24 \\
11 & 91,89 & 24 & 97,43 & $\mathrm{X}$ & 90,47 \\
12 & 87,42 & 25 & 88,89 & $\mathrm{Y}$ & 80,00 \\
13 & 89,74 & 26 & 60,00 & $\mathrm{Z}$ & 81,84 \\
14 & 90,00 & 27 & 66,67 & & \\
\hline
\end{tabular}

Der Vergleich der identifizierten Exons mit den beiden porcinen Skelettmuskel-TriadinVarianten zeigte, daß in beiden Fällen das Exon 7 herausgespleißt ist. Darüberhinaus ist der $\mathrm{n} / \mathrm{m}$-Bereich in der Variante pSKM2 nur 51 bp lang, was darauf schließen läßt, daß auch hier weitere Exons alternativ gespleißt sind. In der zweiten gefundenen Variante fehlen neben dem Exon sieben außerdem die Exons 15 und 16. Abbildung 5-42 zeigt eine Übersicht über die gefundenen Spleißvarianten. 


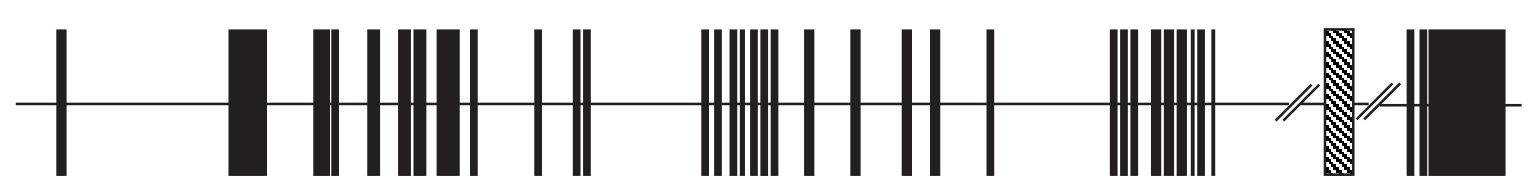

genomische Organisation
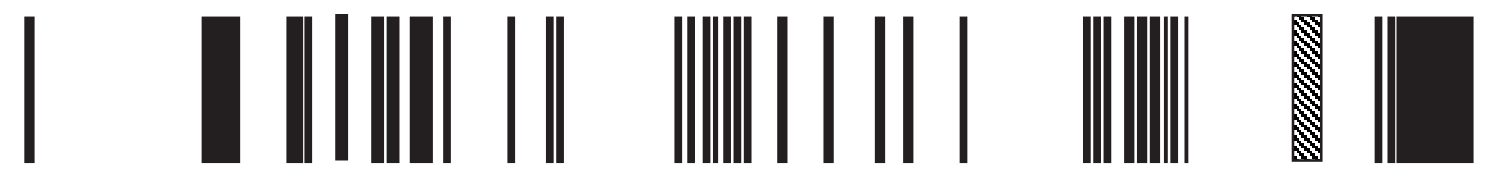

hSKM
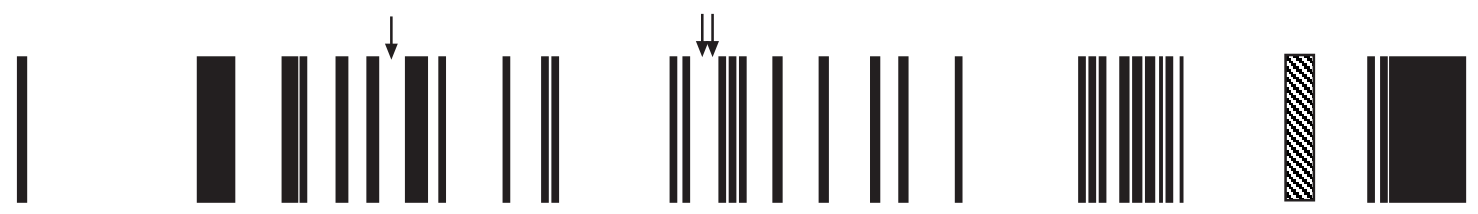

pSKM1
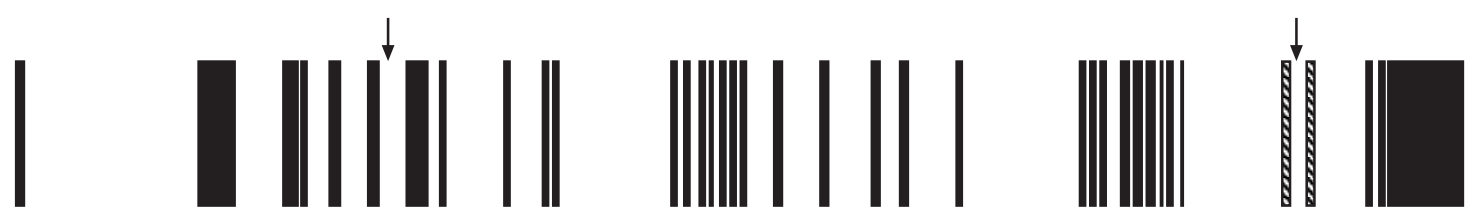

pSKM2

Abb. 5-42 Übersichtsdarstellung der drei untersuchten cDNA-Varianten

Dargestellt sind alle kartierten Exons des Triadin-Gens als schwarze Rechtecke, sowie der n/m-Bereich als schraffiertes Rechteck. Aus den mehr als 38 Exons entsteht ein Transkript, das alle Exons enthält (hSKM), außerdem ein Transkript (pSKM1) bei dem neben dem siebten auch das fünfzehnte und sechzehnte Exon fehlen und ein weiteres Transkript (pSKM2), bei dem das siebte sowie ein Teil des n/m-Bereiches gespleißt sind.

\subsubsection{Chromosomale Lokalisation des porcinen Triadin-Gens}

Zur chromosomalen Lokalisation des porcinen Triadin-Gens wurden ein somatischer Cell Hybrid Panel [82] sowie ein Radiation Hybrid Panel [83] herangezogen. Die speziesspezifischen Primer Tri Ex Y-for und Tri Ex Y-rev wurden zunächst auf genomischer DNA von Schwein, Maus und Hamster getestet. Zur PCR auf einem somatischen Cell Hybrid Panel wurden 25 ng DNA, 2,5 $\mu 110$ x PCR-Puffer, 50 pmol jedes Primers, 0,5 $\mu 110 \mathrm{mM}$ dNTPs, sowie 2,5 U Taq-Polymerase in einem Gesamtvolumen von $25 \mu l$ eingesetzt. Die Tabellen 5-3 und 5-4 zeigen das Ergebnis der PCR-Analyse. Zellinien in denen ein Signal entstand erhielten die Ziffer 1, Linien die kein Signal ergaben erhielten die Ziffer 0. Im Radiation Hybrid Panel bezeichnet der Buschstabe L die Hybrid- 
Zellinien Maus-Schwein, der Buchstabe F bezeichnet die Hybrid-Zellinien HamsterSchwein.

Tab. 5-3 Ergebnis der PCR-Analyse des somatischen Cell Hybrid Panels

\begin{tabular}{|lllllllllllllll|}
\hline Zellinie & 1 & 2 & 3 & 4 & 5 & 6 & 7 & 8 & 9 & 10 & 11 & 12 & 13 & 14 \\
Signal & 0 & 1 & 0 & 0 & 0 & 0 & 1 & 0 & 0 & 0 & 0 & 0 & 0 & 0 \\
\hline Zellinie & 15 & 16 & 17 & 18 & 19 & 20 & 21 & 22 & 23 & 24 & 25 & 26 & 27 \\
Signal & 0 & 1 & 0 & 1 & 1 & 0 & 0 & 0 & 0 & 0 & 0 & 0 & 0 \\
\hline
\end{tabular}

Das Ergebnis der PCR-Analyse des somatischen Cell Hybrid Panels ist in Tabelle 5-3 dargestellt. Die Auswertung der Analyse ergab eine Lokalisation des porcinen TriadinGens auf SSC 1 q18 bzw. q28 - q21.3. Die Wahrscheinlichkeit beträgt jeweils 90,35 \% mit einer Irrtumswahrscheinlichkeit von weniger als von $0,1 \%$. Dieses Ergebnis mit einer Lokalisation in zwei verschiedenen Regionen mit der gleichen Wahrscheinlichkeit kommt dadurch zustande, daß sich die Regionen $\mathrm{H}$ und $\mathrm{L}$ in der gleichen Zellinie befinden. Abbildung 5-43 zeigt die unterschiedlichen Regionen des SSC 1, die in den 27 Zellinien verteilt sind.

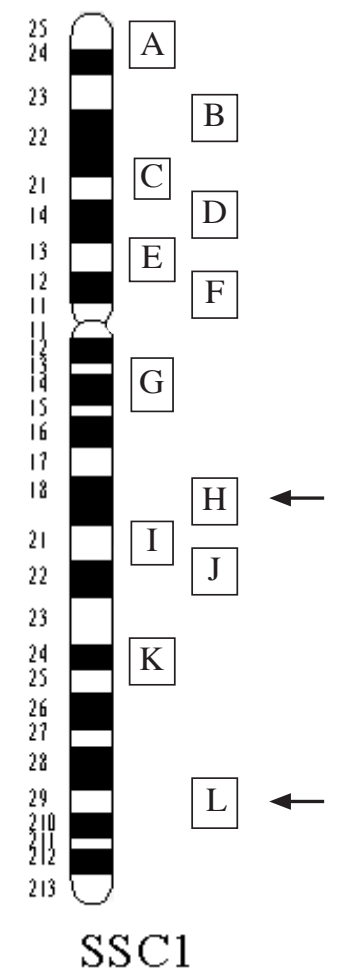

Abb. 5-43 Schematische Darstellung der Regionen des SSC 1

Gezeigt sind die Regionen A - L, die, mit Ausnahme der Regionen H und L, jeweils einzeln in einer der 27 Zellinien zu finden sind. Die Regionen H und L (Pfeile) befinden sich beide in der Zellinie 2. 
Tab. 5-4 Ergebnis der PCR-Analyse des Radiation Hybrid Panels

\begin{tabular}{|lllllllllllllll|}
\hline Zellinie & L1 & L2 & L3 & L4 & L5 & L6 & L7 & L8 & L9 & L10 & L11 & L12 & L13 & L14 \\
Signal & 0 & 0 & 0 & 0 & 1 & 1 & 0 & 0 & 0 & 0 & 0 & 0 & 1 & 0 \\
\hline Zellinie & L15 & L16 & L17 & L18 & L19 & L20 & L21 & L22 & L23 & L24 & L25 & L26 & L27 & L28 \\
Signal & 0 & 0 & 0 & 0 & 0 & 1 & 0 & 0 & 0 & 0 & 0 & 0 & 0 & 0 \\
\hline Zellinie & L29 & L30 & L31 & L32 & L33 & L34 & L35 & L36 & L37 & L38 & L39 & L40 & L41 & L42 \\
Signal & 1 & 0 & 0 & 0 & 0 & 1 & 0 & 0 & 0 & 1 & 0 & 1 & 1 & 0 \\
\hline Zellinie & L43 & L44 & L45 & L46 & L47 & L48 & L49 & L50 & L51 & L52 & L53 & L54 & L55 & L56 \\
Signal & 0 & 0 & 0 & 0 & 1 & 0 & 0 & 0 & 0 & 0 & 1 & 0 & 0 & 0 \\
\hline Zellinie & L57 & L58 & L59 & L60 & L61 & L62 & L63 & L64 & L65 & L66 & L67 & L68 & L69 & L70 \\
Signal & 0 & 0 & 1 & 1 & 0 & 0 & 0 & 0 & 0 & 0 & 0 & 0 & 0 & 0 \\
\hline Zelline & L71 & L72 & L73 & L74 & L75 & L76 & L77 & L78 & L79 & L80 & L81 & L82 & L83 & L84 \\
Signal & 0 & 0 & 1 & 0 & 0 & 0 & 0 & 0 & 0 & 0 & 0 & 0 & 0 & 0 \\
\hline Zellinie & L85 & L86 & L87 & L88 & L89 & L90 & L91 & L92 & L93 & L94 & L95 & L96 & L97 & F98 \\
Signal & 0 & 0 & 0 & 0 & 0 & 0 & 0 & 0 & 0 & 1 & 0 & 0 & 0 & 0 \\
\hline Zellinie & F99 & F100 & F101 & F102 & F103 & F104 & F105 & F106 & F107 & F108 & F109 & F110 & F111 & F112 \\
Signal & 0 & 0 & 0 & 0 & 1 & 0 & 0 & 0 & 0 & 0 & 1 & 0 & 0 & 0 \\
\hline Zellinie & F113 & F114 & F115 & F116 & F117 & F118 & & & & & & & & \\
Signal & 0 & 0 & 0 & 0 & 1 & 1 & & & & & & & \\
\hline
\end{tabular}

Die Auswertung der PCR-Analyse des Radiation Hybrid Panels ergab ebenfalls eine chromosomale Lokalisation des porcinen Triadin-Gens auf SSC 1. Die angrenzenden Marker sind der Mikrosatellit Sw373 und S0112. Sw373 wrude durch Analyse eines somatischen Cell Hybrid Panels, sowie durch in situ Hybridisierung und Kopplungsanalyse auf SSC 1 im Bereich q26 - q27 lokalisiert [84,85]. S0112 wurde durch Analyse eines somatischen Cell Hybrid Panels auf SSC 1 im Bereich q28 - q21.3 lokalisiert [86]. Der LOD-Score der Kopplungsgruppe Sw373 - Triadin - S0112 beträgt 5,17. Damit wurde das porcine Triadin Gen auf SSC1 q26 - q28 kartiert. 


\subsection{Herstellung porciner mut-cDNA aus Lebergewebe}

Um einen Homologievergleich der codierenden Bereiche des humanen und porcinen Methylmalonyl-CoA-Mutase-Gens durchführen zu können, wurden eine wie unter Abschnitt 4.4.3 beschriebene 5' - und 3'-RACE-PCR durchgeführt. Dazu wurde RNA aus porcinem Lebergewebe isoliert. Darüber hinaus wurde mittels RT-PCR und anschließender PCR mit genspezifischen Primern der cDNA-Bereich vom 6. bis 12. Exon amplifiziert. Folgende Oligonukleotide wurden verwendet:

$\begin{array}{ll}\text { 5'-RACE-Primer: } & \text { MMCM5R1 } \\ \text { MMCM5R2 }\end{array}$

3'-RACE-Primer: $\quad$ MMCM3R1

MMCM3R4

genspezifische RT-PCR: $\quad$ MMCM3R2

MMCM3R3

Die Sequenzen der Oligonukleotide sind im Anhang unter Tabelle 8-1 aufgeführt. Die Primerpositionen wurden so gewählt, daß im Bedarfsfall eine e 5'-RACE-PCR wurden in der ersten Runde der Adaptor-Primer 1 (AP1) des Marathon cDNA-Kits, sowie der Primer MMCM5R1 verwendet. Ein spezifisches Amplifikat konnte durch eine zweite PCR mit AP 1 und dem genspezifischen Primer MMCM5R2 hergestellt werden. Dabei wurden $5 \mu$ aus dem ersten PCR-Ansatz als Template für die zweite Runde verwendet. Aus der 5'-RACE entstand ein 412 bp langes PCR-Produkt, das in den Vektor pCR2.1-TOPO einkloniert und doppelsträngig sequenziert wurde. Für die 3'-RACE-PCR wurden in der ersten Runde AP 1 sowie der genspezifische Primer MMCM3R1eingesetzt. Auch hier wurde, um das Resultat zu verbessern, eine zweite Runde mit den Primern AP 1 und MMCM3R4 durchgeführt. Es konnte jedoch kein spezifisches Amplifikat erzeugt werden. Die genspezifische RT-PCR mit den Primern MMCM3R2 und MMCM3R3 lieferte ein 1.905 bp großes Amplifikat. Dieses wurde ebenfalls in pCR2.1-TOPO einkloniert und sequenziert.

\subsection{Molekulargenetische Analyse des porcinen mut-Locus}

Zur molekulargenetischen Untersuchung des porcinen mut-Locus wurde die am Tierärztlichen Institut vorhandene porcine genomische PAC-Genbank (IVMp 714) durchsucht [80]. Zur PCR-gestützten Durchmusterung der PAC-Genbank wurden Oligonukleotide aus dem humanen Methylmalonyl-CoA-Mutase-Gen im Bereich des 
Exons 3 abgeleitet. Die Primersequenzen sind in Tabelle 8-1 eingetragen, die Primer wurden als mut Ex3.1-for und mut Ex3.1-rev bezeichnet. Das daraus resultierende PCRProdukt hatte eine Länge von $285 \mathrm{bp}$. Abbildung 5-44 zeigt die Durchmusterung der porcinen PAC-Genbank mittels PCR. Ausgehend von den 13 Supersuperpools (SSP) wurde die Durchmusterung descendent mit jeweils einem positiven Pool weitergeführt. Die PCR auf den Supersuperpools ergab ein starkes Signal in SSP1, ein schwächers Signal auf SSP6. Daraufhin wurde mit den Superpools des SSP1weitergearbeitet. Aus dieser PCR entstanden drei Signale, wiederum wurde mit dem ersten Signal weiter gearbeitet und entsprechend die Plattenpools des Superpools 1 durchmustert. Von Plattenpool drei wurden schließlich durch PCR auf den Spalten und Reihen der Klon an Position F11 ausgewählt.
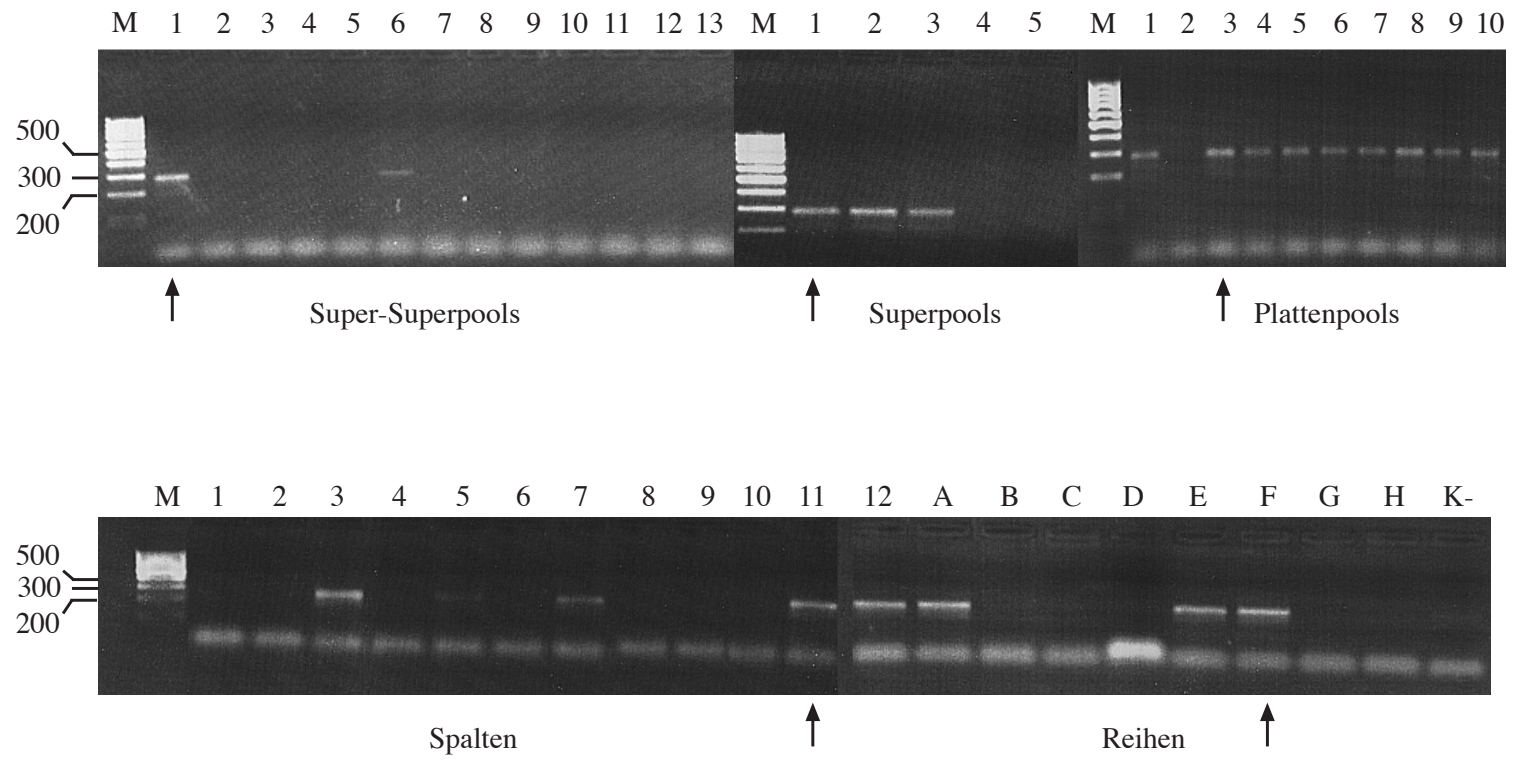

Abb. 5-44 Durchmusterung der porcinen PAC-Genbank mittels PCR

Dargestellt sind die Ergebnisse der PCR auf den Supersuperpools, den Superpools, den Plattenpools und den Spalten und Reihen. Die Pfeile markieren jene Pools bzw. die Platte 3, die jeweils für die nächste Durchmusterungsrunde verwendet wurden. Die Amplifikate wurden auf ein 1,6 \%iges Agarosegel aufgetragen, als Marker (M) diente eine 100 bp-Leiter.

\subsubsection{Subklonierung des PAC-Klones A3F11}

Der nach der Durchmusterung der Genbank ausgewählte PAC-Klon erhielt die Bezeichnung A3F11. Zunächst wurden aus einer Flüssigkultur große Mengen PlasmidDNA isoliert und diese mit den Restriktionsenzymen EcoRI, SacI, HindIII, PstI, XbaI und BamHI gespalten und die so entstandenen Fragmente in einem 0,8\%igen Agarosegel aufgetrennt. Von diesem Gel wurde ein Southern Blot angefertigt und dieser mittels ECLKit nicht-radioaktiv hybridisiert. Als Hybridisierungssonde wurde das 285 bp große PCRAmplifikat aus dem Exon 3 des porcinen Methylmalonyl-CoA-Mutase-Gens verwendet. 
Abbildung 5-45 zeigt das Ergebnis der Hybridisierung. Damit wurde das im Rahmen der Durchmusterung der Genbank erhaltene positive Signal bestätigt. Darüberhinaus konnten jene Fragmente identifiziert werden, die das Exon 3 des porcinen $m u t$-Locus enthielten.

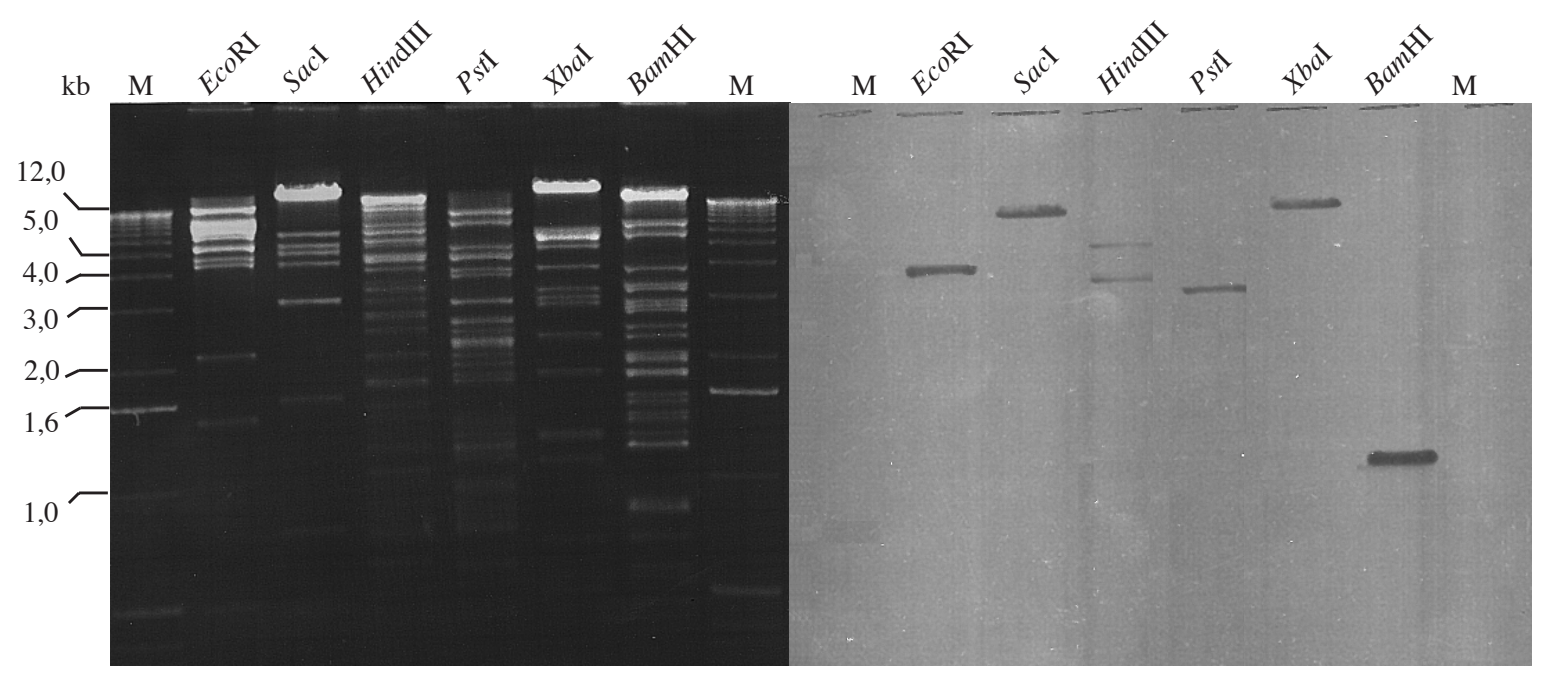

Abb. 5-45 Gelelektrophorese der Restriktionsspaltung des PAC A3F11 und Southern Blot Hybridisierung

Der linke Teil der Abbildung zeigt die elektrophoretisch aufgetrennten Fragmente einer Restriktionsspaltung mit den Enzymen EcoRI, SacI, HindIII, PstI, XbaI und BamHI. Für jeden Ansatz wurden 1,5 $\mu$ g DNA in einem Gesamtvolumen von $50 \mu$ eingesetzt. Die entstandenen Fragmente wurden in einem 0,8 \%igen Agarosegel aufgetrennt. Der rechte Teil der Abbildung zeigt die auf einem Röntgenfilm entstandenen Signale nach nicht-radioaktiver Hybridisierung der auf eine Nylonmembran transferierten DNA. Der Film wurde 5 Minuten exponiert.

Um möglichst viele Informationen dieser genomischen Region zu erhalten, wurde der PAC-Klon vollständig sequenziert. Von jedem Spaltungsansatz wurden dazu möglichst viele einzelne Banden ausgeschnitten und diese in den Vektor pGEM-4Z einkloniert. Die auf diese Weise entstandenen Subklone beinhalteten das gesamte Insert des PAC-Klones. Die Abbildungen 5-46 und 5-47 zeigen eine Restriktionsspaltung ausgewählter Subklone. Die Bezeichnung der Klone und der weiteren Subklone beruht auf folgendem Nomenklatursystem: Jeder Klon erhielt zunächst die Kurzbezeichnung F11 für den PACKlon aus dem er entstanden war. Danach folgte die Abkürzung des Enzymes sowie die fortlaufende Nummer der unterschiedlich großen Fragmente, beginnend mit 1 für das kleinste Fragment. 


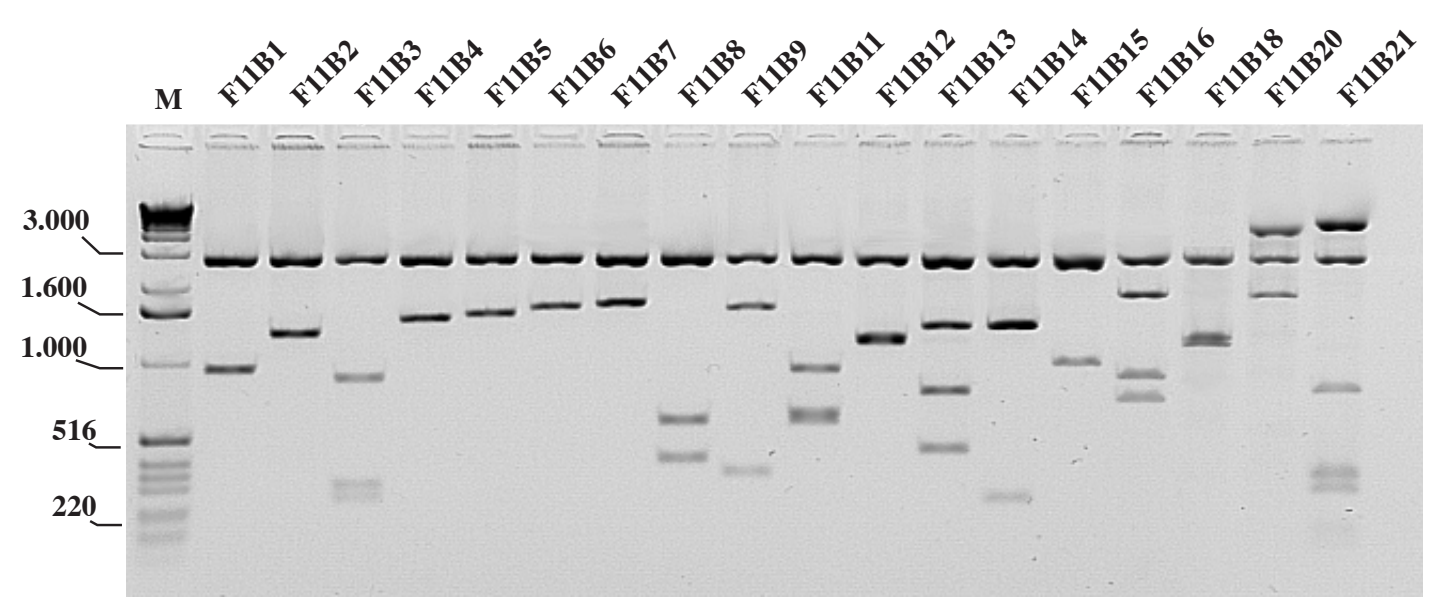

Abb. 5-46

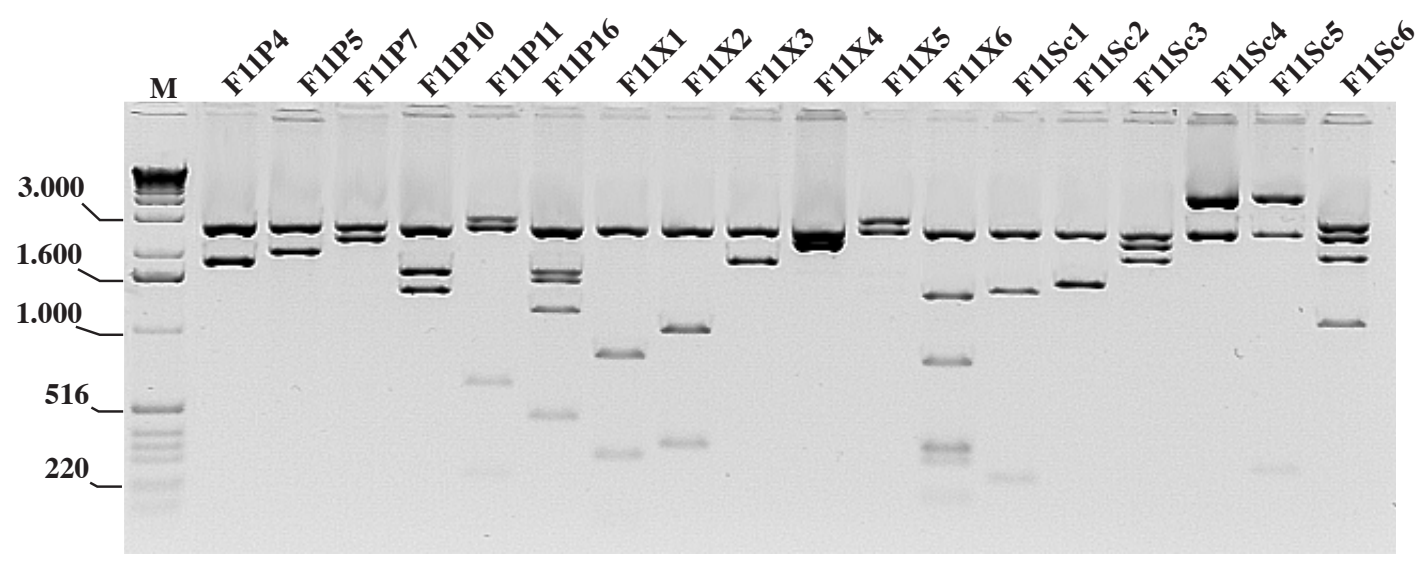

Abb. 5-47. Restriktionsspaltung der ausgewählter Subklone aus A3F11

Die Abbildungen 5-46 und 5-47 zeigen die Spaltprodukte einer Restriktionsspaltung mit den Enzymen EcoRI und HindIII einiger Subklone des PAC A3F11. In jedem Ansatz wurden etwa 150 - 200 ng DNA gespalten. und zur Auftrennung der Fragmente auf ein 1\%iges Agarosegel aufgetragen. „M“ bezeichnet den Marker, eine 1kb-Leiter mit danebenstehenden Fragmentgrößen. Die Bezeichnungen der Subklone sind oberhalb der jeweiligen Auftragsstelle angegeben.

Alle erhaltenen Subklone wurden bidirektional sequenziert. In manchen Fällen konnten die Klone auf diese Weise gleich vollständig durchsequenziert werden, in den meisten Fällen war die Herstellung von Subklonen zweiter Ordnung notwendig. Die erhaltenen Sequenzdaten wurden mit Hilfe der Software Sequencher $3.0 \mathrm{zu}$ einem Projekt vereint und überlappende Klone zu Contigs zusammengefügt. Für Sequenzbereiche, in denen keine geeigneten Schnittstellen vorhanden waren, wurde die Sequenz mit Hilfe von fluoreszenzmarkierten Oligonukleotiden ermittelt. Da die Ableitung geeigneter Sequenzierprimer jedoch nicht immer möglich war, zum Beispiel weil sich an dieser Stelle ein repetitives Element befand, wurden diese Lücken innerhalb des Contigs mittels PCR und anschließender Klonierung und Sequenzierung bzw. direkter Sequenzierung des PCRProduktes überbrückt. Auf diese Weise entstand ein Contig von 68.833 bp für das porcine mut-Gen. Alle codierenden Bereiche wurden doppelsträngig sequenziert, von kürzeren 
Abschnitte nicht-codierender Bereiche wurde, wenn es die Qualität der Sequenz erlaubte, nur einer der beiden Stränge sequenziert.

\subsubsection{Ermittlung der Sequenzcharakteristik}

\subsubsection{Nicht-radioaktive Primer Extension-Analyse zur Festlegung des Transkriptionsstarts}

Zur Feststellung des Transkriptionsstarts wurde eine nicht-radioaktive Primer-ExtensionAnalyse, wie unter Abschnitt 4.4.4 beschrieben, durchgeführt. Hierzu wurden das $30 \mathrm{bp}$ lange Oligonukleotid 5MMCM2 und das 25 bp lange Oligonukleotid 5MMCM2.1 verwendet. Die Primersequenzen sind in Tabelle 8-1 aufgeführt. Beide Oligonukleotide wurden aus der Sequenz des zweiten Exons abgeleitet, die jeweiligen Positionen sind in Abbildung 5-48 dargestellt. Ausgehend von den durch 5'-RACE erhaltenen Daten, sollte das Primer-Extension Produkt etwa eine Größe von 225 bzw. 100 bp haben. Die Analyse mit 5MMCM2 erzeugte insgesamt 3 Extension-Produkte. Das kleinste mit einer Länge von 110 bp würde den Transkriptionsstart genau am ATG festlegen. Das zweite Produkt mit einer Länge von 152 bp, würde den Transkriptionsstart auf ein CGGTCC im zweiten Exon festlegen. Die dritte Bande lag bei etwa 254 bp. Die Postion an einem TTGCGCT des 5'UTR liegt 28 bp vor dem in der 5'-RACE erhaltenen cDNA-Ende. Dieses Signal konnte auch durch die Primer Extension mit dem Oligo 5MMCM2.1, die eine Bande bei etwa 128 bp erzeugte, ermittelt werden. Wie in Abbildung 5-49 gezeigt, konnten in dem weiter stromaufwärts gelegenen Bereich des Exons 1 mehrere Bindungsmotive für Transkriptionsfaktoren gefunden werden. Beim mut-Gen handelt es sich um ein TATABox-loses Gen. Von solchen Genen ist bekannt, daß mehrere verschiedene Transkriptionsstartpunkte möglich sind. Die hier durchgeführte Studie zeigte nur ein Signal, das durch beide Oligonukleotide bestätigt werden konnte. Ebenso spricht das gehäufte Auftreten von Bindungsmotiven für eukaryontische Transkriptionsfaktoren im Bereich zwischen -35 und bis -250 für diese Postion als Transkriptionsstartpunkt. Neben einer Bindungsstelle für Sp1 (GGGCGG) konnten mehrere CAAT-Boxen in positiver und negativer Orientierung, sowie Kernmotive für cAMP-response element-binding protein (CRE), GATA-1, NRF-2 und Elk-1 gefunden werden. 

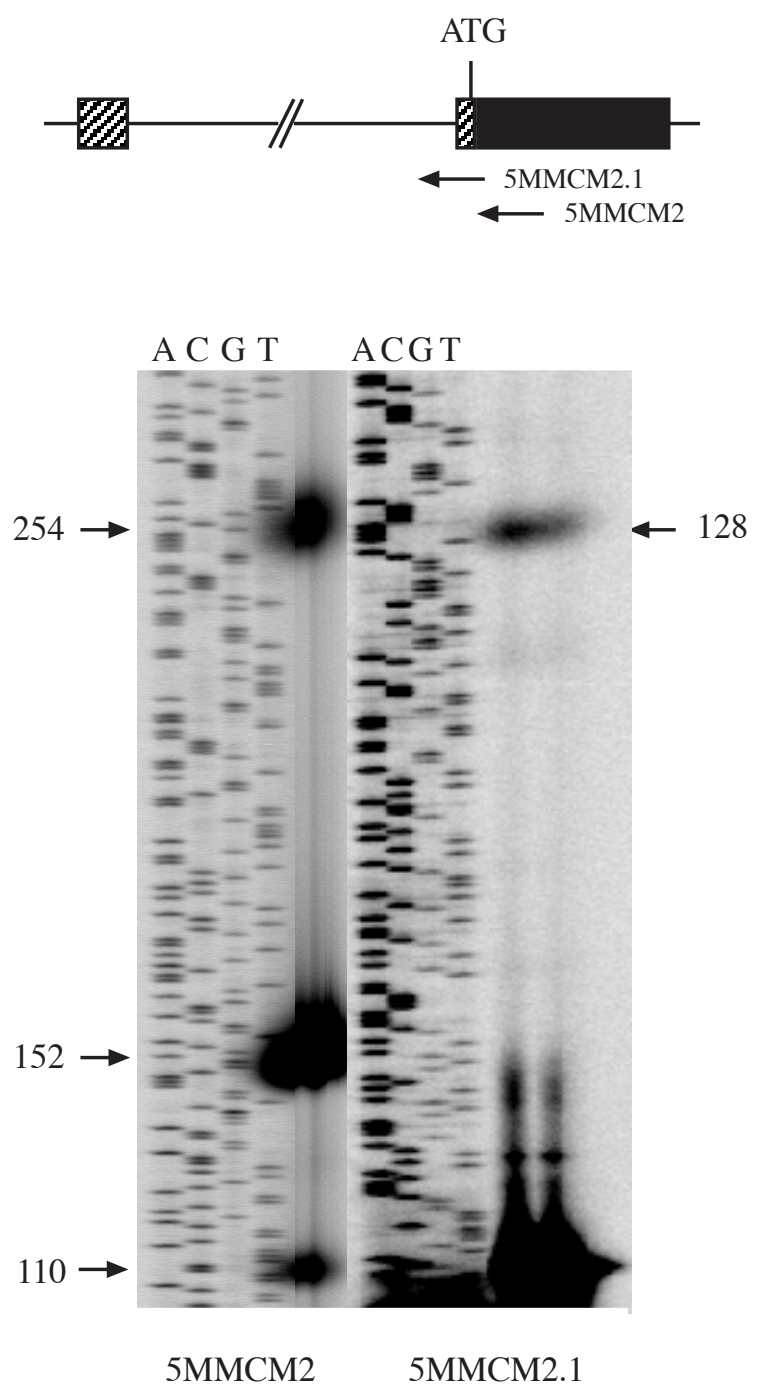

Abb. 5-48 Primer Extension-Analyse

Der obere Teil der Abbildung zeigt schematisch die Lage der beiden verwendeten Oligonukleotide 5MMCM2 und 5MMCM2.1. Diese wurden für eine nicht-radioaktive Primer Extension-Analyse mit dem Fluoreszenzfarbstoff IRD800 markiert und die Reaktion zusammen mit einer Sequenzreaktion auf ein Standard-Sequenzgel aufgetragen. Anhand der Sequenzreaktionen wurde die Länge der jeweiligen Extension-Produkte (Pfeile) bestimmt. 
Tgtgagtaaactgtgcgcc

Abb. 5-49 Promotorregion des porcinen Methylmalonyl-CoA-Mutase-Gens

Der durch Primer Extension-Analyse ermittelte Startpunkt der Transkription ist mit +1 gekennzeichnet. Die Anfangssequenz des ersten Introns ist in Kleinbuchstaben dargestellt. Die Bindungsmotive verschiedener Transkriptionsfaktoren stromaufwärts vom Startpunkt sind durch Rahmen gekennzeichnet.

\subsubsection{Analyse codierender Bereiche}

Der PAC-Klon A3F11 enthält die Exons 1 bis 6 des porcinen Methylmalonyl-CoA-Mutase Gens. Zur exakten Kartierung der Exons wurde die durch 5'-RACE-PCR erhaltene Sequenzinformation herangezogen. Da das erste Exon zur 5'-untranslatierten Region (UTR) des Genes gehört, ist die Homologie auf Nukleotidebene zwischen Mensch und Schwein erwartungsgemäß gering und beträgt 69,74 \%. Der Homologievergleich ist in Abbildung 5-50 dargestellt. Die Kartierung des zweiten Exons erfolgte durch Vergleich der genomischen Sequenz des PAC A3F11 mit der durch 5'- RACE erhaltenen cDNASequenz des porcinen mut-Gens. Das zweite Exon enthält 43 bp der $5^{\prime}$-UTR, sowie die 96 $\mathrm{bp}$, die für das mitochondriale Signalpeptid codieren. Die Homologie zum humanen Exon 
2 beträgt 89,60\% und ist in Abbildung 5-51 dargestellt. Das porcine Exon 2 ist 430 bp lang und damit um 6 Nukleotide länger als das humane Exon 2.

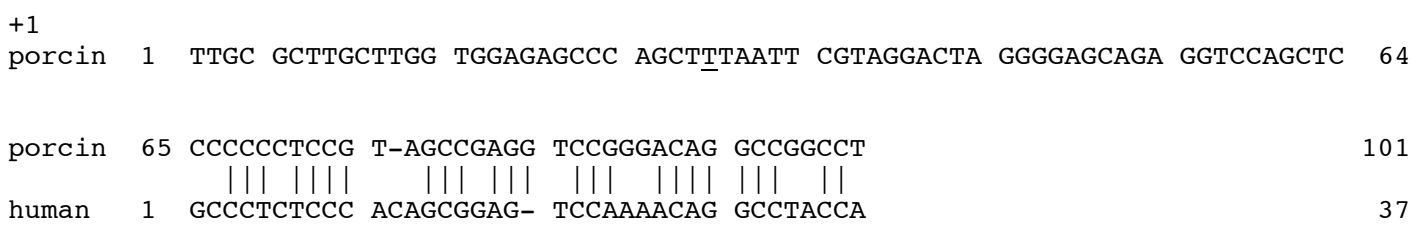

Abb. 5-50 Homologievergleich des ersten Exons

Die obere Sequenz zeigt die aus der 5'-RACE erhaltene porcine Sequenz, die untere Sequenz stellt den in der Datenbank (Accession M 65131) eingegebenen 5'-Bereich der humanen cDNA des mut-Gens dar. Die Numerierung am Rand gibt die Nukleotidposition innerhalb der jeweiligen cDNA an. Gerade Striche (|) markieren jene Nukleotide, die bei beiden Spezies identisch sind. Die Position +1 gibt den Transkriptionsstart an, das unterstrichene T-Nukleotid gibt die letzte Nukleotidposition des 5'-RACE-Produktes an.

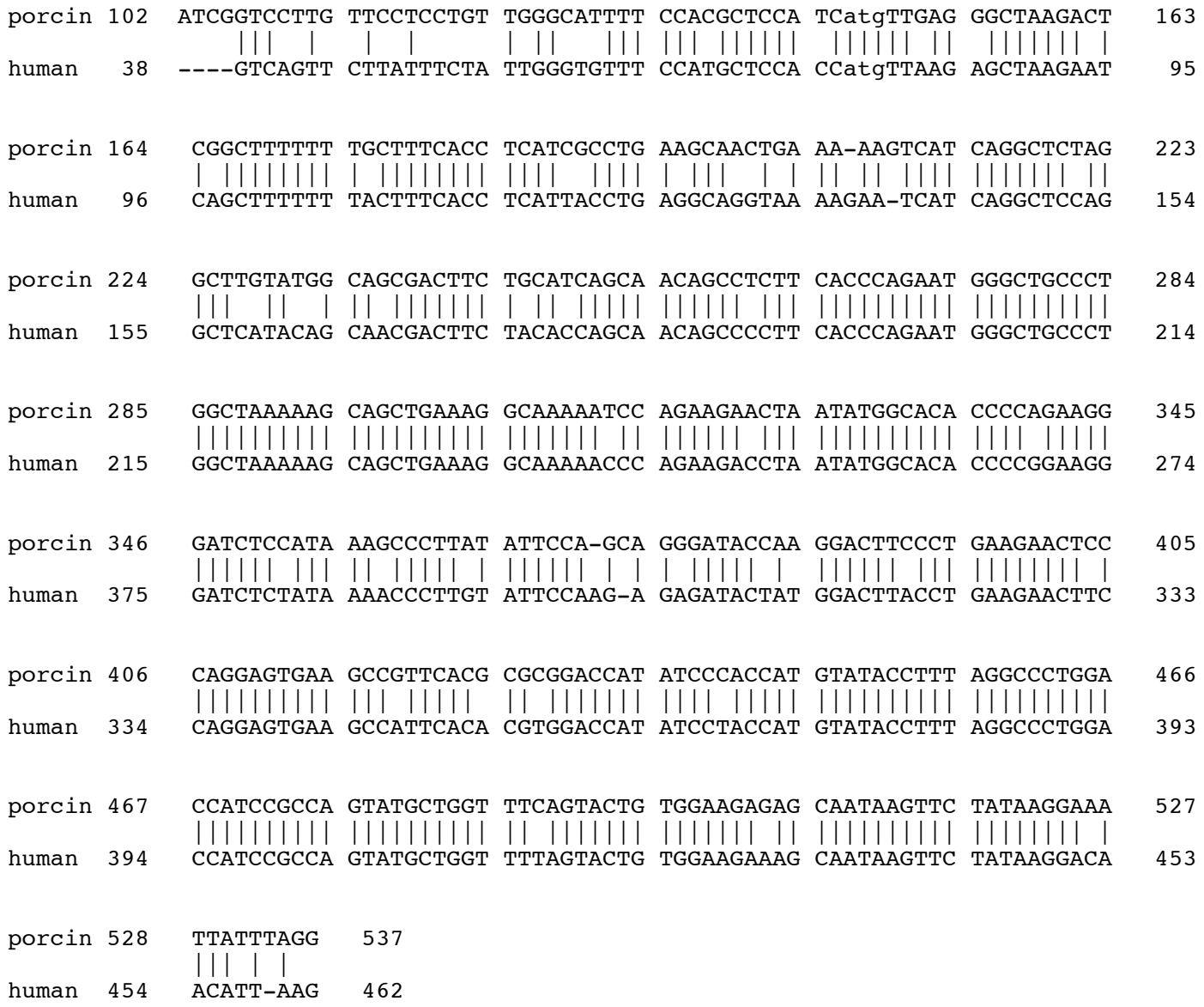

Abb. 5-51 Homologievergleich des porcinen und humanen Exons 2

Die obere Nukleotidsequenz zeigt die porcine, die Untere die humane Sequenz. Das Start-Codon „ATG“ ist in Kleinbuchstaben dargestellt. Die Nummerierung am Rand gibt die jeweilige Position innerhalb der cDNA an. Gerade Striche (|) kennzeichnen jene Positionen, die bei beiden Spezies identisch sind. 
Zur Kartierung der Exons 3 bis 6 wurde in gleicher Weise verfahren. Alle Exon/IntronÜbergänge entsprechen den konservierten Spleiß-Motiven eukaryontischer Gene. Demnach beginnen alle Introns mit „GT“ und enden mit „AG“. Die Abbildungen 5-52 bis 5-55 zeigen einen Sequenzvergleich der humanen und porcinen Exons 3 bis 6. In allen Abbildungen stellt die obere Sequenz die porcine, die untere die humane Nukleotidsequenz dar. Die Homologiewerte sind in Klammern angegeben. Bemerkenswert ist die hohe Homologie von jeweils über $90 \%$.

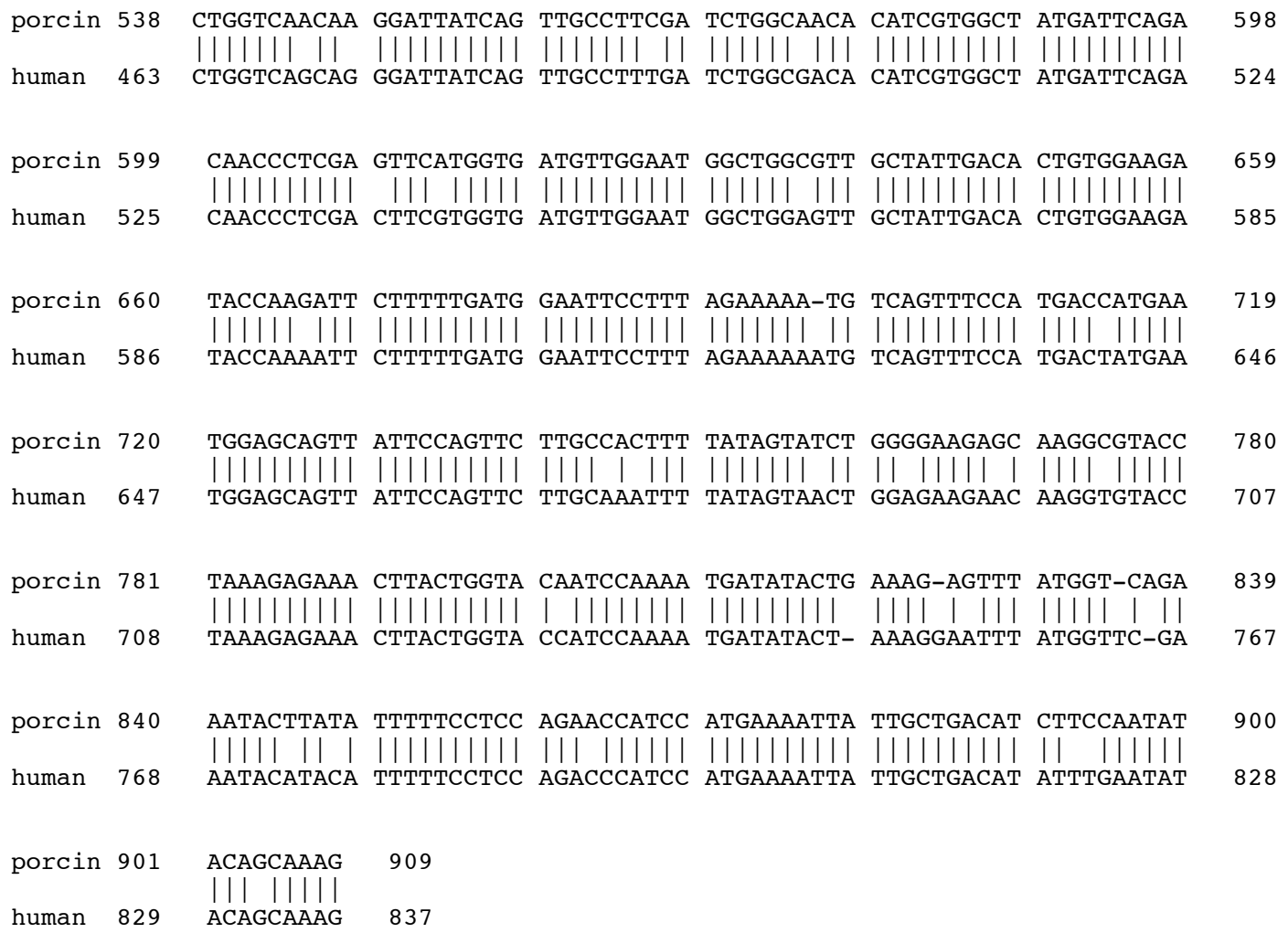

Abb. 5-52 Homologievergleich des porcinen und humanen des Exons 3 (92,80 \%)

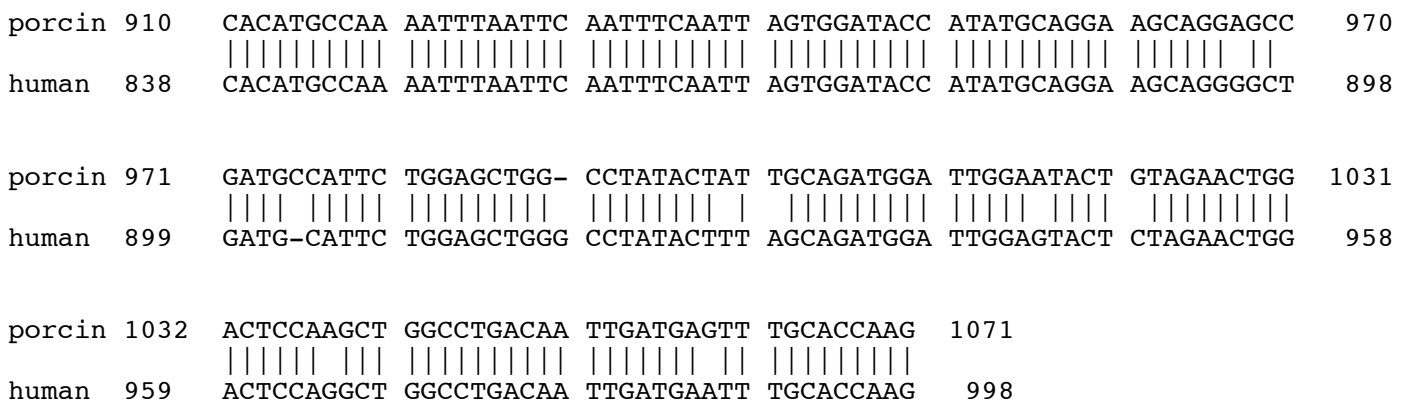

Abb. 5-53Homologievergleich des porcinen und humanen Exons 4 (93,87 \%) 


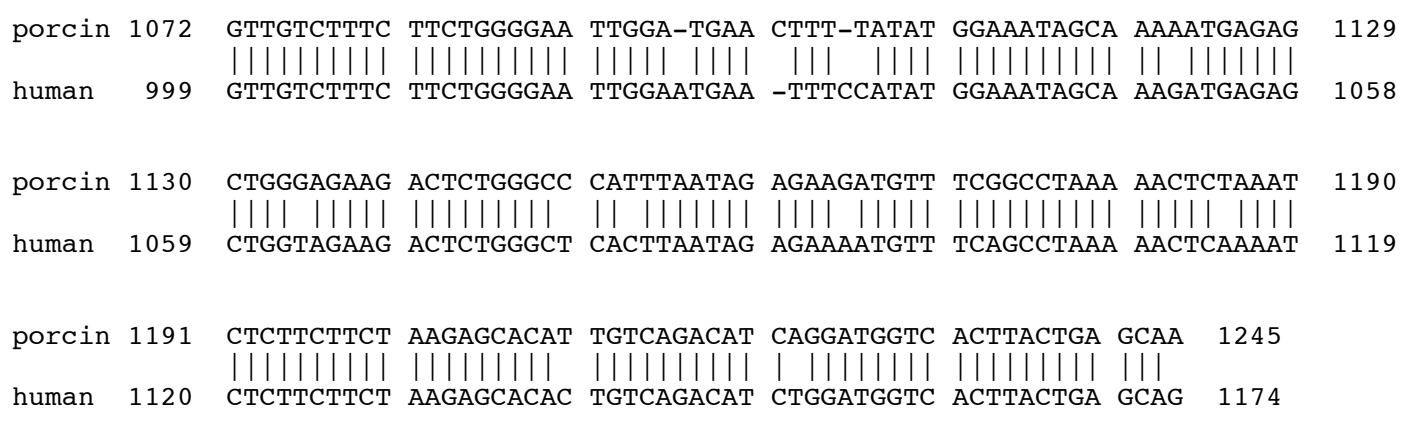

Abb. 5-54Homologievergleich des porcinen und humanen Exons 5 (91,91\%)

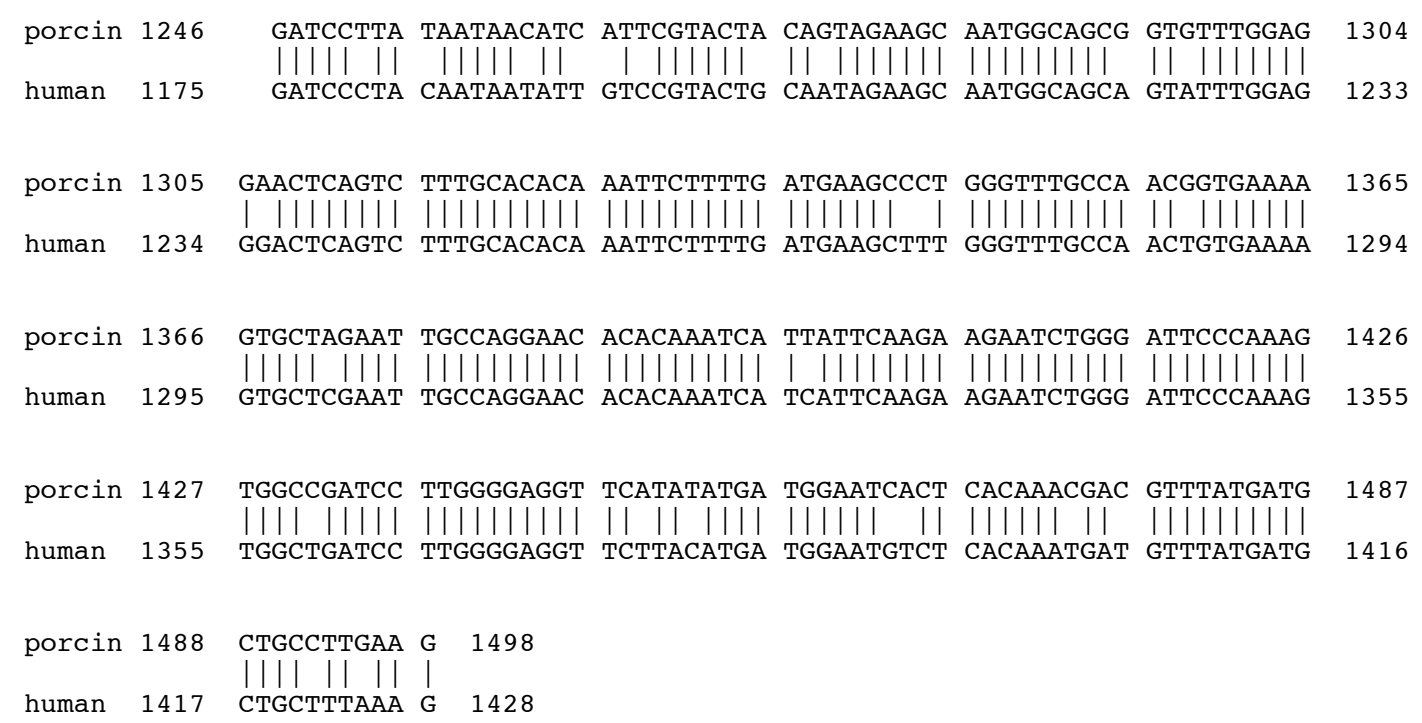

Abb. 5-55 Homologievergleich des porcinen und humanen Exons 6 (92, 89 \%)

Die Abb. 5-51 bis 5-54 zeigen Homologievergleiche zwischen der porcinen und humanen Nukleotidsequenz des dritten, vierten, fünften und sechsten Exons. Die Nummerierung am Rand gibt die jeweilige Nukleotidposition innerhalb der cDNA an, gerade Striche (|) markieren jene Positionen, die bei Schwein und Mensch identisch sind.

\subsubsection{Identifizierung von Polymorphismen innerhalb des porcinen mut-Locus}

Zur Untersuchung möglicher Polymorphismen innerhalb codierender Bereiche des Gens wurden aus der durch Klonierung und Sequenzierung des PAC A3F11 erhaltenen Sequenzinformationen geeignete Primer zur Exon-Amplifikation abgeleitet. Die einzelnen Primer erhielten jeweils an ihrem 5'-Ende zusätzlich die Sequenz des M13 (-20) forward Primers und M13 reverse Primers. Die Sequenzen der Primer sind im Anhang in Tabelle 81 zu finden. Durch direkte Sequenzierung beider Stränge der Amplifikate konnten diese vollständig doppelsträngig sequenziert werden. Das erste, untranslatierte Exon wurde nicht in diese Analyse miteinbezogen. Die genomische DNA von insgesamt 30 Tieren 
unterschiedlichen Geschlechts und unterschiedlicher Rassen diente als Matrize für die Amplifikation der Exons zwei bis sechs. Alle entstandenen PCR-Produkte wurden auf ein 1,5 \%iges Agarosegel aufgetragen. Die Banden wurden ausgeschnitten und die DNA mittels QIAEX II aus dem Gel eluiert und sequenziert. Die Amplifikate der Exons 2, 4 , 5 und 6 zeigten keine Sequenzunterschiede innerhalb der untersuchten Population. Die Amplifikation des Exons 3 konnte zunächst bei einem Großteil der Tiere nicht sequenziert werden. Bei nochmaligem Auftrag eines zehntel Volumens des PCR-Ansatztes auf ein 1,8\%iges Agarosegel konnte festgestellt werden, daß die Amplifikation des Exons 3 bei diesen Tieren zwei unterschiedlich lange, auf dem Agarosegel unterscheidbare Banden erzeugte. Dabei zeigte sich auch, daß der Polymorphismus unabhängig von der Rasse häufig vorkommt. Bei den 30 untersuchten Tieren hatten 22 je zwei unterschiedlich lange Allele, 9 von ihnen waren homozygot für das längere der beiden Allele. Es konnten keine Tiere gefunden werden, die für das kürzere Allel homozygot waren. Da die Banden nicht getrennt ausgeschnitten werden konnten, und deshalb nur das längere der beiden Allele sequenziert werden konnte, war zunächst nicht klar, auf welchen Sequenzbereich der Längenpolymorphismus zurückzuführen ist. Da die verwendeten Primer nur jeweils 28 (der forward Primer) und 9 bp (der revers Primer) vom Exon selbst entfernt sind, und eine Längenvariation innerhalb des Exons unwahrscheinlich ist, lag die Vermutung nahe, daß möglicherweise ein unmittelbar vor dem Exon gelegener Repeat bei den kürzeren Varianten fehlt. Um zu verifizieren, ob der Längenpolymorphismus tatsächlich auf den stromaufwärts gelegenen Bereich des Exons zurückzuführen ist, wurde eine zweite PCR durchgeführt. Dabei blieb der reverse Primer gleich, als forward Primer wurde ein Oligonukleotid aus dem Exon gewählt. Die PCR wurde an den gleichen Tieren durchgeführt. Es zeigte sich in allen Tieren nur noch eine Bande. Abbildung 5-56 zeigt den Längenpolymorphismus und die Sequenz des untersuchten Bereiches.

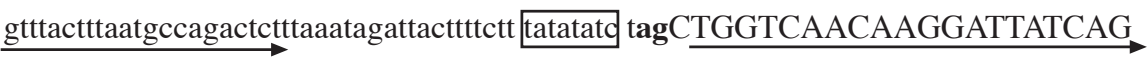

mutEx3for mutEx3for2

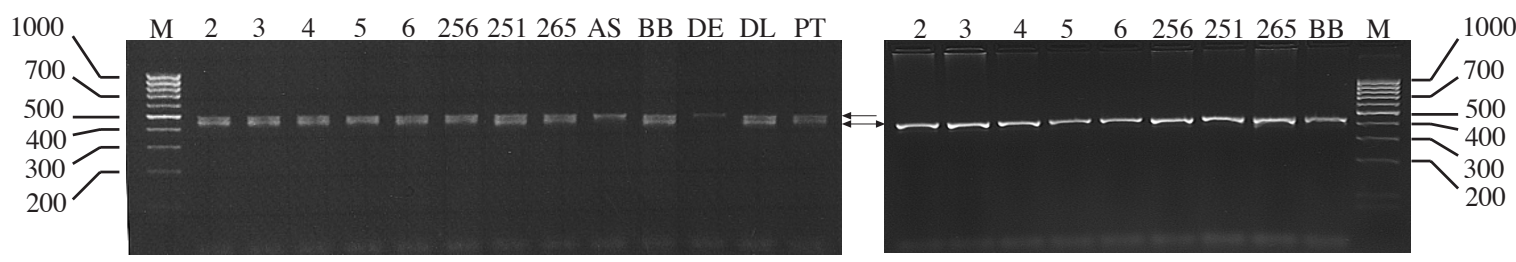

Abb. 5-56 Darstellung des Längenpolymrphismus im Bereich des Exons 3

Die Abbildung zeigt exemplarisch die Auftrennung der PCR-Amplifikate auf einem 1,8\%igen Agarosegel anhand von 13 bzw. 9 beliebig ausgewählter Tieren. AS bezeichnet ein Tier der Rasse Angler Sattelschwein, BB steht für Bunte Bentheimer, DE für Deutsches Edelschwein, DL für Deutsche Landrasse und PT für Piétrain. Als Marker (M) wurde jeweils eine 100 bp-Leiter aufgetragen. Die Pfeile markieren die beiden unterschiedlich langen Allele. Der obere Teil der Abbildung zeigt die Sequenz in dem untersuchten Bereich mit den Oligonukleotiden mut Ex3for und mut Ex3for2. Wie im rechten gezeigten Gel zu sehen, entstand aus der PCR mit dem Primer mut Ex3for2 bei allen Tieren nur eine Bande. 
Neben diesem Längenpolymorphismus im 5'-Bereich des Exons 3 beinhaltet der PACKlon A3F11 vier verschiedene Mikrosatelliten, das heißt Abschnitte mit sich häufig wiederholenden, kurzen (meist zwei) Nukleotidabfolgen. Mikrosatellit 1 befindet sich im ersten Intron des mut-Gens und stellt eine Abfolge von 17 Wiederholungen des Dinukleotids GT dar. Der Mikrosatellit erwies sich innerhalb einer Population von 79 Individuen als monomorph. Zur Amplifikation dieses Mikrosatelliten wurden die Primer MMCM-MS-1.1 und MMCM-MS-1.2 verwendet. Die Primersequenzen sind im Anhang unter Tabelle 8-1 zu finden. Mikrosatellit 2, eine Abfolge von (AT) $)_{3}$ ACATAC (AT) 8 , erwies sich als polymorpher, informativer Marker. Dieser Mikrosatellit befindet sich im zweiten Intron des Gens [87]. Abbildung 5-57 zeigt exemplarisch den Längenpolymorphismus von 6 Tieren der Rasse Pietrain. Anhand der Allelfrenzen der 11 gefundenen Allele wurde ein Heterozygotiegrad von 82,24 \% und ein PIC-Wert (polymorphism information content) von 0,8045 berechnet. Die Allelgrößen und Frequenzen sind in Tabelle 5-5 angegeben. Zur Amplifikation des MikrosatellitenBereiches wurden die Primer MMCM-MS-2.1 und MMCM-MS2.2 verwendet. Die Primersequenzen sind im Anhang in Tabelle 8-1 zu finden. Der Sequenzbereich dieses Mikrosatelliten wurde in die EMBL nucleotide sequence database eingegeben und erhielt die Accession \# Hx957939967.

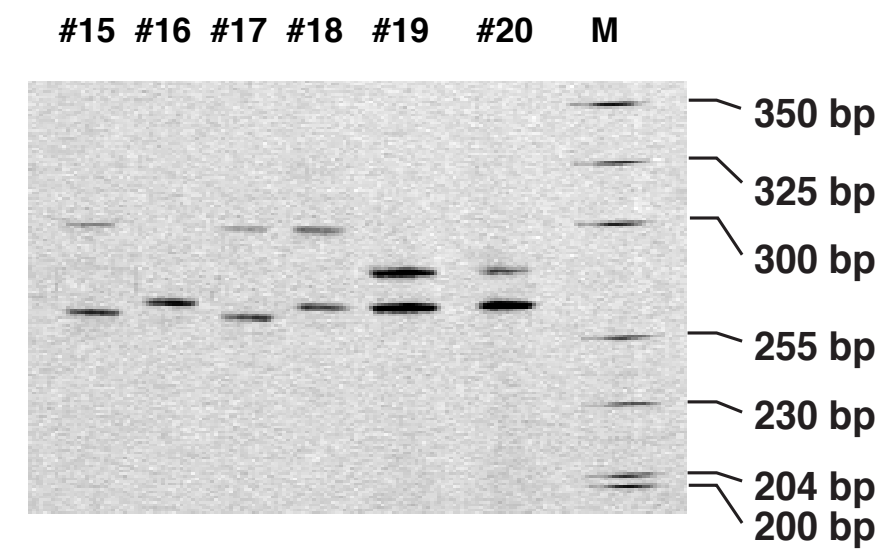

Abb. 5-57 Darstellung von vier unterschiedlich langer Allele des Mikrosatelliten 2 in einer Auswahl von PietrainSchweinen

Die gezeigten Allele wurden auf einem 8\%igen Polyacrylamidgel aufgetrennt und ihre Länge von 288, 274, 264 und 262 bp mit Hilfe der Software RFLPscan Plus 3.0 bestimmt 


\begin{tabular}{llll}
\hline Allel & Länge (bp) & Häufigkeit & Allelfrequenz \\
\hline 1 & 288 & 7 & 0,06087 \\
2 & 286 & 7 & 0,06087 \\
3 & 282 & 4 & 0,03478 \\
4 & 280 & 4 & 0,03478 \\
5 & 276 & 6 & 0,05217 \\
6 & 274 & 23 & 0,20000 \\
7 & 270 & 8 & 0,06957 \\
8 & 268 & 4 & 0,03478 \\
9 & 264 & 3 & 0,02609 \\
10 & 262 & 38 & 0,33043 \\
11 & 250 & 11 & 0,09565 \\
\hline
\end{tabular}

Mikrosatellit 3 mit folgender Abfolge $(\mathrm{GT})_{5}(\mathrm{AT})_{6}(\mathrm{GT})_{5}$ und Mikrosatellit 4, eine Abfolge $(\mathrm{AT})_{3}$ ACATAC $(\mathrm{GT})_{8}$, wurde nicht auf Polymorphismus untersucht.

\subsubsection{Gesamtanalyse des 68 kb großen PAC-Klones A3F11}

Neben diesen codierenden und potentiell informativen, nicht-codierenden Sequenzen enthielt der PAC A3F11 insgesamt 50 sogenannte porcine repetitive Elemente (PRE). Diese Sequenzbereiche gehören zur Gruppe der SINE-Sequenzen (short interspersed nuclear elements). Die Sequenzen dieser PRE sind verglichen mit der SSPRE 1 Konsensussequenz unterschiedlich stark konserviert. Aufgrund dieses Konservierungsgrades ließen sich die in A3F11 gefundenen PRE grob in zwei Kategorien einteilen. 29 PRE waren zu mindestens $80 \%$ mit der Konsensussequenz identisch, die restlichen 21 zeigten nur eine Übereinstimmung von 46 - 70 \%. Die PRE des PAC-Klones A3F11 wurden zusammen mit den weiteren im Rahmen dieser Untersuchung gefundenen porcinen SINE- Sequenzen analysiert. In Tabelle 5-6 sind zusammenfassend die Subklone des PAC A3F11 mit ihren Sequenzcharakteristika aufgeführt. 
Tab. 5-6 Überblicksdarstellung der Subklone des PAC A3F11

\begin{tabular}{|c|c|c|}
\hline Subklone & Größe (bp) & Charakteristika \\
\hline F11E1 & 1.501 & \\
\hline F11E3 & 4.752 & \\
\hline F11E4 & 5.564 & mut Exon 2 und Exon 3, 4 PRE in 5'-3'-Richtung, Mikrosatellit 1: $(\mathrm{GT})_{17}$, nicht polymorph \\
\hline F11E6 & 7.612 & 1 PRE in $5^{\prime}-3^{\prime}$-Richtung, 2 PRE in $3^{\prime}-5^{\prime}$-Richtung, Mikrosatellit 4: $(\mathrm{AT})_{3}$ ACATAC $(\mathrm{GT})_{8}$ \\
\hline F11 P4 & 1.807 & 1 PRE in $3{ }^{\prime}-5^{\prime}$-Richtung \\
\hline F11P5 & 2.012 & 1 PRE in $3^{\prime}-5^{\prime}$-Richtung \\
\hline F11P7 & 1.160 & 1 PRE in $5^{\prime}-3^{\prime}$-Richtung \\
\hline F11P10 & 3.074 & Mikrosatellit 4: $(\mathrm{AT})_{3}$ ACATAC $(\mathrm{GT})_{8}$ \\
\hline F11P11 & 3.799 & $\begin{array}{l}\text { mut Exon } 2 \text { und ein Teil des Exons 3, Mikrosatellit 1: }(\mathrm{GT})_{17} \text {, nicht polymorph } \\
4 \text { PRE in } 5^{\prime}-3^{\prime} \text {-Richtung, eines davon unvollständig auf dem Klon }\end{array}$ \\
\hline F11P12 & 4.042 & $\begin{array}{l}\text { mut Exon 6, SP6-Rand des PAC-Klones } \\
1 \text { PRE in } 5^{\prime}-3^{\prime} \text {-Richtung, } 4 \text { PRE in } 3^{\prime}-5^{\prime} \text {-Richtung, eines davon unvollständig auf dem Klon }\end{array}$ \\
\hline F11P13 & 4.568 & $\begin{array}{l}3 \text { PRE in } 5^{\prime}-3^{\prime} \text {-Richtung, eines davon unvollständig auf dem Klon } \\
4 \text { Pre in } 3^{\prime}-5^{\prime} \text {-Richtung, eines davon unvollständig auf dem Klon }\end{array}$ \\
\hline F11P14 & 4.691 & $2 \mathrm{PRE}$ in $3^{\prime}-5^{\prime}$-Richtung \\
\hline F11P15 & 5.124 & 2 PRE in $5^{\prime}-3^{\prime}$-Richtung, 2 PRE in $3^{\prime}-5^{\prime}$-Richtung \\
\hline F11P16 & 7.589 & $\begin{array}{l}\text { mut Exon } 1 \\
3 \text { PRE in } 5^{\prime}-3^{\prime} \text {-Richtung, } 2 \text { PRE in } 3^{\prime}-5^{\prime} \text {-Richtung }\end{array}$ \\
\hline F11B1 & 872 & 1 Pre in $3^{\prime}-5^{\prime}$-Richtung \\
\hline F11B2 & 1.228 & $1 \mathrm{PRE}$ in $5^{\prime}-3^{\prime}$-Richtung \\
\hline F11B3 & 1.322 & $\begin{array}{l}\text { mut Exon } 6 \\
\text { Teil eines PRE in } 3^{\prime}-5^{\prime}-\text { Richtung }\end{array}$ \\
\hline F11B4 & 1.412 & 2 PRE in $3^{\prime}-5^{\prime}$-Richtung, eines davon unvollständig auf dem Klon \\
\hline F11B5 & 1.457 & 3 PRE in $5^{\prime}-3^{\prime}$-Richtung, 1 PRE in $3^{\prime}-5^{\prime}$-Richtung \\
\hline F11B6 & 1.553 & $\begin{array}{l}\text { mut Exon } 5 \\
1 \text { PRE in } 5^{\prime}-3^{\prime} \text {-Richtung, } 1 \text { PRE in } 3^{\prime}-5^{\prime} \text {-Richtung }\end{array}$ \\
\hline F11B7 & 1.628 & 2 PRE in $5^{\prime}-3^{\prime}$-Richtung, eines davon unvollständig auf dem Klon, 1 PRE in $3^{\prime}-5^{\prime}$-Richtung \\
\hline F11B8 & 905 & \\
\hline F11B10 & 2.023 & 3 PRE in $5^{\prime}-3^{\prime}$-Richtung, eines davon unvollständig auf dem Klon, 2 PRE in $3^{\prime}-5^{\prime}$-Richtung \\
\hline F11B11 & 2.074 & $\begin{array}{l}2 \text { PRE in } 5^{\prime}-3^{\prime} \text {-Richtung unvollständig auf dem Klon } \\
\text { Mikrosatellit } 2:(\mathrm{AT})_{3} \text { ACATAC }(\mathrm{AT})_{8}\end{array}$ \\
\hline F11B13 & 2.538 & $1 \mathrm{PRE}$ in $5^{\prime}-3^{\prime}$-Richtung unvollständig auf dem Klon, 1 PRE in $3^{\prime}-5^{\prime}$-Richtung \\
\hline F11B14 & 2.941 & 1 PRE in $3^{\prime}-5^{\prime}$-Richtung \\
\hline F11B15 & 3.475 & $1 \mathrm{PRE}$ in $5^{\prime}-3^{\prime}$-Richtung unvollständig auf dem Klon \\
\hline F11B16 & 3.363 & 2 PRE in $3^{\prime}-5^{\prime}$-Richtung eines davon unvollständig auf dem Klon \\
\hline F11B17 & 4.011 & 2 PRE in $5^{\prime}-3^{\prime}$-Richtung, eines davon unvollständig auf dem Klon, 1 PRE in $3^{\prime}-5^{\prime}$-Richtung \\
\hline F11B18 & 2.367 & \\
\hline F11B20 & 6.059 & $\begin{array}{l}2 \text { PRE in } 3^{\prime}-5^{\prime}-\text {-Richtung, eines davon unvollständig auf dem Klon } \\
\text { Mikrosatellit } 4:(\mathrm{AT})_{3} \text { ACATAC }(\mathrm{GT})_{8}\end{array}$ \\
\hline F11B21 & 7.256 & 1 PRE in $5^{\prime}-3^{\prime}$-Richtung, 2 PRE in $3^{\prime}-5^{\prime}$-Richtung \\
\hline F11X1 & 1.140 & 1 PRE in $3^{\prime}-5^{\prime}$-Richtung \\
\hline $\mathrm{F} 11 \mathrm{X} 2$ & 1.323 & $\begin{array}{l}1 \text { PRE in } 5^{\prime}-3^{\prime} \text {-Richtung } \\
\text { Mikrosatellit } 3:(\mathrm{GT})_{5}(\mathrm{AT})_{6}(\mathrm{GT})_{5}\end{array}$ \\
\hline F11X3 & 1.890 & 1 PRE in $3^{\prime}-5^{\prime}$-Richtung \\
\hline $\mathrm{F} 11 \mathrm{X} 4$ & 2.367 & 1 PRE in $5^{\prime}-3^{\prime}$-Richtung \\
\hline F11X5 & 3.084 & 1 PRE in $3^{\prime}-5^{\prime}$-Richtung \\
\hline F11X6 & 3.296 & 1 PRE in $5^{\prime}-3^{\prime}$-Richtung \\
\hline $\mathrm{F} 11 \mathrm{X} 7$ & 4.010 & $\begin{array}{l}1 \text { PRE in } 5^{\prime}-3^{\prime} \text {-Richtung, } 1 \text { PRE in } 3^{\prime}-5^{\prime} \text {-Richtung } \\
\text { Mikrosatellit 4: }(\mathrm{AT})_{3} \text { ACATAC }(\mathrm{GT})_{8} \text {, }\end{array}$ \\
\hline $\mathrm{F} 11 \mathrm{X} 8$ & 5.674 & 3 PRE in $5^{\prime}-3^{\prime}$-Richtung, 2 PRE in $3^{\prime}-5^{\prime}$-Richtung \\
\hline F11Sc1 & 1.661 & \\
\hline $\mathrm{F} 11 \mathrm{Sc} 2$ & 3.160 & 1 PRE in $3^{\prime}-5^{\prime}$-Richtung \\
\hline F11Sc3 & 7.532 & $\begin{array}{l}2 \text { PRE in } 5^{\prime}-3^{\prime}-\text { Richtung } \\
2 \text { PRE in } 3^{\prime}-5^{\prime} \text {-Richtung }\end{array}$ \\
\hline F11Sc4 & 4.938 & 4 PRE in $5^{\prime}-3^{\prime}$-Richtung, 2 PRE in $3^{\prime}-5^{\prime}$ Richtung \\
\hline F11Sc5 & 5.392 & $1 \mathrm{PRE}$ in $5^{\prime}-3^{\prime}$-Richtung, 3 PRE in $3^{\prime}-5^{\prime}$-Richtung \\
\hline F11Sc6 & 6.284 & $\begin{array}{l}4 \text { PRE in } 5^{\prime}-3^{\prime} \text {-Richtung, } 3 \text { PRE in } 3^{\prime}-5^{\prime} \text {-Richtung } \\
\text { Mikrosatellit 3: }(\mathrm{GT})_{5}(\mathrm{AT})_{6}(\mathrm{GT})_{5}\end{array}$ \\
\hline
\end{tabular}


Für die gesamte Sequenz wurde mittels BLAST nach weiteren Sequenzmotiven, insbesondere nach weiteren codierenden Bereichen gesucht. Darüberhinaus wurde eine Analyse mittels Genscan durchgeführt. Für die, neben den mut-Exons potentiell codierenden Regionen, die durch das Programm Genscan ermittelt wurden, konnten keine homologen Sequenzen in der Datenbank gefunden werden. Wie in Abbildung 5-58 zu erkennen, befinden sich die weiteren, durch das Programm kartieren Exons in den meisten Fällen innerhalb von Regionen in denen mehrere PR-Elemente in unterschiedlicher Orientierung vorliegen.

\subsubsection{Chromosomale Lokalisation des porcinen Mehtylmalony-CoA-Mutase-Gens}

Die chromosomale Lokalisation des porcinen mut-Gens erfolge mittels Fluoreszenz in situ Hybridisierung. Die in situ Hybridisierung wurde von Herrn Dr. Günther Rettenberger (Labor für Cytogenetik und Genetische Beratung, Neu-Ulm) durchgeführt. Als Sonde diente hierzu der PAC-Klon A3F11. Abbildung 5-67 zeigt das deutlich erkennbare Signal in einer Metaphasepräparation porciner Chromosomen. Damit wurde das porcine mut-Gen auf Chromosom 1q13 - q14 lokalisiert.

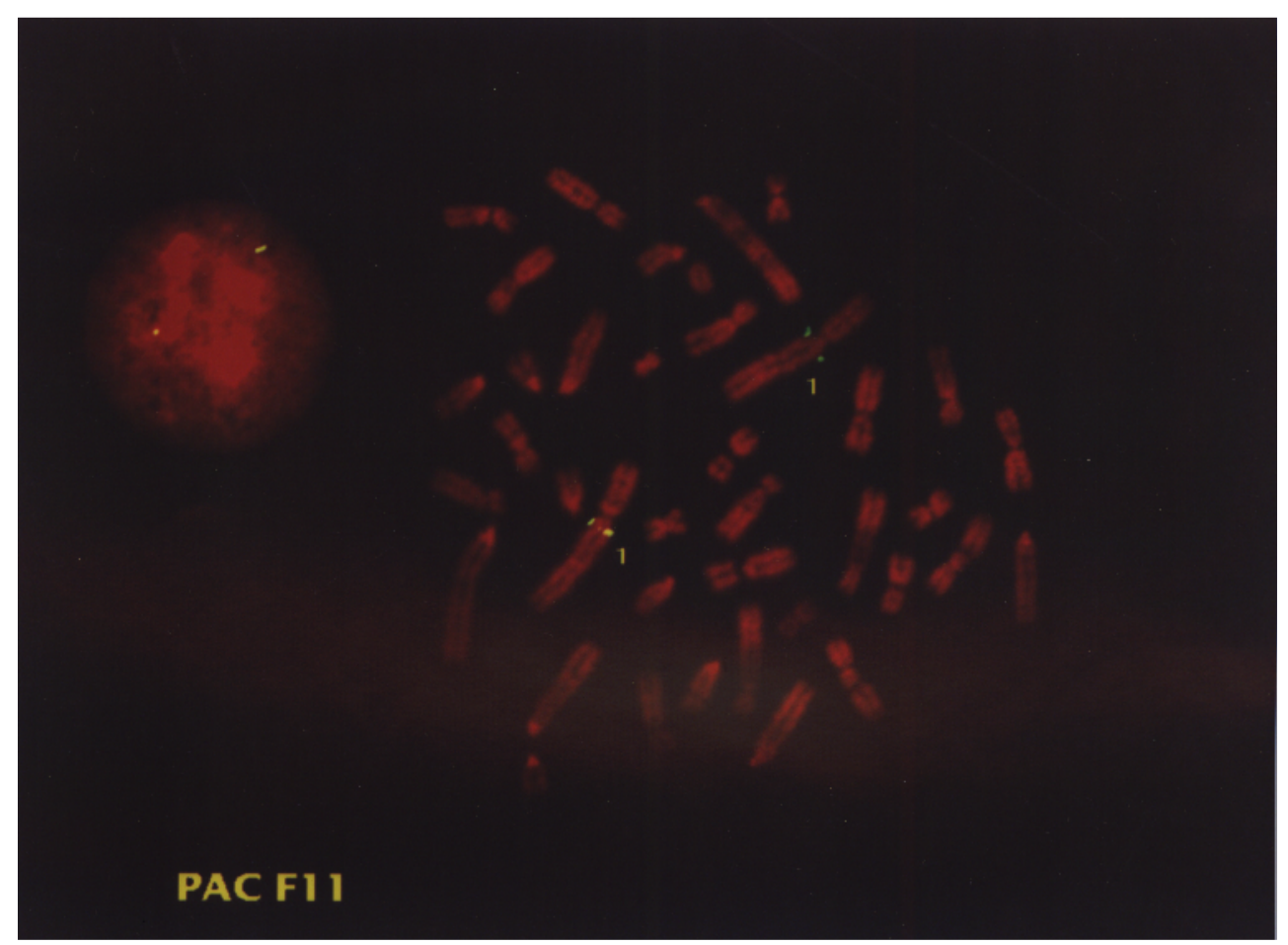

Abb. 5-57 FISH-Analyse zur Lokalisation des porcinen $m u t$-Gens 

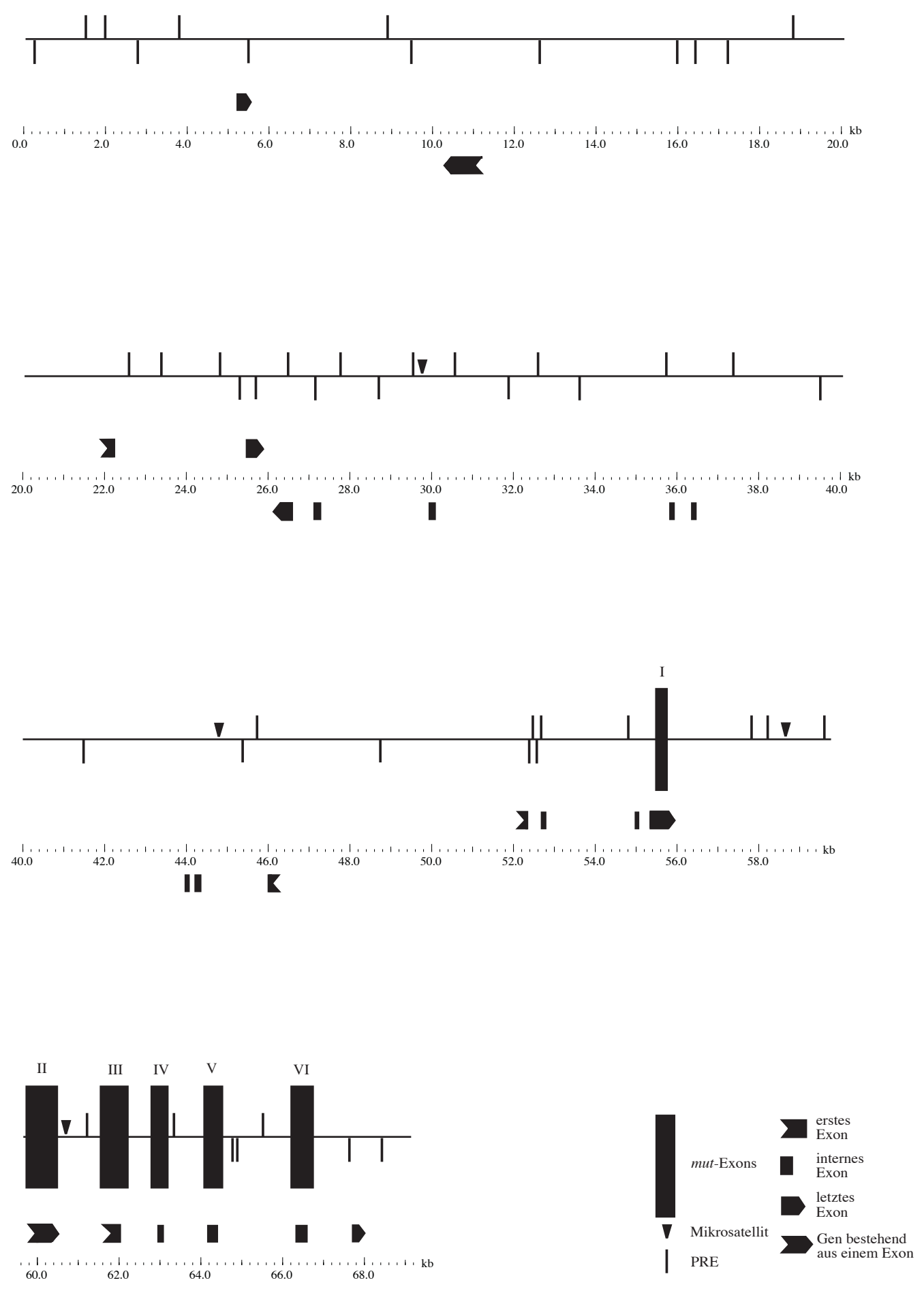

Abb. 5-58 Schematische Darstellung der ermittelten Sequenzcharakteristika und der Genscan-Analyse der PAC A3F11

Auf dem PAC-Klon A3F11 konnten die Exons 1 bis 6 des porcinen mut-Gens kartiert werden. Diese sind als schwarze Rechtecke entlang der oberen Linie eingezeichnet. Ebenso sind die Mikrosatelliten und die gefundenen PR-Elemente eingezeichnet. Die kleinen oberhalb und unterhalb des kb-Lineals dargestellten Symbole zeigen die mittels Genscan ermittelten codierenden Regionen. Das Programm unterscheidet dabei, wie in der Legende dargestellt, erstes, internes oder letztes Exon, sowie Gene, die aus einem einzelnen Exon bestehen. Symbole oberhalb des Lineals markieren Exons die in $+/+$ Orientierung liegen, Symbole unterhalb des Lineals markieren Exons in +/- Richtung zur dargestellten PACSequenz. Alle 6 Exons wurden auch vom Programm Genscan an gleicher Position und in gleicher Orientierung kartiert. 


\subsubsection{Identifizierung weiterer PAC-Klone}

Da der PAC A3F11 nur die ersten sechs Exons des porcinen mut-Gens beinhaltete, wurde nochmals die PAC-Genbank durchsucht. Die Durchmusterung mittels PCR mit dem Primerpaar mut Ex3.1-for und mut Ex3.1-rev hatte noch einige andere positive Signale ergeben, sodaß angenommen werden konnte, daß einer dieser PAC-Klone das gesamte Gen enthält. Die zweite Durchmusterung der porcinen PAC-Genbank wurde mit Primern durchgeführt, die aus dem Exon 13 des humanen mut-Gens abgeleitet wurden. Die Primersequenzen der Oligonukleotide MMCM 13.1 und MMCM 13.2 sind im Anhang in Tabelle 8-1 zu finden. Da die Signale dieser PCR sehr schwach waren, wurde die PCR nur auf jenen Pools durchgeführt, die bereits mit dem Primerpaar mut Ex3.1-for und mut Ex3.1-rev positive Signale ergeben hatten. Diese Durchmusterung führte zur Identifizierung eines Klones auf Platte A13 an Position B5. Die DNA dieses Klons wurde isoliert und mit den Restriktionsenzymen EcoRI, SacI, BamHI, XbaI, PstI und HindIII geschnitten und auf ein 0,8\%iges Agaraosegel aufgetragen. Aus dem Spaltungsmuster war zu erkennen, daß es sich tatsächlich um einen Klon handelte, der nicht mit dem Klon A3F11 identisch ist. Das Ergebnis der PCR konnte auf der isolierten PAC-DNA wiederholt werden, eine Southern Blot Hybridisierung mit dem Amplifikat aus MMCM 13.1 und MMCM 13.2 verlief jedoch negativ. Daraufhin wurden zunächst die Ränder des PACKlones ansequenziert. Mit der erhaltene Sequenz wurde mittels BLAST die Datenbank durchsucht. Dabei zeigte sich Übereinstimmungen mit einem humanen PAC-Klon, der auf Hsap 6p21 - 21.31 lokalisiert worden war. Da dies der Lokalisation des humane mut-Gens entspricht wurden vom PAC-Klon A13B5 mehrere Suklone angefertigt. Um jene Subklone $\mathrm{zu}$ identifizieren, die codierende Bereiche des mut-Gens enthalten, wurde eine Southern Blot Analyse durchgeführt. Zu diesem Zeitpunkt stand noch keine Sequenzinformation der porcinen cDNA zur Verfügung. Da das PCR-Amplifikat aus dem Exon 13 kein Signal erzeugt hatte, wurden die Oligonukleotide MMCM 7.2 und MMCM 8.2 aus dem 7. und 8. Exon des humanen Gens als Hybridisierungssonden verwendet. Dabei wurde die Membran mit niedriger Stringenz gewaschen. Der Klon A13B5 zeigte mit beiden Sonden ein positives Signal. Abbildung 5-58 zeigt das Ergebnis einer Kontrollhybridisierung der ersten erstellten Subklonen dieses PAC-Klones. 


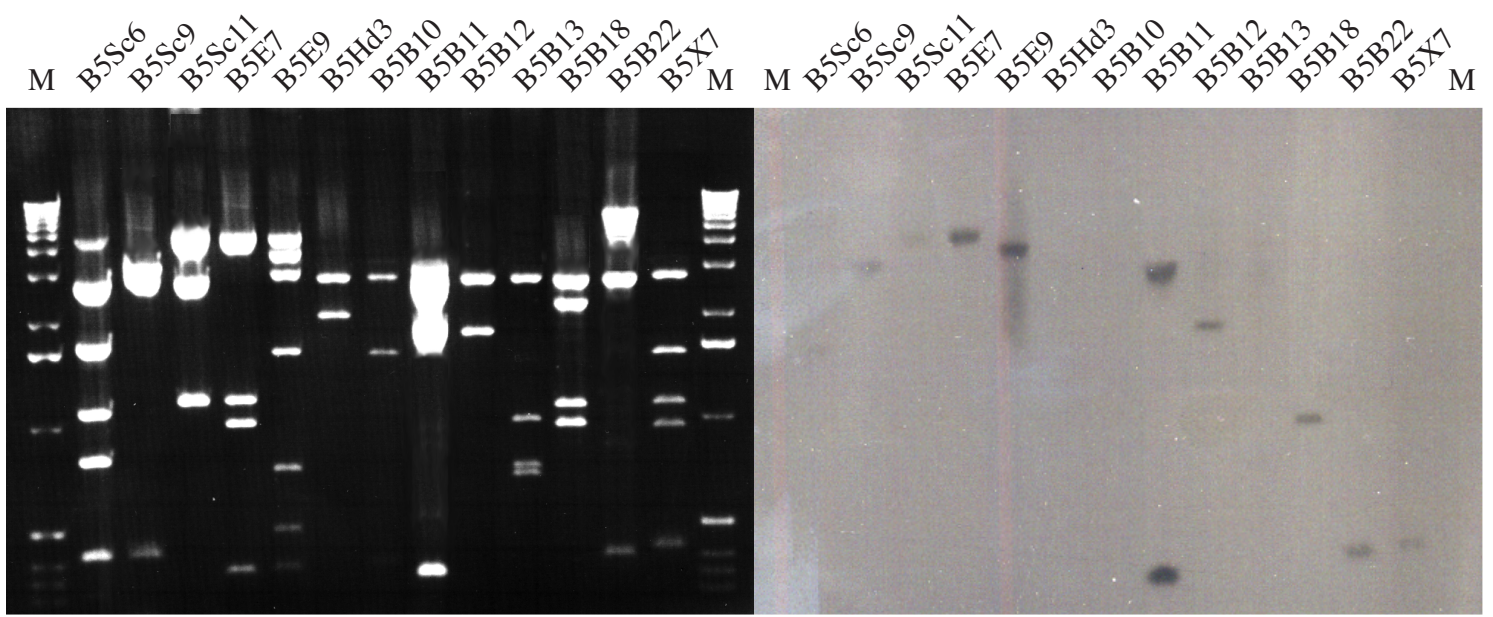

Abb. 5-58 Southern Blot Hybridisierung ausgewählter Subklone des PAC A13B5

Der linke Teil der Abbildung zeigt der Restriktionsspaltung mit den Enzymen EcoRI und HindIII ausgewählter Subkone des PAC A13B5. Als Marker (M) wurde eine 1kb-Leiter aufgetragen, die Bezeichnung der Klone sind jeweils oberhalb der einzelnen Spuren aufgeführt. Der rechte Teil zeigt das Ergebnis der Hybridisierung mit dem Oligonukleotid MMCM7.2 nach einer Expositionszeit von 10 Minuten.

Das Hybridisierungsergebnis läßt bereits vermuten, daß die Signale unspezifisch sind. Das siebte Exon kann sich mit einer Größe von 112 bp nicht auf insgesamt vier BamHISubklonen befinden. Nach Analyse der ersten Sequenzdaten interner Bereiche des PACKlones konnte diese Vermutung bestätigt werden. Da die genomische Organisation des mut-Gens bereits bei Mensch und Maus bekannt waren, wurde kein weiterer Versuch gestartet den 3'-Bereich dieses Gens genomisch zu untersuchen. Der Vergleich der genomischen Organisation zwischen Mensch und Maus ließ nur einen wesentlichen Unterschied erkennen, nämlich die Größe des Introns sechs. Im humanen Gen konnte der intronische Bereich zwischen dem 6. und 7. Exon nicht kloniert werden. Dieser Abschnitt wird in der Literatur als ein etwa $10 \mathrm{~kb}$ großer Bereich beschrieben [64]. Das murine Intron sechs hingegen weist nur eine Größe von 4,4 kb auf. Um die Größe dieses Introns im porcinen Gen zu klären wurde eine sogenannte „long distance“ PCR durchführt. Dabei wurden Primer aus dem 6. und 7. Exon verwendet. Als Primer aus dem Exon 6 wurde das bereits in der RT-PCR erfolgreich verwendete Oligonukleotid MMCM3R2 verwendet, aus dem Exon 7 konnte aufgrund der erfolgreich durchgeführten RT-PCR das Oligonukleotid MMCM 7 rev abgeleitet werden. Aus der PCR entstand ein 3.267 bp großes Amplifikat, das in pGEM-4Z einkloniert und sequenziert wurde. Zur vollständigen Sequenzierung dieses Abschnittes wurden darüberhinaus durch Restriktionsspaltung mit dem Enzym EcoRI vier Subklone hergestellt und ebenfalls sequenziert. Damit konnte das Intron 6 im porcinen Methylmalonyl-CoA-Mutase-Gen auf eine Größe von 3.051 bp festgelegt werden und damit die einzige auffallende Variation der genomischen Organisation dieses Gens bei verschiedenen Spezies auch im porcinen Gen geklärt werden. Die Homologie der Nukleotidsequenzen der Exons 7 bis 13 wurde aufgrund der durch RT-PCR erhaltenen Sequenzen ermittelt. Die Abbildungen 5-59 bis 5-64 zeigen die Sequenzvergleiche der 
Exons sieben bis zwölf. Tabelle 5-4 liefert einen zusammenfassenden Überblick über die Exons und Introns des porcinen mut-Gens.

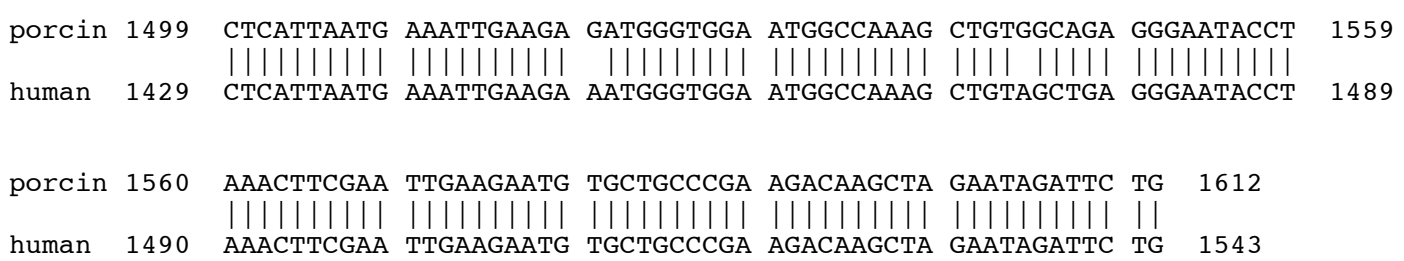

Abb. 5-59 Homologievergleich der porcinen und humanen Nukleotidsequenzen im Bereich des 7. Exons (97,41 \%)

porcin 1613 GTTCTGAAGT AATTGTTGGA GTAAATAAAT ACCAGTTGGA AAAAGAAGAA TCTGTGGAGG

||||||||||||||||||||||||||||||||||||||||||||||| ||||||| human 1544 GTTCTGAAGT AATTGTTGGA GTAAATAAGT ACCAGTTGGA AAAAGAAGAC GCTGTAGAAG 1604

porcin 1674 TTTTGGCAAT TGATAATACT TCAGTGCGCA ACAAGCAGAT tgAAAAACTT AAgAAg 1730

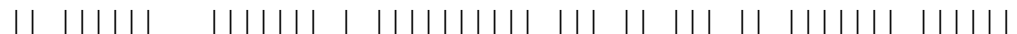

human 1610 TTCTGGCAAC CGATAATACT TCAGTGCGAA ACAGGCAGAT TGGAAAACTT AAGAAG 1666

Abb. 5-60 Homologievergleich der porcinen und humanen Nukleotidsequenz im Bereich des 8. Exons (90,76\%)

porcin 1731 GTCAAGTCCA GCAGGGATCA AGCTTTGGCT GAACGGTGCC TCACTGCCCT CACTGCCTGT

|||| |||| |||||||||| |||||||||||||| || | | |||||||||||||| human 1667 ATCAAATCCA GCAGGGATCA AGCTTTGGCT GAACATTGTC TTGCTGCACT AACCGAATGT 1727

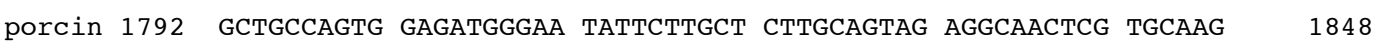
human 1727 GCTGCTAGCG GAGATGGAAA TATCCTGGCT CTTGCAGTGG ATGCATCTCG GGCAAG 1778

Abb. 5-61 Homologievergleich der porcinen und humanen Nukleotidsequenzen im Berich des 9. Exons (90,76\%)

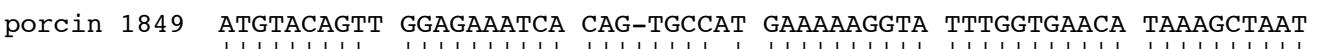

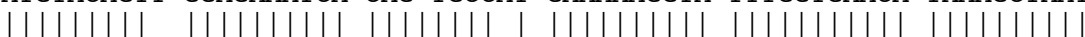

human 1779 ATGTACAGTG GGAGAAATCA CAGATGCCCT GAAAAAGGTA TTTGGTGAACA TAAAGCGAAT 1839

porcin 1910 GATCGTATGg TGAGTGGAGC CTATCGCCAg GAATTTGGAG AAAGTAAAGA GATATCATTTG 1970

||||||||| |||||||||| ||||||||||||||||||||||||||||||||||||||

human 1840 GATCGAATG TGAGTGGAGC ATATCGCCAG GAATATGGAg AAAGTAAAGA GATAACATCTG 1900

porcin 1971 CTATCAAGAG 1980

human 1901 CTATCAAGAG 1911

Abb. 5-62 Homologievergleich der Nukleotidsequenzen des 10. Exons (94,31\%) 
porcin 1981 GGTTCATAAg TTCATGGAAC GTGAAGGTCG CAGACCTCGT CTTCTTGTGG CAAAAATGGG ||||||||| |||||||||||||||||||||| ||||||||||| ||||||||||| |||||||||||

human 1912 GGTTCATAAA TTCATGGAAC GTGAAGGTCG CAGACCTCGT CTTCTTGTAG CAAAAATGGG

porcin 2042 ACAAGATGGA CATGACAGAg GAgCAAAAGT TATTGCTACA GGATTTGCCG ATCTTGGTTT |||||||| |||||||||| |||||||||| |||||||||| |||||||| | |||||||||

human 1973 ACAAGATGGC CATGACAGAG GAGCAAAAGT TATTGCTACA GGATTTGCTG ATCTTGGTTT

porcin 2103 CGATGTGGAT ATTGGTCCTC TTTTTCAG 2111

human 2034 TGATGTGGAC ATAGGCCCTC TTTTCCAG 2062

Abb. 5-63 Homologievergleich der Nukleotidsequenzen des 11. Exons (97,96 \%)

porcin 2112 ACTCCCCGGG AAGTGGCCCA ACAGGCTGTG GATGCAGATG TGCATGCAGT GGGGTGAGCA |||||| | ||||||||| |||||||| ||||| |||| ||||||||| ||| || |

human 2063 ACTCCTCGTG AAGTGGCCCA GCAGGCTGTG GATGCGGATG TGCATGCTGT GGGCGTAAGC 2123

porcin 2173 CACTT-GCT GCGGGGCATA AAACCCTGGT TCCCGAGCTC ATCAAGgAAC TTAGCACCCT || ||| || || |||| ||||||| || ||| || ||| ||||| |||| ||| ||||||

human 2134 TACCCCGCT GCTGGTCATA AAACCCTAGT TCCTGAACTC ATCAAAGAAC TTAACTCCCT

2232

2194

porcin 2233 CGGACGgCCA GATATTCTCG TCATTTGTGG A-GGGTGATA CCACCACAg 2281

human 2195 GTGGACGCCA GATATTCTTG TCATGTGTGg AGgGGTGATA CCACCTCAG 2236

Abb. 5-64 Homologievergleich der Nukleotidsequenzen des 12. Exons (87,41\%)

Tabelle 5-4 Überblick über die kartierten Exons und Intronbereiche des porcinen Methylmalonyl-CoA-Mutase-Gens

\begin{tabular}{|c|c|c|c|c|c|}
\hline $\begin{array}{c}\text { Exon } \\
\text { Nr. }\end{array}$ & Größe (bp) & Intron & Exon & Intron & Introngröße (kb) \\
\hline 1 & 101 & & & gtgagtaaactgtgcgcc & 4,1 \\
\hline 2 & 430 & ttgtgctgctttttctag & atcgg 2 - ttagg & gtgagatttaaatgtgaga & 1,1 \\
\hline 3 & 372 & cttttctttatatatctag & ctggt - 3 - caaag & gtatcctttatggttttgtg & 0,9 \\
\hline 4 & 159 & ttttttattattttatatag & cacat - 4 - ccaag & gtgagtaattaaactcaaat & 1,0 \\
\hline 5 & 172 & cttaatgttactatttcag & gttgt - 5 - agcaa & gtatgtttatcatttaagtg & 2,0 \\
\hline 6 & 249 & ttttactaaatgggttag & gatcc -6 - tgaag & gtttatgatgctgccttgaa & 3,0 \\
\hline 7 & 112 & ttatctgtttttctaatag & ctcatt -7 - ttctg & nicht bekannt & nicht bekannt \\
\hline 8 & 116 & nicht bekannt & gttct - 8 - agaag & $"$ & $"$ \\
\hline 9 & 116 & , & gtcaa - 9 - gcaag & 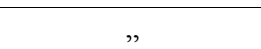 & " \\
\hline 10 & 129 & 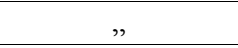 & atgta $-10-$ aagag & 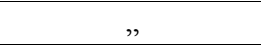 & 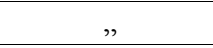 \\
\hline 11 & 148 & , & ggttc $-11-$ ttcag & , & , \\
\hline 12 & 168 & 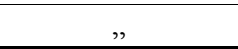 & actcc -12 - cacag & 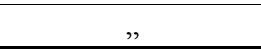 & 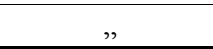 \\
\hline
\end{tabular}




\subsubsection{Shot gun Klonierung des PAC A13B5}

Obwohl der PAC-Klon A13B5 nicht den gesuchten 3'-Bereich des porcinen Methylmalonyl-CoA-Mutase-Gens enthielt erwies er sich doch für die vergleichende Genomanalyse als wertvoll. Aufgrund der zunächst zur Kontrolle sequenzierten PACRänder und einiger Subklone, zeigte die Analyse mittels BLAST über ausgedehnte Bereiche Übereinstimmungen zu einem humanen PAC-Klon. Der humane Klon war auf Chromosom 6 im Bereich p21 - 21.31 kartiert worden und befindet sich damit in einer chromosomalen Region, in der bereits das humane mut-Gen lokalisiert wurde. Die Sequenz des Klones ist in der EMBL nucleotide sequence database unter der Nummer AL049553 zu finden.

Durch eine sogenannte ,shot gun“-Klonierung wurden möglichst viele überlappende Restriktionsfragmente kloniert. Die Sequenzen der erhaltenen Subklone wurden mit Hilfe der Software Sequencher 3.0 zu einem Projekt vereinigt und zu Contigs zusammengefügt. Insgesamt wurden auf diese Weise fünf Contigs erstellt, die den Großteil des gesamten PAC-Klones beinhalten. Abbildung 5-65 zeigt eine Pulsfeldgelelektrophorese die zur Größenbestimmung des PAC-Klones durchgeführt wurde. Dabei wurden $2 \mu \mathrm{g}$ DNA mit 10 Units des Restriktionsenzymes NotI gespalten und 20 Stunden im Pulsfeldgel aufgetrennt. Aus der Summe der Größe der beiden entstandenen Banden wurde die Größe des PACKlones auf etwa $84 \mathrm{~kb}$ festgelegt.
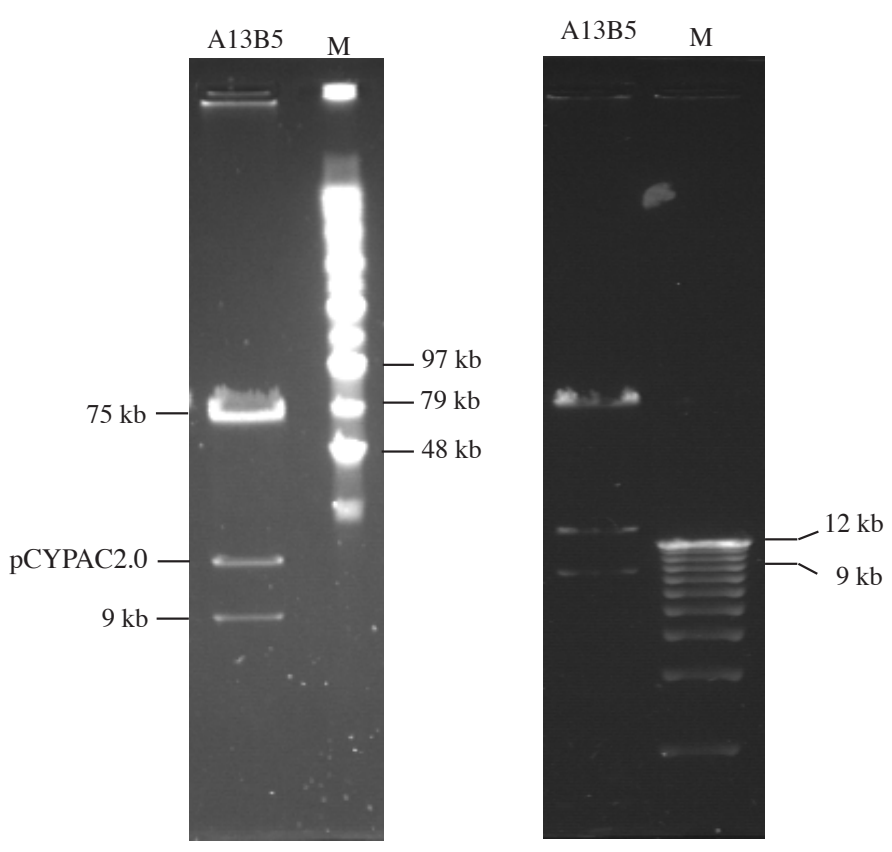

Abb. 5-65 Pulsfeldgelelektrophorese de PAC-Klones A13B5

$\mathrm{Zu}$ sehen sind zwei Ausschnitte einer Pulsfeldgelelektrophorese des PAC-Klones A13B5. Als Marker (M) wurde im linken Bild Mid-Range II, im rechten eine 1-kb-Leiter aufgetragen. Die mittlere Bande stellt den Klonierungsvektor pCYPAC2 mit einer Größe von 18,7 kb dar. 


\subsubsection{Ermittlung der Sequenzcharakteristika}

Aus den Sequenzen der erhaltenen Subklone entstanden neben den zwei Rand-Contigs SP6 und T7 noch drei intern liegende Contigs mit der Bezeichnung B22, SC6 und SC3. Der Rand-Contig SP6 hat eine Größe von 24.269 bp, Contig T7 ist 23.241 bp groß. Die internen Contigs B22, SC6 und SC3 sind 7.095, 21.952 und 3.447 bp groß. Tabelle 5-7 gibt einen zusammenfassenden Überblick über die Subklone und ihre Sequenzcharakteristika. Insgesamt decken die fünf Contigs mit mehr als $80 \mathrm{~kb}$ fast die gesamte Sequenz des Klones ab. Innerhalb der untersuchten Sequenzabschnitte fanden sich 35 PRE. Durch die Analyse der Sequenzen mittels BLAST konnte eine Reihe von homologen Abschnitten gefunden werden. Der Vergleich mit der Sequenz des humanen PAC-Klones AL049553 zeigte mehr als 35 Bereiche, die in jeweils colinearer Abfolge Homologien von über 90\% aufwiesen. Die Suche nach entsprechenden cDNA-Klonen verlief zwar erfolglos, jedoch konnten mehrere EST-Sequenzen gefunden werden. Aufgrund dieser Befunde lassen sich die codierenden Bereiche zwar nicht als Exons kartieren, man kann jedoch davon ausgehen, daß es sich um tatsächlich exprimierte proteincodierende Bereiche handelt. Die Contigs SP6, T7 und SC6 wurden auch einer Genscan-Analyse unterzogen. Wie die Abbildungen 5-66 bis 5-68 zeigen, konnte auch dieses Programm insgesamt 37 potentiell codierende Bereiche festlegen. Die gefundenen PRE wurden ebenfalls in die graphische Darstellung einbezogen. Daraus läßt sich klar erkennen, daß Genscan in einigen Fällen diese SINE-Sequenzen als codierende Bereiche festlegt. 

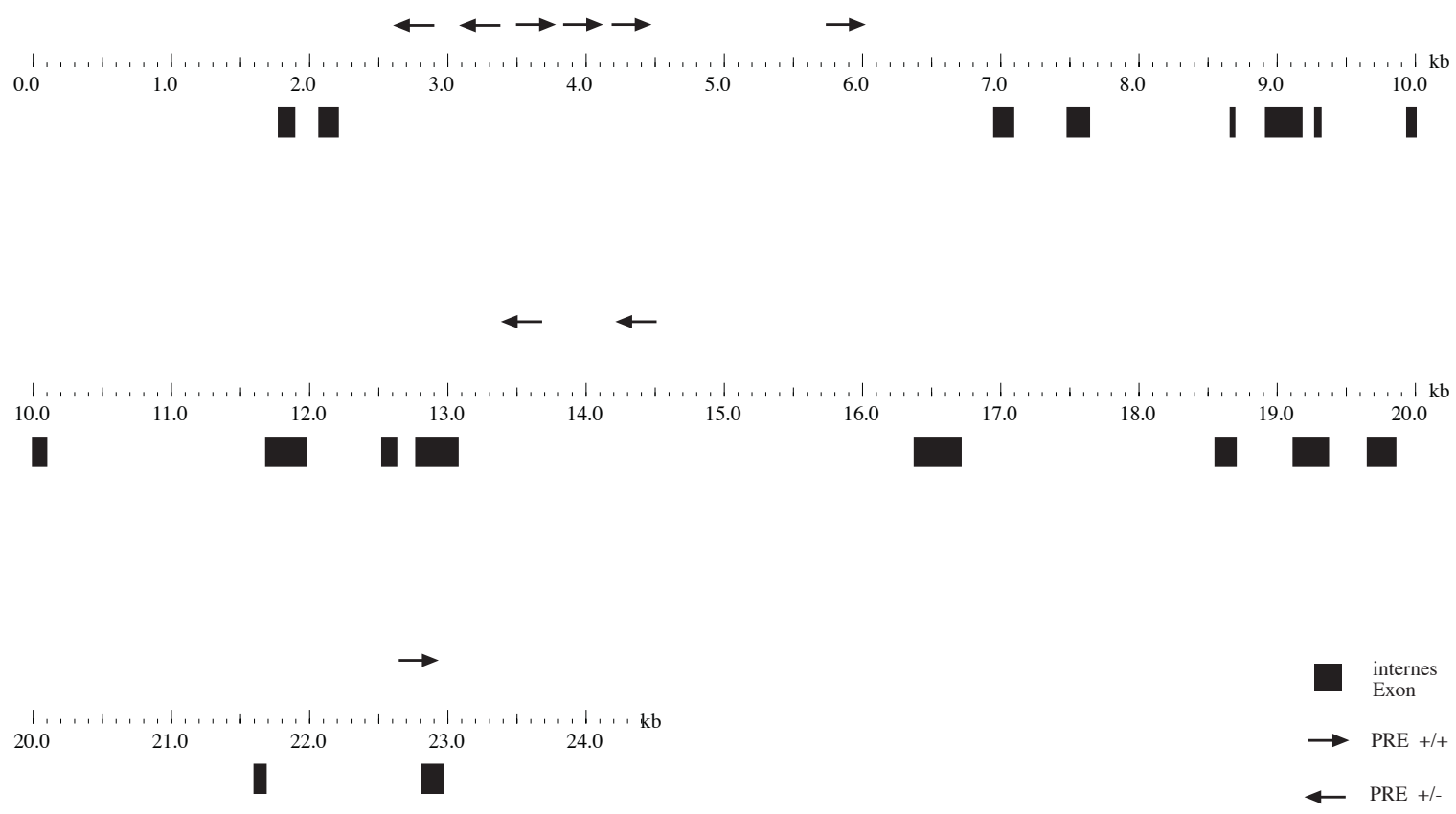

Abb. 5-66 Genscan Analyse des Contigs SP6

Das Programm prognostiziert für diesen Sequenzabschnitt insgesamt 18 interne Exons. Die gefundenen PRE sind als Pfeile oberhalb des kb-Lineals eingezeichnet.
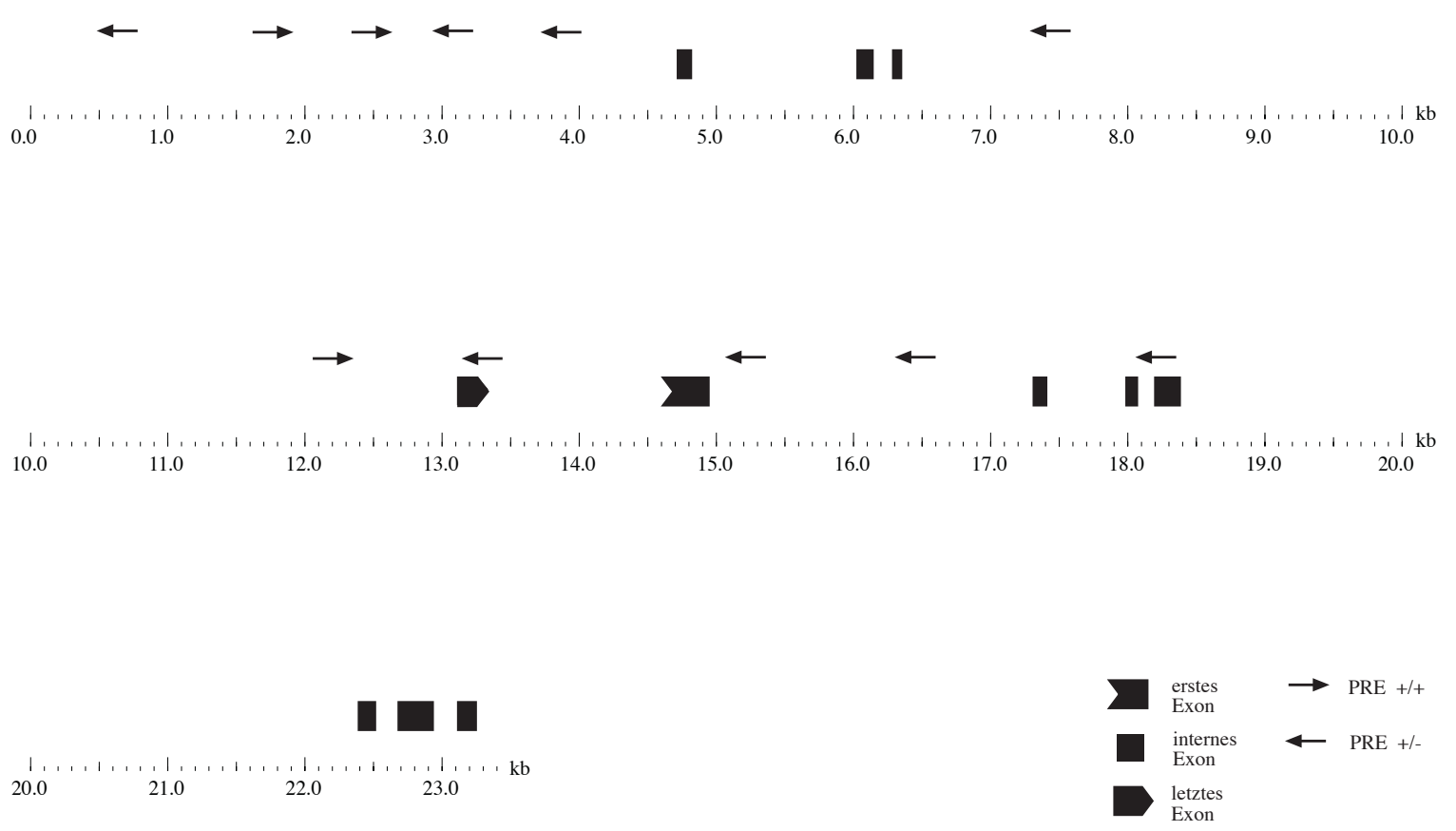

Abb. 5-67 Genscan-Analyse des Contigs T7

Für diesen Sequenzbereich prognostiziert das Programm 11 codierende Bereiche. Wie aus der Legende ersichtlich werden erstes, internes und letztes Exon unterschieden. Die Pfeile markieren jene Positionen, an denen PRE gefunden wurden. 

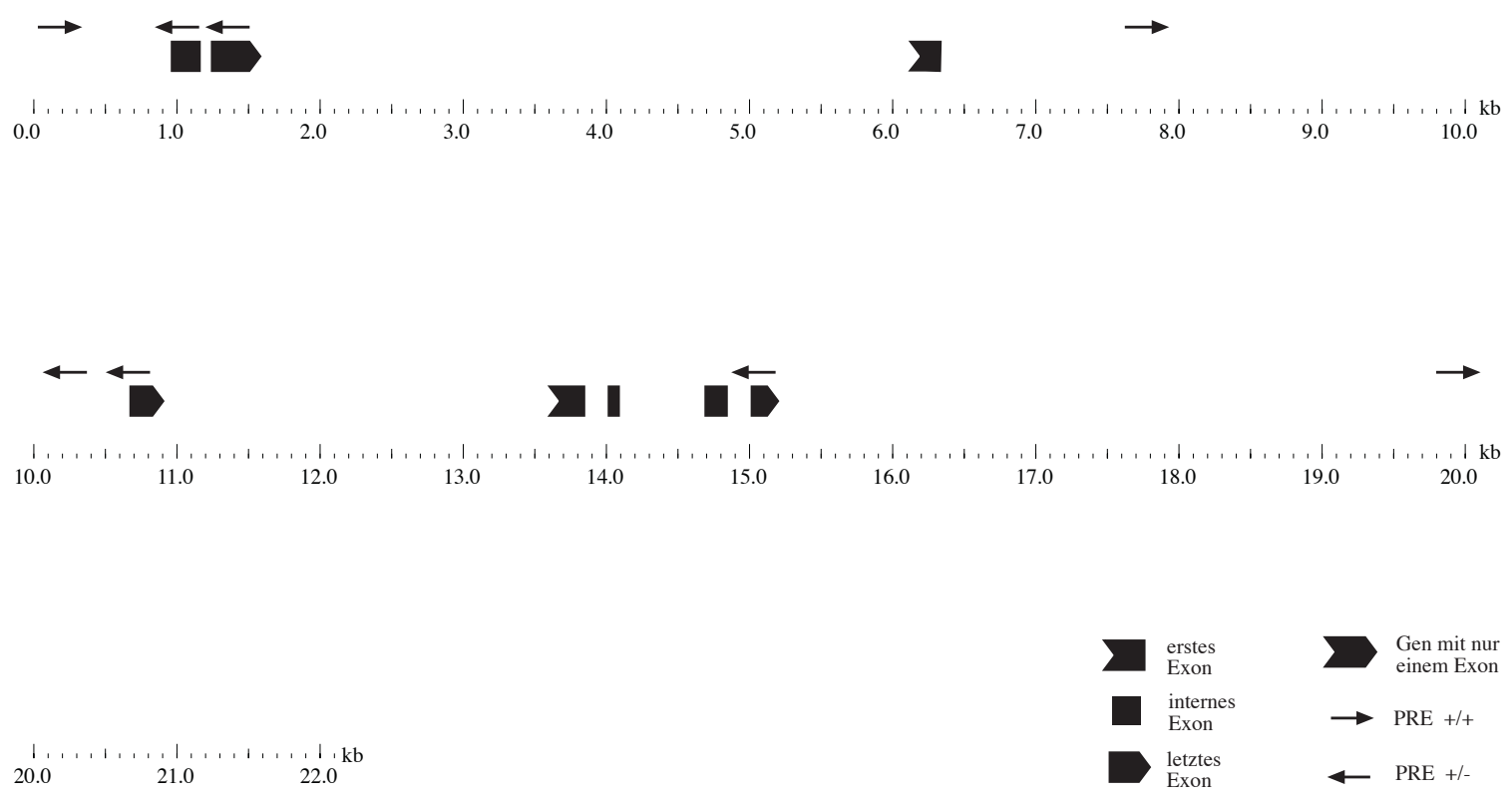

Abb. 5-68 Genscan-Analyse des Contigs SC6

Für diesen Sequenzbereich prognostiziert das Programm 8 codierende Bereiche. Die Positionen der PRE sind durch Pfeile markiert. 


\subsubsection{Northern Blot Analyse}

Um mögliche Expressionsmuster dieser potentiell codierenden Bereiche zu ermitteln, wurde eine Northern Blot Analyse durchgeführt. Dabei wurden aus den porcinen Geweben Lunge, Niere, Milz, Leber, Gehirn, Skelettmuskel und Herz RNA isoliert, wie unter 4.4.5. beschrieben in einem Formamid-Gel aufgetrennt und auf eine Nylonmembran transferiert. Für die Sondenpräparation wurde ein Bereich des Contigs SP6 ausgewählt. Dieser Sequenzbereich zeigte eine Homologie von 96,67 und kann aufgrund dieser hohen Konserviertheit und den angrenzenden Sequenzbereichen mit Vorbehalt als Exon betrachtet werden. Abbildung 5-69 zeigt diesen Bereich verglichen mit der Sequenz des humanen PAC-Klones. Dieser genomische Abschnitt wurde mit den Restriktionsenzymen SacI und AvaI aus dem Subklon B5B13 ausgeschnitten, nicht-radioaktiv markiert und die Nylonmembran damit hybridisiert. Die Hybridisierung ergab jedoch in kein Signal.

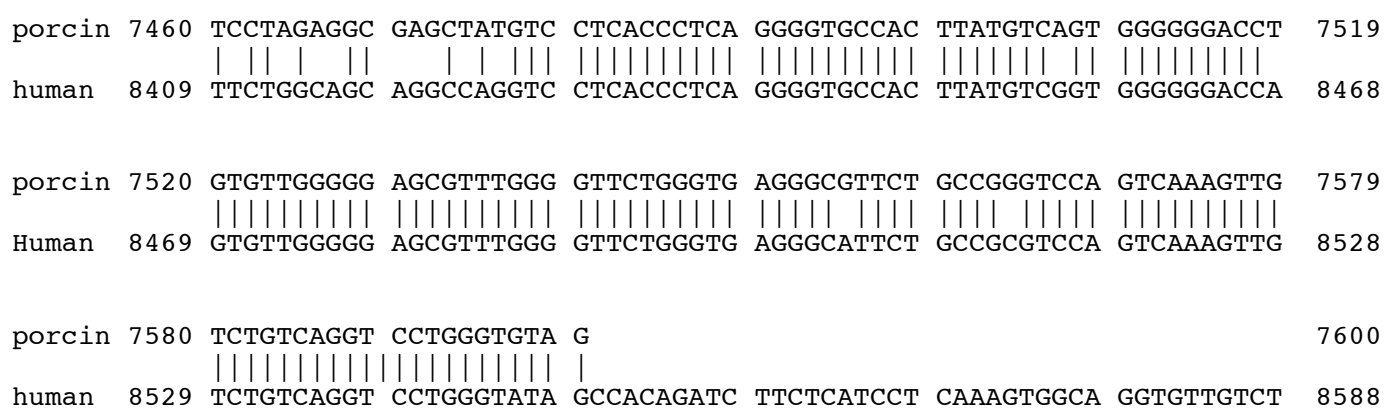

Der Vergleich zeigt jenen Bereich der beiden PAC-Klone, der als Hybridisierungssonde für die Northern Blot Analyse herangezogen wurde. Die Homologie in dem gezeigten Ausschnitt beträgt 96,97 \%. 
Tab. 5-7 Übersicht über die sequenzierten Subklone des PAC A13B5 und deren Charakteristika

\begin{tabular}{|c|c|c|}
\hline Subklon & Größe (bp) & Charakteristika \\
\hline B5Sc2 & 1.897 & Teil des Contigs SC6 \\
\hline $\mathrm{B} 5 \mathrm{Sc} 3$ & 2.344 & Teil des Contigs SC3 \\
\hline B5Sc4 & 2.553 & Teil des Contigs B22, 1PRE in 5'-3'-Richtung \\
\hline $\mathrm{B} 5 \mathrm{Sc} 5$ & 2.936 & Teil des Contigs SC6, EST \\
\hline B5Sc6 & 3.960 & Teil des Contigs SC6, 1 PRE in $5^{\prime}-3^{\prime}$-Richtung, EST \\
\hline $\mathrm{B} 5 \mathrm{Sc} 8$ & 3.958 & Teil des ContigsSP6, 2PRE in $3^{\prime}-5^{\prime}$-Richtung, EST \\
\hline B5Sc9 & 3.404 & Teil des Contigs SP6 \\
\hline B5Sc10 & 7.062 & $\begin{array}{l}\text { Teil des Contigs T7, } 2 \text { PRE in } 5^{\prime}-3^{\prime} \text {-Richtung, } 1 \text { PRE in } 3^{\prime}-5^{\prime}- \\
\text { Richtung }\end{array}$ \\
\hline B5Sc11 & 5.758 & $\begin{array}{l}\text { Teil des Contigs SC6, } 1 \text { PRE in } 5^{\prime}-3^{\prime} \text {-Richtung, } 2 \text { PRE in } 3^{\prime}-5^{\prime}- \\
\text { Richtung }\end{array}$ \\
\hline B5P2 & 1.959 & Teil des ContigsSP6, EST \\
\hline B5P5 & 3.236 & Teil des Contigs SP6, EST \\
\hline B5E5 & 6.795 & Teil des Contigs SP6, 1 PRE in $3^{\prime}-5$-Richtung \\
\hline B5E6 & 3.195 & Teil des Contigs T7, 1 PRE in $3^{\prime}-5^{\prime}$-Richtung \\
\hline B5E7 & 4.171 & Teil des Contigs SC6, 1 PRE in 5'-3'-Richtung, EST \\
\hline B5E8 & 4.540 & $\begin{array}{l}\text { Teil des Contigs T7, } 2 \text { PRE in } 5^{\prime}-3^{\prime} \text {-Richtung, } 2 \text { PRE in } 3^{\prime}-5^{\prime}- \\
\text { Richtung }\end{array}$ \\
\hline B5E9 & 3.449 & $\begin{array}{l}\text { Teil des Contigs SC6, } 1 \text { PRE in } 5^{\prime}-3^{\prime} \text {-Richtung, } 1 \text { PRE in } 3^{\prime}-5^{\prime}- \\
\text { Richtung }\end{array}$ \\
\hline B5P4 & 1.959 & Teil des Contigs T7 \\
\hline B5Hd5 & 3.250 & Teil des Contigs SP6, EST \\
\hline B5B2 & 1.097 & $\begin{array}{l}\text { Teil des Contigs SC6, } 1 \text { PRE in } 5^{\prime}-3^{\prime} \text {-Richtung, } 1 \text { PRE in } 3^{\prime}-\%^{\prime}- \\
\text { Richtung }\end{array}$ \\
\hline B5B3 & 1.230 & Teil des Contigs B22, 1 PRE in 5'-3'-Richtung \\
\hline B5B4 & 1.027 & Teil des Contigs T7, 1 PRE in $5^{\prime}-3^{\prime}$-Richtung \\
\hline B5B5 & 3.108 & Teil des Contigs SC6, 1 PRE in $5^{\prime}-3^{\prime}$-Richtung \\
\hline B5B6 & 1.206 & Teil des Contigs SC6 \\
\hline B5B8 & 1393 & Teil des Contigs SP6, EST \\
\hline B5B9 & 1.753 & Teil des Contigs T7 \\
\hline B5B10 & 2.019 & Teil des Contigs T7, 1 PRE in $3^{\prime}-5^{\prime}$-Richtung \\
\hline B5B11 & 2.170 & $\begin{array}{l}\text { Teil des Contigs SP6, } 3 \text { PRE in } 5^{\prime}-3^{\prime}-\text { Richtung, } 1 \text { PRE in } 3^{\prime}-5^{\prime}- \\
\text { Richtung, EST }\end{array}$ \\
\hline B5B12 & 1.876 & Teil des Contigs SC3 \\
\hline B5B13 & 2.416 & Teil des Contigs SP6, 1 PRE in 5'-3'-Richtung, EST \\
\hline B5B15 & 2.758 & Teil des Contigs T7 \\
\hline B5B16 & 3.632 & Teil des Contigs SC6, 2 PRE in $3^{\prime}-5^{\prime}$-Richtung \\
\hline B5B17 & 4.589 & Teil des Contigs SC6, 1 PRE in $3^{\prime}-5^{\prime}$-Richtung, EST \\
\hline B5B18 & 4.227 & Teil des Contigs SP6, EST \\
\hline B5B19 & 4.950 & Teil des ContigsT7, 1 PRE in $3^{\prime}-5^{\prime}-$ Richtung \\
\hline B5B20 & 6.008 & Teil des Contigs SC6, 1 PRE in $3^{\prime}-5^{\prime}$-Richtung \\
\hline B5B21 & 7.951 & Teil des Contigs SP6, 1 PRE in $5^{\prime}-3^{\prime}$-Richtung, EST \\
\hline B5B22 & 4.400 & $\begin{array}{l}\text { Teil des Contigs B22, } 2 \text { PRE in } 5^{\prime}-3^{\prime} \text {-Richtung, } 1 \text { PRE in } 3^{\prime}-5^{\prime}- \\
\text { Richtung }\end{array}$ \\
\hline B5X1 & 1.323 & Teil des Contigs SP6 \\
\hline $\mathrm{B} 5 \mathrm{X} 2$ & 1.664 & Teil des Contigs T7 \\
\hline B5X7 & 4.344 & Teil des Contigs SC6, EST \\
\hline B5X8 & 4.783 & Teil des Contigs SP6, 2 PRE in $3^{\prime}-5^{\prime}$-Richtung, EST \\
\hline $\mathrm{B} 5 \mathrm{X9}$ & 6.814 & Teil des Contigs T7, 4 PRE in 3'-5'-Richtung \\
\hline
\end{tabular}




\subsubsection{Chromosomale Lokalisation des PAC A13B5}

Die chromosomale Lokalisation des PAC-Klones A13B5 wurde sowohl durch PCRAnalyse eines somatischen Cell Hybrid Panel, wie auch durch in situ-Hybridisierung durchgeführt. Die Tabellen 5-8 zeigt das Analyseergebnis des Cell Hybrid Panels.

Tab. 5-8 Ergebnis der PCR-Analyse des Cell Hybrid Panels

\begin{tabular}{|lllllllllllllll|}
\hline Zellinie & 1 & 2 & 3 & 4 & 5 & 6 & 7 & 8 & 9 & 10 & 11 & 12 & 13 & 14 \\
Signal & 0 & 1 & 0 & 0 & 0 & 0 & 0 & 0 & 0 & 1 & 1 & 1 & 0 & 0 \\
\hline Zellinie & 15 & 16 & 17 & 18 & 19 & 20 & 21 & 22 & 23 & 24 & 25 & 26 & 27 \\
Signal & 0 & 1 & 0 & 0 & 0 & 0 & 1 & 0 & 1 & 0 & 1 & 0 & 0 \\
\hline
\end{tabular}

Die Auswertung dieses Ergebnisses ergab eine chromosomale Lokalisation des PAC A13B5 auf Chromosom 7 im Bereich q12 - q23 bzw. q26 mit einer Wahrscheinlichkeit von jeweils $45 \%$ und einer Irrtumswahrscheinlichkeit von weniger als 0,1\%. Die Korrelation beträgt für beide Regionen 100 \%. Dieser Befund kommt dadurch zustande, daß der Cell Hybrid Panel keine Unterscheidung der Bereiche E und G erlaubt. Abbildung 5-71 zeigt eine schematische Darstellung mit der Verteilung der Fragmente des SSC 7.

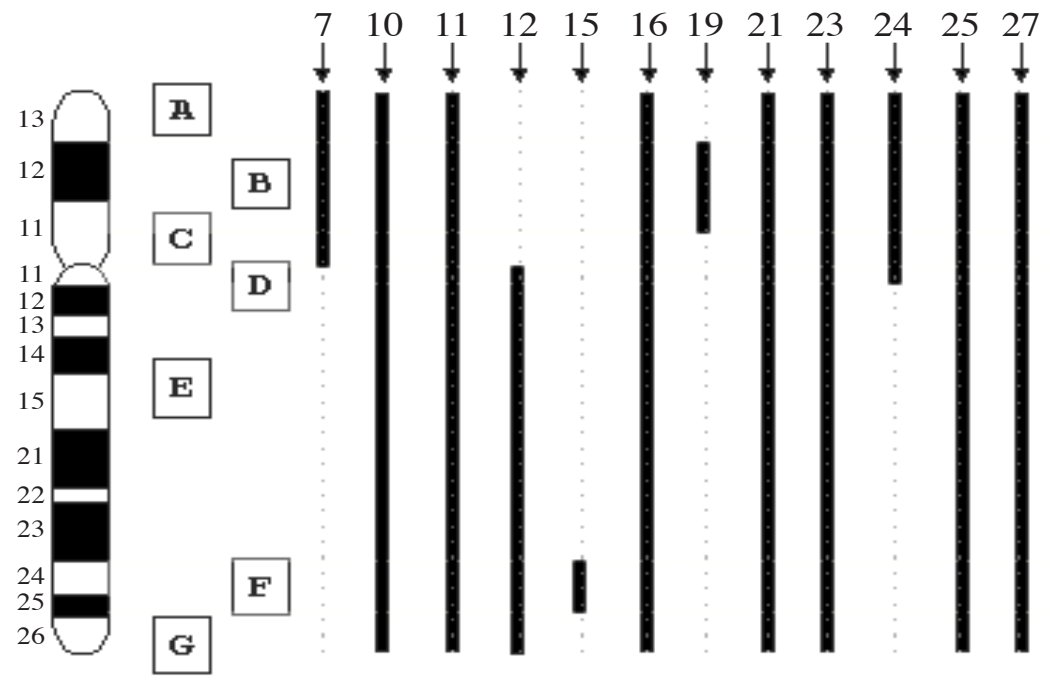

Abb. 5-70 Schematische Darstellung der Regionen des SSC 7 und ihrer Verteilung innerhalb des Cell Hybrid Panels

Die sieben Regionen des SSC7 verteilen sich wie oben abgebildet innerhalb des Cell Hybrid Panels. Diese Verteilung erlaubt keine Unterscheidung der Regionen E und G, da keiner dieser Bereiche einzeln in einer Zellinie vorhanden ist. 
Für die in situ-Hybridisierung wurde der gesamte PAC-Klon als Sonde verwendet. Abbildung 5-72 zeigt das Ergebnis dieser Hybridisierung. Der PAC-Klon wurde auf SSC 7 in Bereich q13 - q11 lokalisiert. Dieser Befund stimmt, mit dem Ergebnis der Cell Hybrid Panel Analyse überein, wenn man dabei die G-Region außer Betracht läßt.
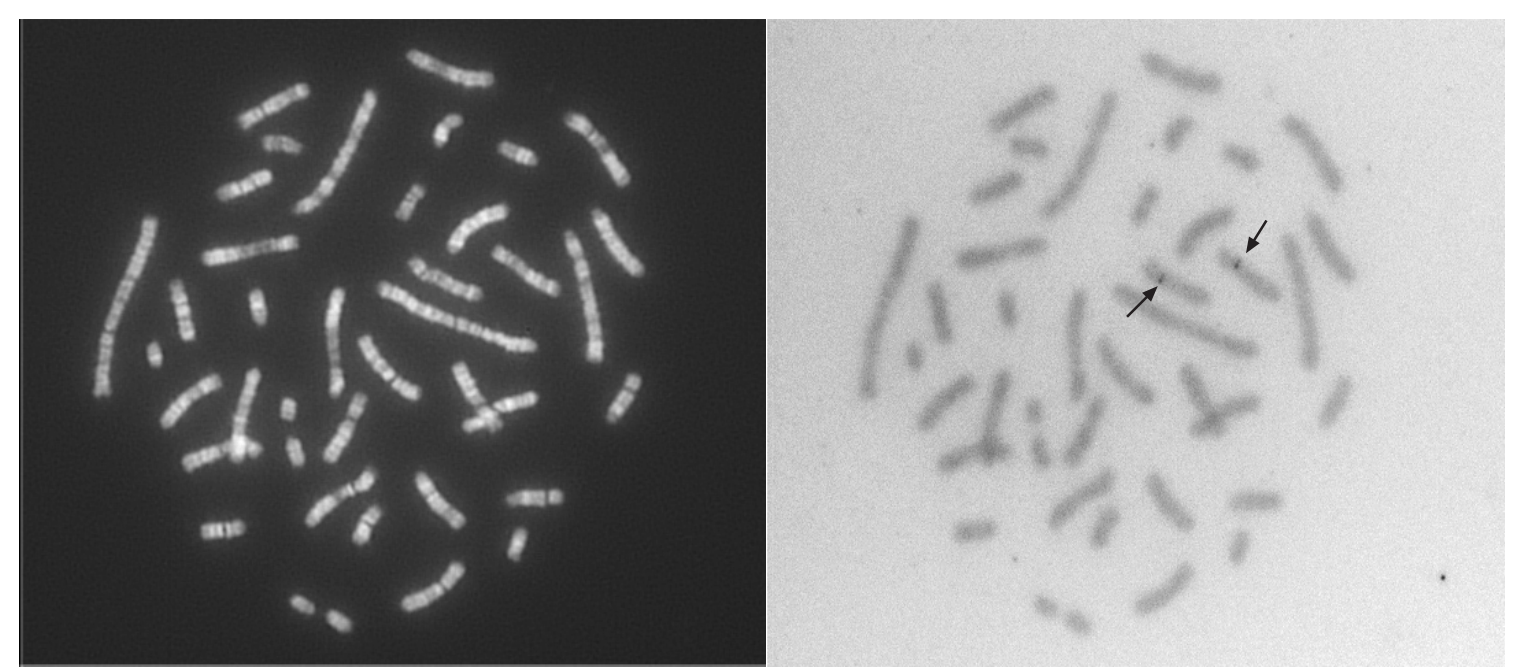

Abb. 5-71 Metaphasenpräparate der porcinen Chromosomen vor und nach der Hybridisierung

Die linke Abbildung zeigt eine Metaphasenpräparation porciner Chromosomen, die rechte Abbildung zeigt das positive Hybridisierungssignal auf dem selben Präparat (Pfeile). 


\subsubsection{Analyse der PRE}

Die PRE wurden auf die von Brenig beschriebenen Homologieverhältnisse untersucht [88]. Von den Sequenzen der in PAC A3F11 und PAC A13B5 gefundenen 85 PRE wurden zunächst mit Hilfe der Software ClustalX [89] in ein Alignment zusammengestellt. Dieses wurde manuell optimiert und zur phylogenetischen Analyse in das Programm PAUP* [90] importiert. Unter dem Optimalitätskriterium Maximum Likelihood (ML) wurde ein sogenannter Quartett Puzzling Baum angefertigt [91]. Mit dieser Methode wird für jedes mögliche Quartett aus der Menge der Sequenzen eine Topologie berechnet. Diese werden wiederum zu einer Gesamttopologie zusammengesetzt. Wiederholte Puzzling-Schritte, bei denen neue mögliche Gesamttopologien konstruiert werden, führen $\mathrm{zu}$ einer Konsensustopologie, mit Angaben über die Häufigkeit, wie oft eine bestimmte Verzweigung gefunden wurde. Dieser Wert entspricht der WiederfindungsWahrscheinlichkeit (boot strap) der gefundenen Verzweigungen. Wie Abbildung 5-73 deutlich zeigt, ergeben fast ausschließlich terminale Verzweigungen boot strap Werte über 50. Diese Problematik der Berechnung der phylogenetischen Verwandtschaft der PRE ist auch aus zwei ausgewählten möglichen Maximum Parsimonie (MP) Bäumen zu erkennen. Die Topologie der beiden Bäume ist völlig verschieden und nicht reproduzierbar. Um dies zu verdeutlichen, wurden 14 PRE die im linken Baum scheinbar eine Gruppe bilden, im rechten Baum mit einem Stern gekennzeichnet. Fast alle dieser PRE sind im rechten Baum zwar innerhalb einer größeren Gruppe wiederzufinden, die meisten von ihnen sind aber in anderen phylogenetischen Beziehungen gruppiert. Drei dieser Sequenzen, sind darüberhinaus weit von der Gruppe entfernt. 


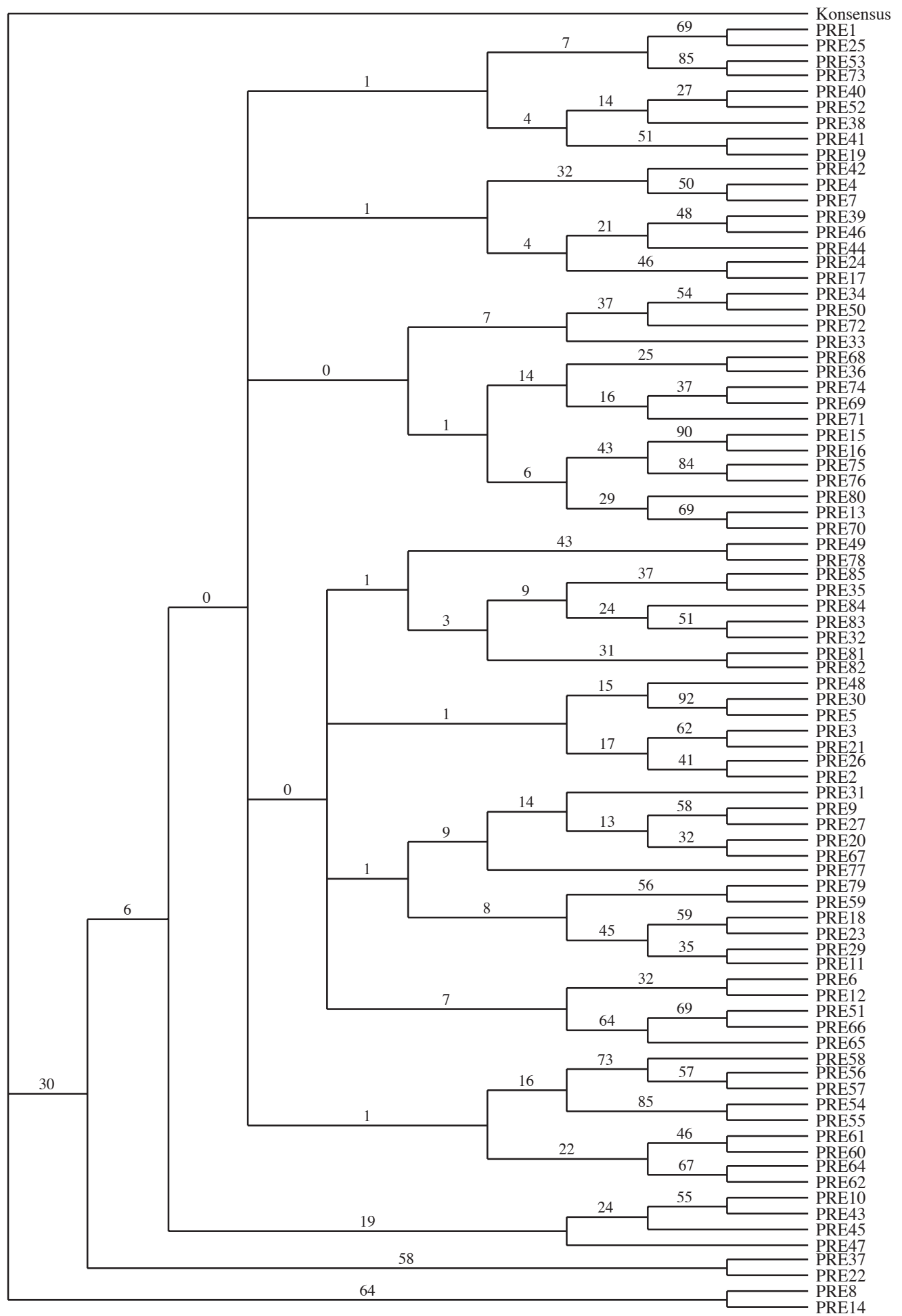

Abb. 5-72 Darstellung des Quartett Puzzling Baums für 85 PR-Elemente und der Konsensussequenz

Dieser Baum stellt einen Konsensus aller optimalen, gleichwertigen gefundenen Topologien dar. Die Werte über den Kanten geben an, wie oft diese in 500 unabhängigen Puzzling-Schritten gefunden wurden. Nur Werte, die deutlich über 50 liegen, geben ein gutes Indiz für die Unterstützung einer möglichen Monophylie. 

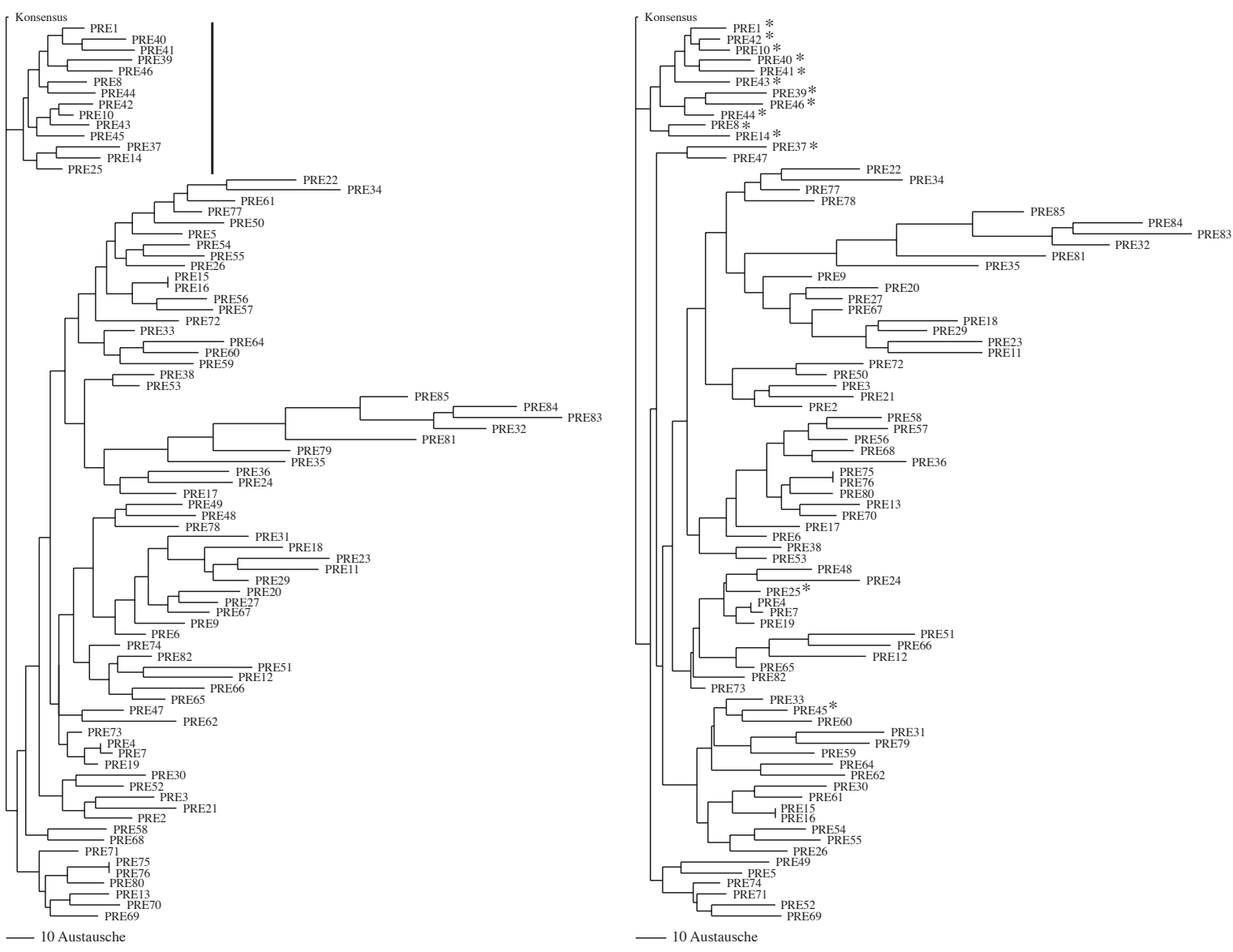

Abb. 5-73 Darstellung zweier möglicher Bäume konstruiert unter dem Optimalitätskriterium Maximum Parsimonie

Zur Erstellung dieser Bäume wurde die Star Decomposition Methode in PAUP* gewählt, unter zufälliger Lösung der terminalen Sequenzen.

Exemplarisch wurden aus dem Quartett Puzzling Baum einzelne PRE deren BootstrapWerte über 50 lagen ausgewählt, um ein weiteres Sequenzalignment zu erstellen. Das Alignment ist in Abbildung 5-74 zu sehen, der dazugehörige Quartett Puzzling Baum ist in Abbildung 5-75 dargestellt. Die konservierten A- und B-Boxen, mit der allgemeinen Basenabfolge RRYNNARY-GG und GGTTCTANNC sind in der Konsensussequenz markiert. Die durch Brenig definierten diagnostischen Positionen sind ebenfalls gekennzeichnet. Tabelle 5-9 zeigt eine Analyse dieser Positionen. In Klammern sind Anzahl der PRE/subfamilie angegeben. Es werden die Subfamilien mit hoher, moderater und niedriger Homologie (hh, mh und $\mathrm{lh}$ ) unterschieden. Aufgeführt sind 74 PRE. Die restlichen sind aus dieser Analyse entfernt worden, da ihre Sequenz erst hinter den diagnostischen Positionen beginnt. 
Konsensus

PRE10

PRE42

PRE1

PRE8

PRE37

PRE18

PRE54

PRE13

PRE15

PRE75

PRE9

PRE3

PRE64

PRE30

PRE58

PRE51

PRE34

PRE53

Konsensus

PRE10

PRE42

PRE1

PRE8

PRE37

PRE18

PRE54

PRE13

PRE15

PRE75

PRE9

PRE3

PRE64

PRE30

PRE58

PRE51

PRE34

PRE53

Konsensus

PRE10

PRE42

PRE1

PRE8

PRE37

PRE18

PRE54

PRE13

PRE15

PRE75

PRE9

PRE3

PRE64

PRE30

PRE58

PRE51

PRE34

PRE53

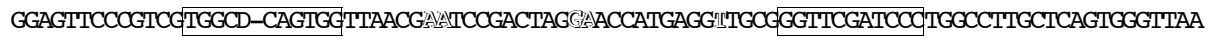

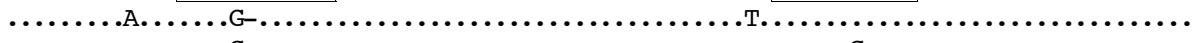

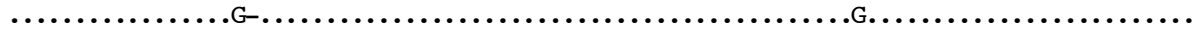
.т........... .............Т.................................................

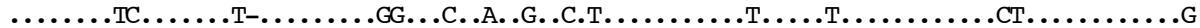

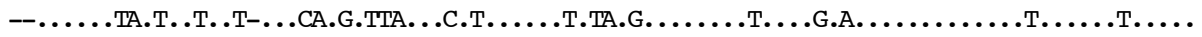
-......Т....Т.Т-..СА....Т..С.Т....Т.Т.....АСТ......Т...............

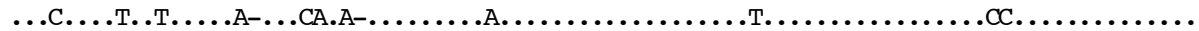

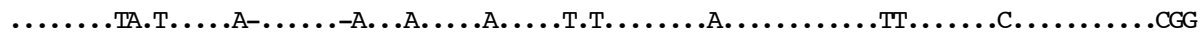
T.G............G......А...........................................

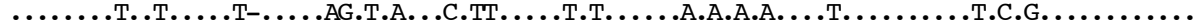

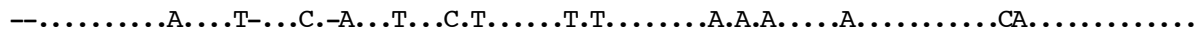
А........АСТ..-АTG...СА.-А...А. .G...T..TT.T............T.С..............GG

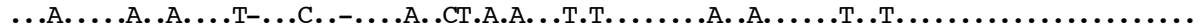

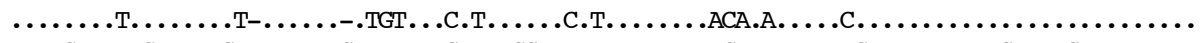
T...G....AGTT...GT-A..ATAG-..-.-.G.ATTGG..TTT.......AC..A.....G..........G....... T...GATG.AGGT.T.AT-.CC..._-C.TC.CT.AGTG..TT.-_-.........T.........A...G....... -

\section{GGATCCGGCGTTGCCGTGAGCIGTGGTGTAGGTCGCAGACGCGGCTCGGATCCBGCGTTGCTGTGGC-_--_-_--TGTGGTGTAGGCC}

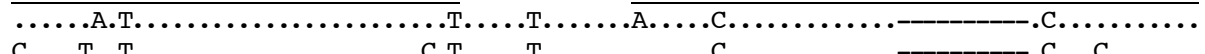

С...т..т......................................._-_-........

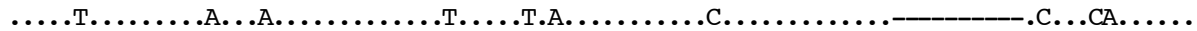

...............................................

.С..Т................................СА.........

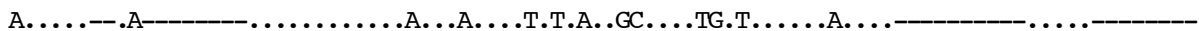

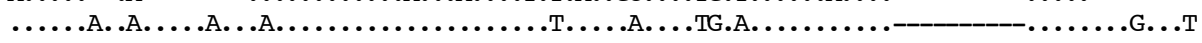

....Т.....................ТА...Т..СТ...А...TG.T........._........

___

.

ТС. Т. А. . А

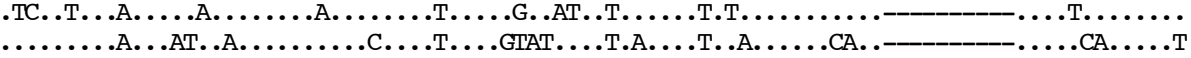

...Т..А.

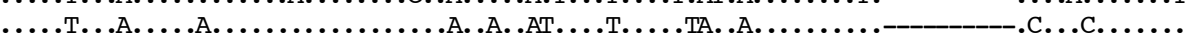

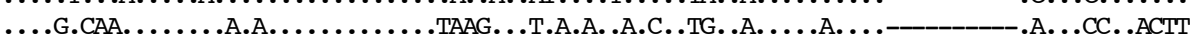

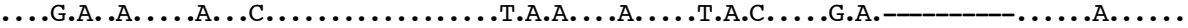
........А....А.....А............СТ..А...G..... .А........GTTTTGTGGC..........

GGCAGCTACAGCTCCGATT--GACCCCTAGCCTGGGAACCTCCATATGCCGCGGGTGCGGCCCT

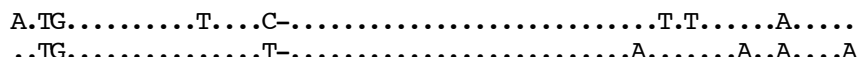

.TG............-А..............................

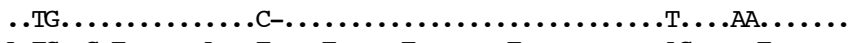

A.TG..G.T........T-..T...........................

--.Т..__....С-.............................-

...... . ........С-А............................

....... ...T.А...С-............................

......GT....T...С-А..............TGG...АT.........

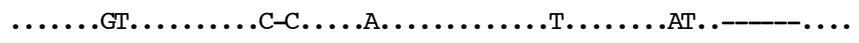

A..........T...TGA.A...G...СA.A.G.T............TA....

AA...........AG..T-............T.........ACA.....T..

...............Т-.Т.................. ТАA.........

...............TGAC...................T.

...................................АТ.........

..............................................

A............ACG..C-A.T..................TTA.A..A.T.....

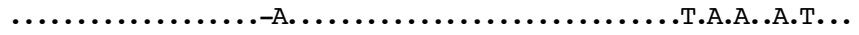

Abb. 5-74 Alignment ausgewählter PRE

Das Sequenzalignment zeigt die Konsensusequenz mit den eingerahmten Motiven der A- und B-Boxen. Zwei Bereiche mit Nukeotidwiederholungen sind unterstrichen. Punkte stehen für identische Positionen, Striche zeigen Deletionen an. Die diagnostischen Positionen sind schattiert. 


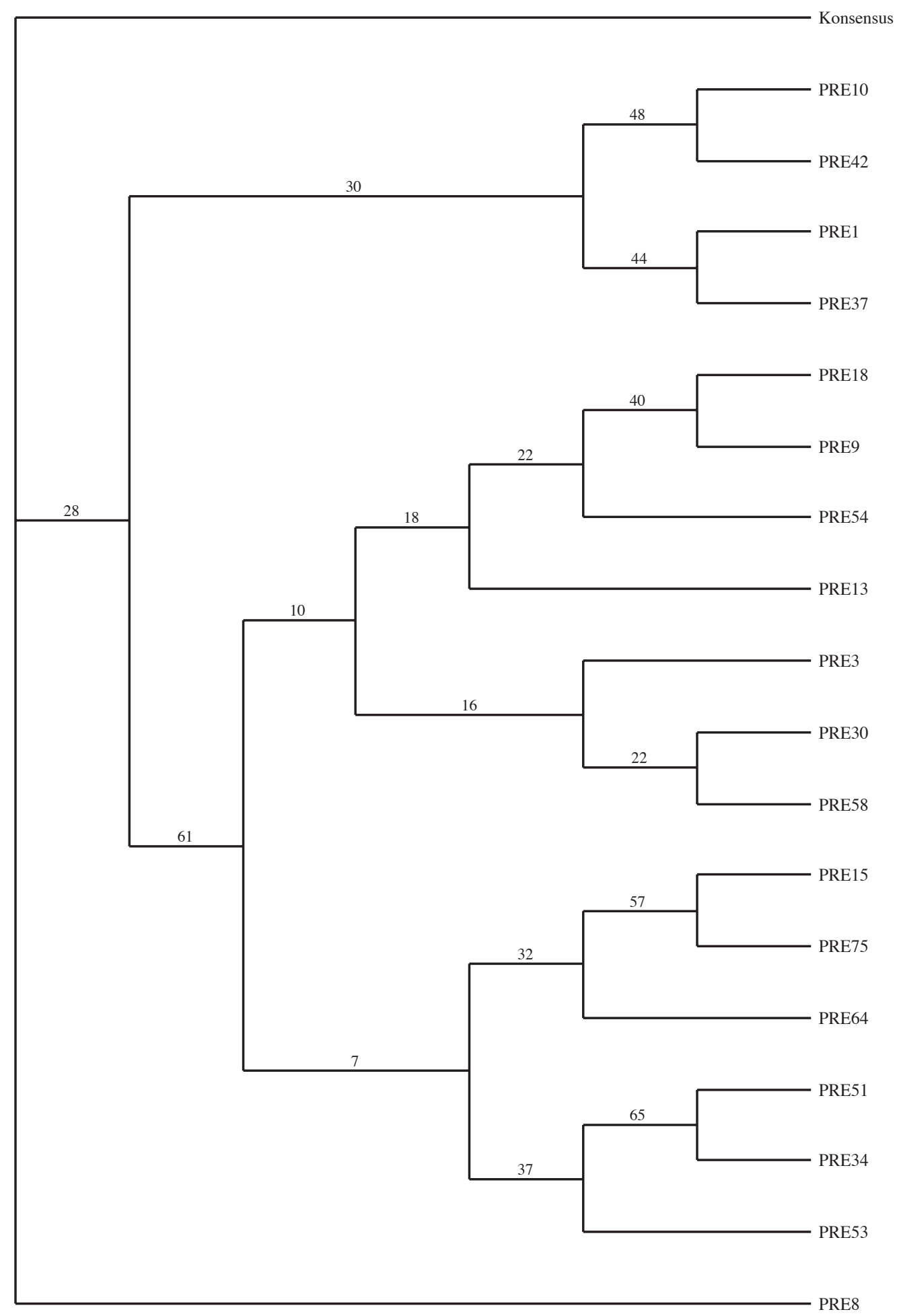

Abb. 5-75 Darstellung des Quartett Puzzling Baumes der ausgewähten 14 PRE 
Tab. 5-9 Analyse der Diagnostischen Positonen

\begin{tabular}{|c|c|c|c|c|c|}
\hline \multirow{2}{*}{$\begin{array}{c}\text { PRE-hh } \\
\text { AAGAT }(21 / 21)\end{array}$} & \multicolumn{2}{|c|}{ PRE-mh } & \multicolumn{3}{|c|}{ PRE-lh } \\
\hline & AATTA $(13 / 24)$ & TATTA $(11 / 24)$ & & & \\
\hline PRE1 & PRE81 & PRE31 & PRE56 & AACTA & $(1 / 29)$ \\
\hline PRE42 & PRE30 & PRE6 & PRE22 & AAGTA & $(3 / 29)$ \\
\hline PRE10 & PRE17 & PRE9 & PRE24 & & \\
\hline PRE8 & PRE64 & PRE12 & PRE5 & & \\
\hline PRE14 & PRE60 & PRE20 & PRE43 & AAGAC & $(1 / 29)$ \\
\hline PRE47 & PRE54 & PRE27 & PRE49 & AAGGA & $(1 / 29)$ \\
\hline PRE68 & PRE55 & PRE67 & PRE61 & AATT- & $(1 / 29)$ \\
\hline PRE40 & PRE26 & PRE23 & PRE3 & AATTA & $(2 / 29)$ \\
\hline PRE41 & PRE62 & PRE29 & PRE65 & & \\
\hline PRE39 & PRE2 & PRE11 & PRE21 & AGCTA & $(1 / 29)$ \\
\hline PRE38 & PRE15 & PRE59 & PRE78 & AATTA & $(1 / 29)$ \\
\hline PRE46 & PRE16 & & PRE66 & ACCTA & $(1 / 29)$ \\
\hline PRE45 & PRE52 & & PRE37 & AGCTT & $(1 / 29)$ \\
\hline PRE44 & & & PRE48 & AGTTA & $(1 / 29)$ \\
\hline PRE71 & & & PRE36 & ATGAT & $(1 / 29)$ \\
\hline PRE13 & & & PRE35 & ATGGA & $(1 / 29)$ \\
\hline PRE70 & & & PRE34 & CCTAA & $(1 / 29)$ \\
\hline PRE69 & & & PRE57 & GACTA & $(1 / 29)$ \\
\hline PRE75 & & & PRE51 & GATTA & $(1 / 29)$ \\
\hline PRE76 & & & PRE82 & TAATA & $(1 / 29)$ \\
\hline PRE80 & & & PRE79 & TATTG & $(1 / 29)$ \\
\hline & & & PRE18 & TTTTT & $(1 / 29)$ \\
\hline & & & PRE77 & -ATTA & $(1 / 29)$ \\
\hline & & & PRE58 & -GCTA & $(1 / 29)$ \\
\hline & & & PRE32 & --ATT & $(1 / 29)$ \\
\hline & & & PRE50 & --CAA & $(1 / 29)$ \\
\hline & & & PRE83 & ----G & $(1 / 29)$ \\
\hline & & & PRE85 & ----T & $(2 / 29)$ \\
\hline & & & PRE84 & ----T & \\
\hline
\end{tabular}




\section{Diskussion}

\subsection{Molekulargenetische Untersuchung des humanen und porcinen Triadin-Gens}

\subsubsection{Das Triadin-Gen erstreckt sich mit mehr als 38 Exons über einen genomischen Bereich von mindestens $451 \mathrm{~kb}$}

Das Triadin-Gen erstreckt sich, wie die vorliegende Arbeit ermitteln konnte über mehr als $451 \mathrm{~kb}$. Ähnlich große genomische Ausdehnung kennt man auch von anderen Genen, die für Muskelproteine codieren. So erstrecken sich zum Beispiel die 106 Exons des RyR1 Gens [92] über mehr als $205 \mathrm{~kb}$ und das Dystrophin-Gen gehört ebenfalls zu den komplexesten bekannten eukaryontischen Genen [93]. Welche Bedeutung diese genomische Organisation auf die Transkriptions- und Spleißprozesse hat ist noch nicht völlig klar. Wenn man jedoch wie derzeit vermutet, davon ausgeht, daß aus jedem dritten Gen mehr als ein Genprodukt entsteht, so ist es durchaus denkbar, daß die genomische Organisation eines Gens dabei eine Rolle spielt. Das Triadin-Gen besteht aus mehr als 38 Exons, die durch intronische Bereiche in der Größe von 0,3 bis $65,6 \mathrm{~kb}$ unterbrochen sind. Es ist schwer vorstellbar, daß diese Intronsequenzen ausschließlich aus funktionell unwirksamer DNA bestehen. Mehrfach gibt es bereits Hinweise darauf, daß etwa innerhalb des ersten Introns, aber auch innerhalb anderer nicht-codierender Regionen regulatorische Elemente zu finden sind, die die Expression eines Genes wesentlich beeinflussen [94,95]. Die erstmals aufgeklärte genomische Oranisation des Triadin-Gens bildet die Basis für weitere Untersuchungen, die möglicherweise auch in diesem Gen regulatorische Elemente entdecken. Denkbar ist hier sowohl eine gewebespezifische- wie auch eine entwicklungsspezifische Expression des Triadin-Gens. Wieviele Genprodukte aus dem Triadin-Gen tatsächlich entstehen, werden erst weitere Untersuchungen zeigen. Möglicherweise befinden sich auch noch andere Gene im Einflußbereich der gleichen Regulationsmechanismen.

\subsubsection{Gruppierung und Homologie der Exons}

Die Domänen eines Proteins spiegeln sich manchmal in der Anordnung bzw. Gruppierung der Exons des Gens wider. Über die Topologie des Triadins ist erst wenig bekannt. Im wesentlichen kann man aufgrund der Aminosäuresequenz drei Domänen erkennen. Der cytoplasmatische N-Terminus des Proteins, eine einzige Transmembrandomäne und den C-terminalen Bereich, der sich im sarkoplasmatischen Retikulum (SR) befindet [36]. Darüberhinaus konnte jüngst eine Bindungsstelle für Calsequenstrin zwischen den 
Aminosäuren 210 bis 224 identifiziert werden [48]. Die im Rahmen der vorliegenden Arbeit gewonnen Erkenntnisse bezüglich der genomischen Organisation und der Homologie der einzelnen Bereiche zwischen Mensch und Schwein werden im folgenden im Zusammenhang mit etwaigen Proteindomänen betrachtet.

Die genomischen Organisation des Triadin-Gens läßt fünf bis sechs jeweils zusammenhängende Abschnitte erkennen. Betrachtet man die von den einzelnen Exons codierten Aminosäuresequenzen, so würde Exon 2 sowohl für den cytoplasmatischen NTerminus, wie auch für die Transmembrandomäne codieren. Exon zwei wird gemeinsam mit den Exons 3 bis 11 zur ersten „genomischen Domäne“ gezählt. Innerhalb dieser Domäne beträgt die durchschnittliche Homologie zwischen Mensch und Schwein auf Nukleinsäure-Ebene 91,75 \%. Exon 8 codiert für die Aminosäuren 196 bis 257 und damit auch für die KEKE-Motive der Calsequestrin Bindungsdomäne. Es folgt die zweite „genomische Domäne“ mit den Exons 13 bis 24. Hier beträgt die durchschnittliche Homologie der Exons 90,5 \%. In diesem Abschnitt finden sich als auffallendes Merkmal insgesamt vier, jeweils gleich große Exon-Paare. Dies sind die Exons 14 und 15 mit jeweils 30 bp, die Exons 18 und 19 mit jeweils 27 bp, die Exons 20 und 21 mit jeweils 48 bp und die Exons 22 und 23 mit jeweils 51 bp. Eine weitere domänenähnliche Organisation kann zwischen den Exons 25 und 33 ausgemacht werden. Diese Exons liegen mit einer durchschnittlichen Introngröße von $1,5 \mathrm{~kb}$ auffallend dicht zusammen. Auch hier finden sich zwei jeweils gleich große Exon-Paare. Dies sind die Exons 26 und 27 mit je 30 bp und die Exons 29 und 30 mit je 48 bp. Die durchschnittliche Homologie der Exons dieses Bereiches beträgt 82,5\%. Es folgt der genomisch noch nicht kartierte Bereich mit einer Homologie von 91,1 \% und der Abschnitt mit den letzten drei Exons. Bei den beiden letzteren ist noch nicht absehbar, ob sie genomisch zu einer „Domäne“ gehören. Ob und welcher Zusammenhang zwischen den genomischen und den Protein-Domänen tatsächlich besteht wird sich frühestens nach Klärung der Funktion des Triadins zeigen. Bezüglich alternativ gespleißter Exons kann ebenfalls nur festgehalten werden, daß sich mit dem Spleißen des Exons sieben die Position der KEKE-Bindungsmotive durch das Fehlen von 20 Aminosäuren in Richtung SR-Membran verlagern würde. Da über die anderen Bereiche und ihre Funktion nichts bekannt ist, kann keine Aussage über die Folgen der weiteren Spleiß-Varianten gemacht werden. Möglicherweise liefert die Homologie, die in der dritten „genomischen Domäne“ deutlich unter $90 \%$ liegt einen Hinweis auf funktionell weniger wichtige Bereiche. Diese Domäne könnte zum Beispiel eine Linker-Region codieren, die zwei funktionelle Protein-Domänen verbindet.

\subsubsection{Identifizierung bisher unbekannter Triadin-cDNA-Varianten im Skelettmuskel}

Die durch genspezifische RT-PCR erhaltenen Sequenzinformationen des im Skelettmuskel exprimierten Triadin-Gens zeigten deutlich insgesamt drei verschiedene Varianten. Das einzige aus dem humanen Skelettmuskel erhaltene Transkript war mit der in der EMBL Nucleotide Sequence Database hinterlegten Sequenz des humanen Triadins identisch. Zwei 
weitere Transkripte aus dem porcinen Skelettmuskel, die als pSKM1 und pSKM2 bezeichnet wurden, waren um 111 bp und 180 bp kürzer als die humane cDNA. Bereits 1996 konnten drei verschiedene cDNA-Klone aus einer Herzmuskel-cDNA-Bank des Kaninchens isoliert werden [42]. Diese cDNA-Varianten wiesen am 5'-Ende etwa 800 bp gleiche Sequenzen auf, die weiter stromabwärts gelegenen Sequenzen waren völlig verschieden. Die entsprechenden Protein-Isoformen konnten im Zuge einer Western BlotAnalyse als $92 \mathrm{kDa}, 40 \mathrm{kDa}$ und $35 \mathrm{kDa}$ große Proteine identifiziert werden. Vier Jahre später wurde zum ersten Mal von einer weiteren Skelettmuskel-Triadin-Isoform berichtet [43]. Aus einer Skelettmuskel-spezifischen cDNA-Bank des Kaninchens konnten zwei unterschiedliche cDNA-Klone mit einem offenen Leserahmen (ORF) von 2.061 bp und $1.386 \mathrm{bp}$ isoliert werden. Auch hier konnten die entsprechenden Protein-Isoformen im Western Blot-Verfahren als $95 \mathrm{kDa}$ und $51 \mathrm{kDa}$ große Banden identifiziert werden. Alle bisher gefundenen cDNAs weisen nur in den 3'-Bereichen Sequenzunterschiede auf. Die in dieser Arbeit identifizierten cDNA-Varianten aus dem porcinen Skelettmuskel zeigen hingegen an klar abgrenzbaren, internen Positionen Sequenzunterschiede. Die hier vorgestellten neuen cDNA-Varianten wurden durch RT-PCR aus dem Skelettmuskel des Schweines isoliert. Die Sequenzunterschiede befinden sich in Bereichen, die nicht von der Primerbindung beeinflußt sind. Damit kann ausgeschlossen werden, daß es sich um PCRArtefakte handelt.

Die Identifizierung verschiedener Triadin-Isoformen und die Tatsache, daß es nur einen Triadin-Genlocus gibt, legt die Vermutung nahe, daß die einzelnen Isofomen durch alternatives Spleißen entstehen. Die vorliegende Arbeit konnte zum ersten Mal zeigen daß tatsächlich mehrere Exons alternativ gespleißt sind. Aus dem porcinen Skelettmuskel wurden zwei unterschiedliche cDNA-Formen isoliert. Dabei zeigte sich, daß in beiden Formen das Exon sieben gespleißt wurde. Außerdem werden bei pSKM1 die Exons 15 und 16 gespleißt. Der Vergleich der pSKM2-Form mit den Sequenzen der Transkripte hSKM und pSKM1 zeigte sowohl das Vorhandensein zweier weiterer genomisch noch nicht kartierter Exons, wie auch einen weiteren alternativ gespleißten Bereich. Bisher wurde von allen 5 gefundenen cDNA-Formen auch das entsprechende Protein im Herz- oder Skelettmuskel beschrieben. Welche Formen unter welchen Bedingungen exprimiert werden und ob tatsächlich jedes der identifizierten Proteine ein funktionelles darstellt ist noch nicht geklärt. Die Arbeitsgruppe um Kobayashi zweifelt darüberhinaus das Vorhandensein dreier Herzmuskelformen an und zeigte in einer eigenen Studie, daß CT1 die am häufigsten exprimierte Isoform im Myocard ist. Die Arbeitsgruppe stellte eine sehr geringe Expression von CT3 fest, konnte aber keine Hinweise auf CT2 finden. Bei der Durchmusterung einer caninen Herzmuskel-cDNA-Bank identifizierte man einige Klone, die partielle Anteile von Triadin-cDNA enthielten, und einige kryptische Klone nicht homologer Gene, die offensichtlich durch falsche, interne Primer-Anlagerung bei der Konstruktion der Genbank entstanden waren [44]. Diesen Befunden nach zu schließen, könnte die Isolierung verschiedener Triadin-cDNA-Klone auf Artefakte oder partielle Klone zurückzuführen sein. Auffällig ist in diesem Zusammenhang auch, daß diese Varianten in ihren 5'-Bereichen absolut identisch sind und sich nur in den 3'-Sequenzen unterscheiden. Demnach könnte es sich tatsächlich um Fragmente einer einzigen cDNA handeln. Die hier präsentierten cDNA-Varianten, stellen zwar keine Vollängen-cDNA- 
Klone dar, aufgrund der identischen 5'- und 3'-Bereiche bzw. deren Homologie zur humanen cDNA kann man ausschließen, daß es sich hierbei um fragmentierte Klone handelt. Darüber hinaus konnte aufgrund der Kenntnis der Exon/Intron-Struktur klar gezeigt werden welche Bereiche gespleißt sind.

\subsubsection{Die chromosomale Lokalisation des Triadin-Gens entspricht nicht den bekannten Syntenieverhältnissen}

Das humane Triadin-Gen wurde auf Hsap 6 q22 - 23 lokalisiert. Im Rahmen der vorliegenden Arbeit erfolgte die chromosomale Lokalisation des porcinen Triadin-Gens auf SSC 1 q26 - q27 durch die Analyse eines somatischen Cell Hybrid Panels und eines Radiation Hybrid Panels. Das Ergebnis unterstützt nicht die bisherigen Untersuchungen mittels ZOO-FISH-Analysen und bidirectional chromosome painting. Bisher ging man davon aus, daß Syntenie zwischen dem Hsap 6 q und dem SSC 1 p besteht. Das hier vorgelegte Ergebnis zeigt jedoch, daß auch zwischen dem Hsap 6 q und dem SSC 1 q zumindest abschnittsweise Syntenie besteht. Die zur Analyse der Hybrid Panel herangezogenen Oligonukleotide waren aus den angrenzenden Bereichen des Exons Y des porcinen Triadin-Gens abgeleitet. Ihre Spezifität wurde vor der Analyse auf Maus-, Hamster und Schweine-DNA getestet. Die PCR-Signale waren in allen Zellinien eindeutig und auf ein spezies-spezifisches Amplifikat zurückzuführen. Die durch ZOO-FISH erhaltenen Daten über homologe Chromosomen-Abschnitte waren im Bezug auf den Grenzverlauf ungenau [22]. Durch die Methode des bidirectional chromosome painting konnte für einige Abschnitte genauere Ergebnisse erzielt werden [23]. Die Hybridisierungssonde des Hsap 6 erzeugte auf porcinen Metaphasechromosomen zwei Signale, eines auf SSC $1 p$ und eines auf SSC 7p-q14. Dieser Befund wird durch die Lokalisation der Gene für Östrogen-Rezeptor auf Hsap 6 q25.1 - q12 bzw. auf SSC1 p12, TNF- $\alpha$, und TNF- $\beta$ (tumor necrosis factor) auf Hsap 6 q21.3 bzw. SSC 1 p11 - q11, um nur einige Beispiele zu nennen, bestätigt. Einige Unklarheiten und Neuanordnungen zeigen sich jedoch immer wieder. So wurde zum Beispiel das IGF1R-Gen auf SSC 1 q1.7 - q2.1 bzw. auf Hsap 15 q25 [96] lokalisiert. Die Region Hsap 15 q 25 zeigte im bidirectional chromosome painting allerdings ein eindeutiges Signal auf SSC 7 q13 - q22. An dieser Stelle sind nur einige Beispiele ausgewählt, die zeigen, daß die Syntenieverhältnisse allgemein bekannt sind, neue Befunde aber immer wieder interessante Details erkennen lassen. 


\subsection{Charakterisierung des porcinen mut-Locus}

\subsubsection{Das mut-Gen ist stark konserviert}

Die erfolgreiche Durchführung einer RT-PCR mit genspezifischen Primern des Methylmalonyl-CoA-Mutase-Gens ermöglichte einen direkten Vergleich der codierenden Bereiche des Gens zwischen Mensch und Schwein. Dabei zeigte sich, daß die Methylmalonyl-CoA-Mutase (MCM) nicht nur auf Aminosäure-Ebene, sondern auch auf Nukleinsäure-Ebene stark konserviert ist. Die Homologie codierender Bereiche zwischen Mensch und Schwein beträgt 92,70\%. Die Exons 7 und 11 sind sogar zu mehr als $97 \%$ identisch. Auf Aminosäuren-Ebene bedeutet dies in den untersuchten Bereichen eine Identität von rund $98 \%$. Um auch die untranslatierten Bereiche vergleichen zu können wurden eine 5'-RACE- und 3'-RACE-PCR durchgeführt. Die Durchführung einer nested PCR erlaubte die Erzeugung eines spezifischen Amplifikats des 5'-Bereiches. Die gleiche Strategie erzeugte bei der 3'-RACE-PCR mehrere Banden. Um festzustellen, welches dieser Amplifikate das Richtige ist, wurde jede der drei Banden einzeln ausgeschnitten und die DNA aus dem Agarosegel eluiert. Daraufhin wurde mit den bereits in der RACE-PCR eingesetzten Primern erneut eine PCR durchgeführt. Dies führte in einem Fall zu einem starken Signal, in den anderen Fällen entstanden wiederum mehrere schwächere Banden. In der Annahme, daß es sich bei dem letztendlich in der dritten PCR-Runde erhaltenen starken Signal um ein spezifisches Amplifikat handelt, wurde dieses einkloniert und doppelsträngig sequenziert. In der Sequenz ließ sich allerdings außer der Sequenz des genspezifischen Primers kein Hinweis auf das mut-Gen erkennen. Da die 5'-RACE und 3'RACE-PCR nicht auf Basis der gleichen cDNA durchgeführt wurde legt dieses Ergebnis die Vermutung nahe, daß im Fall der 3'-RACE die Adaptorligation an die doppelsträngige cDNA nicht funktioniert hat. Dadurch konnte zwar der genspezifische Primer an der richtigen Stelle binden, der Gegenprimer lagerte sich jedoch unspezifisch an und es entstand durch die mehrfach durchgeführte PCR ein chimäres Produkt.

\subsubsection{Der 5'-UTR des Methylmalonyl-CoA-Mutase-Gens ermöglicht mehrere Transkriptionsstarts}

Die drei in der Primer-Extension-Analyse entstandenen Extensionsprodukte sind wahrscheinlich auf die Kettenverlängerung an bereits degradierter RNA zurückzuführen, da die zweite Analyse diese Signale nicht bestätigen konnte. Die Möglichkeit mehrer Transkriptionsstartpunkte besteht dennoch. Wie in einer Untersuchung des murinen mutGens gezeigt, entstanden in der Primer-Extension Analyse drei Extensionsprodukte. Diese unterschieden sich in ihrer Länge um jeweils etwa 10 bp [71]. Da es sich beim Methylmalonyl-CoA-Mutase-Gen um ein TATA-Box loses Gen handelt sind alternative Transkriptionsstartpunkte denkbar. Ein 500 bp langer Abschnitt des 5'-UTR des porcinen mut-Gens weist einen GC-Gehalt von rund $58 \%$ auf. Innerhalb dieses Bereiches finden sich eine Reihe von potentiellen Bindungsmotiven eukaryontischer Transkriptionsfaktoren. 
Neben einer GC-Box konnten mehrere CAAT-Boxen in positiver und negativer Orientierung, sowie Bindungsstellen für GATA-1, Elk-1 und CRE identifiziert werden. Ebenso eine für kerncodierte mitochondriale Proteine charakteristische Bidungsstelle für NRF-2.

\subsubsection{Polymorphismen im porcinen mut-Locus}

Die Charakterisierung des porcinen $m u t$-Locus zeigte zwei, innerhalb des Gens liegende Polymorphismen. Zunächst konnte im unmittelbaren 5'-Bereich des Exons 3 ein Längenpolymorphismus identifiziert werden. Der betreffende Sequenzbereich wurde auf $28 \mathrm{bp}$ eingegrenzt, und ist möglicherweise auf eine Insertion eines Repeats zurückzuführen. Inwieweit diese Veränderungen der 5'-UTR des Exons 3 einen Einfluß auf Spleißprozesse haben könnte, läßt sich an dieser Stelle nicht sagen. Es ist jedoch bekannt, daß insbesondere GC-reiche Insertionen, durch die Ausbildung von Loops ein korrektes Herausspleißen eines Introns verhindern können. Dadurch könnte es theoretisch zu einer Verschiebung des Leserahmens kommen. Die codierenden Bereiche selbst, insbesondere der des Exons 3 weisen keinerlei Nukleotidaustausche auf.

Neben dem Polymorphismus im 3'-Bereich des Exons 3 konnten innerhalb des Gens zwei Mikrosatelliten identifiziert werden. Mikrosatellit 1 mit einer Abfolge von $(\mathrm{GT})_{17}$ in einer Population von 79 Tieren als monomorph. Die Amplifikation des Mikrosatelliten 2 erzeugte innerhalb der 79 untersuchten Tiere 11 verschiedene Allele. Daraus ergab sich ein Heterozygotiegrad von 82,24 \% und ein PIC-Wert (polymorphism information content) von 0,8045. Der Mikrosatellit erwies sich damit als informativer DNA-Marker.

Trotz zahlreicher Berichte über Mutationen im humanen mut-Gen gibt es bis jetzt keine Hinweise darauf, ob ähnliche Mutationen auch bei Tieren auftreten [74-77]. Dies mag verschiedene Gründe haben. Zum einen ist eine Diagnose schon beim Menschen in manchen Fällen schwierig zu stellen. Die Krankheitssymptome lassen, nicht zwangsläufig auf Methylmalonazidurie schließen. Bei Tieren, insbesondere bei Nutztieren wird diagnostisch meist wenig Aufwand betrieben. Die Tatsache, daß demzufolge eine derartige Diagnose noch nicht gestellt wurde bedeutet nicht, daß Tiere von dieser Krankheit ausgeschlossen sind. Berichte über symptomatisch vergleichbare Defekte liegen vor [97].

\subsubsection{Die shot gun Klonierung eines weiteren PAC-Klones führt zur Identifizierung bisher nicht bekannter codierender Bereiche}

Eine erneute Durchmusterung der pocinen PAC-Genbank mittels PCR zeigte nur ein schwaches Signal eines Amplifikates. Die verwendeten genspzifischen Primer waren aus dem 13. Exon des humanen mut-Gens abgeleitet. Das im Genbankscreen erhaltene schwache Signal wurde mit Vorbehalten als positiv angesehen. Die Sequenzierung der PAC-Ränder ließ darauf schließen, daß der rekombinante Klon tatsächlich den 3'-Bereich des porcinen $m u t$-Gens enthält. Eine BLAST-Analyse zeigte Überinstimmungen zu einem 
humanen PAC-Klon, der auf Hsap 6 p21 - 21.31 lokalisiert worden war. Da dies der chromosomalen Lokalisation des humanen mut-Locus entspricht, wurde mit der Subklonierung des porcinen PAC begonnen. Eine Kontrollhybridisierung und die ersten Sequenzinformationen der Subklone zeigten jedoch, daß der Klon aufgrund eines falschpositiven Signals ermittelt wurde. Anderereseits zeigten sich weitere interessante Ergebnisse, die dazu Anlass gaben, den Klon einem Schrotschuß-Verfahren zu sequenzieren. Die sich daraus ergebenden Sequenzen wurden mit Hilfe des Programms Sequencher zu einem Projekt vereint und zu insgesamt fünf Contigs zusammengefügt. Die Größenbestimmung des PAC-Klones hatte eine Insertlänge von ca. $84 \mathrm{~kb}$ ergeben. Die erhaltenen Contigs umfassen insgesamt einen Sequenzbereich von mehr als $80 \mathrm{~kb}$, so daß damit fast die gesamte Insertsequenz ermittelt wurde. In den BLAST-Analysen zeigten sich zahlreiche, definierte Abschnitte, die Homologien von 87 - $97 \%$ zu dem bereits in der ersten BLAST-Suche entdeckten humanen PAC-Klon. Diesen beiden genomischen Sequenzen weisen homologe Abschnitte in einer Weise auf, die auf die Exon/IntronStruktur eines Gens schließen lassen. Tatsächlich konnten EST-Sequenzen gefunden werden, die ebenfalls mit einzelnen dieser homologen Abschnitte übereinstimmten. Allerdings konnten keine bekannten Gene oder cDNA-Klone identifiziert werden, die eine Aussage über das hier vorliegende Gen zulassen. Eine Analyse des Programmes Genscan ermittelte ebenfalls insgesamt 37 potentiell codierende Bereiche. Berücksichtigt man die von diesem Programm als codierend ermittelten PRE so verbleiben noch immer 30 codierende Bereiche. Um weitere Informationen bezüglich der Expression eines bisher nicht bekannten Gens zu erhalten, wurde eine Nothtern Blot Analyse durchgeführt. Als Hybridisierungssonde wurde ein durch Restriktionsspaltung erhaltener genomischer DNAAbschnitt gewählt, der eine Homologie von 96,97 \% zur humanen Sequenz aufwies. Zur Markierung der Sonde und Detektion wurde eine nicht-radioaktive Methode In der Analyse konnte kein Signal erhalten werden. Für dieses Ergebnis kommen mehrere Gründe in Frage. Zum einen besteht die Möglichkeit, daß das hier gesuchte Gen in den ausgewählten Geweben aus Lunge, Niere, Milz, Leber, Gehirn, Skelettmuskel und Herz tatsächlich nicht exprimiert wird. Gewebe die hier nicht untersucht wurden, zum Beispiel die Gonaden, könnten eine gewebespezifische Expression anzeigen. Darüberhinaus wäre es auch angebracht die Regionen des Gehirns bezüglich der Genexpression getrennt zu betrachten. Es könnte auch sein, daß das Gen nur in bestimmten Entwicklungsstadien exprimiert wird und deshalb in einem adulten Tier keine Expression feststellbar ist. Eine weitere mögliche Ursache für diesen Befund könnte in der Methode selbst liegen. Die nicht-radioaktive Hybridisierung eines Northern Blots erfordert zwar laut Herstellerprotokoll keine Modifizierungen im Vergleich zur Southern Blot Hybridisierung, es hat sich aber bereits in anderen Experimenten gezeigt, daß eine Detektion mittels Chemilumineszenz nicht immer sensitiv genug ist. Die Methode der Wahl für eine weitere Analyse dieses noch nicht bekannten Gens wäre demnach eine radioaktive Hybridisierung. 


\subsubsection{Die chromosomale Lokalisation des porcinen mut-Gens und des PAC A13B5 deuten auf eine Bruchlinie im Synteniebereich hin}

Das porcine mut-Gen wurde mittels FISH-Analyse auf SSC 1 q13 - 14 lokalisiert. Das humane orthologe Gen befindet sich auf Hsap 6 p12 - p21.1. Aus den bekannten Syntenien humaner und porciner Chromosomen würde man eine Lokalisation des porcinen mut-Gens auf Chromosom 7 vermuten.

Eine vorläufige chromosomale Lokalisation durch Anlyse eines somatischen Cell Hybrid Panels legte den untersuchten PAC-Klon A13B5 auf SSC 7 fest. Da die Analyse des somatischen Cell Hybrid Panels bezüglich des SSC 7 nur eine Unterscheidung von vier Regionen zuläßt und das Ergebnis deshalb äußerst ungenau war, wurde eine Fluoreszenz in situ Hybridisierung (FISH) durchgeführt. Der mit Fluoreszenzfarbstoff markierte PACKlon diente hierzu als Sonde. Der Klon wurde damit auf SSC 7 im Bereich 1q11 - q13 kartiert. Dieses Ergebnis entspricht der bekannten Syntenie der p-Arme des Hsap 6 und SSC 7. Betrachtet man dieses Ergebnis im Zusammenhang mit der Lokalisation des porcinen $m u t$-Locus, so deuten die Ergebnisse darauf hin, daß sich im Bereich Hsap 6 p 21 eine syntenische Bruchlinie befindet. Damit wäre das Homologon zum proximalen Hsap $6 \mathrm{p}$ auf SSC 1q 13 - 14 zu finden. Im Bereich SSC1 q13 - 14 wurden bereits Marker des Hsap 18 und Hsap15 kartiert. Es könnte sich daher in diesem Bereich um eine völlige Neuanordnung von Genen unterschiedlicher syntenischer Regionen handeln.

\subsection{Eine Gruppierung der PRE aufgrund ihrer Homologie ist möglich}

Die Analyse der 85 porcinen repetitiven Elemente (PREs) aus den PAC A3F11 und PAC A13B5 Klonen zeigte deutlich die extreme Divergenz innerhalb der PREs. Die Sequenzunterschiede (unkorrigierte "p"-Distanz) lagen zwischen 6,5\% zwischen der Konsensussequenz und dem PRE10, und 66,2 \% zwischen dem PRE83 und PRE14. Es wurde ein NJ- (exklusive der vier PREs) Baum mit 1000 bootstrap Wiederholungen konstruiert. In dem Baum konnten nur sechs Gruppen differenziert werden, die über $66 \%$ Wiederfindungs-Wahrscheinlichkeit hatten. Dabei gab es nur eine Gruppe, die mehr als zwei Sequenzen zu einer monophyletischen Gruppe rechnete (PRE85, 84, 83, 32, 81). Auch die Reduzierung der Sequenzen auf 14 PRE plus der Konsensussequenz brachte kein überzeugendes Ergebnis. Das Alignment läßt deutlich die Heterogenität der Sequenzen erkennen. Rein optisch scheint das Dendrogramm drei Gruppierungen zu favorisieren. Diese lassen sich aber nicht mit den PRE-Subfamilien in Einklang bringen. Eine phylogenetische Analyse, die Aufschluß über den Insertionszeitpunkt geben könnte, wie dies zum Beispiel bei den Alu-Sequenzen der Primaten möglich ist, führte zu keinem befriedigenden Ergebnis. Für eine derartige Unteruchung müßten zumindest verschiedene Schweine-Rassen herangezogen werden. Dennoch konnte in der Vergangenheit eine Einteilung in Subfamilien erfolgen, die sich auf sogenannte diagnostische Positionen innerhalb des Alignments beziehen [88]. Die in der vorliegenden Arbeit untersuchten PRE wurden auf diese Einteilung hin analysiert. Die drei Subfamilien konnten anhand der diagnostischen Positionen (in der Konsensussequenz 27, 28, 42, 44 und 53 identifiziert 
werden. Interessanterweise wies die relative Verteilung der PRE in die Subfamilien andere Verhältnisse auf, als in der Arbeit von Brenig. Dort gehörte die Mehrheit (37/85) der PREhh Gruppe an, 20 gehörten zur PRE-mh und 28 zur PRE-lh Gruppe. Die hier vorliegenden PRE kamen in aufsteigender Häufigkeit in folgender Reihenfolge vor PRE-lh > PRE-mh > PRE-hh. Während Brenig in seiner Arbeit eine diverse Subfamilie PRE-mh vorfand, waren die in dieser Arbeit gefunden PRE-mh deutlich homologer, mit nur zwei Variationen in den diagnostischen Positionen. 


\section{Zusammenfassung}

Als Ausgangspunkt einer vergleichenden Genomanalyse bei Mensch und Schwein wurden zwei beim Menschen bereits kartierte Gene herangezogen. Zum einen das Triadin-Gen, das auf dem humanen Chromosom 6q22 - q23 lokalisiert wurde, zum anderen das Methylmalonyl-CoA-Mutase-Gen, das auf dem humanen Chromosom 6p12 - p 21.1 kartiert wurde.

Zunächst wurde aus Skelettmuskelgewebe RNA isoliert und mittels RT-PCR humane und porcine Triadin-cDNA hergestellt. Die Sequenzierung der erhaltenen cDNA-Klone zeigte insgesamt drei verschiedene, unterschiedlich lange cDNA-Varianten. Ein Vergleich der einzelnen Sequenzen mit der längsten erhaltenen Variante deutete darauf hin, daß diese unterschiedlichen cDNA durch alternatives Spleißen einzelner Bereiche entstanden waren. Dieser Befund konnte zunächst nur als Vermutung festgehalten werden, da die genomische Organisation des Triadin-Gen bislang nicht bekannt war. Im Rahmen dieser Arbeit wurde deshalb in der EMBL Nucleotide Sequence Database nach genomischen humanen PACoder BAC-Klonen gesucht, deren Sequenzhomologien zur humanen cDNA aufwiesen. In der Datenbank wurden vier überlappende Klone gefunden. Die chromosomale Lokalisation dieser Klone stimmte mit der des humanen Triadin-Gens überein. Durch Vergleich der genomischen Sequenzen mit der cDNA-Sequenz ermöglichte die Kartierung von 33 Exons des humanen Triadin-Gens. Weitere drei Exons wurden anhand eines genomischen porcinen Phagenklones bereits in einer Voruntersuchung zu dieser Arbeit kartiert. Durch Vergleich der Sequenzen der unterschiedlichen cDNAs konnten nochmals zwei Bereiche als Exons definiert werden. Damit wurden insgesamt 38 Exons den Triadin-Gens kartiert, die sich genomisch über mehr als $451 \mathrm{~kb}$ erstrecken. Durch die Kartierung dieser Exons konnte auch bestätigt werden, daß einzelne cDNA-Varianten durch alternatives Spleißen entstehen. Im Rahmen der vorliegenden Arbeit konnten damit zum ersten Mal die genomische Organisation des Triadin-Gens fast vollständig aufgeklärt werden. Darüberhinaus wurden mehrere alternativ gespleißte Exons identifiziert.

Die chromosomale Lokalisation des porcinen Triadin-Gens erfolgte durch PCR-Analyse eines somatischen Cell Hybrid Panels sowie eines Radiation Hybrid Panels. Das porcine Triadin-Gen wurde auf Chromosom 1q23 - 26 lokalisiert. Diese Lokalisation entspricht nicht den bisher bekannten Syntenieverhältnissen humaner und porciner Chromosomen. Das Ergebnis deutet vielmehr auf einen anderen Verlauf der Synteniegrenzen hin, als bisher angenommen.

Um einen Vergleich codierender Bereiche des humanen und porcinen MethylmalonylCoA-Mutase-Gens (mut) zu ermöglichen wurde durch RT-PCR und 5'-RACE-PCR porcine mut-cDNA hergestellt. Der Vergleich der Sequenzen zeigte, daß das mut-Gen stark konserviert ist. Einzelne codierende Bereiche stimmen zu mehr als $97 \%$ überein. Zur molekulargenetischen Chrakterisierung des porcinen mut-Locus wurde eine porcine PACGenbank durchmustert und ein rekombinanter Klon isoliert, der die Exons 1 bis 6 des Gens enthielt. Der PAC-Klon wurde vollständig sequenziert, um möglichst viele Informationen dieser genomischen Region zu erhalten. Das erste und untranslatierte Exon des mut-Gens 
wurde anhand dieses PAC-Klones rund 4,1 kb stromaufwärts des zweiten Exons kartiert. Durch eine nicht-radioaktive Primer-Extension-Analyse wurde der Transkriptionsstartpunkt auf ein TT-Nukleotid 28 bp vor dem Ende des 5'-RACEProduktes festgelegt. Im Promotorbereich des Gens konnten mehrere Konsensussequenzen eukaryontischer Transkriptionsfaktoren identifiziert werden. Darüberhinaus wurden innerhalb des Gens zwei Polymorphismen charakterisiert. Ein Längenpolymorphismus im unmittelbaren 5'-Bereich des Exons 3, sowie ein Mikrosatellit wurden anhand 30 bzw. 79 Tieren unterschiedlicher Rassen untersucht. Die chromosomale Lokalisation des mut-Gens erfolgte mittels Fluoreszenz in situ Hybridisierung auf Chromosom 1q13 - 14. Auch diese Lokalisation zeigt einen neuen Aspekt syntenischer Regionen auf.

Ein weiterer porciner PAC-Klon, der der Lokalisation des humanen mut-Gens entspricht, wurde nach shot gun kloniert und sequenziert. Die Sequenzen zeigen in mehrere definierten Bereichen Homologien von über $90 \%$ zu einem weiteren humanen PAC-Klon aus der Datenbank. Die Anordnung der homologen Abschnitte deuten auf die Exon/IntronStruktur eines bisher unbekannten Gens hin. Die chromosomale Lokalisation des porcienen PAC-Klones entspricht den bekannten Syntenieverhältnissen humaner und porciner Chromosomen. Die vorliegende Arbeit stellt einen wichtigen Beitrag zur vergleichenden Genomanalyse dar. 


\section{$8 \quad$ Literaturverzeichnis}

[1] Smith, S. (2000) Nat Genet 26, 388-9.

[2] Morton, N.E. (1991) Proc Natl Acad Sci U S A 88, 7474-6.

[3] Davisson, M.T. and Akeson, E.C. (1993) Genetics 133, 649-67.

[4] Ellegren, H., Fredholm, M., Edfors-Lilja, I., Wintero, A.K. and Andersson, L.

(1993) Genomics 17, 599-603.

[5] Ellegren, H., Chowdhary, B.P., Fredholm, M., Hoyheim, B., Johansson, M., Brauner Nielsen, P.B., Thomsen, P.D. and Andersson, L. (1994) Genomics 24, 342-50.

[6] Ellegren, H., Chowdhary, B.P., Johansson, M., Marklund, L., Fredholm, M., Gustavsson, I. and Andersson, L. (1994) Genetics 137, 1089-100.

[7] Andersson, L. et al. (1994) Science 263, 1771-4.

[8] Winzeler, E.A. and Davis, R.W. (1997) Curr Opin Genet Dev 7, 771-6.

[9] Zagulski, M., Herbert, C.J. and Rytka, J. (1998) Acta Biochim Pol 45, 627-43.

[10] Plasterk, R.H. (1999) Bioessays 21, 105-9.

[11] Kennedy, D. (2000) Science 290, 2255.

[12] Drysdale, R. and Bayraktaroglu, L. (2000) Yeast 17, 154-7.

[13] Wigge, P.A. and Weigel, D. (2001) Curr Biol 11, R112-R114.

[14] Daniels, G.R. and Deininger, P.L. (1985) Nature 317, 819-22.

[15] Roy, A.M., West, N.C., Rao, A., Adhikari, P., Aleman, C., Barnes, A.P. and Deininger, P.L. (2000) J Mol Biol 302, 17-25.

[16] Liu, W.M., Chu, W.M., Choudary, P.V. and Schmid, C.W. (1995) Nucleic Acids Res 23, 1758-65.

[17] Maraia, R.J., Driscoll, C.T., Bilyeu, T., Hsu, K. and Darlington, G.J. (1993) Mol Cell Biol 13, 4233-41.

[18] Schmid, C.W. (1998) Nucleic Acids Res 26, 4541-50.

[19] Zhang, J. and Madden, T.L. (1997) Genome Res 7, 649-56.

[20] Bedell, J.A., Korf, I. and Gish, W. (2000) Bioinformatics 16, 1040-1041.

[21] Burset, M. and Guigo, R. (1996) Genomics 34, 353-67.

[22] Rettenberger, G., Adham, I., Engel, W., Klett, C. and Hameister, H. (1995b)

Genomics 26, 372-378.

[23] Goureau, A., Yerle, M., Schmitz, A., Riquet, J., Milan, D., Pinton, P., Frelat, G. and Gellin, J. (1996) Genomics 36, 252-62.

[24] Lahbib-Mansais, Y., Dalias, G., Milan, D., Yerle, M., Robic, A., Gyapay, G. and Gellin, J. (1999) Mamm Genome 10, 145-53.

[25] Larsen, N.J., Marklund, S., Kelly, K.A., Malek, M., Tuggle, C.K., Yerle, M. and Rothschild, M.F. (1999) Mamm Genome 10, 488-91.

[26] Rios, E. and Brum, G. (1987) Nature 325, 717-20.

[27] Ferguson, D.G., Schwartz, H.W. and Franzini-Armstrong, C. (1984) J Cell Biol 99, $1735-42$.

[28] Rios, E., Ma, J.J. and Gonzalez, A. (1991) J Muscle Res Cell Motil 12, 127-35.

[29] Meissner, G. and Lu, X. (1995) Biosci Rep 15, 399-408.

[30] Zhang, L., Kelley, J., Schmeisser, G., Kobayashi, Y.M. and Jones, L.R. (1997) J Biol Chem 272, 23389-97.

[31] Caswell, A.H., Brandt, N.R., Brunschwig, J.P. and Purkerson, S. (1991)

Biochemistry 30, 7507-13.

[32] Marty, I., Robert, M., Ronjat, M., Bally, I., Arlaud, G. and Villaz, M. (1995)

Biochem J 307, 769-74. 
[33] Fan, H., Brandt, N.R. and Caswell, A.H. (1995) Biochemistry 34, 14902-8.

[34] Realini, C., Rogers, S.W. and Rechsteiner, M. (1994) FEBS Lett 348, 109-13.

[35] Knudson, C.M., Stang, K.K., Jorgensen, A.O. and Campbell, K.P. (1993) J Biol Chem 268, 12637-45.

[36] Knudson, C.M., Stang, K.K., Moomaw, C.R., Slaughter, C.A. and Campbell, K.P. (1993) J Biol Chem 268, 12646-54.

[37] Froemming, G.R., Murray, B.E. and Ohlendieck, K. (1999) Biochim Biophys Acta $1418,197-205$.

[38] Guo, W. and Campbell, K.P. (1995) J Biol Chem 270, 9027-30.

[39] Guo, W., Jorgensen, A.O. and Campbell, K.P. (1996) Soc Gen Physiol Ser 51, 19-

28.

[40] Brandt, N.R., Caswell, A.H., Carl, S.A., Ferguson, D.G., Brandt, T., Brunschwig, J.P. and Bassett, A.L. (1993) J Membr Biol 131, 219-28.

[41] Peng, M., Fan, H., Kirley, T.L., Caswell, A.H. and Schwartz, A. (1994) FEBS Lett $348,17-20$.

[42] Guo, W., Jorgensen, A.O., Jones, L.R. and Campbell, K.P. (1996) J Biol Chem 271, 458-65.

[43] Marty, I., Thevenon, D., Scotto, C., Groh, S., Sainnier, S., Robert, M., Grunwald, D. and Villaz, M. (2000) J Biol Chem 275, 8206-12.

[44] Kobayashi, Y.M. and Jones, L.R. (1999) J Biol Chem 274, 28660-8.

[45] Caswell, A.H., Motoike, H.K., Fan, H. and Brandt, N.R. (1999) Biochemistry 38, $90-7$.

[46] Sacchetto, R., Turcato, F., Damiani, E. and Margreth, A. (1999) J Muscle Res Cell Motil 20, 403-15.

[47] Groh, S., Marty, I., Ottolia, M., Prestipino, G., Chapel, A., Villaz, M. and Ronjat, M. (1999) J Biol Chem 274, 12278-83.

[48] Kobayashi, Y.M., Alseikhan, B.A. and Jones, L.R. (2000) J Biol Chem 275, 1763946.

[49] Ohkura, M. et al. (1998) Biochemistry 37, 12987-93.

[50] Kirchhefer, U., Neumann, J., Baba, H.A., Begrow, F., Kobayashi, Y.M., Reinke, U., Schmitz, W. and Jones, L.R. (2000) J Biol Chem .

[51] Taske, N.L., Eyre, H.J., O'Brien, R.O., Sutherland, G.R., Denborough, M.A. and Foster, P.S. (1995) Eur J Biochem 233, 258-65.

[52] Duscher, S., Pfeiffer, I., Leeb, T. and Brenig, B. (1998) Anim Genet 29, 476.

[53] Duscher, S., Pfeiffer, I. and Brenig, B. (1999) Anim Genet 30, 466-7.

[54] Cooper, A.J. (1983) Annu Rev Biochem 52, 187-222.

[55] Barker, H.A. (1981) Ann Rev Biochem 50, 23-40.

[56] McGarry, J.D. and Foster, D.W. (1980) Ann Rev Biochem 49, 395-420.

[57] Marsh, E.N. (1999) Essays Biochem 34, 139-54.

[58] Ludwig, M.L., Drennan, C.L. and Matthews, R.G. (1996) Structure 4, 505-12.

[59] Thoma, N.H. and Leadlay, P.F. (1996) Protein Sci 5, 1922-7.

[60] Mancia, F., Smith, G.A. and Evans, P.R. (1999) Biochemistry 38, 7999-8005.

[61] Maiti, N., Widjaja, L. and Banerjee, R. (1999) J Biol Chem 274, 32733-7.

[62] Halpern, J. (1985) Science 227, 869-75.

[63] Chowdhury, S. and Banerjee, R. (2000) Biochemistry 39, 7998-8006.

[64] Nham, S.U., Wilkemeyer, M.F. and Ledley, F.D. (1990) Genomics 8, 710-6.

[65] Threadgill, D.W., Wilkmeyer, M., Womack, J.E. and Ledley, F.D. (1990)

Cytogenet Cell Genet 53, 112-4.

[66] Sertic, J., Vincek, V., Ledley, F.D., Figueroa, F. and Klein, J. (1990) Genomics 6, $560-4$. 
[67] Rosenberg, L.E., Lilljeqvist, A. and Hsia, Y.E. (1968) Science 162, 805-7.

[68] Mahoney, E.H. (1975) Arn J 1, 17-9.

[69] Giorgio, A.J., Trowbridge, M., Boone, A.W. and Patten, R.S. (1976) N Engl J Med 295, 310-3.

[70] Matsui, S.M., Mahoney, M.J. and Rosenberg, L.E. (1983) N Engl J Med 308, 85761.

[71] Wilkemeyer, M.F., Andrews, E.R. and Ledley, F.D. (1993) Biochem J 296, 663-70. [72] van den Bergh, F.A., del Canho, H. and Duran, M. (1992) J Inherit Metab Dis 15, 897-8.

[73] Shevell, M.I., Matiaszuk, N., Ledley, F.D. and Rosenblatt, D.S. (1993) Am J Med Genet 45, 619-24.

[74] Crane, A.M. and Ledley, F.D. (1994) Am J Hum Genet 55, 42-50.

[75] Adjalla, C.E. et al. (1998) Hum Mutat 11, 270-4.

[76] Adjalla, C.E., Hosack, A.R., Matiaszuk, N.V. and Rosenblatt, D.S. (1998) Hum Mutat Suppl 1, S248-50.

[77] Fuchshuber, A., Mucha, B., Baumgartner, E.R., Vollmer, M. and Hildebrandt, F. (2000) Hum Mutat 16, 179.

[78] Watkins, D., Matiaszuk, N. and Rosenblatt, D.S. (2000) J Med Genet 37, 510-513.

[79] Mikami, H., Ogasawara, M., Matsubara, Y., Kikuchi, M., Miyabayashi, S., Kure, S. and Narisawa, K. (1999) J Hum Genet 44, 35-9.

[80] Al-Bayati, H.K., Duscher, S., Kollers, S., Rettenberger, G., Fries, R. and Brenig, B. (1999) Mamm Genome 10, 569-72.

[81] Altermann, E., Klein, J.R. and Henrich, B. (1999) Biotechniques 26, 96-8, 101.

[82] Yerle, M. et al. (1996) Cytogenet Cell Genet 73, 194-202.

[83] Yerle, M. et al. (1998) Cytogenet Cell Genet 82, 182-8.

[84] Troyer, D.L., Goad, D.W., Xie, H., Rohrer, G.A., Alexander, L.J. and Beattie, C.W. (1994) Cytogenet Cell Genet 67, 199-204.

[85] Robic, A., Riquet, J., Yerle, M., Milan, D., Lahbib-Mansais, Y., Dubut-Fontana, C. and Gellin, J. (1996) Mamm Genome 7, 438-45.

[86] Ruyter, D., Verstege, A.J., van der Poel, J.J. and Groenen, M.A. (1994) Anim Genet 25, 53.

[87] Duscher, S., Peters, U. and Brenig, B. (2000) Animal Genetics 31, 333-246.

[88] Brenig, B. (1999) Anim Genet 30, 120-5.

[89] Thompson, J.D., Gibson, T.J., Plewniak, F., Jeanmougin, F. and Higgins, D.G.

(1997) Nucleic Acids Res 25, 4876-82.

[90] Swofford, D.L. (2000) Sinauer Associates, Sunderland, Massachusetts.

[91] Strimmer, K. and von Haeseler, A. (1997) Proc Natl Acad Sci U S A 94, 6815-9.

[92] Phillips, M.S., Fujii, J., Khanna, V.K., DeLeon, S., Yokobata, K., de Jong, P.J. and MacLennan, D.H. (1996) Genomics 34, 24-41.

[93] Roberts, R.G., Coffey, A.J., Bobrow, M. and Bentley, D.R. (1993) Genomics 16, 536-8.

[94] Klamut, H.J., Bosnoyan-Collins, L.O., Worton, R.G., Ray, P.N. and Davis, H.L.

(1996) Hum Mol Genet 5, 1599-606.

[95] Lloyd, C. and Gunning, P. (1993) J Cell Biol 121, 73-82.

[96] Lahbib-Mansais, Y., Yerle, M. and Gellin, J. (1995) Cytogenet Cell Genet 71, 225 7.

[97] O'Toole, D., Ingram, J., Welch, V., Bardsley, K., Haven, T., Nunamaker, C. and Wells, G. (1994) J Vet Diagn Invest 6, 62-71. 


\section{$9 \quad$ Anhang}

Tab. 9-1 Verzeichnis der verwendeten PCR-Primer

\begin{tabular}{|c|c|}
\hline Bezeichnung & Sequenz $5^{\prime} \rightarrow 3^{\prime}$ \\
\hline Tri-60R & GACAGCAAAAATGGATCTGTGCCC \\
\hline $\operatorname{Tri-75R}$ & САTGACTGAGATCACTGCTGAAGG \\
\hline $\operatorname{Tri}-76 \mathrm{R}$ & TTGGATGGTGTATTTCCGCAGGAG \\
\hline $\operatorname{Tri} 77 \mathrm{R}$ & АААTTCTTGTGCTCCAGACССTCC \\
\hline Tri Ex Y-for & TAGCCACCTTGACTGGGC \\
\hline Tri Ex Y-rev & CCAGATCAAGAATAGTTAAGAC \\
\hline MMCM5R 1 & GCTCTCTTCCACAGTACTGAAACCAGC \\
\hline MMCM5R2 & TATACATGGTGGGATATGGTCCGCG \\
\hline MMCM3R 1 & TACTACAGTAGAAGCAATGGCAGCGG \\
\hline MMCM3R 4 & CAACAGGCTGTGGATGCAGATGTGC \\
\hline MMCM3R2 & CGGTGAAAAGTGCTAGAATTGCCAGGG \\
\hline MMCM3R3 & TACATACTTATAGCATGACACCAGGCC \\
\hline mut $\operatorname{Ex} 3.1$-for & TGGTCAACAAGGATTATCAG \\
\hline mut $\mathrm{Ex} 3.1-\mathrm{rev}$ & TTCATGGATGGGTCTGGAG \\
\hline 5MMCM2 & AGCCAGGGCAGCCCATTCTGGGTGAAGAGG \\
\hline 5ММСМ2 .1 & TAGCССTCAACATGATGGAGCGTGG \\
\hline MMCM 7.2 & СТTТСТСАСТАТСТTAССАG \\
\hline MMCM8 .2 & AGCCCAGTTCACAGTTCAC \\
\hline MMCM $7 \mathrm{rev}$ & ААТСTАTTСTAGСTTGTCTTCGGGC \\
\hline M13 (-20) forward Primer & TGTAAAACGACGGCCAGT \\
\hline M13 revere Primer & CAGGAAACAGCTATGACC \\
\hline MMCM-MS- 1.1 & ACTTAGTGTAAGACTCTGC \\
\hline MMCM-MS- 1.2 & TACTACGCCACTGTTTCC \\
\hline MMCM-MS-2.1 & AGTACTGTGGAAGAGAGC \\
\hline MMCM-MS-2.2 & TCCTTTCACACCATGTGC \\
\hline mutEx2for & TGTAAAACGACGGCCAGTTCAGCAGTAATGAACCCG \\
\hline mutEx2rev & CAGGAAACAGCTATGACCCATCATAAATATTAGGTCTCAC \\
\hline mutEx3for & TGTAAAACGACGGCCAGTGTTTACTTTAATGCCAGACTC \\
\hline mutEx3for 2 & TGTAAAACGACGGCCAGTTGGTCAACAAGGATTATCAG \\
\hline mutEx3rev & CAGGAAACAGCTATGACCACAGCAAAACCCACAAAACC \\
\hline mutEx 4 for & TGTAAAACGACGGCCAGTTTTGATGTTTTTATTCAC \\
\hline mutEx4rev & CAGGAAACAGCTATGACCAAGCCACAATGGGAACTCC \\
\hline mutEx5for & TGTAAAACGACGGCCAGTCACTTATAATCAAATTCTGGACT \\
\hline mutEx5rev & CAGGAAACAGCTATGACСTCACTATGCCAAGTGCTTAG \\
\hline mutEx6for & TGTAAAACGACGGCCAGTTCAATATATATCAACTGTTGCC \\
\hline mutEx6rev & CAGGAAACAGCTATGACCGAGAAACTGACCTTCAAGGC \\
\hline MMCM13.1 & CAATGTATTTGGTCCTGG \\
\hline MMCM13. 2 & GAGAAATGGGAATAGTCAG \\
\hline
\end{tabular}




\begin{tabular}{|c|c|c|c|}
\hline$\mu g$ & Mikrogramm & mRNA & Messenger-RNA \\
\hline$\mu l$ & Mikroliter & mut & Methyl-Malonyl-CoA- \\
\hline Abb. & Abbildung & & Mutase-Gen \\
\hline AdoCbl & Adenosincobalamin & $\mathrm{n} / \mathrm{m}$ & not mapped \\
\hline APS & Ammoniumperoxidsulfat & $\mathrm{NaOAc}$ & Natriumacetat \\
\hline BLAST & $\begin{array}{l}\text { Basic local alignment search } \\
\text { tool }\end{array}$ & $\begin{array}{l}\mathrm{ng} \\
\mathrm{nm}\end{array}$ & $\begin{array}{l}\text { Nanogramm } \\
\text { Nano-Meter }\end{array}$ \\
\hline $\mathrm{bp}$ & Basenpaare & OD & Optische Dichte \\
\hline BSA & Bovines Serumalbumin & ORF & offener Leserahmen \\
\hline $\mathrm{Cbl}$ & Cobalamin & PAC & P1-derived artificial \\
\hline cDNA & Complementäre DNA & & chromosome \\
\hline CIA & Chrloroform/Isoamylalkohol & PCR & Polymerase Kettenreaktion \\
\hline $\mathrm{cM}$ & Centi-Morgan & PP & Plattenpool \\
\hline DEPC & Diethylpyrocarbonat & PRE & porcine repetitive element \\
\hline DHPR & Dihydropyridin-Rezeptor & QTL & Quantitative trait loci \\
\hline DMSO & Dimethylsulfat & RACE & rapid amplification of cDNA \\
\hline DNA & Desoxyribonukeinsäure & & ends \\
\hline \multirow[t]{2}{*}{ dNTP } & 2'-Desoxyribonukleosid-5'- & RNA & Ribonukleinsäure \\
\hline & triphosphat & RT & Reverse Transkription \\
\hline DTT & Dithiothreitol & RyR & Ryanodin-Rezeptor \\
\hline EDTA & Ethylendiamintetraessigsäure & SDS & Natriumdodecylsulfat \\
\hline EST & Expressed sequence tag & sec & Sekunden \\
\hline ETL & Economic trait loci & SINE & SSPhort interspersed \\
\hline \multirow[t]{2}{*}{ FISH } & Fluoreszenz in situ & & repetitive element \\
\hline & Hybridisierung & SKM & Skelettmuskel-Triadin \\
\hline $\mathrm{g}$ & Gramm & SP & Superpool \\
\hline $\mathrm{h}$ & Stunde & SR & sarkoplasmatisches \\
\hline Hsap & homo sapiens chromosomE & & Retikulum \\
\hline \multirow[t]{2}{*}{ IPTG } & Isopropyl- $\beta$-Thiogalacto- & SSC & Sus scrofa \\
\hline & pyranosid & SSP & Super-Superpool \\
\hline $\mathrm{kb}$ & Kilo-Basen & TEMED & $\mathrm{N}, \mathrm{N}, \mathrm{N}^{\prime}, \mathrm{N}^{\prime}-$ \\
\hline KDa & Kilo-Dalton & & Tetramethylethylendiamin \\
\hline KOAc & Kaliumacetat & Tris & Tris-(hydroxymethyl)- \\
\hline \multirow[t]{2}{*}{ LINE } & long interspersed nuclear & & Aminomethan \\
\hline & element & $\mathrm{U}$ & Units \\
\hline M & Molar & UTR & Untranslatierte Region \\
\hline \multirow[t]{2}{*}{ MCM } & Methyl-Malonyl-CoA- & UV & Ultraviolett \\
\hline & Mutase & $\mathrm{V}$ & Volt \\
\hline $\min$ & Minuten & $\mathrm{V} / \mathrm{v}$ & Volumen per Volumen \\
\hline $\mathrm{ml}$ & Milliliter & Vol & Volumen \\
\hline ML & Maximum Likelihood & $\mathrm{w} / \mathrm{v}$ & weight per volume \\
\hline $\mathrm{mm}$ & Millimeter & & \\
\hline \multirow[t]{2}{*}{ MOPS } & 3-(n-Morpholino)- & & \\
\hline & Propansulfonsäure & & \\
\hline MP & Maximum Parsimonie & & \\
\hline
\end{tabular}




\subsubsection{Sequenz des cDNA-Klones pSKM1}

CATGACTGA ATCACTGCTG AAgGAAATGC ATCTACAACC ACAACTGTGA TAGACAgCAA

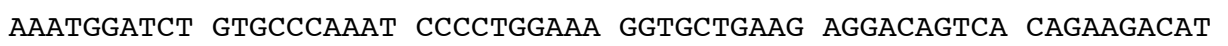
AgtGACAACA TTCAgCTCCC CAgCAgCCTG GCTTCTGGTC ATCGCTCTGA TCATCACGTG

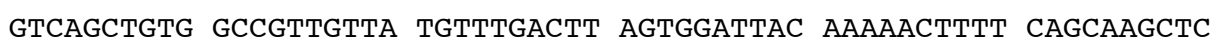

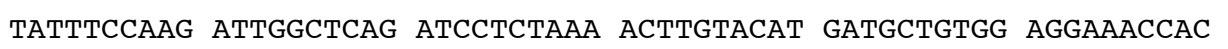

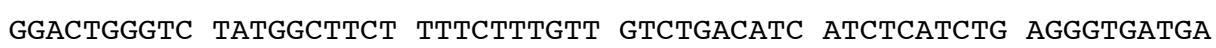

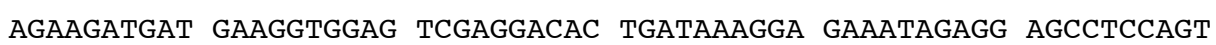
GAAAAAAAAA GAAATACATA AAGAAAAGAC TGAAAAGCAG GAAAAACCTG AAAGGAAAAC ACAAACTAAA GTTACACACA GAGAAAAAGA CAAAGCAAAA GAAAAAGAAA AACCTGAAAA GAAAGAAGAG AAGAAAACTA AGACTAAAGA AAAGGCTGAA GAAAAGAGTA AAAAGGAAGT GAAAGGTGGG AAACAGGAGA AAGTGAAGCA AACAGCTGCA AAAATAAAAG ACGCACAGAA ACCATCCCCT AAACCCAAGg GGAAGGATGA GAAAGATGCT GCAGCTCTGT CCAAGCATGA ACAGAAAgAt CAgTATGCAT TCTGTCGATA TATGATTGAC ATATTTGTCC ATGgGGATTT AAAACCAGGA CAAAGCCCAG CCATACCACC TCCATTACCA ACAGAACAAG CTTCCAGACC CACTCCAGCA TCACCTACTC TTGAAGAAAA AgAAgGAGAA AAgAAGAAAg CTGAGAAGAA 900 AgtgACTCCT GAAGCAAAAA AgAAAgAAAA AgAAgACGCC AAAAAGAAAA CGGAGAAgGA 960 AAtAgCCACG GAtgtgaAAA AAAAAgAgCC tggCAAAgCC CCAGAAACCA AACAAggGaC 1020 AATAAAAGTT GCAGCACAAG CAGCAACTAA AAAAGATGAA AAGAAAGAAG AACAGGAAAT 1080 GAAAGAAAAA CATGTGGAAC CAgCAAAATC ACCAAAgAAg GAACATTCAg CTCCAAGTGA 1140 AAAACAAGTT AAAGCAAAAA CTGAACGAGC CAAAGAAGAg GTTGGTGCTG CCTCAACTAA 1200 AAAAgCTGTA CCTGGAAAgA AgGAAgAgAa AACAACCAAG ACAgTGGAGC AAGAAATTAG 1260 AAAAGAAAAA CCTGGGAAGA CTTCTTCAGC TCCAAAGGAC AAAGAACCTG TTAAAGGGAA 1320 AgAAgtgaAg GCTCCAGCTT CCCTAAAgGA AAAAgAACCT GAAATtAAAA AAgAtgAAAA 1380 GATGTCCAAA GCAGGCAAAg AAgTCAAGCC CAAGTCTCCA CAGCCACAAG TAAAAAGAAG 1440 AgAAgCCAgA GTCACAAGTT AAAAgGAAgC AAAACCAGTT TCATCTGAAA AAgCtCAAAT 1500 ACACAAACCA GACTTACCCA ACCGGAAAgA CTGTTTCTCA TGgtAACCAg ATGAAAAAgT 1560 TGCCAAGCAg GTAAAAGCTA ATGCAACAgA AAAAATAGTT AAACCCAAAC CAGCAAAAAA 1620 AGCTGAACAT CAAGAAAAAg AATCTCCATC TATAAAAACA GACAAACCAA AACCAACTCC 1680

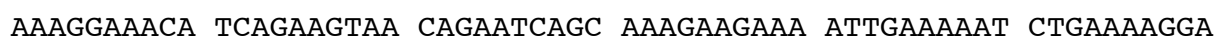
1740 AAGCAAAGAA AAAGCAGAAA TGAAACACCT TAAAGAAGAA AAAGTCCCAG CAAGTAAAGA 1800 AAGTCTTCAA TCACACAATG TGACAAAAGC AGAAAAACCT GCAAGACTAT CAAGgGAAGA 1860

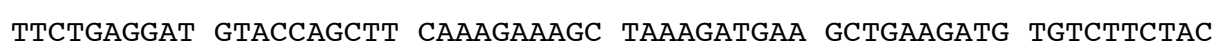




\begin{tabular}{|c|c|c|c|c|c|c|}
\hline AAAGAAGCAA & AAAGCCCCAT & САGСTTСTTC & CAGTGTGTCT & АСTTGGATGG & ATACAATGGC & 1980 \\
\hline TATGGATTTC & AGTTTCCTGT & САСТССТGСА & CACCGCCCTG & GGGAGAGCTC & TGGTCAACCA & 2040 \\
\hline АGTTCTCCAG & GACAGAAGCA & ACAAGGGCAA & TAAGAGACAC & ATGCACAGCC & ССТАCAAGTG & 2100 \\
\hline СTTTAAGACT & TTGAAAATAG & GATCTTCCAT & TTGCCCACAG & TGGCACAGGC & AATTGAAATC & 2160 \\
\hline ATATAGTCCA & GAGAATTTCT & TTGAAAATAT & TTTAСТTTTС & TGTCTGGTGT & AGAAAGAAAG & 220 \\
\hline GGTGAGCAAA & GGGATTGAAT & AATAAGCAGA & CAAACGGGAG & GGTCTGGAGC & ACAAGAATTT & 280 \\
\hline GTCATTTGTT & GCTGGGTGTG & GGTGCTTATA & ТTTTTTAАAC & TTCСАТTCAC & TGTAGGGTTG & 340 \\
\hline TTCACAАATТ & АATTTAAAGT & TTGCTTAAАT & АTGGTCTTTT & AAACATAATT & GACACAATTA & 2400 \\
\hline CAAAATGAAG & TTCCTGGCTT & CAGTTAGATA & ТТTАСТТTТА & AGTGAAAATA & AGACCATGCT & 460 \\
\hline TTAAGTTGAA & AGGGTATACT & AGCATAGGCT & GTTTTTTTTC & CATCATGTAG & TAGGTAAACT & 2520 \\
\hline СААСТТАССС & AGTAAGTTGA & TGTGTAATAG & TTTAATTTTA & TTTСТАТСТG & AACTTTTAGC & 30 \\
\hline TGTGACTATG & СТСТААААAА & GGGGTAACAG & TTGCACCAAA & GAATGCTATA & AGTTCTTTGT & 40 \\
\hline GATGTTCTCT & TAGAGCTCAA & ААТАТСТСТG & АACTTTAGAC & ATGGTAAGAT & GGAGTAGAAA & 2700 \\
\hline TGTCTGATGA & АTCTTGTCTC & TAAGATTTGT & CTTGAAGTAC & AATTAGGACA & TTСАСТСТGC & 2760 \\
\hline & & ТC & & & & \\
\hline
\end{tabular}




\subsubsection{Sequenz des cDNA-Klones pSKM2}

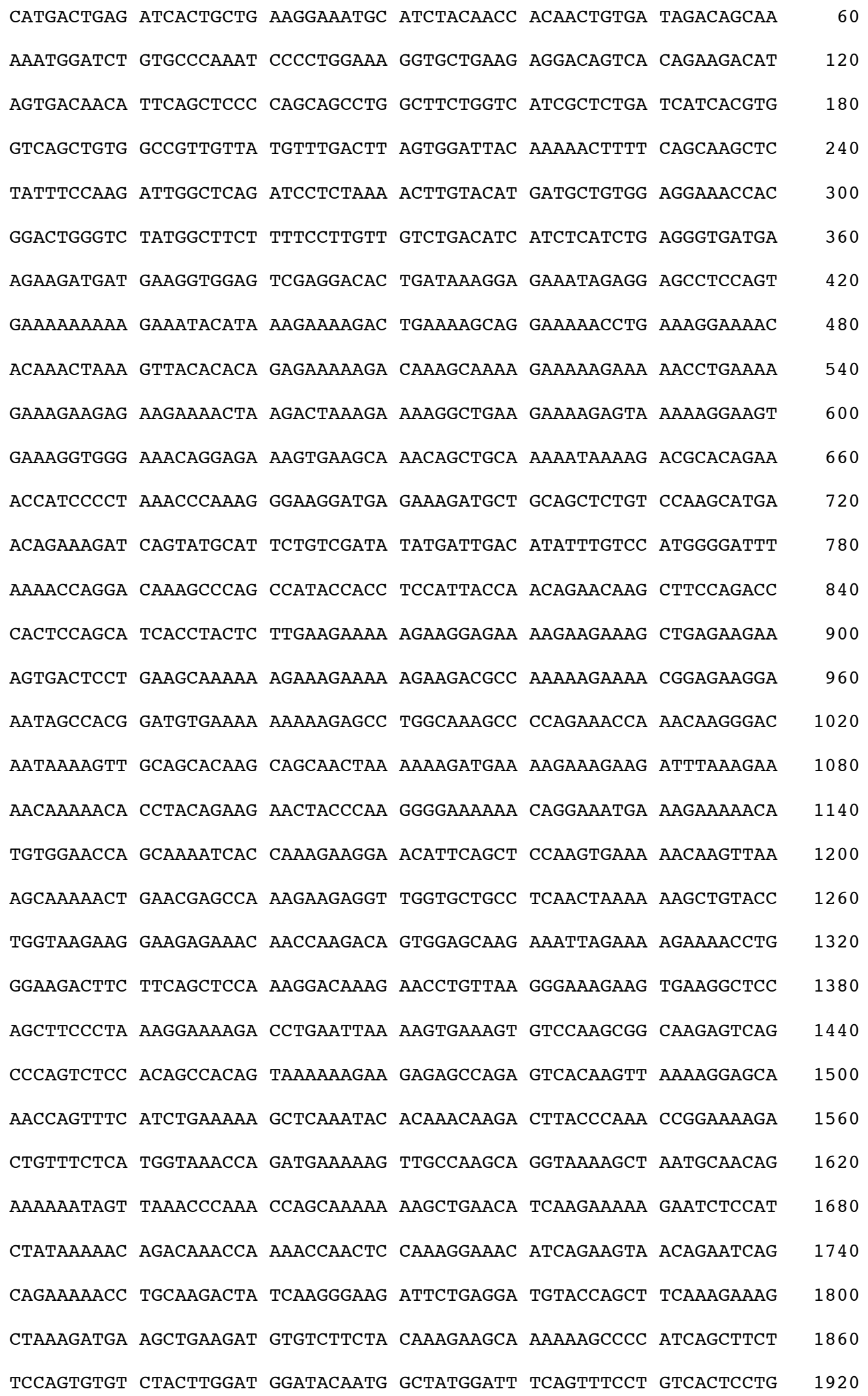


CACACCGCCC TGgGgagAgC TCtgGtCAAC CAAgtTCtCC AgGACAgAag CAACAAggGC 1980 AAtAAGAGAC ACATGCACAg CCCCTACAAG TGCTTTAAGA CTTTGAAAAT AgGATCTTCC 2040 ATTTGCCCAC AGTGGCACAG GCAATTGAAA TCATATAGTC CAGAGAATTT CTTTGAAAAT 2100

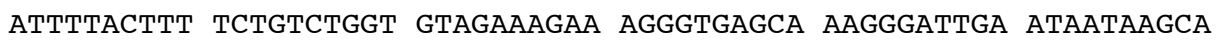
2160 GACAAACGGG AGGGTCTGGA GCACAAGAAT TTGGGGATCC 


\subsubsection{Sequenz der porcinen mut-cDNA}

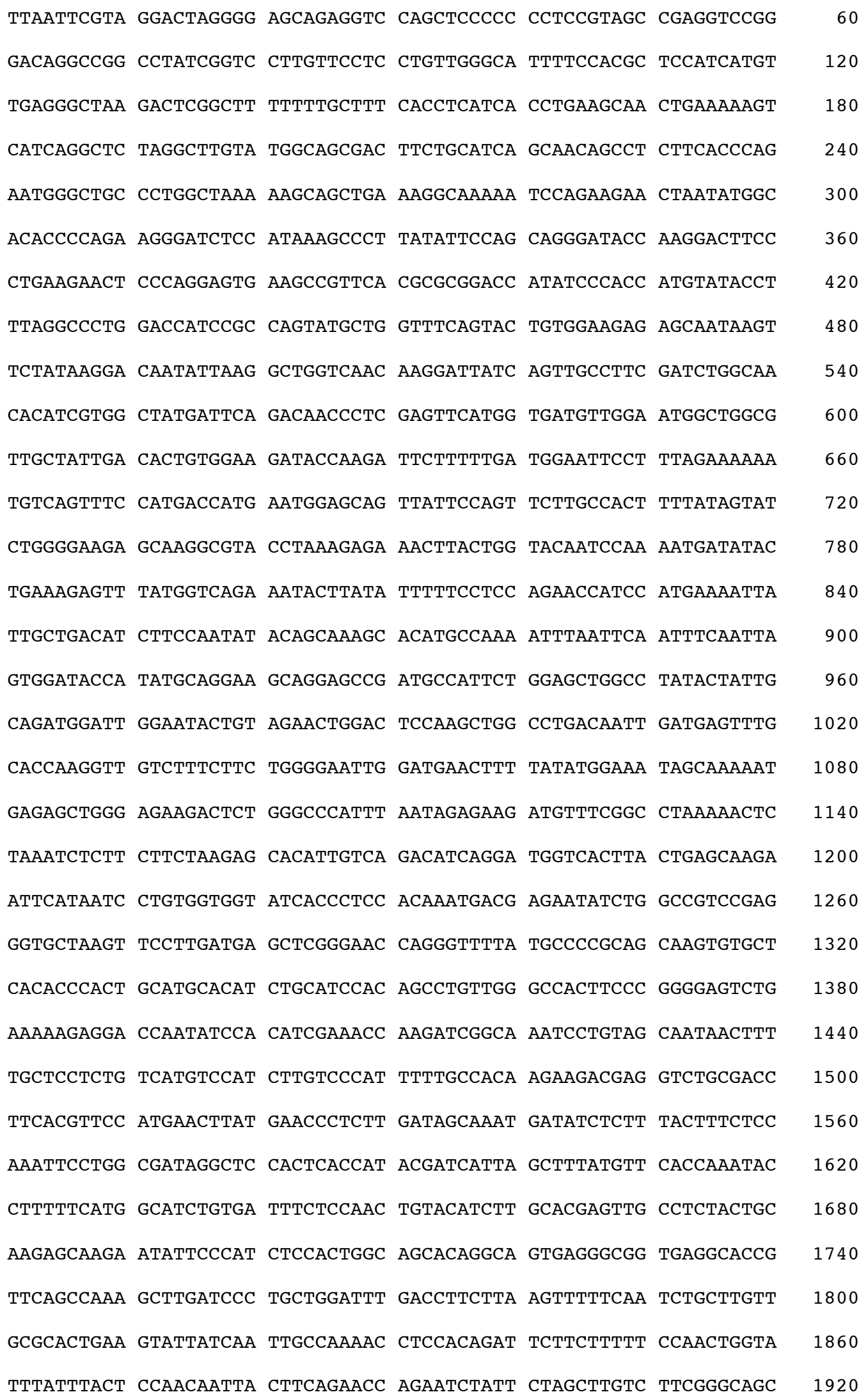


ACATTCTTCA ATTCGAAGTt tAgGtATtCC CTCTGCCACA GCTTTGGCCA TTCCACCCAT

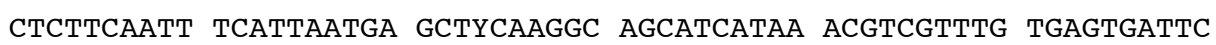

2040

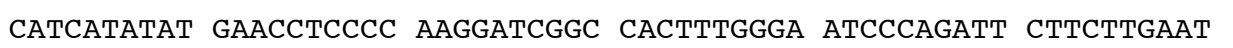

2100

AATGATTTGT GTGTTCCTGg CAATTCTAGC ACTTTTCACC GTTGGCAAAC CCAGGGCTTC

2160

ATCAAAAGA TTTGTGTGCA AAGACTGAGT TCCTCCAAAC ACCGCTGCCA TTGCTTCTAC

2220

TGTAGTACGA ATGATGTTAT TATAAGGATC 


\section{LEBENSLAUF}

\section{PERSÖNLICHE DATEN}

Name, Vorname

Anschrift

Geburtsdatum

Geburtsort

Staatsbürgerschaft

\section{BERUFLICHER WERDEGANG}

$1978-1982$

$1982-1986$

$1986-1992$

Juni 1992

$1992-1998$

April 1997 - Mai 1998

10.08.1998

Sep. 1998 - März 2001
Duscher, Sonja

Springstraße 46a

37077 Göttingen

24.03.1972

Vöcklabruck, Österreich

Österreich

Volksschule in Niederthalheim

Hauptschule in Schwanenstadt

Höhere Bundeslehranstalt für wirtschaftliche Berufe in Wels

Reifeprüfung

Studium der Biologie, Studienzweig Genetik an der ParisLondon Universität Salzburg

Anfertigung der Diplomarbeit mit dem Thema "Analyse der 3'-Region des porcinen Skelettmuskel-Triadin-Gens" am Tierärztlichen Institut der Georg-August-Universität Göttingen

Kommissionelle Diplomprüfung

abgelegt an der Paris-London Universität Salzburg

Dissertation am Tierärztlichen Institut der Georg-AugustUniversität, Göttingen unter der Leitung von Prof. Dr. Dr. B. Brenig 